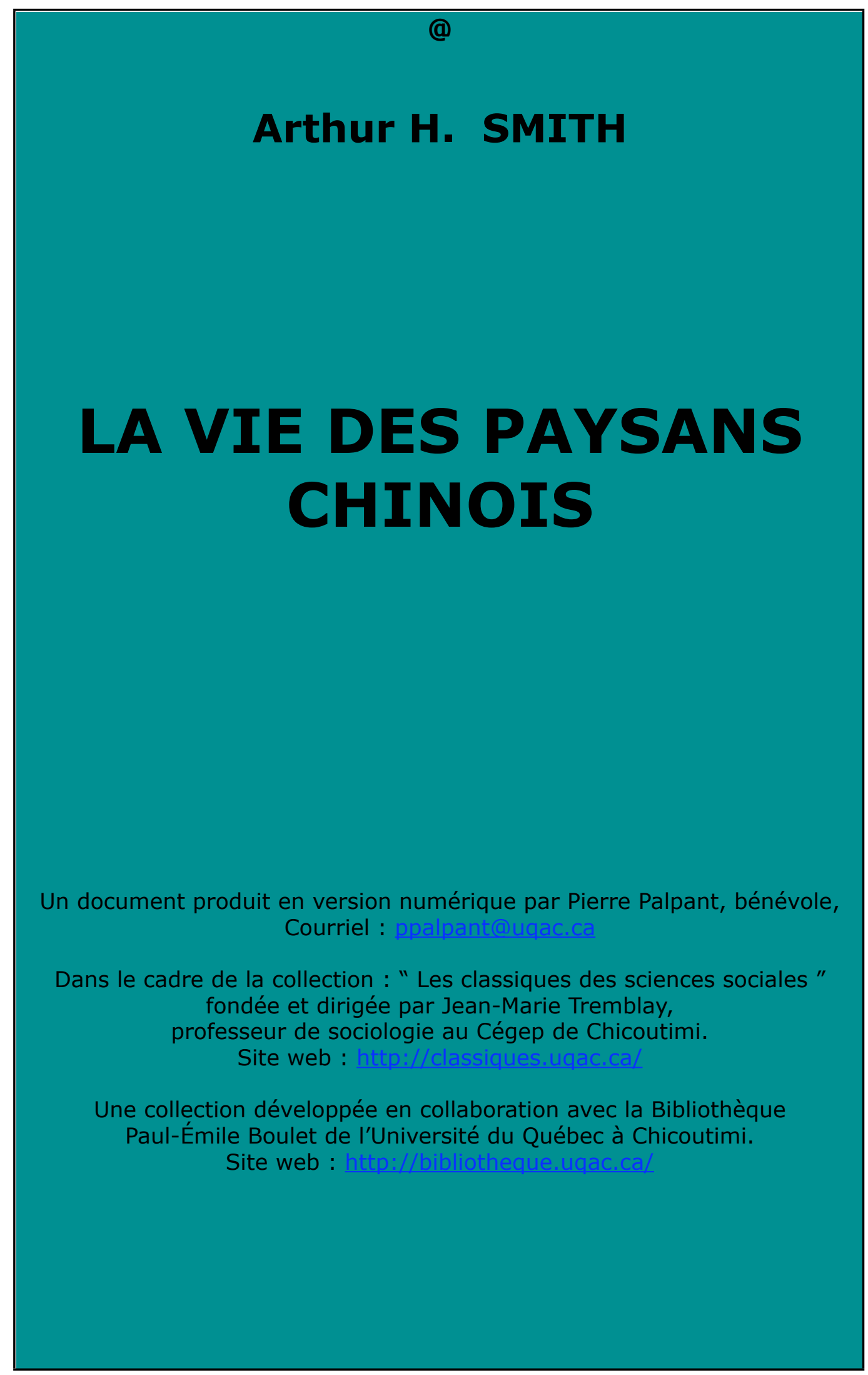




\section{La vie des paysans chinois}

Un document produit en version numérique par Pierre Palpant, collaborateur bénévole,

Courriel : ppalpant@uqac.ca

à partir de :

\section{LA VIE DES PAYSANS CHINOIS,}

par Arthur H. SMITH (1845-1932)

Traduit par B. MAYRA et le Lt-Cl de FONLONGUE

Collection d'études, de documents et de témoignages pour servir à I'histoire de notre temps, Librairie Payot, Paris, 1930, 356 pages.

Police de caractères utilisée : Verdana, 12 et 10 points.

Mise en page sur papier format Lettre (US letter), $8.5^{\prime \prime} \times 11^{\prime \prime}$

[note : un clic sur @ en tête de volume et des chapitres et en fin d'ouvrage, permet de rejoindre la table des matières]

Édition complétée le 15 décembre 2006 à Chicoutimi, Québec. 


\title{
La vie des paysans chinois
}

\section{TABLE DES MATIÈRES}

Préface.

\author{
PREMIĖRE PARTIE
}

\section{LE VILLAGE. SES INSTITUTIONS. SES COUTUMES. SES FONCTIONNAIRES.}

I. Le village chinois.

II. Les maisons.

III. Les noms des villages.

IV. Les chemins ruraux.

V. Les bacs fluviaux.

VI. Les puits.

VII.Les boutiques.

VIII.Le théâtre.

IX. Les écoles. Etudiants ambulants.

X. L'instruction supérieure en Chine. L'école supérieure de village. Examens. Derniers édits concernant l'instruction.

XI. Les temples.

XII.La coopération dans les pratiques religieuses.

XIII.La coopération dans l'organisation des foires et des marchés.

XIV.Les sociétés de prêts.

$X V$. La surveillance des récoltes.

XVI.Incantation de la pluie.

XVII.La chasse.

XVIII.Mariages et funérailles.

XIX.Le Jour de I'An.

$X X$. Le matamore.

XXI.Les administrateurs communauX.

\section{DEUXIÈME PARTIE \\ LA VIE DE FAMILLE AU VILLAGE}

XXII.Garçons et hommes.

XXIII.Jeunes filles et femmes.

XXIV.La monotonie et le vide de l'existence au village.

$X X V$.Équilibre instable de la famille chinoise.

XXVI.Faiblesse du lien familial.

\section{Glossaire}

\section{Gravures :}

Paysans chinois chez eux - Dans un village du sud - Puits de village Cordons de cash - Confection des cordons - Campement de surveillant des récoltes - Moisson du millet - Couple de jeunes mariés - Pavillon funéraire provisoire - Femmes préparant le repas - En route pour le festin - Une plaie de la Chine : le mendiant - Un élément de force : I'artisan. 


\section{La vie des paysans chinois}

\section{PRÉFACE}

L'auteur de ce livre, possédant une longue expérience de la Chine, éprouve par cela même un profond respect pour les nombreuses et admirables qualités des Chinois, et il a pour beaucoup d'entre eux individuellement la plus haute estime. Cette grande race a derrière elle un passé sans égal, il se peut qu'un merveilleux avenir s'ouvre aussi devant elle, mais, afin qu'une pareille destinée s'accomplisse, il faut que le Céleste pare à de nombreuses insuffisances, insuffisances qui semblent d'autant plus probantes que I'on connaît mieux la Chine. Le commerce, la diplomatie, le développement des relations politiques avec I'Extérieur et même un contact toujours plus étroit avec les civilisations occidentales n'ont pas réussi à accomplir une seule des réformes dont la Chine a besoin.

Le village chinois, c'est l'Empire en raccourci. Après I'avoir étudié, nous nous trouverons mieux armé, pour suggérer un remède à tout ce qui exige des améliorations. Il est un point sur lequel on ne saurait trop insister. En Chine, la variété dans I'unité est telle que lorsqu'un observateur donne un fait comme certain, il devrait en même temps spécifier que, véridiques dans certaines parties de la Chine, ses affirmations peuvent ne pas l'être en ce qui concerne d'autres régions de l'Empire. Par contre, I'unité dans la variété est telle aussi qu'un fait vraiment typique de la Chine, s'il ne se présente que rarement, n'en est pas moins utile à connaître. 


\section{La vie des paysans chinois}

Jamais la Chine n'a soulevé comme aujourd'hui les préoccupations du monde et rien ne nous autorise à penser que sa situation attirera moins l'attention des nations au début du XXe siècle. Tout ce qui peut concourir à faire mieux comprendre le caractère chinois est de nature à faciliter l'intelligence du problème chinois lui-même. Puisse ce livre apporter à une pareille œuvre sa modeste contribution.

(a) 


\section{LE VILLAGE \\ SES INSTITUTIONS \\ SES COUTUMES \\ SES FONCTIONNAIRES}




\section{La vie des paysans chinois}

\section{I \\ LE VILLAGE CHINOIS}

L'Inde compte à elle seule plus d'un demi-million de villages ; sans doute I'Asie entière en possède-t-elle quatre fois autant. La plupart des nations à population nombreuse, presque toutes, pourrions-nous dire, vivent dans des villages. En Chine, le voyageur partant d'un port de mer, Tien-Tsin par exemple, pourra cheminer pendant plusieurs mois toujours dans la même direction, sans atteindre la frontière opposée. Au cours d'une pareille randonnée, il sera frappé, comme seul peut l'être celui qui observe de ses propres yeux, par la quantité incroyable de Chinois vivant en dehors des grands centres urbains. Contrairement à ce que s'imaginent généralement les Occidentaux, le nombre des grandes villes, par rapport à celui de la population totale, est, en Chine, très inférieur à celui des pays d'Europe. Bien des cités, chefs-lieux de divisions administratives analogues à nos comtés, ne sont autre chose que de gros villages ceints d'une muraille, dans lesquels sont installés les bureaux du gouvernement, les yamen. Nul n'ignore qu'aux Indes la population est aux trois quarts rurale; en Chine, tout nous porte à croire que la proportion est la même.

Au cours d'un voyage tel que celui que nous imaginons, le touriste qui ne connaît pas les Chinois se demande sans cesse : A quoi pensent ces innombrables millions d'êtres humains ? Quel 


\section{La vie des paysans chinois}

genre de vie mènent-ils ? Qu'est-ce qui le caractérise ? Quelles sont leurs aspirations?

L'on ne peut répondre utilement à de pareilles questions sans recourir à de nombreux commentaires. Les conditions et l'ambiance de la vie chinoise diffèrent tellement de celles qui nous sont familières qu'il est dangereux d'affirmer quoi que ce soit. En dehors de quelques-uns de ses éléments essentiels, il y a dans l'existence des Chinois une étonnante variété qu'il est difficile d'expliquer. Pour aussi longtemps qu'un étranger ait vécu en Chine, le domaine de l'inconnu lui apparaît toujours aussi vaste ; que de choses dont il n'a jamais entendu parler mais que tout le monde est supposé connaître par intuition ! Quelle que soit la durée de son séjour dans le pays, il reste un écolier tout comme le nouvel arrivé.

Pareil état de choses est l'inéluctable conséquence de cette civilisation chinoise si ancienne, de même que de la très grande échelle sur laquelle elle dut opérer pour produire ses effets. M. A. R. Colquhoum a très judicieusement observé que

« le produit résultant de la durée multiplié par le nombre des êtres qui se sont succédé doit être formidable et que, si l'on fait intervenir un troisième facteur, l'isolement de ce peuple, nous ne sommes plus en droit de nous montrer surpris du caractère complexe de la civilisation chinoise, pas plus que de sa forme particulièrement conservatrice.

Et c'est ainsi qu'il nous paraît impossible de donner un exposé méthodique et cohérent des phénomènes de la vie chinoise. Une 


\section{La vie des paysans chinois}

telle entreprise demanderait le collationnement des renseignements fournis par tous les étrangers résidant en Chine ; il faudrait plusieurs existences pour la mener à bien et la bibliothèque bodléienne suffirait à peine à contenir les volumes résultant de cette publication. Le seul moyen pratique de développer nos connaissances sur un sujet aussi vaste que l'océan consiste à examiner plus ou moins à fond tels phénomènes que le hasard projette dans notre modeste horizon. Il ne se rencontrera pas deux personnes ayant le même horizon et aucun horizon n'englobera une sphère.

L'un des meilleurs moyens de voir ce qui se passe dans un édifice serait d'en enlever le toit, à condition qu'une pareille opération puisse se faire sans troubler ses habitants. Or, si nous voulons comprendre les Chinois, il nous faudrait pénétrer dans leur home, ce qu'aucun étranger n'est admis à faire ; il peut toutefois imiter le Céleste qui applique un doigt mouillé sur une vitre en papier. A ce contact il se produit un petit trou par lequel un œil scrutateur est à même d'observer ou, tout au moins, d'entrevoir quelque chose. Les chapitres hétérogènes, sans suite toujours logique, qui composent cet ouvrage, furent écrits un peu au hasard de nos observations, mais tous sont des études de phénomènes aperçus à travers un judas et se rapportant à la vie actuelle du peuple chinois. Quiconque en sait assez sur ce sujet pour être en droit de se faire une opinion ne manquera pas de constater que notre travail est imparfait, insuffisant. Il n'en représente pas moins des réalités ayant un intérêt humain qui leur est propre. 


\section{La vie des paysans chinois}

Le voyageur qui parcourt la Chine rencontre à chaque pas des villes, des hameaux et, très naturellement, il voudrait se faire une idée générale de la population des contrées qu'il traverse. Qu'il ne s'avise pourtant pas de demander à un autochtone le nombre d'habitants d'une cité ou d'un district. Pour toute réponse on lui dira : « il n'y en a pas très peu ! » ou encore : «qui sait»? Presque toute personne intelligente est capable d'indiquer, au moins approximativement, le nombre des villages de sa propre région ; mais ici, les uns étant grands, les autres petits, et le Chinois, comme tout autre Oriental, ne se souciant guère de la statistique et ne possédant que des notions très simplistes sur ce que nous appelons une moyenne, les renseignements qu'il fournit n'ont aucune valeur.

D'autre part l'expérience a montré qu'on ne saurait s'en rapporter aux relevés établis par les fonctionnaires chinois et pourtant ces données, constituant les seuls éléments sur lesquels I'on puisse baser des évaluations rationnelles, offrent une certaine valeur. Désire-t-on estimer avec quelque exactitude la population par mille carré, il faut la déduire de ce que I'on sait du nombre des habitants d'une province entière ou, tout au moins, du territoire d'une préfecture. Inutile d'insister sur ce qu'a de précaire une pareille opération.

Il y a quelques années l'on voulut pourtant, dans un certain district, obtenir une supputation plus exacte de la population d'une zone très limitée, espérant constituer ainsi une sorte d'unité de mesure. A cet effet, autour de la résidence étrangère prise comme centre, on traça un cercle d'un rayon de 20 li. La 


\section{La vie des paysans chinois}

liste fut dressée des villages ayant reçu des secours de famine en I'année 1878 ; et I'on put ainsi déduire approximativement le nombre moyen des familles. La zone examinée comprenait 150 villages à chacun desquels furent attribuées 80 familles comprenant 5 personnes, soit un total de 60.000 têtes. En admettant l'équivalence de 20 li pour 6 milles, la population devait être de 531 habitants par mille carré, densité à peu près égale à celle du royaume de Belgique, le pays le plus peuplé de I'Europe, où le dénombrement de 1890 a donné une moyenne de 534 habitants par mille carré.

A quelques milles en dehors de ce cercle se trouve une région appelée «les treize villages » parce que tel est le nombre de ceux qui s'y trouvent sur une étendue de 5 li ! Cette proportion montre que la zone dans laquelle fut faite l'évaluation susindiquée ne présentait pas des conditions favorables pour le but en question, celui d'établir une moyenne, attendu que, depuis les ravages causés par les inondations du Fleuve Jaune, elle présente des surfaces incultes considérables et une grande bande de terrain ne porte plus aucun village. Enfin elle est traversée par un cours d'eau allant du Grand Canal à la mer, une partie des habitants a dû abandonner le sol qui s'étend en une large et profonde dépression, parce que trop sujet aux envahissements des eaux.

Il fut alors décidé de procéder à un nouveau dénombrement dans une région moins déshéritée. On choisit à cet effet un autre district situé à 90 li de la sous-préfecture de Lin Ch'ing. La surface désignée n'était guère que la moitié de la précédente 


\section{La vie des paysans chinois}

mais, au lieu d'évaluer la population moyenne des villages, I'on s'efforça d'établir, d'après les renseignements fournis par les indigènes, le nombre de familles faisant partie de chaque agglomération. Ce travail fut confié à un homme du village central doué de beaucoup de bon sens. Il adopta prudemment pour chaque village des évaluations inférieures aux estimations populaires, toutefois il conserva le chiffre de 5 têtes par famille bien qu'il l'estimât trop faible. Beaucoup de « familles » vivent en effet en commun et sont comptées pour une unité alors que le nombre de leurs membres peut s'élever, comme dans le cas de cet individu en particulier, jusqu'à 20. En parcourant cette région on a l'impression d'un pays très habité ; les villages sont grands, très rapprochés les uns des autres et les relevés établis confirment ce fait. Dans un rayon de 10 li (3 milles) se trouvent 64 villages dont les plus petits comptent 30 familles et les plus importants jusqu'à 1.000, soit une moyenne de 188 familles par village. On arrive à un total de 12.040 familles et de 60,200 habitants, à raison de 5 par famille. En doublant le rayon de la zone, la population s'élève à plus du double du chiffre ci-dessus. Ce dénombrement donne ainsi 2.129 têtes par mille carré.

A s'en rapporter aux apparences, il existe dans le Chih-li méridional et central, dans le Shantoung occidental et sud-ouest, dans le Ho-nan septentrional, des milliers de milles carrés où les villages sont aussi denses que dans la région dont nous venons de parler et nous pouvons ainsi en supputer approximativement la population. Mais, dans les plaines de la Chine septentrionale, il semble plus raisonnable d'admettre 300 habitants par mille carré pour les districts à villages plus distants les uns des autres et de 


\section{La vie des paysans chinois}

1.000 à 1.500 dans les zones où ils sont plus rapprochés. Dans tous les cas, nos calculs, pour aussi sommaires qu'ils soient, laissent l'impression très nette d'un nombre énorme d'êtres humains rassemblés dans ces plaines fertiles, au passé historique. Du même coup I'on se rend compte des difficultés presque insurmontables qu'il $y$ a à vouloir établir un « recensement » quelque peu précis. 


\section{La vie des paysans chinois}

\section{II \\ LES MAISONS.}

Cinq cents ans environ se sont écoulés depuis que le neveu de Hung $\mathrm{Wu}$, fondateur de la dynastie des Ming, exécuta le grand raid qui allait l'amener de la capitale méridionale de la Chine jusqu'à la ville qu'on appelle maintenant Pékin, dans l'État dénommé Yen à cette époque. L'on dit généralement que ce fameux homme de guerre massacra tous les gens qu'il rencontra sur son passage et transforma en un véritable désert la région entière qui s'étend depuis le fleuve Yang-tzû jusqu'à Pékin. Les Annales relatent ses exploits par les mots : «Yen Wang balaya le Nord. » Après que ce jeune ambitieux eut dépossédé son neveu, véritable héritier du trône, il prit le titre de Yung Io, vocable qui allait devenir célèbre dans I'Histoire de la Chine. Pour réparer les ravages causés par une pareille randonnée, il ordonna l'émigration dans le Nord d'une partie de la population du Shanhsi et du Shan-toung oriental. La tradition rapporte que des masses de gens furent rassemblés près de la ville de HuntungHsien dans le Shan-hsi méridional et répartis dans la zone dévastée par la guerre et demeurée en friche. Il est certain que dans une grande partie des plaines de la Chine septentrionale, les habitants ne savent guère qu'une chose sur leurs origines, c'est qu'ils sont venus de Huntung-Hsien.

Il est surprenant qu'un peuple éminemment pratique comme les Chinois et qui possède un sens si aigu de l'orientation que 


\section{La vie des paysans chinois}

chacun localise le mal dont il souffre en indiquant, par exemple, « le côté Est de l'estomac », que ce peuple, dis-je, se montre indifférent à la régularité du plan de ses villes. Toute cité chinoise semble de forme quadrangulaire, mais ce n'est pas, je crois, trop s'avancer que de dire qu'aucune d'elles ne répond en réalité à ce tracé. L'on s'aperçoit, au contraire, que les enceintes présentent des parties courbes, des irrégularités voulues, et cela dans des buts géomantiques. En d'autres termes, les formes réalisées apportent la chance ou écartent la malchance en appliquant la science mystérieuse du feng shui ou géomancie. C'est ainsi que deux portes opposées d'une ville ne doivent pas être vis-à-vis l'une de l'autre ; si elles le sont, il faudra interposer une chicane pour empêcher les esprits méchants de tout bouleverser sur leur passage.

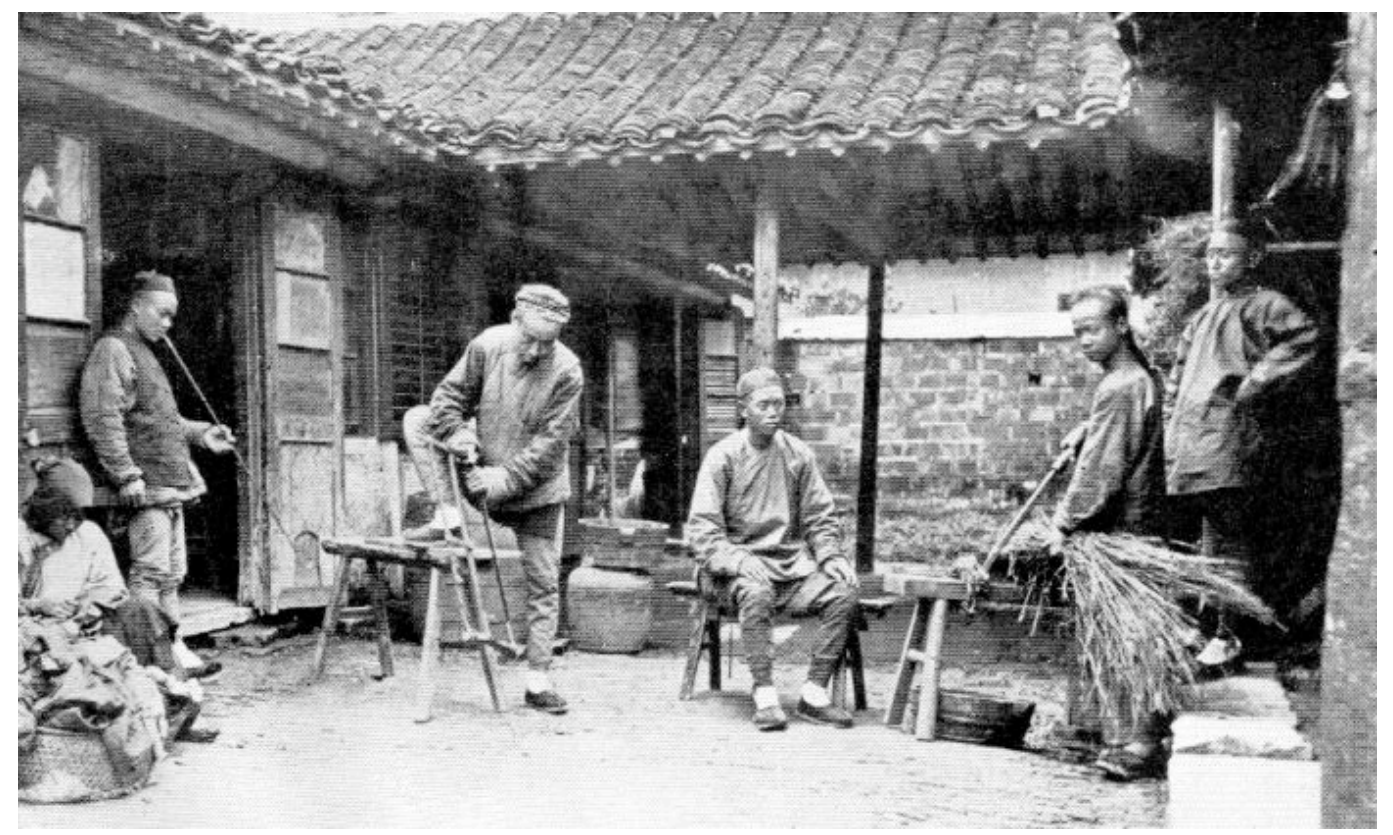

Paysans chinois chez eux

Dans les régions ouest de l'Empire, il est d'usage de parler du « tracé » d'une cité ou d'une ville. Pareille expression 


\section{La vie des paysans chinois}

s'appliquerait très mal à un village, car elle ferait croire à une étude graphique de la disposition des maisons alors que, en réalité, la fantaisie seule y préside. Un village chinois « a poussé »; comment et pourquoi, nul ne le sait, ni n'en a cure. A quelque époque lointaine, impossible à préciser dans l'obscurité du passé, des familles arrivèrent d'un endroit quelconque, campèrent là, et s'y firent une « habitation locale », à laquelle ils donnèrent sans doute leur nom, et ce fut le village. Il y a une rue, peut-être même un réseau de rues, mais il n'y en a pas deux parallèles, sauf accidentellement, et aucune n'est rectiligne. La rue est simplement cet endroit de passage qu'une longue expérience démontra comme le facteur nécessaire pour faciliter les communications entre les diverses parties du village et le monde extérieur. Non seulement elle est sujette à prendre des tournants aussi brusques qu'inexplicables, mais encore de mystérieuses fantaisies président à sa largeur essentiellement variable. Parfois, dans un village d'un quart de mille de longueur, aucune voie transversale ne permettra à un véhicule de passer de la rue de devant à une autre située en arrière. Et cela simplement parce que la ville a poussé ainsi et que personne ne put ou ne voulut intervenir utilement alors que bien des gens eussent peut-être souhaité autre chose. Dans la rue principale, dans d'autres encore débouchent, à angle droit, des allées étroites donnant accès aux cours sur lesquelles s'ouvrent les habitations. Les bâtiments qui bordent les principales voies publiques n'offrent aux regards du passant que de longs murs aveugles. Si, par hasard, une entrée est pratiquée sur l'une d'elles, une sorte d'avant-mur la protège contre les influences 


\section{La vie des paysans chinois}

mauvaises auxquelles sinon elles seraient exposées, en même temps qu'il dérobe l'intérieur à la curiosité des gens. Un village est de la sorte une ville en miniature, affligé de tous les maux de l'entassement excessif, quand même il serait planté au beau milieu d'une large plaine relativement peu peuplée. Que le terrain soit cher ou à vil prix, les villages présentent toujours le même aspect encombré et, dans les grosses agglomérations comme dans les petites, se manifeste la même indifférence à l'égard des exigences d'un développement ultérieur.

Les montagnes fournissent en abondance de la pierre que I'on utilise dans toutes les constructions des environs. Sombres, humides, malsains, ces logis deviennent particulièrement détestables pendant la période des grandes pluies. Plus désagréables encore sont les maisons souterraines creusées dans les épaisses couches de loess. Éclairées seulement sur le devant, elles ignorent tout mode de ventilation : aérer un logis est en effet un luxe qui n'est pas prévu lorsqu'on édifie une demeure chinoise.

Les matériaux mis en œuvre dépendent des ressources naturelles que fournit la région et qui sont le plus à portée de la main. La brique se fabrique partout en grande quantité ; elle est généralement d'un bleu gris analogue à la couleur des vêtements des autochtones. Cette teinte s'obtient en scellant hermétiquement le four dès que la cuisson des briques est terminée et en versant aussitôt sur l'extrados du bâti, disposé en forme de cuvette, des centaines de seaux d'eau. Celle-ci pénètre par infiltration à l'intérieur où elle se transforme aussitôt en 


\section{La vie des paysans chinois}

vapeur : au contact de cette dernière la couleur des briques se modifie. La rareté du combustible et la répugnance des Chinois à I'employer en quantité suffisante - ce serait du gaspillage ! - a pour conséquence de fournir un produit mal cuit, de qualité très inférieure en tant que matériaux de construction. Au lieu d'obtenir des briques dures comme de la pierre, semblables à celles de fabrication étrangère et revêtues d'un épais vernis de fusion, il arrive qu'une forte proportion des briques indigènes s'émiette dès qu'on les manie et, à les examiner de près, on s'aperçoit qu'elles sont remplies de trous comme du pain de bonne qualité ; chacune de ces cavités devient un tube d'aspiration par lequel pénètre dans les murs l'humidité du sol au grand détriment de l'immeuble dont les fondations et parfois aussi les murs sont bâtis en briques.

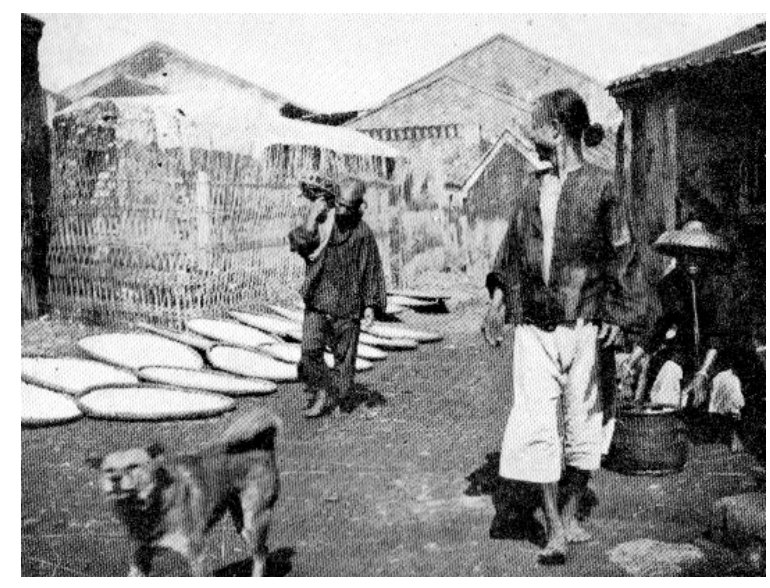

Dans un village du sud

Dans les campagnes, la plupart des habitations se construisent en adobes faits de limon pétri dans un moule puis durci au soleil auquel ces briques demeurent exposées jusqu'à la limite de leur contraction. Les plus grandes sont de deux à trois pouces d'épaisseur et larges d'un pied ; leur longueur atteint 


\section{La vie des paysans chinois}

souvent vingt pouces. Au terme de la dessiccation, elles pèsent plus de quarante livres. Fabriquées au moule, leur prix de revient ne dépasse guère un cash ou sapèque par unité. Si l'argile est damée dans le moule avec une lourde hie en pierre, elles valent deux à trois fois autant. Lorsque I'on confie cette fabrication à des spécialistes, la dépense est plus forte attendu que le propriétaire prend un homme supplémentaire pour l'approvisionnement d'eau et doit en plus distribuer du thé et du tabac à toute l'équipe d'ouvriers.

Les fondations des immeubles sont toujours en briques. A la hauteur d'un pied ou deux au-dessus du sol on les recouvre d'une couche de roseaux ou de quelque autre substance destinée à empêcher l'humidité de monter jusque dans les murs car, dans le cas contraire, ceux-ci s'effritent et se dissolvent comme du sucre sous l'action de la pluie. Dans toutes les parties de la grande plaine de la Chine septentrionale, le sol est tellement saturé de soude qu'à moins de prendre un soin extrême les murs les mieux établis présenteront en très peu d'années des signes manifestes de décrépitude.

En principe, et quels que soient les matériaux employés pour la maçonnerie, le toit de la maison reposera sur des poteaux indépendants des murs, ceux-ci ne constituant qu'un simple remplissage entre les pièces de bois, mais, dans les constructions à bas prix on supprime souvent ces supports par raison d'économie. Aussi, pendant les périodes de fortes pluies, lorsque I'humidité a suffisamment détrempé les fondations, des milliers de maisons, littéralement saturées d'eau, s'effondrent 


\section{La vie des paysans chinois}

sous le poids de la toiture, écrasant des gens et en blessant beaucoup d'autres. Dans certains districts, I'on se rapproche parfois du système de charpente des maisons étrangères, mais le mode courant est celui que nous venons de décrire. En I'un et l'autre cas, les pièces de bois, jouant le rôle de sablières, supportent de petits chevrons sur lesquels reposent des briques minces ou plus souvent des roseaux, des nattes et des tiges de sorgho ; par-dessus celles-ci est damée une couche de terre, élément essentiel de la couverture de la plupart des immeubles chinois. Le tout représente un poids énorme, extrêmement dangereux lorsque les bois de charpente commencent à pourrir sous I'action de I'humidité. Enfin les toitures plates servent de lieu de dépôt pour le combustible et les récoltes.

Si le village est établi dans un bas-fond, on a soin de construire sur des remblais artificiels. Mais, quelle que soit la nature du sol, un pareil volume de terres déplacées laisse autour de chaque agglomération une série de trous gigantesques qui recueillent les eaux de la zone environnante. Le village est ainsi ceinturé d'innombrables mares dont les canards, les oies, les cochons et, en été, les petits enfants sans autre vêtement que celui qu'ils doivent à la prévoyante nature, se disputent la jouissance.

Une humidité abondante constitue un merveilleux stimulant pour la pousse des arbres, et les bosquets à la végétation luxuriante produisent, à distance, un charmant effet dans la campagne. Cependant en s'approchant, I'on s'aperçoit que ces merveilleuses frondaisons abritent simplement des trous de boue 


\section{La vie des paysans chinois}

tandis que les maisons du village demeurent exposées impunément aux rayons torrides du soleil. Il se trouve bien parfois quelques arbres dans la rue principale, mais les cours des maisons sont généralement dépourvues de toute végétation. La vigne elle-même, qui pourrait atténuer l'inexprimable monotonie de ces plaines à teinte neutre est, tout au moins dans certaines régions, rigoureusement prohibée. Et pourquoi ? Simplement parce que ses branches s'abaissent vers le sol alors que les arbres pointent généralement leurs pousses vers le ciel : cultiver la vigne «porterait malheur » tandis que cuire au soleil pendant l'été faute d'ombrages ne porte pas malheur.

Un homme dont le grand-père avait été riche et qui se distinguait de ses voisins parce qu'il possédait un immeuble à deux étages, raconta à l'auteur de ce livre le fait suivant. Il se souvenait très bien que sa grand'mère passait son existence dans l'arrière-cour et qu'elle $y$ vivait dans une irritation perpétuelle parce que les hautes bâtisses du devant et les magnifiques ormes qui ombrageaient l'enclos ne lui permettaient pas de sécher son linge au soleil. Par la suite, la famille se trouva réduite à la pauvreté, l'immeuble à deux étages fut abattu et les beaux arbres en même temps, si bien que la génération actuelle est condamnée, comme bien d'autres familles, à étouffer dans une cour sans ombre et sans air ; en revanche, elle dispose d'espaces illimités - dont elle se sert très peu - pour faire sécher ses lessives. Ce luxe d'ombrages, refusé aux habitations des vivants, est, par contre, généreusement octroyé aux dieux qui n'ont pas de linge à sécher, et il arrive qu'un temple des plus modestes soit parfois entouré d'un bosquet de très vieux arbres. 


\section{La vie des paysans chinois}

L'architecture des Chinois a été décrite, d'un simple trait de plume et non sans exactitude, comme consistant uniquement en deux bâtons plantés debout et reliés dans le haut par un troisième disposé horizontalement. Les toits adoptent les formes les plus variées et certains semblent avoir eu pour modèle la tente du nomade bien que, comme I'ont remarqué le Dr Williams et d'autres voyageurs, rien ne prouve qu'il y ait le moindre rapport entre le toit chinois et la tente. Les Chinois répugnent en général aux habitations très hautes, aussi presque toutes les villes de l'Empire offrent-elles l'aspect d'une uniformité monotone qui contraste singulièrement avec celui d'autres grandes cités, celles d'Occident par exemple.

Si la ville chinoise n'offre rien qui puisse charmer l'œil du voyageur, il serait encore plus vain de demander au village des satisfactions esthétiques. Du reste, le mot « esthétique » n'existe même pas dans la langue chinoise et, s'y trouverait-il une expression équivalente, que les villageois $n^{\prime} y$ prendraient aucun intérêt. Les maisons bordent généralement le côté nord de l'espace réservé à la cour afin que leur façade regarde le sud, et si I'on a besoin de bâtisses supplémentaires, on les élève en équerre aux extrémités du pavillon principal : elles font ainsi face à l'Ouest et à l'Est. Lorsque le terrain disponible le permet, le côté sud de la cour est parfois occupé par une maison analogue à celle du nord ; comme celle-ci, elle peut être prolongée à ses extrémités par d'autres constructions à angle droit. Quelque nombreuse que soit la famille, quelle que soit sa fortune, tel est le type normal de I'habitation chinoise. Dans les villes, il subit des modifications multiples du fait de l'espace 


\section{La vie des paysans chinois}

assez restreint dont dispose le plus souvent le propriétaire, mais à la campagne, il prévaut partout.

Les questions de commodité n'interviennent pas dans la distribution intérieure d'un immeuble : I'on cherche seulement, en établissant les cloisonnements, à ce que les pièces puissent être couvertes par des bois de charpente d'une seule longueur. Ces solives étant généralement de faible équarrissage et de longueur médiocre, on s'en tient souvent à des chambres de dix à douze pieds de long et de forme légèrement trapézoïdale depuis le devant jusqu'au fond. Une maison ordinaire se composera de trois divisions de ce genre, à moins qu'il n'y en ait qu'une dont on aura fait une grande chambre et une plus petite au moyen d'une cloison. Il n'y a pas de plafond : le plan inférieur de la toiture, généralement peu élevée au-dessus du sol, en tient lieu. Les portes sont pour la plupart à deux vantaux qui viennent buter en haut et en bas contre les murs ; dans celle de l'entrée, il existe souvent une chatière pour chiens et chats. Les battants, faits de planches mal dressées et assemblées à joints plats, ne peuvent assurer une bonne fermeture : les bois de cette grossière menuiserie travaillent vite, ils se rétrécissent laissant entre eux des fentes qui permettent au passant de voir facilement ce qui se passe à l'intérieur.

L'été est très chaud dans la plupart des dix-huit provinces de I'Empire et pourtant ce n'est que dans quelques régions que I'on trouve, sur la façade de derrière des maisons, une porte faisant face à celle du devant, et assurant la ventilation de l'intérieur. Le châssis en bois qui sert de fenêtre est pris dans le mur en guise 


\section{La vie des paysans chinois}

de sécurité contre les voleurs ; souvent on le recouvre, même pendant la saison chaude, de papier huilé. Les portes d'entrée n'ouvrent pas directement sur la rue, et s'il existe des fenêtres sur la façade qui donne à l'extérieur, elles sont très petites et placées très haut.

Juste derrière la porte d'entrée est installé le fourneau de cuisine ; il a la forme d'une soucoupe et ses parois sont aussi minces que possible afin d'économiser le combustible. Dans tous les districts où il faut prendre des dispositions pour chauffer la chambre principale, on y arrive en amenant dans le $k^{\prime} a n g$, au moyen d'une tuyauterie plus ou moins compliquée, l'air chaud dégagé par ce fourneau primitif. Si les maisons sont recouvertes de chaume, l'ouverture pour le dégagement des fumées doit être percée près du sol afin d'éviter les risques d'incendie.

A l'extrémité du k'ang, - lequel sert de lit - sont les couvrepieds de la famille et toutes les caisses et malles qu'elle se vante de posséder, car c'est le seul coin de la maison qui, très probablement, est soustrait à I'humidité. Le foyer se trouve placé près de la porte où il souffle de violents courants d'air ; de plus les conduits de chauffage sont sujets à de fréquentes crevaisons, enfin il n'existe pas de cheminée vraiment digne de ce nom : sous de pareilles conditions, la fumée se répartit impartialement dans toutes les pièces du logis et les produits de la combustion viennent se coller aux murs sur lesquels ils forment une couche de colmatage créosoté qui atteint parfois jusqu'à un pouce d'épaisseur et même davantage. 


\section{La vie des paysans chinois}

Au-dessus du foyer est accrochée l'image du dieu de la cuisine que le peuple considère comme une déification de Chang Kung, homme illustre du VIII ${ }^{e}$ siècle, qui réussit à couler une existence de paix dans un logis où cohabitaient neuf générations de sa famille. Quant aux cent chiens complétant ce phalanstère, ils avaient, paraît-il, la politesse d'attendre pour se mettre à table celui d'entre eux qui se trouvait en retard.

L'Empereur régnant, de la dynastie T'ang, envoya un jour chercher Chang Kung et voulut connaître le secret d'une si merveilleuse harmonie : le sage Céleste, ayant demandé un pinceau à écrire, traça à plusieurs reprises le mot « patience ». Depuis lors, il est de tradition de placer dans chaque demeure l'image du patriarche afin de stimuler les gens à suivre son exemple, mais malheureusement ce but n'est guère atteint.

Que les demeures chinoises soient froides en hiver, chaudes en été, remplies de fumée tout le long de l'année, ce sont des inconvénients que l'on ne peut éviter. Même par les températures les plus basses, on ne réussit à se défendre un peu du froid qu'en se blottissant sur le k'ang. Et c'est ainsi que les femmes chinoises parlent souvent du k'ang comme d'une « mère ». Une pièce privée de ce moyen de chauffage est presque considérée comme inhabitable mais, au point de vue européen, rien ne semble plus incommode que ces sortes de calorifères. La chaleur se répand très lentement et, au cours d'une longue nuit, I'on peut être tour à tour trempé de sueur ou glacé jusqu'aux os lorsque la température du $k^{\prime} a n g$ diminue. Les briques d'adobe dont est composé le k'ang se brisent et 


\section{La vie des paysans chinois}

s'émiettent lorsqu'elles sont soumises à des pressions inégales ; cette maçonnerie rudimentaire se fend, se désagrège, de sorte que les k'ang des auberges réservent parfois au voyageur des surprises désagréables. Ils sont toujours I'habitat de choix d'innombrables parasites auxquels les Chinois sont trop accoutumés pour songer à s'en plaindre. Même lorsque, au printemps, I'on pulvérise les adobes afin qu'ils servent d'engrais créosoté dans les champs, la vie animale qui grouille dans les murs suffirait pour assurer en peu de temps le repeuplement de I'univers.

L'on ne saurait être surpris de voir disparaître au cours des années les titres de propriété des habitants ; il n'existe pas en effet, dans un immeuble chinois, le moindre recoin où l'on puisse garer des papiers avec quelque sécurité. Un placard se fabrique en arrachant des briques pour pratiquer dans le mur une cavité ; une simple planche reposant sur deux chevilles constitue la seule étagère dont dispose un lettré dans son appartement. Les portes se ferment en accrochant l'anneau d'une chaîne à un crampon de fer fixé dans le chambranle du haut. Quant aux cadenas chinois, un bout de fil de fer, une grosse aiguille, une branche d'arbre sèche suffisent pour les crocheter : ils n'assurent aucune protection véritable. Les voleurs sont toujours munis d'un jeu de fausses clefs, mais souvent ils n'ont, pour pénétrer dans I'intérieur, qu'à soulever les pentures des portes hors des fiches qui servent de gonds. Du reste, rien n'est plus simple que de percer ces murs en adobes. Dans les riches villages du Shan-hsi, on leur donne au moins six pieds d'épaisseur pour les garantir contre les entreprises des perceurs de murailles. 


\section{La vie des paysans chinois}

Dans les maisons ordinaires le sol naturel tient lieu de plancher, mais la terre n'est pas battue en surface plane, elle présente des dénivellations systématiques car, nous fut-il répondu un jour que nous demandions la raison de ces inégalités, les liquides répandus par terre s'écoulent ainsi plus facilement et d'eux-mêmes. C'est dans les angles des chambres que sont suspendus, mais souvent aussi couchés par terre ou rangés debout le long des murs, les nombreux ustensiles ménagers pour lesquels il ne se trouve aucun autre emplacement. Des jattes de grain, des outils agricoles, de grossiers métiers à tisser le coton, des rouets à filer, des paniers de toutes dimensions et de toutes formes, un ou deux bancs, peut-être une chaise, obstruent le reste d'espace disponible, tandis que du toit, gluant de suie, pendent des articles divers qui désencombrent ainsi le sol ; chacun les décroche avec un bout de perche lorsqu'il veut s'en servir. La maxime « une place pour chaque chose et chaque chose à sa place » serait d'une application malaisée dans un intérieur chinois à surface toujours très réduite.

Dans la petite cour règne une égale confusion. Chiens, chats, poulets, bébés jouissent d'une sphère d'action extrêmement limitée ; généralement ils se répandent dans la rue, simple extension de la maison. Si la famille possède des animaux, il faut leur trouver une place dans la cour. Néanmoins, lorsque ces bêtes ne sont pas au travail, elles passent leur temps retenues par une petite corde à un piquet solidement enfoncé dans le sol devant la demeure de leur maître. Quant aux cochons, on les parque dans une sorte de cavité profonde aux parois consolidées 


\section{La vie des paysans chinois}

par un revêtement en adobes ; un escalier très raide leur permet de monter jusqu'à un petit trou, sorte d'auge creusée dans l'aire de la cour près de l'orifice de leur écurie - dans beaucoup de régions, les seuls domiciles que I'on puisse trouver ayant deux étages !

Le village chinois est toujours une ville en miniature, non seulement par ses arrangements intérieurs - ou par son manque d'arrangements - mais aussi à cause du mur d'enceinte qui le protège.

Il y a quelques années, plusieurs régiments en station à Shantung, près du Fleuve Jaune, se mutinèrent, massacrèrent un officier, après quoi ils rentrèrent chez eux. La nouvelle de cet événement se répandit aussitôt dans la province entière; les habitants de la région, pris de peur, s'attendaient à tout moment à recevoir la visite des soldats qui sûrement allaient piller et tuer. La panique fut si grande que les villageois des agglomérations situées à des centaines de milles du théâtre de l'émeute s'entassèrent dans des chariots de ferme, abandonnèrent leurs récoltes, et, renonçant à la moisson, s'en vinrent chercher un abri derrière les murailles des grandes villes. Les pertes subies de ce chef furent énormes.

Pareil incident peut se renouveler à n'importe quel moment ; la grande rébellion des Taïpings, il y a un demi-siècle, a laissé dans les campagnes une impression ineffaçable d'insécurité, d'insécurité telle que l'offre un village sans mur d'enceinte. Quoique ces murailles aient rarement plus de 15 à 20 pieds de hauteur, elles ont leur utilité lorsque des bandes de pillards 


\section{La vie des paysans chinois}

battent la campagne dans les années de mauvaises récoltes. Quelle que soit leur valeur défensive contre une attaque méthodique bien dirigée, l'expérience a démontré qu'elles suffisent souvent à éloigner le flot des envahisseurs et à le détourner vers d'autres villages plus accessibles. La simple rumeur d'un soulèvement incitera fréquemment les villageois à lever une taxe dans la région afin de réparer leurs remparts en terre auxquels ils accordent, non sans de bonnes raisons, beaucoup plus de confiance qu'aux manœuvres prudentes et dilatoires des autorités locales : ces représentants du Gouvernement ne sont généralement pas en état de tenir tête à des forces résolues et organisées, et plus particulièrement à des rebelles surexcités par de sérieux et réels griefs. 


\section{La vie des paysans chinois}

\section{III \\ LES NOMS DES VILLAGES.}

L'idiome chinois est qualifié à juste titre de langue poétique. Les titres des Empereurs, les noms des individus, les enseignes des magasins, ont tous une signification ingénieuse. Aussi éprouve-t-on quelque déception à constater que les noms des villages chinois - contrairement à ceux des villes - ne sont généralement ni poétiques, ni heureusement imaginés. En raison de l'incessant accroissement du nombre des hameaux, I'on fait trop d'emprunts au langage pour que ceux-ci soient toujours réussis. Presque tous les surnoms chinois servent à désigner des villages, de même que dans d'autres pays nombre d'établissements portent les noms des familles qui les ont créés. Parfois deux surnoms ou davantage sont accolés pour indiquer une localité, tel Chang Wang Chuang, le village des familles Chang et Wang. Il arrive souvent que par suite des changements survenus avec le temps dans les familles qui donnèrent leur nom à une agglomération, il ne reste plus sur place un seul de ses représentants. En pareil cas, on conserve la dénomination, mais parfois aussi on la modifie, bien que le souvenir des circonstances dans lesquelles le changement se produisit puisse être perdu depuis longtemps.

Le temple est généralement la construction la plus en évidence dans un village et il donne souvent son nom au centre rural. S'élève-t-il dans un enclos ceint d'un mur enduit en plâtre 


\section{La vie des paysans chinois}

rouge, le village s'appellera le Temple Rouge. Au bout de quelques années le revêtement tombe, mais le nom reste. De temps à autre, on associe les temples aux familles qui contribuèrent pour une grosse part à leur construction et, très probablement, le nom du village en découlera, comme Wang Chia Miao - temple de la famille Wang -, Hua Chia Ssu - le monastère de la famille Hua - . S'il existe deux temples voisins et de même aspect, le village pourra s'appeler le Temple Double et, de façon générale, lorsqu'un édifice de ce genre présente quelque particularité, celle-ci se trouve stéréotypée dans le nom du village.

La coutume de recourir aux noms de famille - et aux temples - pour baptiser les agglomérations rurales est une source inépuisable de confusions, le même nom se répétant à l'infini. De plus le système postal n'oblige nullement les bureaux de poste à avoir chacun une désignation spéciale qui empêche de les confondre avec leurs similaires de la même province. En conséquence les noms communs deviennent tellement communs qu'ils perdent toute valeur en tant que désignations précises. «Chang, Wang, Li et Chao » sont les quatre surnoms les plus répandus, les deux premiers tenant largement la corde sur leurs rivaux. Dans un district, le nombre d'endroits qui portent le ou les mêmes noms est si considérable qu'il échappe à tout relevé. Prenons en exemple huit ou dix villages de la famille Wang : on dira le grand village Wang, le petit village Wang, le village de devant, celui de derrière, celui près de la rive, etc. En dépit de cette complexité des vocables, il serait plus facile de s'en tirer si les autochtones employaient toujours la même appellation pour 


\section{La vie des paysans chinois}

désigner la même localité, mais tout nom où entre le mot Wang est simplement appelé le village Wang, et ce n'est qu'après de laborieuses investigations que l'on arrive à identifier parmi tous ces Wang celui que I'on cherche.

Pareille ambiguïté se retrouve le long des routes impériales. Les hameaux où I'on vend des vivres et dans lesquels les voyageurs trouvent un gîte pour la nuit sont appelés « magasins »; chacun d'eux est désigné d'après la distance à laquelle il se trouve de la ville du district la plus proche, et I'on dit : Magasin de Cinq milles, de Dix, de Vingt, de Trente milles, etc. Toute ville de district peut avoir ainsi des magasins échelonnés sur chacun des côtés de la route et, tandis que celui qui se trouve à vingt milles (Ii) au nord se nommera Magasins de Vingt $L i$, il s'en trouvera un autre désigné pareillement dans la direction du Sud, d'où grand embarras pour le voyageur qui finit par ne plus savoir où il est. Enfin, le Magasin Trente Li d'une ville peut être confondu avec le magasin Trente Li de la ville voisine. Il arrive fréquemment qu'on rencontre un hameau insignifiant dont le nom se compose de quatre ou cinq caractères ; la prononciation locale en est généralement difficile à saisir, les mots étant émis comme le son prolongé de plusieurs syllabes. On se trouve alors amené à faire des abréviations, la même dénomination ayant parfois deux ou trois modes différents de prononciation, à la stupéfaction de l'étranger et au grand amusement du rustaud né dans l'endroit même, lequel ne peut concevoir qu'il y ait quelque difficulté à comprendre une appellation qui lui est aussi familière que son propre nom. 


\section{La vie des paysans chinois}

Une autre source de confusion dans la nomenclature des villages résulte de cette habitude presque universelle des autochtones de faire, sans raison apparente, des variantes dans un ou plusieurs caractères du mot. Ces changements n'ont aucun rapport avec l'euphonie, ils ne facilitent en rien la prononciation mais semblent provenir d'un besoin irrésistible de changement et d'une profonde antipathie du Céleste pour tout ce qui est uniforme. Ainsi un village dont le nom véritable est $\mathrm{Li} \mathrm{Ku}$ Ssû, - ancien monastère de la famille $\mathrm{Li}$, - sera généralement appelé Li Kuang Ssû - un autre connu sous la dénomination de Yên Tê Chuang - bienveillance et vertu - deviendra couramment Yên Wang Chuang. Pareillement I'on désignera un même petit hameau par deux noms différents qui n'ont entre eux aucune attache, duplication ne servant qu'à créer de la confusion. C'est ainsi qu'un village dont le nom dérive de celui d'un temple, tel Hsûan Ti Miao - le temple de Hsûan Ti - est aussi connu sous le nom de Chang Chuang - le village de la famille Chang - mais comme il existe dans les environs beaucoup d'autres villages des familles Chang, I'on dénommera I'un d'eux pour le distinguer des autres, «village de la famille Chang qui a le temple de Hsûan $\mathrm{Ti} \gg$ ! Bien des gens ont I'occasion d'écrire des noms de villages tout en n'ayant qu'une notion très vague des caractères chinois, et ils composeront probablement un caractère faux qui aura la même consonance que le véridique. Aussi est-on toujours dans I'incertitude quant au vrai nom d'un endroit. Pour tous les Chinois, en effet, un nom en vaut un autre, et, dans ces questions de même que dans 


\section{La vie des paysans chinois}

beaucoup d'autres, il semble que les Célestes n'ont aucune intuition de ce qui est bon ou mauvais.

Les villages chinois, tels les Chinois pris individuellement, sont sujets à recevoir des surnoms. C'est ainsi que très souvent, comme pour les êtres humains, le surnom supplante le nom originel dont il ne reste bientôt plus trace dans la mémoire des gens. Cette observation permet d'expliquer les appellations singulières de beaucoup de localités. Un marché situé sur la grande route et dont les sources ne fournissaient qu'une eau jaunâtre fut appelé le «Magasin d'Eau Amère », mais comme ce surnom sonnait désagréablement à l'oreille, il fut changé sur le registre des impôts en celui de «Magasin d'Eau Douce ». Si quelqu'un demande comment il se fait que la même source puisse donner à la fois de l'eau amère et de l'eau douce, on lui répond avec une simplicité qui désarme : « Magasin d'eau douce » est la même chose que «Magasin d'eau amère »! Un village situé au bord d'un fleuve portait les noms des deux familles les plus notables du lieu ; survint une crue énorme ; les habitants perdirent de vue l'appellation courante et la remplacèrent spontanément par « Regardez I'Eau ». Mais celle-ci à son tour ne suffit pas à satisfaire leur soif de variété et maintenant le nom est écrit et prononcé comme s'il signifiait «Regardez le Tombeau »! Un hameau qui tenait son nom de la famille Liu comptait parmi ses habitants un certain matamore. Un jour, au cours d'un procès, cet homme apparut avec un œil poché, et aussitôt le village de s'appeler «Village de Liu à l'œil poché ». On peut encore citer une ville qui reçut le surnom de « Dent Tombée » simplement parce que l'agent de police de 


\section{La vie des paysans chinois}

I'endroit venait de perdre son incisive médiane (Lao Ya Chên). Puis l'incident fut oublié et l'appellation se transforma en Lao Kua Chên - « Ville au Marché à Corneilles » - toujours en usage.

Dans un certain village la plupart des familles, faisant cause commune avec des concitoyens catholiques, abattent tous les temples et aussitôt on applique au village le sobriquet Wu Shên Chuang - Village sans Dieux - Les exemples suivants d'appellations bizarres proviennent d'une région qui n'a que quelques milles carrés, et toute autre zone en fournirait sans doute d'analogues. Nous citerons Yü Ma Yüan - la Cour Impériale des chevaux - que la tradition locale fait remonter à l'époque du fondateur de la dynastie des Sung et qui a été transformé en Chih Ma Yüan - Jardin des Sésames - . « Fin de Cave » est un village situé dans une grande plaine et de vagues légendes prétendent qu'il s'y trouve un souterrain. «On voit le Cheval »; «Village des paroles du Cheval » conserve la légende d'un cheval parlant. Pour en finir nous citerons encore : «Village du Taureau de la Famille Sun », «Village de la Chienne », «Village du grand Melon de la famille Wang », «Village du Panier du Village Liu », «Village du Tigre qu'on attrape », « Nid du Canard de la famille Chou », «Cheval sans Sabot», «Village de Chang à la Bouche de Fer », «Village du Faisan Sauvage de la famille Ts'iu », « Dent de Chien de la famille Wang », «Village du Magistrat affectueux et bienveillant », «Village des Fabricants de Peignes fins », - Pi-tzuchiang Chang - devenu maintenant le «Village où ils ont des Nez Épatés »! 
La vie des paysans chinois

(a) 


\section{La vie des paysans chinois}

\section{IV \\ LES CHEMINS RURAUX.}

(a)

Les Chinois vivent très à l'étroit dans des quartiers extrêmement resserrés, si bien que la plus grande partie du travail ménager se fait au dehors. Même dans les villes percées de voies particulièrement exiguës la rue est toujours encombrée de vendeurs ambulants en nombre aussi grand qu'il y a d'articles qui se vendent et par des artisans qui n'ont d'autre boutique ou

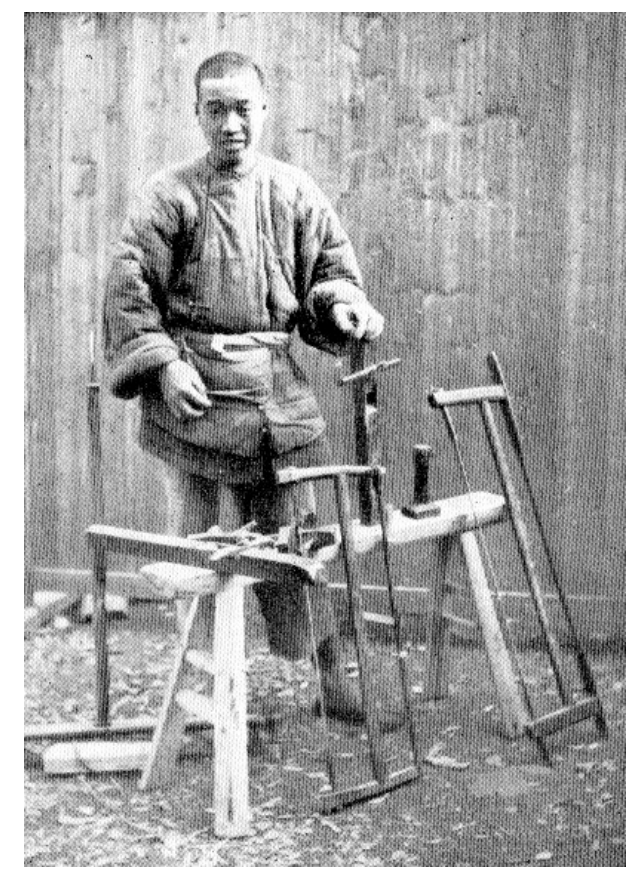

Un élément de force : I'artisan

atelier que la rue même. Le boucher, le boulanger, le fabricant de bougies, d'autres fournisseurs encore dépêchent leurs vendeurs sur la voie publique où ils entravent à qui mieux mieux la circulation. Plus la rue est vaste et plus on l'utilise pour des fins auxquelles elle ne fut jamais destinée, si bien qu'il est souvent 


\section{La vie des paysans chinois}

aussi difficile de passer par les rues de Pékin, pourtant très larges, que de se frayer un chemin dans les boyaux étroits de Canton. En Chine une «grande route impériale » n'est pas une voie que I'Empereur entretient soigneusement, mais plutôt une voie que I'on devrait entretenir pour I'Empereur. Toutes ces grandes artères ne sont en réalité que de mauvaises routes, car n'étant jamais réparées, elles deviennent bientôt pires pour le trafic que l'absence même de tout chemin.

Si ces observations s'appliquent en toute justice aux routes principales de l'Empire, que dirons-nous de celles qui servent à faire communiquer les villages entre eux ? Chacune représente simplement la contribution forcée du propriétaire terrien au bienêtre de la collectivité. C'est autant de terre sur laquelle il doit payer l'impôt et dont il ne retire pas plus d'avantages que n'importe quel autre usager. Chaque possesseur de terres s'appliquera donc à imposer un tracé longeant la limite de son bien de façon à ne fournir au chemin qu'une moitié de sa largeur. Mais comme les extrémités de ses parcelles de terrain représentent généralement une ligne brisée, la route aura soin d'épouser ce contour polygonal afin de satisfaire aux conditions voulues par le propriétaire. De la sorte, l'on est souvent obligé, en pleine campagne, de parcourir une très longue distance pour se rendre à un endroit très proche.

Les voies ordinaires de communication suffisent à peine au passage d'un véhicule. Lorsqu'un voiturier veut dépasser celui qui le précède, il n'a d'autres ressources que de passer sur les moissons voisines et le fermier, de son côté, creuse le long de 


\section{La vie des paysans chinois}

son champ un fossé profond pour empêcher les empiètements. Bien entendu, quand il est appelé, lui aussi, à circuler en voiture, il fait comme les camarades et ne respecte pas davantage le bien d'autrui, d'où résulte entre cultivateurs un état de guerre permanent auquel il est impossible de remédier. Le principe adopté par les Occidentaux d'après lequel toute route est reconnue d'utilité publique, non soumise à l'impôt et d'une largeur fixe délimitée, échappe totalement à la compréhension du Céleste. Là où le terrain a une valeur intéressante et est entièrement propriété privée, il ne saurait être question d'entretien de la route. Où prendre les terres nécessaires aux réparations ? Tout chemin en arrive ainsi à un état tel que l'on ne peut songer à le réparer. La circulation très active durcit et use le sol ; elle l'abaisse au-dessous du niveau des champs adjacents. Les roues des véhicules creusent des ornières profondes, écrasent la terre ainsi déplacée et les gros vents se chargent de l'enlever et de couvrir les champs d'une poussière épaisse.

Par contre, pendant la saison des pluies, les eaux de ruissellement s'écoulent de ces mêmes champs dans le chemin creux bientôt transformé en mare. Quelque fissure leur permet de s'échapper dans une route encore plus basse et il s'établit ainsi un cours d'eau qui, simple filet d'abord, devient ruisseau pour se transformer plus loin en un torrent impétueux dont le courant approfondit sans cesse le lit creusé dans des terres friables. Cette évolution, renouvelée depuis des décades et des centaines d'années, transforme la route primitive en une rivière coulant à plusieurs pieds au-dessous du niveau des champs. Un vieux proverbe chinois nous apprend qu'une route vieille de mille 


\section{La vie des paysans chinois}

ans se transforme en un cours d'eau, tout comme une belle-fille « devient avec le temps une belle-mère ».

Lorsqu'un chemin en est arrivé à l'état que nous venons de décrire, il ne peut plus servir à la circulation : impraticable en tant que route, il n'est pas navigable comme voie d'eau. Les communications entre villages situés le long d'une même grande route se trouvent ainsi interrompues pendant des semaines. Les eaux de ruissellement désagrègent et entraînent I'humus des champs et mettent à nu un sous-sol aride. Lorsque, après les pluies, le paysan vient examiner l'état de ses terres et qu'il constate les dégâts, il n'est guère embarrassé pour parer au dommage. Les matières solides enlevées aux champs ont laissé dans les canaux où s'écoulent les eaux d'épais dépôts de bonne marne argileuse, plus abondants encore dans les lits des anciennes routes. Les fermiers y font de copieux emprunts pour reconstituer leurs champs, de sorte qu'en une seule saison le niveau de ces voies devenues momentanément des ruisseaux peut s'abaisser de plusieurs pieds. Ces terres sont après tout leur bien, pourquoi ne les reprendraient-ils pas ? Si le public désireux d'utiliser la route ne la trouve pas en assez bon état, qu'il aille en chercher une autre !

Pourtant, lorsqu'une voie de communication devenue très mauvaise doit être définitivement abandonnée, il faudra bien en ouvrir une nouvelle, à moins que l'on ne réussisse à remettre en service un chemin précédemment délaissé. Et telle est la solution le plus souvent adoptée. Qui, en effet, se résignerait à sacrifier quelques parcelles de sa pauvre ferme pour obliger un être aussi 


\section{La vie des paysans chinois}

impersonnel que le public ? En face d'une inondation provoquée par de fortes pluies ou par les débordements d'un cours d'eau, le Céleste ne connaît qu'un seul remède : il s'assied tranquillement devant l'eau qui coule et attend que le flot envahisseur se soit retiré. Quant à construire une route en remblai à travers des champs exposés aux inondations, on n'y songe même pas, et cela pour trois raisons. Personne n'accepterait d'abandonner un pouce de terrain à cet effet, personne ne lèverait le doigt pour entreprendre un pareil travail - sauf peut-être les riverains éventuels de ce nouveau tracé - et enfin, jamais un paysan ne consentirait, quelque intéressé qu'il soit à pouvoir disposer d'une bonne route, à fournir des matériaux pour sa construction.

En voici une confirmation intéressante. Dans un petit village du Chih-li central habitait une dame d'un certain âge, de situation aisée, et dont les terres se trouvaient chaque année exposées à des dégâts provoqués par les grosses pluies. Le mal devenait si sérieux qu'il était souvent impossible de charrier les récoltes jusqu'à la ferme; il fallait les faire transporter à dos d'homme par des gens qui pataugeaient dans la boue ou, si le plan d'eau était suffisant, utiliser péniblement de petits radeaux. Cette femme, d'esprit relativement éclairé et assez pratique, eut l'idée de faire creuser par son personnel de grands fossés le long de la route et de relever celle-ci par des remblais jusqu'audessus du niveau maximum des inondations. On remédierait ainsi, de façon permanente, aux ravages des eaux. Le travail fut exécuté aux frais de la dame et la route ainsi établie apporta à la région entière d'indiscutables avantages. L'hiver suivant, le village eut à enregistrer plusieurs cas mortels d'influenza. Après 


\section{La vie des paysans chinois}

le cinquième ou le sixième décès, les villageois s'agitèrent : désireux de découvrir à cette calamité une cause quelconque, ils s'en prirent à la nouvelle grande route. Si un nouveau décès se fût produit on les aurait certainement vus s'armer de bêches pour ramener ce chemin à son ancien niveau et opposer ainsi à la grippe une barrière infranchissable !

Pourtant, il serait possible d'assurer en tout temps la viabilité des grandes routes au lieu de laisser la circulation être interrompue pendant plusieurs mois de l'année. Il suffirait pour cela que les gouverneurs des provinces décidassent les divers magistrats des districts traversés par ces voies à imposer aux riverains le curage et le bon entretien des fossés de façon à débarrasser ces importantes artères des eaux croupissantes. Quant aux chemins de petite communication entre les villages, il n'y a absolument aucun espoir d'amélioration aussi longtemps que le Chinois de la campagne se refusera à comprendre qu'en pareille matière l'intérêt d'un seul se confond avec l'intérêt de tous, et qu'une dépense judicieusement consentie est une véritable économie : pour l'instant, le Céleste demeure aussi fermé à une pareille conception qu'à l'intelligence du binôme de Newton. 


\section{La vie des paysans chinois}

\section{V \\ LES BACS FLUVIAUX.}

Dans la région septentrionale de la Chine les cours d'eau, bien que moins nombreux que dans le Sud, y créent plus d'obstacles à la circulation en raison du grand nombre de véhicules et d'animaux occupés aux transports par voie de terre. Le camion chinois est une spécialité du Nord dont le type n'a guère changé depuis les temps les plus reculés. Le chariot à voyageurs, traîné dans les villes par une seule bête, comporte à la campagne un attelage double. La charrette qu'emploie la grande masse de la population rurale pour transporter son matériel de culture ainsi que pour parer à tous ses besoins domestiques, est d'un poids inimaginable. Nous eûmes un jour la curiosité d'en peser quelques éléments sur une bascule européenne : la roue seule pesait 177 livres et son essieu 57 , soit 411 livres pour un train de roues du véhicule. Les timons sont d'une solidité à toute épreuve - telle qu'il la faut ici - et lorsque la charrette verse, ce qui n'est pas rare, la bête de derrière tombe également et se trouve dans l'impossibilité de se relever. Les mules, les chevaux, les vaches, les ânes sont indistinctement attelés à ces chars primitifs et concourent à la traction au moyen de traits, simples cordes fixées à l'essieu. Arriver à ce que toutes ces bêtes fournissent simultanément leur effort est une tâche qui, sans doute, ne tenterait jamais un Occidental et même s'y risqueraitil, qu'il échouerait certainement. Dans son livre sur la campagne 


\section{La vie des paysans chinois}

de 1860 , le général Wolseley raconte qu'au cours de la marche des troupes anglaises sur Pékin, le convoi fut un jour abandonné à Ho Hsi Wu par tous ses convoyeurs indigènes; aucun soldat britannique ne parvint à remettre en marche les attelages composés d'animaux du pays.

Dans ces conditions de voyage, la barque chinoise représente I'un des spécimens les plus caractéristiques du génie national. Les bacs sont nombreux, nombreux également les chariots destinés a être transbordés sur ces bacs. La façon de procéder des Célestes en pareille occurrence est intéressante à observer, elle réserve à l'étranger d'agréables surprises.

Une piste à flanc de berge descend de la plaine jusqu'au bord de la rivière en un endroit légèrement remblayé pour permettre au bac d'accoster par un de ses petits côtés. Cette voie d'accès est naturellement trop étroite pour que deux charrettes puissent $s^{\prime} y$ croiser ou se dépasser. Ce n'est pas petite affaire que de conduire un chariot sur cette piste étroite et raide. L'opération requiert toute I'habileté du charretier chinois, ce qui n'empêche pas les accidents d'être assez fréquents. Lorsque l'équipage est heureusement arrivé en bas, on dételle les bêtes qu'il s'agit alors de faire passer dans le bateau. Certaines ne donnent aucun mal, elles se précipitent d'un seul bond à n'importe quel endroit du bac aux risques et périls des voyageurs qui peuvent déjà être à bord. Aucun animal ne se sent en sécurité sur cette aire faite de planches étroites, irrégulières, gondolées en tous sens, les seules qui se rencontrent dans le commerce. Mais plus ce plancher est ondulé mieux cela vaut, et cela pour une raison que 


\section{La vie des paysans chinois}

le passager n'est pas long à découvrir. Il ne s'agit nullement d'introduire les bêtes sur le bateau avec le minimum de peine, les Célestes recherchent au contraire le maximum de difficultés, seul moyen pour des hordes de fripons sans sou vaillant de pourvoir à leur misérable subsistance. Lorsqu'un animal se refuse absolument à quitter la terre ferme - ce qui arrive presque à chaque traversée - on lui bande les yeux avec la ceinture de l'un des passagers, puis on le fait tourner sur place indéfiniment jusqu'à ce qu'il ait oublié l'endroit où il se trouve et le bac lui-même ; on l'amène auprès du bateau et on le presse d'enjamber l'extrémité du plancher, ce qu'il continue à refuser obstinément. On lui entortille alors la queue - à moins qu'il ne s'agisse d'une mule - , on place au-dessous et à sa naissance un fort bâton destiné à servir de levier : six hommes s'attellent à chacune de ses extrémités tandis que six autres tirent à qui mieux mieux sur des cordes fixées aux cornes ou à la tête de I'animal. Après une lutte qui se prolonge souvent pendant une demi-heure, non sans de nombreux et cruels coups aux malheureux récalcitrants, ceux-ci finissent par être tous installés à bord ; les plus agités passent leur temps à piaffer dans tous les sens au plus grand dam des malheureux passagers.

Parfois les bêtes affolées bondissent par-dessus les platsbords et tombent dans l'eau ; elles s'efforcent de gagner la rive à la nage, mais le plus souvent elles se noient. L'auteur peut même citer à ce propos le cas d'un convoyeur qui fut précipité par-dessus bord tandis qu'il s'efforçait de retenir ses bêtes sur le bateau. Entraîné par le courant rapide de la rivière, il ne put se sauver. Circonstance malheureuse qui valut d'autre part un 


\section{La vie des paysans chinois}

retard interminable à un voyageur en route pour aller passer son examen d'été, car le magistrat du district le retint à son yamen à titre de témoin.

Abandonnons maintenant les animaux et occupons-nous du chariot. Celui-ci doit être roulé à bras d'homme sur le bac. Il se peut qu'on ne dispose à cet effet que d'un seul manœuvre accompagné parfois d'un petit garçon, alors que pour faire franchir à un véhicule lourdement chargé le ressaut existant entre le bord du remblai et l'arrière du bac aux planches raboteuses, il faudrait le concours de dix à quinze hommes. On se tire d'affaire en usant du procédé couramment employé dans les enterrements chinois : un chef d'équipe rassemble une bande plus ou moins nombreuse de manœuvres et les excite au travail en leur faisant pousser des hurlements sauvages.

Tout individu qui a simplement posé la main sur la charrette doit toucher un salaire. La seule limitation à une pareille exploitation est le nombre restreint d'individus pouvant se grouper en même temps autour du véhicule. Comme dans toute affaire chinoise, il n'existe pas de tarif normal pour ces transbordements, et l'on s'en tient à la règle adoptée par certains directeurs de voies ferrées administrées par des Occidentaux, laquelle consiste à charger le véhicule jusqu'à sa limite de résistance : si, par exemple, il a été convenu que le

voyageur paierait seulement 100 cash pour passer d'une rive à l'autre avec son équipage, l'entreprise du bac ne touchera que le tiers de cette somme et le reste sera attribué aux hommes qui, après s'être offerts à traîner le véhicule sur le bateau, l'en ont 


\section{La vie des paysans chinois}

retiré de l'autre côté du fleuve. Il arrive ainsi que chacun de ces manœuvres bénévoles ne reçoit pour son travail intermittent que 4 cash, parfois 2 et même souvent un seul.

Sur la rive opposée le débarquement présente un tout autre aspect ; il s'opère en moins de temps car les bêtes ont hâte de retrouver la terre ferme, mais leur sortie et l'enlèvement des véhicules rencontrent également des obstacles. L'opération tourne à la bousculade tellement les gens qui attendaient le bac pour traverser à leur tour sont impatients de s'assurer une place, ils se précipitent sur le bateau sans même attendre qu'il ait été évacué par ses occupants. Ici, comme partout ailleurs en Chine, aucun inspecteur, aucune police n'assure le bon ordre, tout est laissé à la chance ou à la fatalité. Il est vraiment surprenant que personne ne soit tué au cours de ces transbordements.

L'Occidental au cerveau fourmillant d'idées sur la manière dont les choses devraient se passer en Orient, imagine sans peine une méthode qui mettrait un peu d'ordre dans cette extravagante confusion. Avant tout, il y aurait des tarifs fixes et une large rampe d'accès pour descendre jusqu'au niveau des eaux ; sur chaque rive on disposerait d'une plateforme mobile, au plancher bien dressé, à l'aide de laquelle les animaux et les voitures pourraient passer facilement sur le bac. Les bêtes seraient parquées dans un coin délimité du bateau, les passagers disposeraient également d'un espace déterminé : de la sorte, on gagnerait du temps, on s'épargnerait bien des efforts, et la traversée d'un cours d'eau serait quelque peu modernisée. 


\section{La vie des paysans chinois}

Maintenant, réfléchissez un instant. Comment l'une ou I'autre de ces « réformes » pourrait-elle se réaliser ? Les rampes d'accès seront abîmées à la première crue du fleuve : qui les réparera ? Pas le batelier, « car ce n'est pas l'affaire du pédicure d'enlever les bas de ses clients ». Si le bac est un bac « public » cela implique simplement que le magistrat local a un « squeeze » sur les recettes et non qu'il soit en conséquence obligé d'assurer la bonne exécution du service. Qui fournira les madriers nécessaires pour la plateforme d'accès ? Pas le batelier. Pas davantage le voyageur qui n'a qu'un désir, celui d'arriver à bon port sur l'autre rive, cette fois seulement. Pas la cohue des manœuvres dont l'intérêt consiste à n'avoir aucune planche pour faciliter les transbordements.

D'ailleurs, alors même que les routes seraient maintenues en bon état et qu'un despote bénévole consentirait à fournir le matériel nécessaire au bon fonctionnement du bac, il ne se passerait pas huit jours avant que tout ait disparu, et les choses continueraient comme précédemment, ainsi qu'elles se sont toujours passées depuis le commencement du monde chinois. La création d'inspecteurs, d'agents de police n'améliorerait rien, à moins qu'il ne fût de l'intérêt de ces fonctionnaires de favoriser la réforme, mais il va de soi que ce ne sera jamais le cas.

Imaginez un fonctionnaire anglo-indien, possédant une connaissance approfondie des races orientales et de leurs caractéristiques, qui se verrait du jour au lendemain chargé de I'administration des bacs établis sur un cours d'eau, sur le Grand Canal par exemple. Que ferait-il ? Que pourrait-il faire, même s'il 


\section{La vie des paysans chinois}

disposait de moyens d'action théoriquement irrésistibles ? Absolument rien. Il lui sera impossible d'imposer des améliorations susceptibles de quelque durée aussi longtemps que les Célestes ne comprendront pas le besoin de modifier les systèmes en cours et qu'ils n'auront pas constaté le manque absolu de tout système chez eux. Il est facile de supplier combien d'années, d'après le rythme ordinaire de l'évolution humaine, il faudrait pour en arriver là. Pensez un instant aux objections qui surgiraient de tous côtés contre ces innovations. Qui sont ces gens ? Quels sont leurs motifs d'agir ? Aucun Chinois ne peut comprendre ce qu'implique cette simple phrase : Pro bono publico. Il n'a jamais entendu parler du bien public et, qui plus est, il ne tient aucunement à en entendre parler.

Nous avons gaspillé un temps indu à traverser un fleuve chinois ; nul autre exemple, en effet, ne pourrait mieux caractériser ces abus flagrants, qui, indifférents aux Célestes, rendraient fous des Occidentaux, et auxquels il semble si facile, bien qu'impossible, de remédier ; et cependant, mutatis mutandis, ces choses sont une parabole de I'Empire chinois. La réforme est inéluctable. Il faut qu'elle se fasse de l'intérieur. Mais l'impulsion initiale ne peut venir que du dehors. 


\section{La vie des paysans chinois}

\section{VI \\ LES PUITS.}

Dans la grande plaine de la Chine septentrionale les puits ont généralement peu de profondeur, de 10 à 30 pieds pour la plupart. L'on rencontre rarement un puits de 50 pieds, cependant il en existe çà et là de beaucoup plus profonds. Le puits représente l'un des éléments essentiels de l'équipement d'un village chinois, bien qu'il ne soit jamais, comme aux Indes, un lieu de rendez-vous pour les ablutions. Afin de s'épargner la peine d'apporter de l'eau dans sa cour, chaque habitant conduit ses bêtes jusqu'au puits; elles s'abreuvent près de l'orifice et la boue qui résulte de ces piétinements rend fort désagréables les approches du puits, surtout en hiver. Le puits débouche au niveau même du sol environnant, aucun auvent ne l'abrite, et I'on se demande comment animaux, enfants ou aveugles ne tombent pas dedans à chaque instant, accidents qui se produisent pourtant, mais rarement. Les plus petits gamins professent d'instinct une peur salutaire de ces trous béants et des siècles de pratique ont accoutumé tous les Chinois à envisager pareil danger avec une sereine philosophie.

Le creusement d'un puits relève d'un art très spécial et, dans les régions où l'eau sert à irriguer, les villageois acquièrent une grande réputation d'habileté pour l'exécution de ces travaux délicats. Un village désireux de s'offrir un nouveau puits se met à la recherche de praticiens, ceux-ci accourent aussitôt au 


\section{La vie des paysans chinois}

nombre de quinze à vingt. Bien que ce travail soit pénible, difficile et souvent dangereux, les puisatiers ne reçoivent généralement aucune rémunération pécuniaire - ils sont du reste les premiers à ne pas en vouloir, - mais ils réclament un festin copieux composé des meilleurs mets. Si l'on veut un puits

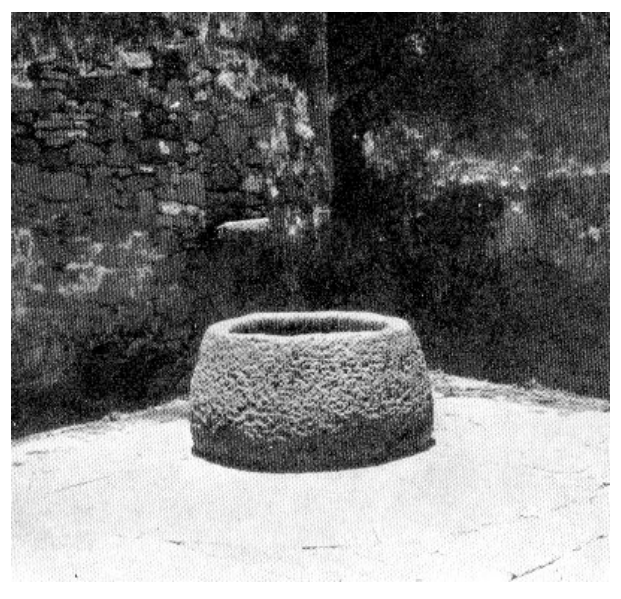

Puits de village

qui soit autre chose qu'un simple trou en terre contenant de l'eau, les hommes creuseront aussi profondément que le permettent sans danger la résistance et la cohésion du sol, puis ils feront descendre doucement d'en haut le revêtement maçonné. A cet effet, on dispose sur l'orifice une solide plateforme en madriers, sorte d'anneau dont le diamètre extérieur correspond sensiblement à celui du trou déjà creusé, et sur laquelle on commence à établir la maçonnerie, également circulaire, qui doit servir de revêtement. De fortes cordes, des liens en roseaux tressés sont fixés à ce plateau pour empêcher le tout de descendre trop brusquement. Cette couronne de briques ressemble bientôt à un tonneau sans fonds ; elle est si résistante que, bien qu'elle doive subir sur son pourtour des poussées 


\section{La vie des paysans chinois}

souvent inégales, l'expérience a démontré qu'elle ne cède jamais à la pression des terres.

Lorsqu'elle est haute de plusieurs pieds, on la descend dans la cavité jusqu'à ce que son plan supérieur affleure le niveau du sol, et le travail se poursuit de la sorte. Parfois on se contente d'enfoncer dans le sol un gros bambou armé à son extrémité inférieure d'une forte pointe en fer. Ce tube est descendu aussi profondément que possible et lorsque, après en avoir curé l'intérieur, le niveau des eaux s'y élève suffisamment, on le consolide en briquetant le pourtour de son orifice supérieur. Ces sortes de puits assurent du liquide en permanence ; relativement rares, ils sont d'autant plus précieux.

Partout où le terrain se prête à de pareils travaux, et quand le sous-sol contient une belle nappe d'eau permettant les cultures maraîchères, la campagne abonde en puits d'irrigation. Ceux-ci ont généralement six pieds de diamètre et sont pourvus soit d'un treuil, soit d'une sorte de chadouf des plus rudimentaires ; le soir, I'on rencontre des jardiniers qui rapportent au logis leur matériel de puisage, les cordes, les seaux, même le treuil : aucun de ces engins ne peut être laissé à pied d'œuvre pendant la nuit avec quelque sécurité. Certains puits de village sont parfois creusés sur un terrain indivis entre plusieurs familles. De même que toute propriété en Orient, ils fournissent matière à de violentes discussions, comme au temps des patriarches. Chaque fois qu'un propriétaire se rend impopulaire, il est aussitôt menacé de se voir couper ses approvisionnements d'eau. Ajoutons que de pareilles menaces se réalisent rarement. 


\section{La vie des paysans chinois}

Dans certains districts la nature sablonneuse et peu consistante du sous-sol s'oppose à la création de puits permanents. Les villageois se trouvent alors dans I'obligation de faire queue toute la nuit autour du trou d'eau pour s'assurer une maigre provision de liquide; aussi les rixes et les voies de fait sont-elles fréquentes. Dans les années de sécheresse, la disette d'eau devient une cause sérieuse de privations et de souffrances. En pareil cas, le puits tubé apporterait sans doute une amélioration sensible à la situation, mais jusqu'ici les moyens techniques dont dispose le paysan chinois n'ont pas toujours permis de descendre jusqu'à la couche souterraine aquifère. Un coolie qu'un étranger employait à un travail de ce genre, nous expliqua, un jour, très simplement la nature de ces difficultés. Comme on lui demandait pourquoi il n'avait pas enfoncé son tube plus profondément, il répondit que « plus on descendait et moins il y avait d'eau »! Il semble que dans ces questions d'alimentation en eau le savoir et l'expérience des Occidentaux pourraient servir utilement les Chinois, sinon sur une grande échelle, tout au moins sur une petite.

Un incident vieux déjà de plusieurs années et qui eut pour théâtre un village du Shantoung mérite d'être rappelé ; il illustre la manière dont on peut $s^{\prime} y$ prendre en pareille occurrence. L'un des missionnaires eut la joie de voir sa famille s'augmenter d'un second fils : l'événement apparut aux Chinois de si bon augure qu'ils décidèrent d'ouvrir une souscription à laquelle chaque famille du village participerait pour une somme fixée d'avance afin d'offrir au nouveau-né un collier en argent. Le pasteur n'ayant pas opposé un veto formel à cette manifestation de 


\section{La vie des paysans chinois}

sympathie, le comité commanda la chaîne et le fermoir. Restait alors une question délicate : comment la famille du bénéficiaire reconnaîtrait-elle cet acte de générosité collective ? Après avoir écarté différentes suggestions l'on tomba d'accord sur un projet qui semblait satisfaire à toutes les conditions requises, c'est-àdire que tout le monde bénéficierait du don en question et que chacun pourrait l'apprécier. L'on proposa de mettre une pompe au-dessus d'un puits de village, situé assez près de la maison des missionnaires et dans lequel les habitants venaient quotidiennement puiser avec beaucoup de peine un grand volume d'eau. Avec la pompe, pareille besogne ne serait plus qu'un jeu d'enfant. Ce projet paraissait si évidemment devoir rallier l'approbation de tous les intéressés que l'un des missionnaires, bien qu'il n'eût pas le bonheur de posséder deux fils, se laissa aller à promettre pour sa part une auge en pierre que I'on installerait près de la pompe et que la phraséologie imagée des Célestes appellerait : « Joie pour dix mille générations ». Le comité du village écouta gravement ces propositions, sans manifester toutefois I'enthousiasme qu'aurait dû susciter une innovation destinée à améliorer de façon si sensible l'alimentation en eau des habitants. Finalement il s'engagea à étudier la question et à fournir ensuite un rapport avec des conclusions motivées. A la réunion suivante, les Chinois exprimèrent le désir de poser quelques questions préalables. D'aucuns firent observer qu'il existait dans le village quatre à cinq puits; les « pasteurs » étrangers, venus de l'Occident, avaient-ils l'intention d'installer une pompe sur chacun d'eux ? Non, naturellement ! répondirent ceux-ci, il ne s'agissait que du 


\section{La vie des paysans chinois}

puits le plus proche. A quoi les Célestes répliquèrent que le bijou offert à l'enfant du pasteur provenait de cotisations fournies bénévolement par toutes les familles du village ; quelques-unes habitaient la rue de devant, d'autres celle de derrière, certaines résidaient à l'ouest et aussi à l'est de l'agglomération : était-il conforme à l'impartialité idéale du Christianisme de monter une pompe dans un endroit tel qu'une partie seulement des habitants en bénéficierait commodément ?

Après quelques minutes d'un silence impressionnant, le comité fit remarquer qu'il lui restait encore une question à poser. Le village, bien que dans une situation plus aisée que la plupart de ses voisins, n'en contenait pas moins quelques familles ne possédant pas un pouce de terrain. Leurs membres devaient gagner leur vie par tous moyens et notamment en circulant avec des seaux d'eau dont ils vendaient le contenu de maison en maison. D'après les explications fournies par les « pasteurs », la pompe permettrait de s'approvisionner si facilement que n'importe qui pourrait assurer cette besogne, l'industrie des porteurs d'eau serait ainsi réduite à merci. Il ne pouvait être dans l'intention des missionnaires de supprimer à une classe entière de travailleurs son gagne-pain. Quel genre de travail les « pasteurs » avaient-ils I'intention de proposer à ces gens pour compenser le dommage dont ils étaient menacés ? Nouveau silence, plus impressionnant encore que le premier. Puis, le comité reprit l'exposé de ses observations. Quelques-uns de ses membres firent remarquer que les inventions occidentales sont très ingénieuses, mais que les villageois chinois ne brillent pas par l'intelligence, qu'ils ne comprennent rien à ces machines. 


\section{La vie des paysans chinois}

Tant que les « pasteurs » étrangers demeureraient à portée pour expliquer et surveiller l'usage de la pompe, tout marcherait certainement fort bien, niais les membres du comité n'étaient pas sans avoir remarqué que les mécaniques d'Occident se détériorent parfois avec le temps et par manque de ménagements lorsqu'on les emploie. A supposer qu'un accident arrivât et qu'aucun « pasteur » ne fût à portée pour réparer le dégât et remplacer les pièces mises à mal, que deviendraient les villageois qui se seraient déjà accoutumés à compter sur la pompe ? On se souvenait que, plusieurs années auparavant, un appareil analogue avait été installé sur un puits profond de Pékin. Les valves ne tardèrent pas à être obstruées par le sable fin en suspension dans le fond ; la machine ne fonctionnant plus, on dut la démonter !. Personne ne s'étonnera qu'à la suite de ces multiples objections, les pasteurs, quelque peu découragés, aient renoncé à intervenir dans les us et coutumes des villageois. L'obligation contractée par la réception du collier fut acquittée au moyen d'un don en argent. On employa ostensiblement ces ressources imprévues à réparer les remparts autour du village, mais en réalité nul ne sait ni où ni à qui elles allèrent. 


\section{La vie des paysans chinois}

\section{VII \\ LES BOUTIQUES.}

@

De tout temps les Chinois se sont divisés en quatre classes: les étudiants, les fermiers, les ouvriers et les marchands. Si I'on réfléchit au penchant singulier du Céleste pour le commerce, on est surpris de voir figurer au dernier rang les marchands.

On se tromperait grandement en supposant que l'existence du marchand chinois est facile : le plus simple examen d'un cas concret suffira pour désabuser l'observateur à ce sujet. En réalité, bien rares sont en Chine les personnes pour lesquelles la vie est facile : elle ne l'est certes pas pour les fonctionnaires et les gens riches, qui sont à la fois les personnes de l'Empire les plus enviées et les plus incomprises.

Dans le Shantoung, chaque village, quelle que soit son importance, a son petit « tsahuo-p'u », boutique aux marchandises diverses, qui n'a rien de commun avec le magasin du petit boutiquier occidental, car ici le tenancier n'a pas l'espérance de vendre immédiatement les articles qu'il entrepose. Un grand nombre de ceux-ci demeureront en magasin pendant plusieurs années, mais ils finiront tous probablement par s'écouler. Les Occidentaux ont en général l'idée que le Chinois vit de « curry » et de riz; or, dans le Shantoung, rares sont les gens qui aient jamais goutté au riz ; cependant le «tsahuo-p'u » en conserve toujours un petit 


\section{La vie des paysans chinois}

approvisionnement pour le cas où l'on en demanderait à un festin ou pour un malade. On y trouve également une bonne provision de ce papier rouge avec lequel se confectionnent les cartes d'invitation, ainsi que du papier bleu destiné aux annonces de funérailles. Il faut pouvoir satisfaire immédiatement à des demandes de ce genre et le marchand doit être toujours approvisionné en conséquence. Le magasin possède aussi un lot important de pétards : on en réclame régulièrement pour les jours de fête, les mariages et les enterrements, de même que du papier-monnaie et autres fournitures pour les cérémonies idolâtres qu'impliquent ces événements. L'assortiment de la boutique comporte encore bien d'autres fournitures, car il n'en existe guère qui ne soient demandées de temps à autre, mais c'est la vente des menus objets que nous venons d'énumérer qui procure les bénéfices les plus intéressants.

Que le lecteur peu familier avec la gestion des affaires chinoises, n'aille pas se figurer que le tenancier du «tsahuo$p^{\prime} u$ » demeure tout le jour tranquillement assis sur une chaise en attendant les clients, ou qu'il profite de ses loisirs entre la sortie de l'un d'eux et l'arrivée d'un autre pour jouer au renard, à l'oie ou aux échecs. Il ne fait rien de pareil. Si la boutique est très petite, elle reste close et ne s'ouvre que devant l'acheteur qui se présente. $\mathrm{Si}$, au contraire, le commerce est important, il réclame la présence de plusieurs personnes, non pour la garde de l'officine, mais pour assurer les ventes à l'extérieur, dans les campagnes. La majeure partie des affaires d'un «tsahuo-p'u » ne se traite pas en effet chez le marchand, mais bien dans les marchés qui se tiennent aux environs du village. Les 


\section{La vie des paysans chinois}

propriétaires de certains magasins se transportent donc avec leur pacotille aux foires voisines, lesquelles ont lieu tous les jours du mois, le $1^{\text {er }}$ et le 6 à un endroit, le 2 et le 7 dans un autre, puis le 3 et le 8 , le 4 et le 9 et enfin le 5 et le 10 , date à laquelle le périple est clos et recommence.

Rien ne ressemble moins à un rendez-vous de fête que ces journées de négoce. Il faut se lever dès l'aube, même plus tôt, choisir les marchandises à emporter, en faire un état détaillé et les emballer avec soin. Puis le mercanti pousse sa brouette ainsi chargée sur de très mauvaises routes et bien souvent par un temps horrible. A la ville-marché il n'existe ni échoppes, ni baraques où s'installer; chaque vendeur se plante à un endroit quelconque tandis que le propriétaire du sol, toujours à l'affût, s'empresse de percevoir un petit droit de place. Toute la journée il faut veiller attentivement sur la brouette et son contenu, se chamailler avec toutes sortes d'hommes et de femmes et c'est seulement lorsque les acheteurs commencent à se faire rares que I'on réemballe avec soin, avant de rentrer au logis, en traînant toujours son petit véhicule.

Puis vient le fastidieux travail du récolement, opération à l'égard de laquelle le commerçant se montre extrêmement pointilleux. En Chine, personne n'a confiance en son semblable pour l'excellente raison que tout marchand sait fort bien que, dans des circonstances analogues, il ne serait guère prudent de croire en lui. En conséquence, l'intéressé ou son agent examine méticuleusement les articles rapportés et les compare à la liste des marchandises établie le matin avant le départ : seul moyen 


\section{La vie des paysans chinois}

de refréner chez le commis la tentation de vendre quelque chose sans en rendre compte. Les affaires traitées dans la journée ne représentent chacune qu'une petite somme, et comme la totalité de la monnaie reçue doit être comptée et enfilée sur une cordelette de chanvre de façon à former une ligature de 1.000 cash (500 seulement dans certaines régions), ce relevé de comptes et cet enfilage demandent non seulement un temps considérable, mais constituent un travail des plus fastidieux lorsque la quantité de sapèques est considérable : remarque qui s'applique du reste à la plupart des opérations chinoises, commerciales et autres, jugées du point de vue des Occidentaux.

Le commis du «tsahuo-p'u » prend ses repas quand il le peut, c'est-à-dire après avoir terminé tout le travail que son employeur exige de lui. Il doit posséder des dons commerciaux de qualité rare pour ne pas courir le risque d'être renvoyé à la fin de l'année, au moment où les affaires du patron subissent un temps d'arrêt, ou lorsque celui-ci croit avoir mis la main sur un employé encore meilleur. Dans toutes les catégories de travaux la quantité d'ouvriers est si considérable qu'il est difficile de trouver une place et encore plus difficile de s'y maintenir.

Un campagnard que l'auteur connaît fort bien avait trop peu de terres pour pouvoir vivre avec sa famille sur leurs produits, aussi accepta-t-il l'offre d'un voisin qui lui proposait de venir l'aider dans une affaire que celui-ci avait récemment entreprise. Il s'agissait de brouetter chaque jour un assortiment de viandes dans quatre villages différents et d'en faire la vente. Les hommes qui assuraient cette tâche devaient se lever bien avant 


\section{La vie des paysans chinois}

le jour afin que la marchandise fût prête à l'heure du départ, c'est-à-dire débiter les morceaux et en détacher les os qui se vendaient au détail. Notre homme relevait le poids du chargement de chaque brouette, viandes et os. Le soir, au retour, nouvelle pesée des marchandises rapportées et comparaison de l'argent encaissé avec les quantités vendues. Pour chacune des quatre brouettes, il fallait faire cette série d'opérations ; I'associé du boucher devait ainsi tenir quatorze livres de comptes.

- Mais, après le départ matinal des brouettes et avant qu'elles ne rentrent le soir, lui dîmes-nous vous avez sans doute des heures de repos relatif pendant lesquelles vous êtes libre?

- Hélas, non !, répliqua-t-il, j'emploie tout ce temps à faire sur les quatorze différents livres la balance des poids enregistrés la veille !

Or, à en juger d'après ce que l'on connaît de la comptabilité chinoise, il devait sans aucun doute suffire avec peine à cette tâche quotidienne. Sur les livres de comptes chinois, le produit des ventes n'est pas inscrit, comme sur nos registres commerciaux, dans des colonnes distinctes où il est facile de faire les additions. Le détail des opérations figure au contraire en une série de lignes verticales, telle une collection de bas mis à sécher et pendus côte à côte sur une corde. Chaque article doit être traité isolément sur le suan-pan - feuille de comptes - et il n'existe aucune manière de contrôler les erreurs. Le Chinois qui nous fournissait ces renseignements était si las du travail que lui 


\section{La vie des paysans chinois}

imposait son contrat qu'il saisit l'occasion d'un enterrement dans sa famille pour disparaître de l'officine et venir conter ses doléances à l'ami étranger qui avait déjà eu l'occasion de lui manifester sa sympathie à des heures difficiles.

Une année plus tard, l'auteur de ce livre le rencontra de nouveau et il apprit que notre homme avait abandonné la comptabilité compliquée du commerce des viandes pour un autre genre de comptes dans une famille aisée, propriétaire de beaucoup de terres et chez laquelle régnait en conséquence une grande activité. L'écrivain lui demanda s'il disposait enfin de quelques loisirs et pouvait lire son ouvrage qui paraissait I'intéresser vivement : sans hésiter, il répondit négativement. Pas même s'il se levait tôt ? Non vraiment, car à peine habillé, il devait être à son travail. Ne pouvait-il se coucher un peu plus tard ? Pas davantage, car il se couchait déjà fort tard. Donc, jamais de temps à lui ? Cependant, quand il prenait ses repas, n'était-il pas libre?

- Bien loin de là ! fit-il, car la femme qui dirige l'entreprise profite de ces instants pour venir me consulter et parler affaires !

Dans les firmes ayant un gros courant commercial, les commis sont souvent réclamés après leurs heures normales de travail. Ils passent la soirée à trier une à une les sapèques des nombreuses ligatures rentrées au cours de la journée, dans le but de découvrir, si, parmi ces monnaies, il ne s'est pas glissé quelque pièce rare susceptible d'être vendue à bon prix. Tout est poisson de ce qui tombe dans un filet chinois et il s'y trouve peu 


\section{La vie des paysans chinois}

d'objets qui, tôt ou tard, ne seront pas une source de profits pour leur propriétaire. Si jamais vient le jour - tout arrive dans ce monde - où l'Ouest lointain entre en rivalité avec le Céleste à I'indicible patience, si jamais il lui dispute le droit à l'existence, I'un où l'autre sera sûrement distancé dans cette course féroce, et l'on peut, dès à présent et sans crainte de se tromper, prédire que ce n'est pas le Chinois qui restera en arrière !

La boutique de village a deux poids et deux mesures suivant qu'elle achète ou qu'elle vend : elle sait se débarrasser habilement du « cash » qui n'a pas cours, elle n'hésite pas à passer un mauvais effet commercial à qui elle peut en imposer et, de façon générale, à faire de durs marchés avec les gens obligés d'avoir recours à ses services ; ceux-ci, du reste, s'empressent de lui rendre, dès qu'ils le peuvent, la monnaie de sa pièce. 


\section{La vie des paysans chinois}

\section{VIII \\ LE THÉÂTRE.}

Tout étranger qui habite la Chine depuis quelque temps sait fort bien que les Célestes raffolent des représentations théâtrales. Les Chinois font remonter I'origine de la scène à l'époque de l'Empereur Ming Huang, de la dynastie des T'ang, lequel, mort en 762, est toujours adoré, sous le voile d'un pseudonyme, comme dieu des comédiens. Une tradition courante veut que si les acteurs négligent de lui rendre hommage, ils ne réussiront pas dans leurs entreprises.

Nous n'avons pas à nous préoccuper ici de l'histoire de la scène chinoise. D'après les Chinois eux-mêmes, l'art dramatique indigène a dégénéré ; il n'est plus le censeur attitré de la morale publique et privée; son rôle consiste désormais à amuser le peuple. Nous remarquons tout d'abord une anomalie singulière : alors que les Chinois, en tant que nation, poussent jusqu'à l'extravagance l'amour des représentations théâtrales quelles qu'elles soient, la profession de comédien est l'une des rares qui ferme à ses tenants I'accès aux examens littéraires. On rapporte cet ostracisme à l'avilissement du théâtre qui, trop facilement, flatte les goûts corrompus et libertins de la population. Mais il n'est pas possible à un étranger de se rendre compte par luimême si le répertoire courant mérite d'être ainsi qualifié. Il semblerait plus exact de dire que le mépris général qui frappe en théorie - la scène et les acteurs, résulte de l'enseignement 


\section{La vie des paysans chinois}

moral du Confucianisme lequel condamne inexorablement le mauvais usage que I'on est arrivé à faire des représentations dramatiques. Pourtant, alors que ce point de vue est généralement accepté théoriquement, il faut bien constater que, comme tant d'autres préceptes de Confucius, il est unanimement oublié dans la pratique.

Avant de traiter la question des théâtres chinois, nous déclarerons en toute sincérité que nous n'en possédons qu'une connaissance très incomplète, attendu que nous n'assistâmes jamais personnellement à une seule représentation. Il existe plusieurs obstacles à ce que l'étranger puisse se rendre compte, de auditu et de visu, de la qualité des pièces jouées. La plupart de ces œuvres dramatiques sont d'une telle étendue que leur audition se prolonge parfois pendant bien des heures, voire même des jours. L'Européen le plus résistant ne saurait écouter une représentation entière sans succomber à la fatigue, d'autant plus que le dialecte dans lequel s'expriment les acteurs diffère tellement de la langue parlée qu'il est difficile de suivre exactement ce qui se dit sur la scène. Leur ton aigre, perçant, falsetto, devient très vite pénible à entendre pour des oreilles étrangères et, de plus, rend le dialogue inintelligible.

Ajoutez à ces inconvénients l'atroce musique, le manque de confort consécutif à un auditoire entassé, la confusion qui règne invariablement dans un théâtre chinois et vous comprendrez combien ce genre de distractions offre peu d'attraits pour un Occidental, une fois que d'un simple coup d'œil il a pu satisfaire grosso modo sa curiosité. Le Chinois ne peut comprendre notre 


\section{La vie des paysans chinois}

indifférence à l'égard de son théâtre. Qu'un étranger, arrivant dans une ville où il compte passer la nuit, s'empresse de poursuivre sa route dès qu'il apprend que les représentations théâtrales battent leur plein dans la cité, voilà qui dépasse le Céleste.

A l'exception de quelques grandes villes, il n'existe pas en Chine de salle de spectacle installée à l'européenne, c'est-à-dire close et pourvue de sièges. La scène est un endroit banal que rien ne dérobe à la vue des spectateurs; elle est parfois construite comme un temple avec une façade ouverte. Les compagnies théâtrales qui vont de ville en ville se contentent d'une scène établie à la hâte sur des tréteaux la veille même du jour où commencent les représentations et que l'on enlève dès la fin de la tournée. Les acteurs rappellent en certains points leurs collègues de la Grèce antique : bande d'oiseaux de passage à la recherche d'un coin où ils pourront se poser, c'est-à-dire en quête d'un engagement.

L'équipement de la scène est, comme celle-ci, de l'ordre le plus simple; le spectateur doit suppléer par son imagination à l'absence de ces décors qui, de nos jours, ont atteint dans les théâtres occidentaux une telle perfection. La pièce n'est pas coupée en actes ou scènes distinctes ; tout ce qui ne peut se comprendre par le costume ou la pantomime des artistes sera verbalement expliqué à l'auditoire, par exemple : qui sont ces personnages ? Qu'ont-ils déjà fait ? etc. La musique d'orchestre accompagne toute représentation théâtrale. Non seulement elle éclate à chaque interruption du dialogue, mais encore elle 


\section{La vie des paysans chinois}

résonne bruyamment, lors d'une scène émouvante, d'une attaque, d'une bataille, etc., et prétend même ajouter de la force à tout événement ordinaire.

A propos de cette ressemblance entre le théâtre grec et celui des Chinois, analogie qui a dû frapper bien des observateurs, M. H. E. Krehbiel déclare - dans un article du mois de janvier 1891 publié par le Century - que

« le drame chinois est en principe un drame lyrique tout comme le fut la tragédie grecque. Les moments d'émotion intense sont accentués non seulement par un accompagnement de musique, ainsi que cela se passe dans nos mélodrames, mais aussi par l'acteur qui se met à chanter. La simplesse et la médiocrité des mélodies n'ont, d'après nous, rien à y voir ; c'est une question de goût héréditaire.

La compagnie dramatique d'un village doit le plus souvent son existence au geste de quelque richard de l'endroit séduit par cette manière de placer ses fonds. Comme les affaires foncières ne peuvent fournir matière, dans la plus grande partie de la Chine, à la moindre transaction, les personnes disposant de quelque argent trouvent difficilement un emploi rémunérateur pour leurs capitaux. Si le Chinois engage des fonds dans une exploitation théâtrale, ce n'est pas avec l'espoir d'en retirer de très gros dividendes : il veut surtout fournir un amusement populaire à un grand nombre de gens, tout en en retirant un revenu plus ou moins important. 


\section{La vie des paysans chinois}

Le bailleur de fonds pour les costumes, lesquels constituent l'élément essentiel de l'équipement d'un théâtre chinois, est appelé le « maître de la caisse ». Tout ce matériel peut lui être loué par une association de personnes qui le lui prêtent moyennant une redevance fixe et sont tenues d'entretenir les costumes en bonne condition. Dans un théâtre de premier ordre, ceux-ci sont très coûteux : ils comprennent ce que I'on appelle des «robes de dragon », des « robes de python », accompagnées chacune d'un double jeu de vêtements de dessous de belle qualité et richement brodés. Il y a en plus cinq assortiments d'armures et une série innombrable d'autres articles vestimentaires tels que pantalons, jupes, bottes, cothurnes, ainsi que des épées, des lances, etc., faites en bois doré.

La valeur d'une pareille garde-robe représente 5.000 dollars au moins et, dans les théâtres de second ordre, la moitié ou même le tiers de cette somme. La surveillance des trois « coffres » où se serrent les accoutrements est confiée à trois hommes qui en sont responsables.

Les artistes sont classés en diverses catégories désignées chacune par un nom particulier et dont les membres reçoivent un salaire fixé d'après l'importance de leurs rôles. Ainsi deux d'entre eux tiendront les emplois, I'un civil, I'autre militaire, de grands personnages de I'Histoire, tels que Chiang T'ai-Kung, etc. Ces acteurs sont appelés lao-shêng. Une autre classe - hushêng - représente des personnages tels que Wên Wan ou Chao K'uang-yin. Une troisième sera spécialisée dans les rôles de 


\section{La vie des paysans chinois}

caractère, par exemple Lü $\mathrm{Pu}$; etc. : ce sont les hsiao-shêng. Puis, d'autres artistes de moindre importance représenteront l'élément féminin, les femmes de fonctionnaires, les jeunes filles, etc. Après eux viennent les pitres ou clowns dénommés hua-lien - à visage fleuri-, répartis en trois classes. Ils tiennent les emplois de gens à mauvais caractère, tels que Chou Wang, Ts'ao Ts'ao et ses pareils jusqu'à la dernière catégorie qui incarne les personnages les plus méprisés et les plus détestables. En plus de ce personnel artistique, il existe une masse de figurants pour les rôles de soldats, domestiques, commissionnaires, bateliers, aubergistes, etc. Et le tout est complété par un groupe nombreux de cuisiniers, porteurs d'eau et consorts, chargé d'assurer le confort matériel de la troupe au cours de sa vie vagabonde.

En dehors des compagnies théâtrales régulières, I'on rencontre souvent des sociétés d'amateurs qui se plaisent à donner des représentations à plus petite échelle appelées un « petit théâtre ». De jeunes fermiers épris de changement, séduits par l'imprévu et l'excitation de la vie d'artiste sont heureux de s'engager dans une troupe jusqu'à la reprise, au printemps, des travaux des champs. La compagnie peut ne compter que 15 ou 20 comédiens, mais les fonds sont bas, et la nourriture qu'on leur fournit est très supérieure à celle qu'ils auraient à la ferme ; de plus en fin de saison, ils touchent parfois une jolie part de bénéfices.

Le directeur, locataire à bail de l'entreprise, se nomme changpan ; il engage des artistes pour une période de dix mois 


\section{La vie des paysans chinois}

environ : celle-ci commence au printemps et finit un peu avant la fin de l'année. La compagnie entière comprend de cinquante à cent personnes. Les appointements varient entre 100 dollars pour les premiers rôles et quelques dizaines de dollars pour les derniers emplois, et tout le monde est nourri. L'affaire comporte une sérieuse mise de fonds : afin de rentrer dans ses avances, l'impresario devrait pouvoir s'assurer une suite ininterrompue d'engagements avantageux, mais les faits montrent bien que le plus souvent, ce n'est pas le cas.

Le directeur forme lui-même son personnel artistique. Il prend à sa charge des enfants dont l'apprentissage est consenti pour une période fixe - trois ans en moyenne - par un contrat bilatéral. A la fin de cette période de formation, les élèves sont libres de s'engager dans n'importe quelle compagnie, aussi irontils naturellement à celle dont les offres seront les plus tentantes mais, pendant l'apprentissage, leur temps appartient au manager qui les a loués aux parents. Ces derniers sont poussés par l'espoir d'assurer ainsi un moyen d'existence à leurs rejetons. Quelquefois les enfants s'enfuient du domicile familial et s'engagent eux-mêmes, attirés par la soi-disant liberté de l'existence théâtrale.

Le salaire que reçoivent ces jeunes apprentis est des plus médiocres : ils sont supposés apprendre en trois mois les éléments essentiels du métier et, les premiers temps, ils n'auront autre chose à faire que de se pavaner sur la scène et déclamer sur un ton grandiloquent des tirades plus ou moins inintelligibles. Si l'un d'eux doit paraître dans un grand nombre 


\section{La vie des paysans chinois}

de pièces, sa mémoire est mise à une lourde contribution ; il est vrai que les enfants chinois peuvent apprendre par cœur avec une facilité surprenante et qu'une pratique constante fixe sans peine dans leur esprit tout ce qu'un jeune acteur a besoin de savoir.

A notre point de vue occidental, il serait malaisé d'imaginer quelque chose qui ressemble moins à une existence de plaisirs que les perpétuels déplacements, le travail routinier, la rémunération incertaine et médiocre de l'artiste chinois d'ordre moyen. Nous n'en avons jamais rencontré un seul qui n'ait avoué combien ce genre d'existence était décevant. L'on cite la boutade d'un premier sujet japonais qui déclarait que l'idée que le peuple se fait de la vie de théâtre - et il en est très vraisemblablement de même en Chine - diffère autant de la réalité que les nuages diffèrent de la boue.

« Les tribulations qu'on y endure sont pareilles aux souffrances de l'Hadès et le monde ne bénéficie en aucune façon du mal que se donnent les artistes : I'art du comédien est donc inutile à la société ; c'est un genre de vie qu'il faut redouter et dont on doit se méfier.

Sans doute existe-t-il bien peu d'acteurs chinois qui se soient jamais demandé si leur art constituait un bien ou un mal pour la «société ».

Il n'est pas rare d'entendre parler d'un magistrat de district exceptionnellement intelligent - qui lance des proclamations interdisant les représentations théâtrales dans tout le territoire 


\section{La vie des paysans chinois}

de sa juridiction et exhorte le peuple à réserver son argent pour acheter du grain, soulager les pauvres gens ou ériger des écoles publiques. Mais le seul moyen pratique par lequel un fonctionnaire à l'âme paternelle fera observer des prescriptions aussi raisonnables consistera à entreprendre de fréquentes tournées personnelles sur son territoire et à veiller lui-même à ce que ses ordres soient suivis. S'il n'agit pas de la sorte, une somme d'argent consacrée à de judicieux pots de vin dans le yamen assurera aux tenanciers des théâtres une complète immunité. Les écoles gratuites, les institutions charitables sont d'un goût trop fade pour des gens qui réclament des mets plus épicés, des spectacles mouvementés, toutes choses que leur offre une représentation théâtrale.

Il est à remarquer que, par une de ces nombreuses contradictions qui fourmillent dans la vie sociale des Chinois, alors que l'artiste est tenu en très légère estime, I'on considère la représentation d'une pièce comme un grand honneur rendu à la personne que I'on veut fêter. Parfois des étrangers seront conviés à une séance théâtrale en témoignage de gratitude pour l'aide qu'ils ont fournie, pendant une période de disette par exemple. Mais les motifs d'une pareille initiative peuvent être d'ordre divers : il y entrera probablement, de la part des promoteurs de la fête, le désir de satisfaire leurs propres goûts tout en se libérant publiquement d'une dette de reconnaissance.

Quant à insinuer que l'argent ainsi dépensé devrait être affecté à quelque œuvre d'utilité publique, telle que l'édification d'une école, I'on ne rencontrera pas un Céleste sur mille qui 


\section{La vie des paysans chinois}

approuve une telle suggestion, parce que, seul un nombre limité d'élèves en bénéficierait, tandis que le théâtre est un agrément à la portée de tous. De plus, un théâtre est démonstratif, il s'impose à l'attention du public d'une manière à laquelle tout Oriental est extrêmement sensible, alors que la création d'une école gratuite équivaudrait à « porter une belle parure dans l'obscurité » : personne ne la remarquerait.

La représentation d'une pièce est parfois la conséquence d'un vœu formulé au cours d'une maladie, expression de la gratitude du malade parce qu'il a recouvré la santé. Lorsque le village entier en prend l'initiative, c'est qu'il entend adresser des remerciements à quelque divinité à l'occasion d'une bonne moisson ou de pluies tombées en temps opportun. Une querelle entre individus se trouve souvent apaisée par les « prêcheurs de paix » qui décident que l'une des deux parties offrira comme amende une représentation théâtrale à l'agrément de laquelle la population entière pourra ainsi participer. Étant donnée la mentalité chinoise, il n'est pas surprenant que cette façon simpliste de liquider les disputes soit très populaire. Nous l'avons vue employée par un magistrat de district désireux de régler un procès entre deux villages, et le cas doit certainement être assez fréquent.

Parfois la seule raison pour laquelle on élève un théâtre, c'est une encaisse accumulée dans les finances publiques et qu'on ne voit pas le moyen de dépenser autrement. Un étranger ne serait pas en peine de suggérer une cinquantaine de projets permettant d'utiliser plus intelligemment les fonds de la 


\section{La vie des paysans chinois}

communauté, mais à un Céleste, de pareilles suggestions semblent toujours intempestives, pour ne pas dire absurdes.

Lorsque I'on a décidé d'engager une troupe, il faut tout d'abord passer avec son directeur un contrat écrit qui en spécifie le prix ; celui-ci peut varier de 25 à plusieurs centaines de dollars. Le premier de ces deux prix, le plus bas qui se puisse offrir, ne sera proposé qu'à une compagnie de qualité très inférieure ; celle-ci s'y résignera peut-être, poussée par la nécessité et acceptera même, faute de mieux, une somme moindre, lorsqu'il y a pénurie d'engagements pendant la mortesaison. Au contraire, dans la période de l'année où les spectacles sont très demandés, une compagnie peut se trouver en face d'offres adressées simultanément par plusieurs localités. Afin de ne rien perdre de ces profits inespérés, la troupe se partagera souvent en deux tronçons, et le directeur engagera un certain nombre d'amateurs pour combler les vides, ce qui permettra à la compagnie de jouer à la même date dans des endroits différents.

L'on dit généralement que les villageois venus pour une représentation n'assistent qu'à un gros vacarme, et ceci n'est pas loin d'être la vérité. Le directeur joue de cette ignorance des paysans lorsqu'il fournit un spectacle de qualité inférieure à celle que lui impose son contrat. Mais si les assistants découvrent la fraude, s'ils constatent un nombre trop faible d'acteurs ou jugent insuffisant le jeu des artistes, un villageois se lève majestueusement et frappe la compagnie d'une amende qui se traduit par une, deux ou même trois représentations supplémentaires : et cette décision demeure sans appel. 


\section{La vie des paysans chinois}

L'individu chargé des relations administratives et financières avec le village se nomme pao-tan-ti, porteur de programmes. C'est lui également qui assure le transport des malles renfermant les costumes et tout le matériel de décors lorsque la troupe se déplace d'une localité dans une autre.

Dans la partie centrale de l'Empire, là où les transports demandent des bêtes de trait, on a besoin d'un grand nombre de chariots pour faire voyager tout ce matériel encombrant ; de plus, les déplacements doivent s'exécuter à date fixe et très rapidement afin de ne pas perdre une journée à une époque où les engagements sont particulièrement nombreux car, même pour les Chinois, le temps est précieux lorsqu'il s'agit de nourrir et de payer un personnel si considérable.

Parfois l'impresario lève une taxe spéciale dans le village où il se trouve pour couvrir ses frais de déplacement jusqu'à la station suivante ainsi que la location des moyens de transport.

Quelle journée affairée dans un village que la veille d'une représentation ! Il s'agit de réunir des quantités de nattes pour les installations provisoires de la troupe et, au bout de peu de temps, l'endroit choisi en vue du spectacle - assez près, mais en dehors de l'agglomération citadine - prend l'aspect d'une cité improvisée car, en plus du théâtre, I'on établit avec des nattes un tas de petits hangars destinés aux boutiques, à la cuisine, au thé, aux salles de jeu, etc. Le jour de la représentation, le village le plus modeste donne l'illusion d'un très grand marché.

Dans les villes plus importantes, où se tiennent des foires à des intervalles plus ou moins réguliers, il est d'usage, ainsi que 


\section{La vie des paysans chinois}

nous l'avons déjà expliqué, d'ouvrir la foire par une représentation théâtrale : le premier jour il ne se fera guère de transactions commerciales et les assistants ne seront occupés qu'à écouter la pièce. En pareil cas le nombre des spectateurs peut atteindre sans exagération jusqu'à dix mille personnes. Dans les très grandes foires et pendant toute leur durée, on donne généralement une représentation chaque jour, manière d'opérer très avantageuse au point de vue financier, attendu qu'elle tient en éveil I'attention du public et attire ainsi la foule des clients.

$\mathrm{Au}$ point de vue social ce qui intéresse plus spécialement I'observateur étranger à propos du théâtre au village, c'est l'impression que produisent les pièces sur l'ensemble des assistants. On pourrait assez exactement la comparer a l'émoi provoqué chez les enfants dans les pays occidentaux par I'approche de Noël, ou bien encore, aux États-Unis, par la journée du 4 juillet. En Chine, tout autre intérêt mondain s'efface devant l'attrait du spectacle.

L'annonce de l'arrivée prochaine d'une compagnie théâtrale dans un village met en ébullition la région entière. Les visites des jeunes mariées chez leurs mères - visites qui jouent un si grand rôle dans la vie courante des unes comme des autres sont arrangées longtemps à l'avance en ne tenant compte que du gros événement qui se prépare. Dans les écoles des villages voisins, les élèves escomptent déjà des vacances pour toute la durée des représentations. Si le professeur s'avisait de refuser éventualité invraisemblable car lui aussi désire y assister, - son 


\section{La vie des paysans chinois}

veto demeurerait sans effet et il se verrait abandonné par tous les enfants de sa classe.

Ce ne sont pas seulement les mariées qui profitent de la circonstance pour aller rendre visite à leurs parents ; I'on peut dire de façon générale que lors d'une représentation théâtrale hommes, femmes ou enfants plus ou moins apparentés à quelque habitant du village, et pour autant qu'ils n'en soient pas empêchés par un motif grave, ne manqueront pas de profiter de cette occasion de se déplacer. Toute famille chinoise étant affublée d'un essaim de parents à tous les degrés, c'est le moment, lors d'une représentation théâtrale, d'aller dire un petit bonjour à ses amis : que ces alliés lointains aient été ou non invités, cela n'a dans l'espèce aucune importance, les visiteurs accourraient alors même qu'ils sauraient pertinemment que I'on n'a aucune envie de les recevoir.

Bien que le Céleste prône très haut sa façon de pratiquer I'hospitalité, I'on ne peut cependant pas aller jusqu'à dire qu'elle soit une vertu caractéristique du peuple chinois. Mais, quels que soient, dans la circonstance, ses sentiments intimes, le Chinois estime nécessaire de soutenir le semblant d'une hospitalité pleine d'effusion, de sorte qu'il s'empressera de retenir à sa table toute personne pénétrant dans la cour de son logis et insistera pour qu'elle passe la nuit chez lui quand même il désirerait s'en débarrasser au plus tôt. En temps ordinaire l'invité n'acceptera que si l'hôte, par son insistance, lui montre qu'il agit bona fide. Mais au cours d'une saison théâtrale, peu importe à l'arrivant 


\section{La vie des paysans chinois}

d'être accueilli avec plus ou moins de cordialité : il restera en tout cas, car la pièce doit être vue.

L'on ne saurait dès lors être surpris du trouble que la présence d'une compagnie de comédiens apporte dans un village. Chaque famille y est, en effet, envahie par un flot de visiteurs et, le plus souvent, le logis ne dispose pas d'assez de place pour coucher tout ce monde; les gens passent la nuit debout à bavarder : excellente préparation, dira-t-on, pour la tâche fatigante du lendemain ! Le cycle théâtral durant au moins trois jours et parfois quatre, il est facile d'imaginer à quel point le village en fête est mis à contribution. Si I'on songe que chaque femme mariée en visite dans sa famille, de même que toute femme qui va voir quelque parent, amène avec elle ses jeunes enfants et que ces derniers se considèrent en droit de faire main basse sur tout ce qu'ils découvriront en fait de nourriture, il est clair que la maîtresse de maison se trouve soumise à des épreuves avec lesquelles les exigences les plus sévères de la vie occidentale offrent bien peu d'analogie.

La subsistance de ces hordes de visiteurs nécessite de grands frais et il semble dur à un Chinois, économe par nature, de voir disparaître en une semaine la quantité de combustible suffisant en temps normal à assurer le chauffage du logis pendant six mois, et cela pour « rôtir » l'eau et nourrir des gens qu'il n'a pas invités, et que, de plus, il ne désirait aucunement voir. Il n'est pas exagéré de dire que ces frais de réception s'élèvent à dix fois au moins le prix du théâtre seul. Ainsi se trouve vérifié une fois 


\section{La vie des paysans chinois}

de plus le dicton familier : ce n'est pas le cheval qui coûte, mais la selle.

La foule accourue des environs pour assister aux représentations contient généralement des éléments fort peu recommandables, les habitants doivent se tenir sur leurs gardes. Pour ce motif, aussi bien qu'en raison des devoirs d'hospitalité que leur impose la présence de tant de visiteurs, les gens du village sont les seuls à ne pouvoir profiter comme ils le voudraient des réjouissances artistiques. Les hôtes et les voleurs occupent tout leur temps. Une vigilance constante peut seule procurer quelque sécurité à I'habitant : plus il aura à perdre, moins il sera à même de s'amuser tant que le danger ne sera pas écarté. Une longue expérience a démontré qu'après une tournée de spectacles, I'on ne trouvera probablement plus un seul poulet dans le village. Pour éviter que les volailles ne deviennent la proie d'habiles filous, les habitants ont soin d'en disposer eux-mêmes à l'avance.

Telles sont les conditions faites en Chine au théâtre ambulant. Il est donc surprenant qu'un si grand nombre de compagnies artistiques trouvent moyen de gagner leur vie dans un métier à ce point précaire. En effet, l'acteur risque de se trouver sans aucun emploi pendant les années, toujours si fréquentes, de famine ou d'inondations, ainsi que pendant les périodes de deuil impérial qui réduisent souvent les artistes à la plus extrême misère. Quant à l'attachement passionné du peuple pour le théâtre, I'on peut avec assez de vraisemblance l'attribuer au fait que le Céleste ne dispose que de très peu d'amusements et que 


\section{La vie des paysans chinois}

la masse des villageois n'a de distractions publiques que lors des rares jours de fête - deux ou trois dans l'année - , au moment des grandes foires accompagnées de représentations théâtrales, ou bien encore pendant les tournées que les comédiens font en dehors des foires.

Il est évident qu'une forme de représentation si chère aux Chinois peut devenir un puissant agent d'excitation et soulever, dans des circonstances données, les passions des foules. Telle est sans aucun doute l'origine de certains mouvements populaires. Les étrangers ne connaissent-ils pas tous plusieurs cas où, dans l'intérieur de la Chine, I'on a joué des pièces représentant les massacres de Tien-tsin ou quelque événement analogue. Parfois il faut en faire remonter la responsabilité jusqu'aux magistrats locaux, de connivence avec les directeurs des troupes. L'impression que font sur l'esprit du peuple de pareils spectacles doit être bien mauvaise - si tant est que les représentants du Gouvernement tiennent à maintenir chez leurs administrés le respect des étrangers.

Ne serait-il pas facile en Chine, comme dans d'autres pays, de s'arranger pour que les pièces offertes au public traitent des événements courants qui intéressent la masse de la population ? Nous rappellerons à ce propos la querelle survenue entre deux comités qui réclamaient, chacun, le droit de faire élever une digue destinée à contenir les inondations. A force d'attendre, il y eut plusieurs vies de perdues du fait des crues et il s'ensuivit un formidable procès. Quelques incidents furent d'un caractère si dramatique qu'on les intercala dans un pièce : celle-ci remporta 


\section{La vie des paysans chinois}

un succès considérable dans les villages situés non loin de l'endroit où I'affaire s'était déroulée.

L'on peut certainement dire que la représentation d'événements historiques par les théâtres chinois constitue I'un des plus grands obstacles à ce que les masses populaires acquièrent la connaissance de I'Histoire. Peu de personnes lisent les ouvrages historiques tandis que tout le monde écoute les pièces, et, alors qu'on oublie les livres d'histoire parce qu'ils sont ennuyeux, chacun retient la pièce parce qu'elle est amusante. Le théâtre, à peine est-il besoin de le rappeler, ne prétend pas donner au public la représentation exacte d'un fait historique, il le déforme pour n'en retenir que les incidents qui se prêtent à une adaptation dramatique. Mais les gens ordinaires ne sauront pas discerner ce qui s'est véritablement passé, ni à quelle époque, quelles en furent les causes et les conséquences pratiques : les faits réels et la fiction se confondent dans leur esprit.

Les pièces qui traitent de la vie dans son réalisme quotidien jouissent toujours des préférences du public. L'on vend partout, et en grand nombre, des brochures bon marché, mal imprimées, où se trouvent en substance les pièces représentées. Ces sortes de livrets permettent au public de se familiariser avec l'intrigue qui s'y déroule.

Nous terminerons notre examen du drame chinois en donnant l'analyse d'un de ces librettos et en prenant pour exemple une pièce particulièrement prisée du public : le langage populaire $y$ fait à chaque instant allusion. Elle passe pour avoir été écrite par 


\section{La vie des paysans chinois}

un homme originaire du Shan-hsi et elle vise à la satire de cette société dans laquelle, comme c'est si souvent le cas en Chine de nos jours, il est presque impossible à un pédagogue de ne pas mourir de faim, bien que, en théorie, la corporation dont il fait partie soit tout spécialement honorée.

Il est de notoriété courante dans le Shantoung que le nombre de ceux qui veulent enseigner est supérieur à celui de ceux qui savent lire ! La pièce en question se passe donc au pays des sages Confucius et Mencius, dans un district peu éloigné de la capitale, Chi-nan Fu.

Les protagonistes se réduisent à deux personnages, un professeur appelé Ho Hsien-shêng, momentanément sans emploi et réduit à une détresse extrême, et un bourgeois du nom de $\mathrm{Li}$, désireux d'engager un maître pour ses garçons respectivement âgés de neuf et onze ans. Les répliques du professeur sont émaillées de longues citations puisées dans les classiques, habitude courante chez tous les maîtres d'école chinois qui veulent donner l'impression qu'ils possèdent des connaissances étendues. Notre homme assure que sa méthode d'enseignement est si efficace qu'il se fait fort d'amener ses élèves au premier degré, hsiu-ts'ai - bachelier - en trois ans, puis, dans le ternaire suivant, au second échelon, chü-jên - licencié - et qu'enfin, au bout de douze ans, le doctorat - chin-shih couronnera ce cycle d'études.

La pièce débute par un monologue du professeur qui se lamente, en termes poétiques, sur la perte de son dernier emploi : la situation dans laquelle il se trouve depuis lors, 


\section{La vie des paysans chinois}

prétend-il, est bien pire pour un homme instruit que pour un travailleur manuel lequel, à l'en croire, a toujours assez à manger. Puis, parcourant la scène à grands pas, il crie sur le ton d'un colporteur :

— Enseigner l'école! Enseigner l'école !

Là-dessus apparaît Li.

- Un homme, s'écrie-t-il, qui s'offre à enseigner, sait sans doute au moins lire,

et aussitôt il explique ce dont il a besoin. Il voudrait avoir, dans sa famille, quelqu'un en état de vérifier ses comptes, de déchiffrer les feuilles d'impôts, etc., mais il n'a vraiment pas les moyens de payer un professeur à ses enfants.

Ses rejetons sont d'esprit très borné, continue-t-il, et quant à la nourriture qu'il offrira au maître - il en donne le détail - elle sera de qualité médiocre et peu abondante. Deux repas seulement par jour pour éviter la dépense et jamais de feu dans la soirée. La literie comprendra un couvre-pieds, vieille peau de chien toute déchirée, pas de natte sur le lit, simplement un peu de paille, et pas d'oreiller. Le salaire, ne dépassera pas 8.000 cash par an, mais il est soumis à l'inévitable escompte, 800 cash comptant pour 1.000 . Le professeur ne devra jamais s'éloigner pendant les heures de classe.

Celles-ci auront lieu dans un temple actuellement occupé par des nonnes, lesquelles seront déplacées et installées dans une petite chambre sur l'un des côtés de la cour. Il faudra que le professeur sonne la cloche, balaye les locaux, assure tous les 


\section{La vie des paysans chinois}

services prescrits pour le $1^{\text {er }}$ et le 15 de chaque mois et qu'il apporte à ces diverses tâches un soin méticuleux. Il faudra aussi qu'il prenne garde à ce que sa moralité ne soit pas contaminée par le voisinage des nonnes dont la réputation est proverbialement mauvaise. Il ne recevra aucun à compte sur son salaire et subira une retenue proportionnelle à ses journées d'absence. Pendant les pluies d'été le professeur transportera sur son dos les enfants à l'école pour qu'ils ne salissent pas leurs vêtements et ne causent pas d'ennuis à leur mère. Après les heures de cours, il assurera l'approvisionnement en eau de la maison, s'occupera aux menus travaux du logis, prendra soin des enfants, moudra au moulin et, de façon générale, exécutera tout ce I'on pourra exiger de lui. A toutes ces conditions le professeur consent de bon cœur et il se déclare prit à signer un contrat conforme pour une période de dix ans !

Parmi les différents aspects sous lesquels se présente le théâtre chinois, le plus instructif est peut-être celui qui nous incite à en considérer les pièces comme un miroir de la vie, telle que la comprend le peuple jaune. Aux yeux des Chinois, toute œuvre théâtrale reproduit les contingences de leur existence même ; ils sont fermement attachés à cette théorie, ils y croient pleinement, presque inconsciemment. Un dicton populaire affirme que « le Monde entier n'est qu'une pièce de théâtre : pourquoi les hommes prendraient-ils dès lors la vie comme une réalité ? »C'est bien conformément à cette manière de voir que les Chinois donnent souvent l'impression d'êtres psychologiquement incapables de discerner entre les réalités pratiques, que tout le monde tient pour telles, et les « réalités » 


\section{La vie des paysans chinois}

théoriques lesquelles, en poussant les choses à l'extrême, sont reconnues comme fictives.

Ainsi le Céleste estime que la vie de tous les jours n'est qu'une mise en scène perpétuelle, et cette croyance exige de ses fidèles un tribut qui est libéralement, spontanément, continuellement et universellement payé. Sur pareille théorie se basent la plupart des réjouissances populaires, théorie dont voici la véritable signification : «Vous m'avez porté préjudice, mais je ne vous crains pas et j'en appelle à tous les hommes ! Qu'ils soient témoins du défi que je vous lance ! » De là aussi dérivent les neuf-dixièmes au moins des actes que les Chinois accomplissent sous le prétexte de « sauver la face », c'est-à-dire mettre l'acteur d'accord avec les spectateurs, lui prouver qu'il peut jouer son rôle en pleine connaissance de cause car il sait bien ce que c'est que ce rôle. D'aucun autre pays que la Chine I'on ne peut dire avec plus de vérité que :

« Le Monde entier est une scène de théâtre Et tous les hommes, toutes les femmes n'en sont que les acteurs. 


\section{La vie des paysans chinois}

\section{IX \\ LES ÉCOLES. ÉTUDIANTS AMBULANTS.}

L'instruction occupe en Chine une place proéminente, de sorte que l'école du village est une institution qui retient au plus haut point I'intérêt général : c'est sur ses bancs que la majorité des Chinois cultivés reçoit son premier entraînement intellectuel. Alors qu'il peut exister, d'un district à un autre, quelques différences quant à la qualité de l'instruction donnée dans les écoles, il n'est probablement pas d'autre pays au monde où les méthodes pédagogiques présentent dans leurs moindres détails autant d'uniformité qu'en Chine.

Certains passages des Classiques chinois éclairent d'un jour intéressant les vues qui, depuis des siècles, président à l'éducation des enfants. Rappelons à ce propos un extrait suggestif des écrits de Mencius. On demanda un jour à ce philosophe pourquoi I'homme instruit ne se charge pas lui-même de la formation intellectuelle et morale de son fils. Et Mencius répondit que des considérations psychologiques le lui défendent. L'instructeur devrait inculquer à son élève la façon correcte de se comporter ; s'il le fait et qu'il s'aperçoit que ses leçons ne sont pas mises en pratique, il se fâche. Il s'aliène ainsi son fils qui ne manquera pas de constater que son père enseigne d'une façon et agit d'une autre, et il en résultera une méfiance réciproque qui ne fera que s'accroître. Entre père et fils, ajoute Mencius, il ne doit y avoir ni blâmes, ni admonestations au sujet de ce qui est 


\section{La vie des paysans chinois}

bien ou mal, car cette lutte plus ou moins sourde les amène à éprouver de l'éloignement I'un pour l'autre. Les Anciens, déclarait-il encore, échangeaient leurs fils et chacun élevait I'enfant de son ami.

Un autre passage significatif se trouve dans les Analectes Confucéennes. Le texte ci-dessous est emprunté à la traduction anglaise du Dr Legge.

« Ch'ên K'ang posa à Po Yû, fils de Confucius, la question suivante :

- Votre père vous a-t-il donné des leçons différentes de celles qu'il nous enseignait en public ?

Et Po Yû répondit :

- Non. Je le rencontrai un jour dans le vestibule. Il s'y promenait seul et me demanda : «Avez-vous appris les Odes ? » Sur ma réponse : «Pas encore ! 》 il ajouta : «Si vous ne savez pas les Odes, vous ne serez pas à même de tenir une conversation. » Je me retirai et étudiai les Odes. Un autre jour je le trouvai encore debout, tout seul, pendant que je traversais à la hâte le vestibule et il me dit : « Avezvous appris les règles de la bienséance ? » Sur ma réponse : «Pas encore ! » il dit : « Si vous n'apprenez pas les règles de la bienséance vous ne pouvez compter sur une bonne réputation. » Je me retirai et étudiai les règles de la bienséance. Telles sont les deux seules leçons que je reçus de mon père. 》 


\section{La vie des paysans chinois}

Ch'ên K'ang se retira enchanté et dit :

- Je demandai une chose et j'en appris trois : j'ai entendu parler des Odes, puis de la Bienséance et je sais maintenant que I'homme supérieur garde toujours vis-à-vis de son fils une attitude distante.

Confucius était un Maître qui se sentait en possession de hautes vérités, vérités dont ses contemporains avaient le plus grand besoin. Il offrait ses enseignements aux pauvres et aux riches, indistinctement, à la seule condition que leur intelligence fût en état de se les assimiler et de les faire fructifier.

- Je ne révèle pas la vérité, disait-il, à celui qui ne désire pas ardemment savoir, et je n'aide personne qui ne souhaite pas comprendre. Lorsque j'ai présenté à un disciple un côté de mon sujet et qu'il ne sait pas en déduire les trois autres, je ne répète pas ma leçon.

Pour autant qu'il nous semble, le fils de Confucius puisait tout son savoir dans les préceptes de son père. D'après Confucius, la connaissance des Odes et des Règles de la Bienséance constitue en grande partie l'équipement intellectuel d'un étudiant. Ces deux livres embrassent des sujets qui ne peuvent, semble-t-il, être compris et assimilés qu'avec l'aide d'un professeur compétent. Chose curieuse, le Maître s'est contenté, pour l'éducation de son propre fils, de poser accidentellement une question, de faire une simple allusion à l'étude de ces deux branches de l'enseignement, qui étaient, cependant, d'une importance capitale à ses yeux. Et si le fait que nous venons de 


\section{La vie des paysans chinois}

relater ne provenait pas de la même autorité que celle qui nous a fait connaître la vie du Sage, nous pourrions être portés à douter de sa véracité.

La règle d'après laquelle le Maître dirigeait sa conduite est très heureusement qualifiée par Ch'ên K'ang « d'attitude distante ». Même aux yeux de son propre fils, I'homme supérieur se meut sur un plan plus élevé ; ses moindres paroles renferment de fructueuses semences d'instruction ; il s'attend à ce que son élève agisse sur une simple allusion, comme si un mot jeté négligemment était l'énoncé formel d'une loi de la nature. Il est le soleil autour duquel gravitent ses planètes suivant des orbites proportionnés à la force d'attraction centrale, attraction qui varie avec la capacité de force attractive inhérente à chacune d'elles. Cependant, dans chaque cas, il existe un point limite qu'aucun élève ne peut dépasser : nul ne doit approcher son soleil de trop près.

Dans la pensée des Occidentaux, l'enseignement idéal est fourni par les méthodes d'éducateurs tels que le Dr Arnold sorti de Rugby, etc., dont I'action stimulatrice se fit sentir sur toute une génération. D'après la manière de procéder de Confucius, il est difficile de voir, non comment ce Maître aurait pu gagner I'affection de ses élèves - incidence qui fut sans aucun doute aussi étrangère à sa pensée qu'à celle de ses auditeurs - mais comment son enseignement aurait réussi à marquer l'un d'eux d'une forte empreinte, sauf quelques esprits d'élite. Peu nombreux sont les élèves - nous osons l'affirmer - qui, après une question lancée au hasard des circonstances, se retireront et 


\section{La vie des paysans chinois}

étudieront sans y être aidés certaines branches de I'enseignement, lesquelles, leur a-t-on dit, les rendront capables de soutenir une conversation ou « d'établir » leur réputation.

Comparez à cette méthode de Confucius les règles suivies dans un cas analogue par James Mill, telles que nous les expose en détail son fils, John Stuart Mill, dans son autobiographie. Voici un père, simple homme d'affaires et non philosophe de profession, qui, tout absorbé qu'il fût par ses travaux historiques et autres, sut trouver le temps de diriger l'éducation de son fils depuis l'âge le plus tendre jusqu'à la maturité. Non seulement il le familiarisa avec les langues anciennes, mais encore il développa à un degré éminent ses connaissances en histoire, en philosophie, en économie politique ; il lui apprit l'art d'écrire, de discourir. Et tout cela sur un plan d'une admirable richesse. Avec une persistance, un labeur que rien ne lassait, il lui enseigna des principes et non des règles, sans s'écarter jamais, fût-ce dans les plus petits détails, d'une fidélité scrupuleuse. Grâce à son assiduité personnelle comme à l'intelligente direction de son père, Mill se trouva ainsi de beaucoup en avance sur ses contemporains, d'un quart de siècle au moins, ainsi qu'il le constate lui-même, et il devint I'un des hommes les plus remarquablement instruits dont nous ayons souvenir. L'on souhaiterait qu'à ses « entretiens imaginaires entre lettrés et hommes d'État », Walter Savage Landor eût ajouté un dialogue qui ait mis en présence Confucius et James Mill traitant de la « réserve distante en tant que facteur de l'éducation d'un fils ». 


\section{La vie des paysans chinois}

Il ne serait pas exact de dire que tout village chinois a son école, mais on peut déclarer avec quelque certitude que chaque village voudrait en avoir une, car il n'existe pas de coin en Chine où ne règne la plus profonde vénération pour «l'instruction ». Les raisons de pareilles carences sont toujours les mêmes, ressources locales insuffisantes ou population trop peu nombreuse, - et fréquemment ces deux causes à la fois.

En Chine, tout homme instruit est un maître d'école potentiel, aussi la plupart des lettrés ne laissent-ils guère échapper l'occasion de se jeter sur l'un de ces emplois lorsqu'il se présente. Le langage fleuri des Célestes exprime très élégamment pareille tendance, universellement répandue, en disant que « dans le champ des godets à encre, il n'y a jamais de mauvaise récolte », ou bien, en termes moins allégoriques, que « les lettres sont une vocation qui repose sur des bases plus solides que toute autre ». Mais cela c'est la théorie. En réalité, le maître d'école réussit avec peine à se soutenir et il se voit fréquemment obligé d'emprunter des vêtements pour se montrer

décemment devant ses chefs. Quant à son instruction, qu'elle I'ait ou non rendu capable d'enseigner dans une école, il est certain qu'elle en a fait un individu inapte à n'importe quel autre emploi. Celui qui cherche à être un instructeur passe dès lors par de dures émotions lorsque s'ouvre la période où l'on choisit les maîtres d'enseignement.

Lorsque le blé est ramassé et le grenier vide Le cœur du maître d'école est rempli de soucis, 


\section{La vie des paysans chinois}

dit le proverbe, et un autre adage courant assure que, si l'on a à sa portée seulement quelques sacs de grains, point n'est besoin de vouloir régner sur des enfants.

Il n'y a pas de doute qu'il faille attribuer au trop grand nombre de candidats à une place de maître d'école le fait que I'une des professions les plus honorables soit en même temps I'une des plus mal payées. Les professeurs doués d'un véritable talent, ceux qui ont acquis d'une manière quelconque une haute réputation peuvent dicter leurs conditions et fixer eux-mêmes leur salaire, mais l'obscur pédagogue rural, réduit à chercher un emploi dans une zone très limitée, n'est souvent rémunéré que par une maigre pitance en nature et en espèces : une ration de grain supposée suffisante pour assurer sa nourriture, une provision de tiges sèches comme combustible et enfin une modeste somme d'argent qui, souvent, ne dépasse pas pour l'année entière dix dollars mexicains. Il n'est pas rare de rencontrer des professeurs n'ayant qu'un ou deux élèves et dont les émoluments se réduisent à peu de chose en plus de la nourriture, quand ce n'est pas à la nourriture seule. Un maître de cette catégorie auquel on demandait si cela valait vraiment la peine d'enseigner pour un si maigre salaire répondit que c'était encore préférable à l'alternative de rester chez soi sans rien à se mettre sous la dent. L'on dit couramment que les riches n'enseignent jamais à l'école et que les pauvres n'assistent jamais aux leçons : à cela il y a pourtant des exceptions. Fait assez étrange, l'on rencontre parfois des maîtres qui n'ont jamais poussé leur instruction au delà de l'étude des Quatre Livres et ne savent rien par conséquent des Cinq Classiques : 


\section{La vie des paysans chinois}

équipement intellectuel comparable à celui que posséderait un professeur occidental dont les connaissances en arithmétique ne dépasseraient pas une simple règle de division.

L'initiative de faire ouvrir une école incombe aux parents. Après que ceux-ci se sont assurés d'un nombre suffisant d'élèves, on inscrit les noms sur une carte rouge appelée kuangtan, liste d'école. Ce travail se fait généralement à l'époque du solstice d'hiver (21 décembre), bien que, souvent, on ne s'en occupe que six semaines plus tard, vers la fin de l'année chinoise. Dans quelques régions il est cependant d'usage d'arrêter cet état le 15 de la $8^{\mathrm{e}}$ lune, en août ou septembre. Comme bien d'autres choses en Chine, le choix d'un maître d'école est pour le postulant une simple affaire de chance. Il arrive rarement qu'un maître enseigne dans son propre village, règle qui souffre d'ailleurs de nombreuses exceptions. On explique cet ostracisme en disant qu'il est désagréable aux élèves d'habiter trop près de leur maître et de se trouver ainsi exposés plus tard à ses demandes parfois indiscrètes. Certains villages engagent un professeur pour une longue suite d'années, d'autres, au contraire, en changent tous les ans.

Dès qu'un enfant est régulièrement inscrit sur la liste de l'école, il doit acquitter le prix convenu, qu'il suive les cours assidûment ou non, et quelle que soit la raison de ses absences.

Si le maître se trouve empêché d'entrer en fonctions pour cause de maladie grave, son engagement est annulé, mais qu'il commence ses leçons et qu'à un moment donné il ne puisse les poursuivre, chaque élève n'en devra pas moins payer le prix des 


\section{La vie des paysans chinois}

cours, tout comme si le maître avait pu assurer son service jusqu'à la fin de l'année scolaire.

Dans tout établissement d'instruction le plus vif désir du ou des bailleurs de fonds est de retirer du professeur, en échange de l'argent que celui-ci reçoit comme paiement, le plus de travail possible. De son côté, le maître d'école souhaite toucher le plus d'argent qu'il pourra et ne donner que juste le travail qu'on exige de lui. Aussi accepte-t-il toujours avec joie de nouveaux élèves après que la liste a été close parce que ses recettes s'en accroissent d'autant. Mais ceci ne va pas sans l'opposition des parents dont les enfants figurent sur la liste initiale : ils craignent que ceux-ci ne soient négligés du fait de l'intrusion de nouveaux camarades et, à moins du consentement unanime des familles, les derniers postulants ne sont pas admis. Les villageois n'aiment pas non plus que le maître d'école ait auprès de lui un fils ou un neveu, de crainte que le maigre salaire alloué ne soit insuffisant à assurer la nourriture de deux personnes. En pareil cas il se pourra que le pédagogue abandonne la partie avant la fin des cours, mais alors il trouvera difficilement à se caser I'année suivante.

Une chambre inoccupée dans une maison particulière, ou un local disponible dans un immeuble quelconque, telle sera la salle d'école. Personne n'a jamais songé à louer une maison à cet effet. Le maître d'école prépare lui-même ses repas ; s'il en est incapable, il se fait aider par l'un de ses élèves ou par son propre fils, lorsqu'il a pu l'emmener avec lui car, ainsi que nous l'avons 


\section{La vie des paysans chinois}

déjà expliqué, les parents intéressés n'aiment pas beaucoup que le fils suive les cours de son père.

Les familles fournissent le mobilier nécessaire à leurs enfants,

à savoir une table avec un tabouret ou un banc. Les quatre précieux accessoires, indispensables à tout lettré dès le début de ses études, sont le bâton d'encre de Chine avec sa fiole d'eau, le godet à broyer, le pinceau pour écrire et le papier.

L'année scolaire coïncide en Chine avec l'année civile, bien que les cours ne commencent qu'après le milieu de la première lune, vers le mois de Février. Au mois de Juin, il y a congé pendant la moisson et, au moment des récoltes d'automne, en Septembre et Octobre, les enfants jouissent de vacances plus longues. De plus, les cours se terminent dix ou vingt jours avant la fin de l'année.

Si le contrat avec le maître n'était pas renouvelé pour l'année suivante, le travail des élèves en souffrirait probablement pendant la dernière lune, attendu qu'alors le pédagogue se préoccupera beaucoup plus de trouver un nouvel engagement que d'assurer un présent déjà presque mort. Quant à l'assiduité des écoliers, elle est fort irrégulière, spasmodique, et justifie amplement le dicton :

Une fois entré dans le douzième mois

Le maître ne gouverne plus ses garçons.

L'instruction chinoise a pour base la sagesse des Anciens et, parmi ces ancêtres littéraires, Confucius est considéré comme le Maître. Aussi ne s'étonnera-t-on pas que, dès le début des classes, l'école rende un hommage respectueux au Grand Sage 


\section{La vie des paysans chinois}

tenu partout pour le patron de l'enseignement. Les usages varient tellement en Chine que toute généralisation est aléatoire. Dans certaines parties de l'Empire cette vénération a besoin d'autels, d'encens, de cierges et de prières adressées directement au Philosophe, toutes cérémonies auxquelles on consacre les premières journées de l'année scolaire ; par une singulière anomalie, ce culte revêt, dans la province même de Confucius, des formes beaucoup plus simples. Pendant le festin qu'offrent au maître d'école les familles de ses élèves, ceux-ci sont introduits dans la salle où ils font deux révérences, la première à l'adresse de Confucius et l'autre destinée à leur précepteur. Dans ce cas, non seulement il n'y a pas d'image du Sage, mais on ne met en évidence aucune pancarte écrite pour le représenter. Même réduite à cette simplicité, la fête est loin d'être célébrée partout : un professeur, qui appartenait à la carrière depuis une trentaine d'années déjà, nous déclarait n'en avoir été témoin qu'une seule fois.

Dans les écoles chinoises, les cours commencent à une heure très matinale, aussi, dès le lever du jour, les enfants sont-ils déjà en route, agrémentant parfois leur marche de cris perçants. Lorsque sonne I'heure du repas du matin, les écoliers retournent à la maison et reviennent à l'école sitôt le déjeuner terminé. Vers midi, pour le dîner, nouvelle apparition chez eux, puis ils prennent de nouveau le chemin de la classe. Par les grosses chaleurs, tout le monde - hommes, femmes et enfants s'abandonne aux douceurs de la sieste méridienne; seuls les enfants sont à leur place habituelle : le maître les autorise à sommeiller au mieux qu'ils peuvent, penchés sur leurs pupitres 


\section{La vie des paysans chinois}

pendant une partie de l'après-midi. La discipline de l'école est, de la sorte, censée respectée en même temps que la pauvre nature humaine jouit de quelque liberté. Si les élèves étaient autorisés régulièrement à faire un somme dans leur famille, le maître aurait d'excellentes raisons pour craindre de ne plus les revoir avant le lendemain.

Les écoliers chinois sont assurément à plaindre pendant la canicule, mais que dirons-nous des souffrances qu'ils endurent au cœur de I'hiver, alors que le thermomètre demeure obstinément au-dessous de zéro ? L'école du village n'aura probablement pas d'autre feu que celui que l'on obtient en faisant flamber sur l'aire en terre de la salle quelques tiges d'herbe et qui ne donnera qu'une chaleur médiocre, précaire, tandis qu'une fumée âcre rendra l'air irrespirable pendant une heure au moins. Y eût-il même un petit brasero au charbon de bois que la température ne monterait guère et, du reste, le maître seul en profiterait. Les élèves - lorsqu'ils peuvent s'offrir ce luxe - s'enveloppent de longues capes d'hiver et demeurent assis toute la journée à moitié congelés.

Il est d'usage de clore la séance de travail à l'heure seulement où l'obscurité commençante ne permet plus de distinguer un caractère d'un autre. Mais, rendus enfin à la liberté, les écoliers n'ont pas licence de faire une marche hygiénique ou de jouer pour se dégourdir les membres : ils doivent rentrer chez eux en bon ordre, posément, de la seule manière qui convient à des disciples de Confucius. Dans certaines écoles, ils sont invités à revenir encore dans la soirée 


\section{La vie des paysans chinois}

pour faire leurs devoirs, comme si la longue et fatigante journée

d'études ne suffisait pas ; cependant ces séances du soir ne se pratiquent généralement que dans les classes les plus avancées, dans celles où I'on étudie la composition.

D'après la théorie chinoise la fonction de maître d'école est tout ce qu'il y a de plus honorable. Confucius et Mencius, ces deux grands sages de I'antiquité, n'étaient en somme que des pédagogues. Avoir un engagement, c'est pour le postulant à un emploi de professeur un honneur aussi grand que l'investiture du commandement suprême des armées accordée par l'Empereur à un général. En conséquence de ce respect extrême que les Chinois professent pour l'enseignement, le maître jouit d'un contrôle presque illimité sur ses élèves : selon un proverbe courant, les rapports entre le professeur et l'écolier ressemblent à ceux qui existent entre le père et le fils, mais comparer le pédagogue à un chef d'armée exprimerait avec plus de vérité les pouvoirs de l'instructeur ; il peut proclamer une sorte de loi martiale et punir avec la plus grande rigueur.

Dans les premières pages du Classique trimètre, il est dit qu'en laissant ses enfants sans instruction, c'est le père qui commet une faute et que « enseigner sans sévérité marque l'indolence du maître ». Il arrive parfois que des enfants s'enfuient très loin de leur logis parce qu'ils ont été punis à I'école. Un Chinois d'âge mûr raconta un jour à l'auteur de ce livre que, tout jeune encore, il fut roué de coups par son précepteur parce que celui-ci, dans son enfance, avait été luimême cruellement fustigé par le grand'père de son élève : la 


\section{La vie des paysans chinois}

rancune s'était ainsi conservée jusqu'à la troisième génération ! La férule repose toujours bien en évidence sur le pupitre du professeur ; toutes les fois qu'un écolier sort, il doit l'emporter avec lui : on suppose que les légendes qui sont inscrites dessus réagiront avantageusement sur sa tenue. L'une des faces porte en effet : «Sortez respectueusement » et l'autre : «Entrez respectueusement. » Deux élèves ne sont pas autorisés à s'absenter en même temps.

Ne pas arriver à apprendre ses leçons dans les délais prescrits constitue I'offense la plus grave dont un écolier puisse se rendre coupable envers son maître. En raison de cette lenteur, il sera constamment puni et pourra recevoir jusqu'à cent coups de férule. Étant donné que les enfants chinois sont bien rarement châtiés dans leurs familles et qu'il n'existe pour ainsi dire aucune autorité familiale, I'on est étonné de voir la grande latitude laissée aux professeurs pour maintenir la discipline. De mauvais écoliers, des cancres, dirions-nous, - car un étudiant sans moyens est considéré comme un mauvais élève, - sont souvent punis chaque jour ; ils portent parfois des marques si multiples de coups qu'à les voir, ils donnent plutôt l'impression d'esclaves en faute que d'étudiants. Si l'élève, en se faufilant çà et là, cherche à éviter quelques-uns des coups qui le menacent, il les recevra probablement sur la tête, souvent même sans qu'on ait eu l'intention de le frapper si malencontreusement.

On peut citer un cas de ce genre dans lequel un malheureux élève fut endommagé au point de tomber en convulsions. Combien d'autres méfaits de ce genre se commettent ! En 


\section{La vie des paysans chinois}

général, les parents ne semblent guère s'en préoccuper : ils se contentent d'aller se faire expliquer par le maître les causes d'une correction aussi rude. Chaque famille désire naturellement que son enfant arrive à quelque chose et elle admet sans discussion que la seule voie conduisant au succès est d'acquérir de l'instruction. Or ce résultat ne peut se réaliser qu'avec l'aide du professeur : par conséquent les règles qu'il a établies doivent être suivies intégralement, même si le père ou le fils en souffre.

Dans un cas dont eut connaissance l'auteur de ce livre, le père avait décidé que son fils recevrait une éducation littéraire suffisante pour être en état de diriger une petite affaire. Or l'enfant avait résolu de retourner à la fourche et au panier à fumier de l'étable familiale. Le maître fut invité à seconder les vues paternelles. Lorsqu'arriva l'ouverture des cours, le jeune garçon refusa net d'y assister et, de même que la plupart des parents chinois en pareille circonstance, le père ne put arriver à faire céder son fils. On en fut réduit à le placer, pieds et mains liés, dans une corbeille suspendue à une perche et deux hommes le portèrent comme ils eussent fait d'un simple porc. Après qu'on l'eut déposé devant l'école, puis introduit à l'intérieur, le maître le fit attacher à deux sièges avec défense d'essayer de sortir de la salle. Il ne prêta aucune attention à la leçon, choisie comme de coutume dans le Classique trimètre, bien qu'il reçût des coups chaque fois que le maître en avait le temps. Non seulement le garçon s'obstina dans sa paresse, mais il ne cessa de gémir bruyamment sur la dureté de son sort. Après plusieurs jours de cette contrainte sans effet, le père dut se rendre à l'évidence, comprendre qu'il n'obtiendrait rien de son fils et qu'une fois 


\section{La vie des paysans chinois}

encore se réaliserait l'antique proverbe : « Vous ne pouvez pas aider un chien mort à passer par-dessus le mur ! » Aussi le jeune gars eut-il désormais toute licence de s'adonner aux travaux des champs, seule occupation pour laquelle il manifestait quelque aptitude.

La manière de punir varie naturellement suivant le caractère de chaque maître, mais quelle que soit la nature de ces punitions, un véritable disciple de Confucius sera toujours enclin à les exagérer plutôt qu'à se départir de sa rigueur, attendu que la méthode qu'il emploie lui semble être la seule susceptible de réaliser le but désiré. Le cycle des études, les méthodes de travail, les capacités des élèves sont des éléments que l'on peut considérer comme constants, seul diffère le degré de diligence que I'on obtiendra de l'élève, soit par force, soit par persuasion. Le professeur chinois idéal est donc souvent un véritable Pharaon!

Lorsque l'enfant, à l'âge de sept ou huit ans, prend place pour la première fois sur les bancs de l'école, il ne possède aucune notion quant à la façon de prononcer un caractère d'écriture, pas plus que sur sa signification. Le professeur lit une ligne de texte et l'élève répète les sons, sans cesse repris jusqu'à ce qu'il arrive à les prononcer correctement. Il apprend ainsi à associer un certain son à une forme donnée de caractère. Après que l'élève aura épelé environ deux lignes, son « étude » consistera à crier chaque mot sur un ton aussi élevé que possible, gymnastique vocale qui fait partie essentielle de l'éducation de l'enfant et à laquelle tout Chinois attache la plus grande importance. Si 


\section{La vie des paysans chinois}

l'élève ne crie pas, comment le maître pourra-t-il être assuré que chacun étudie avec zèle ? Crier étant pour lui synonyme de travailler, tout marche à souhait lorsque la classe entière crie. En outre, grâce à ce système, le professeur, qui est supposé reconnaître dans cette Babel de sons la voix de chaque élève, est à même de corriger dans son germe la moindre faute de prononciation. Dès que l'élève peut répéter tous ces caractères sans en manquer un seul, sa leçon est « apprise » et l'étude se termine de la façon suivante : L'enfant se tient debout le dos tourné à son professeur - afin que celui-ci soit sûr qu'il ne voit pas le livre - et, dans cette position, il récite une dernière fois, à la vitesse d'une locomotive, tout ce qu'il vient d'apprendre.

Toute personne qui enseigne sait combien il est difficile d'empêcher les enfants de prendre, pour lire la langue anglaise, un ton emprunté. Couper court à des errements de ce genre représente un travail aussi laborieux que celui d'extirper d'un champ des mauvaises herbes et, pour peu qu'on néglige de les combattre dès le début, il devient presque impossible d'en triompher plus tard. Ces défauts se rencontrent presque toujours aussi, et dans leur forme la plus accentuée, chez les élèves chinois. L'attention de l'enfant se fixe exclusivement sur deux points : répéter les caractères dans le même ordre qu'ils se présentent sur le texte, et les répéter le plus vite possible. Bien entendu l'élève chinois ne se préoccupe ni du sens, ni de l'expression, car les mots représentent des idées qui ne lui sont encore jamais venues à l'esprit ; il n'a d'autre pensée que de réciter sa leçon au rythme le plus accéléré. S'il possède véritablement le texte appris, l'élève débutera tout de suite par 


\section{La vie des paysans chinois}

un bourdonnement bruyant rappelant le ronronnement d'une scie circulaire et n'ayant que fort peu de rapport avec la parole humaine. Il serait très difficile, sinon impossible, à l'auditeur de comprendre le sens du passage ainsi récité, lui fût-il même familier.

Mais lorsque la leçon a été imparfaitement apprise et que la mémoire fait de temps à autre défaut au récitant, celui-ci ne ralentira pas son débit pour tâcher de rassembler ses idées, car il n'en a pas. Tout ce qui lui reste, c'est le vague souvenir de certains sons et, dans l'espoir de rattraper ceux qu'il a oubliés, il répète inlassablement le dernier retenu, le dernier lambeau de phrase, même la dernière page dont il se souvient, jusqu'à ce qu'il retrouve enfin le fil de son récit. Alors le train reprend sa course vertigineuse.

Supposons par exemple que le texte à réciter comprenne le passage suivant des Analectes de Confucius, celui qui se rapporte aux habitudes du Maître : « Il ne touchait pas à la viande séchée et au vin achetés au marché. Il ne mangeait rien sans mâchonner en même temps du gingembre. Il mangeait très peu. » Le jeune élève qui ne possède qu'une connaissance très imparfaite de ce chapitre, débite sa leçon de la manière suivante : « Il ne touchait pas... il ne touchait pas... touchait pas... touchait pas... touchait pas... touchait pas à la viande séchée et au vin achetés au... achetés au... achetés au marché.... marché... au marché... au marché. Il ne mangeait rien sans mâchonner... sans mâchonner... mâchonner du... 


\section{La vie des paysans chinois}

gingembre... gingembre. Il ne mangeait pas... mangeait pas... beaucoup. 》

Telle est la méthode d'instruction des Chinois. A entendre ces cris poussés par les élèves, l'étranger, peu au courant de la pédagogie des Célestes, croit approcher d'une maison de fous. Aucun enfant étranger ne pourrait apprendre, aucun professeur étranger ne pourrait enseigner au milieu d'un tel vacarme ; I'instructeur chinois lui-même ne peut se rendre compte si l'élève répète exactement les sons qu'il lui a appris. Cet effort guttural imposé de façon constante est contraire à la nature et déraisonnable, aussi arrive-t-il fréquemment qu'en Chine des étudiants soient atteints d'un tel enrouement qu'ils ne peuvent plus prononcer un seul mot à haute voix.

Le premier petit livre mis entre les mains de l'élève sera probablement le trimètre ${ }^{1}$ (déjà mentionné), ainsi nommé de la présentation du texte en lignes doubles de trois caractères chacune. Ce texte en contient plus de mille. Il fut composé par un précepteur, il y a huit siècles et demi, à l'usage de son école particulière, et sans doute n'existe-t-il, en dehors de celui-ci, que peu d'ouvrages dont on ait farci avec une pareille persistance la mémoire de tant de millions d'hommes. Et cependant, parmi la masse incommensurable de gens qui étudièrent ce livre, combien en trouverait-on qui aient la moindre notion sur son auteur, sur l'époque et le lieu où le bouquin fut écrit. Le Dr Williams a fait remarquer très justement que la phrase même qui sert de début à ce manuel fondamental de l'éducation

${ }^{1}$ [on trouvera le texte de cet ouvrage, et sa traduction en Français, sur le site de l'afpc.] 


\section{La vie des paysans chinois}

chinoise renferme l'une des doctrines les plus disputées du monde païen de l'antiquité : « A leur naissance, les hommes sont, de par leur nature, radicalement bons ; par leur nature également, ils se rapprochent les uns des autres, mais, dans la pratique, ils diffèrent grandement. »Puis, après avoir expliqué en quelques lignes que l'instruction modifie le caractère de I'individu et qu'il importe de suivre avec attention les phases de cette évolution, I'auteur cite la mère de Mencius et fait ressortir I'intelligence dont elle fit preuve dans les leçons de choses qu'elle donna à son célèbre fils. Enfin il termine en rappelant aux étudiants que « juste fut la vie de Tou, de Yen : cinq fils il éleva et tous furent des hommes célèbres ».

L'écrivain retourne alors à son premier sujet et insiste en termes énergiques sur la nécessité de l'instruction pour la jeunesse «puisque tout germe non fécondé est sans utilité et que les illettrés ne sauront jamais le Code des Bienséances ». Après avoir cité d'autres exemples typiques puisés dans I'Histoire de la Chine et qu'il accompagne de commentaires moraux, l'auteur complète son œuvre par plus de soixante lignes d'une mosaïque littéraire bien chinoise. Le jeune élève est éclairé sur la nature progressive des nombres, sur les désignations des corps célestes, les «trois relations » entre prince et ministre, père et fils, homme et femme, enfin le traité se poursuit par l'étude des quatre saisons, des quatre orientations, des cinq éléments, des cinq vertus cardinales, des six espèces de grains, des six animaux domestiques, des sept passions, des huit genres de musique, des neuf degrés de parenté et des dix devoirs moraux. 


\section{La vie des paysans chinois}

Après avoir absorbé cette interminable nomenclature, l'élève doit, à mesure qu'il progresse dans ses études, apprendre un résumé général des Livres Classiques. Lorsqu'il s'est rendu maître de tous les ouvrages décrétés « Classiques », on lui prescrit de continuer par ceux des philosophes et des sages, ainsi que cela lui a déjà été recommandé dans le Classique trimètre. Il devra porter son attention particulièrement sur I'Histoire - c'est-à-dire sur les nombreuses dynasties chinoises - bourrée de noms de souverains ou plutôt des détails qui caractérisent les fondateurs des ramilles impériales les plus importantes. La liste s'arrête au premier empereur de la dynastie actuelle et finit brusquement à l'année 1644. L'étudiant désireux de connaître, au moins de nom, les derniers souverains de la dynastie des Ch'ing pourra s'en procurer la liste lorsque ceux-ci auront été renversés et seront de la sorte devenus matière à études historiques. Enfin l'élève est exhorté à méditer sur les Annales de I'Histoire jusqu'à ce qu'il comprenne les choses anciennes et modernes comme s'il les avait devant les yeux. Telle sera sa tâche du matin comme du soir.

La partie où sont formulées les conclusions présente plus d'intérêt pratique que tout ce qui précède. On nous y raconte en effet que le grand Confucius apprit un jour quelque chose de la bouche d'un enfant ; que les étudiants de jadis ne possédaient aucun livre et qu'ils copiaient leurs leçons sur des brins de roseau ou de bambou ; que pour mater le corps ils se suspendaient par les cheveux à une poutre ou s'enfonçaient un poinçon dans la cuisse; que certains lisaient à la clarté des vers luisants et que d'autres attachaient leur livre à la corne d'une 


\section{La vie des paysans chinois}

vache pendant qu'ils labouraient. Parmi les prodiges sous le rapport du travail, il en fut deux qui « bien que filles, étaient intelligentes et cultivées ». Dans les dernières pages, l'auteur s'efforce de stimuler l'ambition du débutant, non seulement par des exemples tirés de l'antiquité, mais aussi en rappelant la fidélité du chien de garde, l'assiduité du ver à soie et de l'abeille à leurs besognes respectives. « Si les hommes négligent de s'instruire, ils sont inférieurs aux insectes »; mais « celui qui apprend dans sa jeunesse et agit dans son âge mûr, étend son influence jusque sur le prince ; il fait du bien au peuple, rend son nom célèbre, donne du lustre à sa famille ; sa gloire rejaillit même sur ses ancêtres et elle enrichit sa postérité ». Si chaque jeune Chinois ne devient pas un prodige de savoir ce n'est certainement pas la faute de ce remarquable compendium dont l'incommensurable influence justifie seule la longue analyse que nous venons de faire.

Un autre petit livre que l'on met très tôt entre les mains de l'élève chinois contient la nomenclature de tous les surnoms chinois : il y en a plus de 400 et l'enfant, pour les fixer dans sa mémoire, doit fournir un gros effort. Les caractères de chaque mot sont disposés en séries horizontales de quatre et lorsqu'un Céleste indique son surnom à un camarade, il récite machinalement les quatre du groupe ; l'auditeur en est réduit à se demander lequel de ces quatre mots dont la consonance est la même s'applique à son interlocuteur. Dans certaines parties de l'Empire, le «Classique des Mille Caractères » est mis à l'étude après le « Classique Trimètre » tandis que, dans d'autres régions, il semble que l'usage de ce livre soit tout à fait inconnu. 


\section{La vie des paysans chinois}

Ainsi que l'indique son nom, il contient mille caractères tous différents les uns des autres. Ces caractères remplacent couramment les nombres en chiffres pour désigner les places dans les salles d'examens ; l'étudiant a donc intérêt à les connaître à fond.

Lorsque l'élève possède suffisamment les petits manuels du début, on attaque les «Quatre Livres », les Analectes de Confucius, la doctrine du Juste-Milieu, le Grand Enseignement et les écrits de Mencius. L'ordre de ces études varie d'après les différentes villes mais, ainsi que nous l'avons déjà fait observer, la méthode d'enseignement est à peu près la même partout. Livres après livres s'accumulent dans l'abdomen - organe dans lequel les facultés intellectuelles sont supposées être logées et, dès que l'élève possède le fil d'une demi-phrase, il peut dévider de mémoire tout son savoir, et cela pendant un temps indéfini.

Après ces quatre ouvrages viennent, en ordre souvent variable, le Classique poétique, le Livre d'Histoire, le Livre des Changements et l'œuvre historique de Confucius connue sous le nom d'Annales du Printemps et de l'Automne. Mais il faut assurément beaucoup d'années pour que la mémoire puisse s'assimiler pareille pâture. Ici encore nous verrons des usages variant suivant les lieux ; cependant il n'est pas rare de rencontrer des étudiants qui ont appris par cœur les Quatre Livres en entier et peut-être aussi deux des derniers Classiques - les Odes et I'Histoire - avant qu'ils n'aient entendu la moindre glose sur le Classique Trimètre par lequel leur 


\section{La vie des paysans chinois}

instruction a pourtant débuté. Pendant toutes ces années d'études, l'élève est demeuré dans un état mental d'hébétement que les Chinois désignent par un caractère particulier signifiant « un cochon dans des roseaux » - mêng. - Son entrée en classe se nomme : «soulever l'obscurité » - ch'i mêng - et instruire le débutant c'est « instruire l'obscurité ». Ces deux phrases expressives correspondent à des réalités. Parmi les étudiants qui ont pu graver dans leur mémoire tous les ouvrages nommés ci-dessus, quelques-uns des plus brillants ont sans doute réussi accidentellement à glaner une idée ci et là.

Des professeurs chinois expérimentés, connaissant bien la capacité intellectuelle de leurs élèves, estiment que l'on ne saurait s'attendre à ce que même les mieux doués d'entre eux comprennent la centième partie de ce qu'ils ont appris par cœur. La grande majorité conserve du champ pédagogique parcouru une conception assez analogue aux impressions que laisserait un district montagneux dans la mémoire d'un gamin condamné à parcourir cette région sous un épais brouillard, et cela au pas de course, pieds nus, les yeux bandés, talonné en plus par un tortionnaire qui ferait claquer un long fouet à bœufs au-dessus de sa tête. Rares sont les élèves capables de saisir la véritable signification d'un texte, même après avoir entendu des explications que le maître juge pleinement suffisantes. Une petite épreuve à laquelle le pédagogue soumet de temps à autre ses élèves démontre bien ce fait. Il les invite à écrire un passage : celui-ci foisonne le plus souvent de faux caractères au point qu'il est évident que non seulement ses explications n'ont pas été comprises, mais encore que le texte lui-même n'est 


\section{La vie des paysans chinois}

arrivé à l'oreille que sous forme de sons et n'a jamais pénétré jusqu'au cerveau.

La pédagogie chinoise use en général de méthodes exactement contraires à celles qu'un Occidental tient pour rationnelles. «En parlant », dit Confucius, « on devrait s'exprimer de façon intelligible, tout est là ». Pourtant le professeur confucéen est souvent loin de sentir la nécessité d'être intelligible, c'est-à-dire de s'assurer que les élèves ont saisi pleinement sa pensée. Il sera très capable de donner ses explications tout en ne les commençant que si l'élève a déjà eu un nombre d'années d'études suffisant pour qu'il trouve que cela en vaille la peine - d'une manière pompeuse et solennelle, en quelque sorte ex cathedra, bien plus préoccupé de faire étalage de ce qu'il sait que de communiquer son savoir à ceux qui l'écoutent. L'on entend dire couramment d'un maître qui s'est déjà distingué que, lorsqu'il commente les Classiques, chaque phrase tombée de ses lèvres pourrait « figurer avec succès dans une composition pour examens ». Telle semble être l'expression suprême de la louange. Des phrases susceptibles de triompher dans un concours ne sont pas - à peine est-il besoin de le faire remarquer - particulièrement adaptées aux facultés de compréhension de jeunes écoliers qui ignorent tout ce qui se rapporte aux compositions pour examens, le style de ces compositions étant très au-dessus de leurs moyens.

Le Commentaire sur les Classiques rédigé par Chu Hsi au XII siècle de notre ère, est arrivé à jouir d'une autorité presque aussi grande que le texte original lui-même. Il va sans dire 


\section{La vie des paysans chinois}

qu'aucun pédagogue chinois n'aurait l'idée d'inciter ses élèves à mettre un instant en question la valeur de cette glose et d'examiner si les explications en sont exactes et suffisantes. Le professeur n'a d'autre but que de préparer son auditoire à subir avec succès les examens : il ne se connaît d'autre tâche que celle d'apprendre à rédiger une composition de concours sous une forme qui ralliera l'approbation des examinateurs et conduira le candidat au rang de gradué littéraire. Mais ce résultat n'est possible que pour ceux qui acceptent l'interprétation orthodoxe des Classiques : d'où I'on conclura aisément que les écoles chinoises ont grande chance de ne jamais devenir des pépinières d'hérétiques. L'idée de discuter avec ses élèves le texte ou le commentaire ne vient pas à l'esprit d'un maître chinois. Le voudrait-il qu'il en serait incapable et le pourrait-il qu'il ne le voudrait pas.

Tâche sérieuse que celle d'apprendre à tracer les caractères chinois ! L'art d'écrire dans n'importe quelle langue européenne n'est qu'un jeu comparé à la calligraphie des Célestes. De plus la reproduction correcte d'un caractère n'est pas moins importante que la connaissance de l'idée qui s'y rapporte, car le succès de certains examens dépend tout autant de la calligraphie que du style.

Quelque étrange que cela paraisse, les caractères choisis par le maître pour les exercices d'écriture de ses élèves ne se rapportent aucunement aux matières étudiées au moment même. Ils sont, au début, empruntés à de petits manuels de 


\section{La vie des paysans chinois}

versification composés à cette intention et contenant des caractères à la fois simples et communs.

De ces livres élémentaires I'on passe à des morceaux choisis dans les œuvres des poètes de la dynastie T'ang et dont l'étude comporte la connaissance des sons et de la rime, connaissances que l'élève ne possède pas encore. Sans doute n'a-t-il jamais à ce jour vu les caractères qu'il est en train d'apprendre à écrire et ceux-ci d'ailleurs ne l'aident en rien pour ses autres études. Le professeur ne fait attention qu'à une chose, à la correction des caractères tracés ; quant au texte même, il n'en est pas question.

L'on peut se demander pourquoi l'on choisit, pour les leçons écrites, des poésies de la dynastie des T'ang au lieu de puiser dans les phrases de la leçon orale du jour. L'on vous répondra que I'habitude est d'utiliser la poésie à cet effet, qu'il n'est pas dans les usages d'employer autre chose et qu'à agir différemment le professeur s'exposerait au ridicule. De plus, la poésie a un sens en elle-même (si l'élève pouvait seulement le comprendre !), tandis que tel n'est pas le cas avec des caractères isolés. Comme conséquence de cette méthode d'instruction, des étudiants, par centaines de mille, quittent l'école ignorant presque tout des caractères et le peu qu'ils en savent est généralement inexact. Les défectuosités d'un pareil enseignement expliquent, en partie du moins, un fait qui semble au premier abord inexplicable : ce pourquoi I'on rencontre si peu de gens de condition moyenne qui connaissent bien les caractères de l'écriture. De ce système il résultera fatalement 


\section{La vie des paysans chinois}

que le simple fait d'écrire quelques-uns des caractères les plus courants, se rapportant à des objets que I'on emploie journellement, dépassera la compétence d'un homme qui aura été pendant des années à l'école, car il ne les a jamais vus écrits ou imprimés. Ainsi dans la rédaction d'un inventaire de biens, soit mobiliers soit immobiliers, il n'y a pas une chance sur dix que les caractères soient écrits correctement, puisqu'ils ne se rencontrent, ni dans les Classiques, ni chez les poètes de la dynastie T'ang. Bien mieux, il est plus que probable qu'un gradué moyen d'une école de village ne saura ni rédiger une lettre ordinaire, ni tracer une page de caractères sans faire de nombreuses fautes.

Si le professeur est un homme de quelque notoriété, il connaîtra beaucoup de monde. Parmi ses nombreux camarades d'école il se peut que l'un d'eux vienne un jour ou l'autre lui rendre visite dans le lieu où il professe. L'étiquette chinoise veut que I'on ait certaines attentions pour des hôtes de ce genre, et bien qu'il soit entendu que le traintrain scolaire ne subira de ce fait aucune interruption, il n'en reste pas moins que dans la plupart des écoles de pareils incidents sont devenus une véritable plaie ; cependant le professeur ne peut, et le plus souvent ne veut pas, y porter remède.

Le rythme pédagogique tel que nous venons de le définir, par lequel le maître est supposé donner tout son temps à l'instruction de ses élèves, ne tient compte d'aucune absence éventuelle du professeur. Pourtant peu d'êtres humains possèdent une santé assez parfaite, et sont, d'autre part, 


\section{La vie des paysans chinois}

suffisamment affranchis de relations avec le monde extérieur, pour être à même de se consacrer à la direction d'une école, mois après mois, sans la moindre interruption.

Il arrive fréquemment que le maître fait lui-même partie de cette armée de lettrés toujours à l'affût d'un examen dans l'espoir d'y gagner quelque grade. Si tel est le cas, les absences motivées par ces concours imposeront aux élèves de sérieuses interruptions. Certains patrons estiment que ces inconvénients seront bien compensés par la gloire qui rejaillira sur l'école du fait que le maître aura conquis un grade pendant le temps qu'il est à leur service. De plus, en dehors des périodes normales de vacances, au moment des fêtes de la moisson, chaque professeur ne manquera pas d'être mandé une fois ou l'autre auprès de sa famille à propos de quelque événement imprévu ; son village, ses nombreux amis peuvent également réclamer sa présence. En pareils cas, le maître se pourvoit d'un remplaçant intérimaire, si toutefois il juge à propos de prendre ce soin. Ces suppléants sont connus sous le nom de su-pai lao-shih « précepteurs-cousins-éloignés » - et ne peuvent guère compter sur le respect de leurs élèves occasionnels. Lorsque le professeur s'absente pour une journée seulement, au lieu de donner congé à la classe, il la confie parfois à la surveillance théorique - d'un élève parmi les plus anciens et, dans I'occurrence, le travail descend inévitablement non pas à $0^{\circ}$, mais à $40^{\circ}$ au-dessous de 0 . Les garçons barricadent à l'intérieur la porte d'entrée et s'amusent entre eux. La férule du maître leur sert de crosse et le Classique Trimètre ou les Analectes de Confucius deviennent une balle qu'ils se renvoient. La 


\section{La vie des paysans chinois}

démoralisation que provoquent ces désordres nuit sans aucun doute au travail de la classe.

Les irrégularités dans le service du maître sont, malgré tout, peu de chose, comparées à celles, plus grandes encore, causées par l'absence de ses élèves. L'urgence des besoins domestiques est telle que bien des familles, parmi les plus pauvres, ont toujours quelque prétexte excellent pour retirer leurs enfants de l'école. Aujourd'hui le garçon doit ramasser du combustible ; la semaine suivante, il est chargé de guider la charrue dans les champs ; un mois plus tard on l'emmène en visite chez des parents pendant deux ou trois jours. Puis c'est une troupe de passage qui donne des représentations dans le village, ou peutêtre même dans quelque agglomération voisine, et l'école compte bien sur le congé traditionnel en pareil cas. Ainsi que j'ai déjà eu l'occasion de le faire remarquer, les élèves le prendraient d'eux-mêmes s'il ne leur était pas accordé spontanément. En plus de ces diverses causes d'interruption, nous rappellerons les récoltes de printemps et d'automne, lesquelles motivent la fermeture des cours pendant deux mois, peut-être même trois, et les vacances du jour de l'An qui durent depuis le milieu de la $12^{\mathrm{e}}$ lune jusqu'au dernier quart de la première. Et cependant, parmi ces multiples arrêts du travail, aucun ne s'applique aux dures journées de la canicule, et les pauvres enfants continuent à fainéanter sur leurs bancs pendant toutes les chaleurs de l'été.

D'autre part nul stimulant ne vient entretenir le zèle des élèves. Jamais le maître n'a entendu parler d'une chose telle qu'un classement par ordre de mérite : l'irrégularité 


\section{La vie des paysans chinois}

qu'apportent les élèves à fréquenter les cours empêcherait, affirme-t-il, un pareil classement, alors même que ce serait possible d'une autre façon. En raison du temps consacré aux récitations, une école ordinaire ne contient que 8 à 10 élèves; le nombre de 20 est considéré comme dépassant les capacités d'un professeur.

Il serait difficile de trouver dans le premier enseignement donné à un enfant chinois ordinaire quelques points qui fassent appel à son intelligence. En général le maître s'occupe peu de ses élèves; son unique souci se réduit à leur faire suivre une progression fixée d'avance, ou tout au moins à essayer. Les parents pratiquent à l'égard des progrès de leurs enfants la même indifférence, elle est peut-être même plus grande encore. Si le père sait lire, il se souvient que pour y arriver il a dû suivre une route longue et épineuse et il trouve normal que son fils passe par les mêmes épreuves. Si le père ne sait pas lire, il reconnaît au moins sa complète incompétence dans la question et admet que ce n'est pas son affaire. Le maître est engagé pour enseigner, qu'il s'acquitte de sa tâche ! Quant à venir à l'école pour constater les progrès de son fils, c'est un usage dont il n'a jamais entendu parler et le connaîtrait-il qu'il ne s'y conformerait pas. Le maître ne se ferait pas faute de laisser entendre, alors même qu'il ne le dirait pas explicitement : «Qu'avez-vous à faire ici ? »

De toute façon un enfant chinois ne peut se livrer à un travail sérieux au milieu des distractions de son intérieur familial ; cette raison seule suffirait pour qu'il passât tout son temps à l'école. 


\section{La vie des paysans chinois}

Même pour les étudiants adultes, il est presque toujours très difficile de travailler à domicile. Chez lui, I'élève ne trouve aucun stimulant intellectuel, ni livres, ni revues, ni journaux et, en admettant qu'il pût se les procurer, ses études scolaires, foncièrement stériles, n'auraient pas préparé son esprit à comprendre ce genre de littérature.

L'éducation chinoise a pour objet de transfuser la sagesse des anciens dans le cerveau des modernes. Mais, pour y réussir, il est nécessaire de maintenir, et à n'importe quel prix, les méninges de l'élève en activité, faute de quoi beaucoup du travail antérieur serait perdu. D'après la théorie chinoise - ou la pratique - une école qui ne fonctionnerait que pendant six mois de l'année serait pure absurdité. Dès qu'un enfant cesse de la fréquenter, il est supposé, et non sans raison, retourner à l'état sauvage.

Le champ d'études est si vaste qu'il exige une assiduité inlassable, quelque avancé que soit l'élève. Ainsi qu'en témoigne un dicton populaire, « Rester un gradué dix ans (sans étudier), et l'on est une nullité ». Ceci s'applique très justement à toutes les catégories de lettrés.

Le fait que I'on doit porter en Chine toute son attention sur les études seulement, conduit les parents à faire une sélection parmi leurs fils et à choisir celui ou ceux qui paraîtront les plus aptes à recevoir une éducation littéraire. L'élu de la famille est habillé aussi bien que le permettent les ressources des parents, sa petite natte est proprement attachée avec un nœud rouge et on lui fournit, selon I'usage, un exemplaire des «Cent surnoms » 


\section{La vie des paysans chinois}

et un autre du «Classique Trimètre ». Ce jeune Confucianiste représente en germe le prototype de l'élève adulte. Son frère jumeau, qui n'a pas été retenu pour ces hautes destinées, rôde tout l'été au dehors sous un vêtement édénique, il ramasse du combustible, prend ses ébats dans la mare vaseuse du village, occupé lorsqu'il doit être occupé, paresseux quand il peut paresser. Il sera peut-être beaucoup plus utile que l'autre à sa famille, mais en tant qu'éducation, il demeure « un sauvage ».

Si l'étudiant montre de la vivacité et de l'intelligence et promet de se distinguer, il court grand risque d'être gâté par des louanges prodiguées sans mesure. «Ce garçon », fait remarquer quelqu'un à un étranger dans une réunion, - tout près de l'intéressé qui n'en perd pas un mot - «n'a que 13 ans, il a déjà lu les Quatre Livres et le Livre de poésie en entier, etc. A 20 ans, il sera certainement gradué. » Interrogé sur ce qu'il sait, l'étudiant répond d'un ton modeste qui lui assure d'emblée la bonne opinion de l'étranger. Sa parole n'a nullement l'assurance impertinente et présomptueuse qui caractérise trop souvent le jeune Occidental en pareille circonstance. Ses manières ne laissent rien à désirer, mais, en réalité, il est la victime de la plus dangereuse des flatteries, celle de lui faire croire qu'il est supérieur à ceux qui l'entourent. Ainsi forcé de ne pas laisser ternir son auréole, il doit - nous l'avons déjà fait remarquer se consacrer à ses études avec un zèle inlassable. Parmi ses frères, les uns sont aux champs toute la journée, d'autres apprennent un métier ou travaillent dans les affaires, mais lui, il ne fait rien, absolument rien, sinon étudier ses livres ! 


\section{La vie des paysans chinois}

A vivre aussi étroitement confiné, à travailler depuis son jeune âge avec une pareille assiduité, l'enfant ne peut manquer de souffrir physiquement. Son frère sarcle la terre, tête nue, pendant les chaleurs de juillet, mais lui, l'étudiant, s'il s'exposait ainsi au soleil, n'échapperait pas aux névralgies. L'autre travaille manuellement avec plus ou moins d'ardeur du matin jusqu'au soir, non sans quelques intermittences ; toutefois, si lui-même devait en faire autant, il en arriverait très probablement aux crachements de sang. Incontestablement ses forces physiques ont diminué depuis la période qui précéda son entrée à l'école. Et quant aux questions pratiques de la vie, il a peu d'occasions, - encore moins de dispositions, - pour en apprendre quelque chose. Le fait qu'un étudiant ne dispose jamais d'un moment à consacrer aux affaires ordinaires ne provient pas tant de son ignorance en la matière, mais de ce que sa dignité lui défend de leur accorder quelque attention. Parmi les quatre classes sociales, les étudiants occupent la première ; assez loin derrière eux se rangent les fermiers, les ouvriers et les marchands.

Il est deux choses que l'enfant apprendra sûrement dans une école chinoise : I'obéissance et l'habitude de concentrer son attention sur ce qu'il lit en demeurant étranger aux bruits qui I'entourent. Précieuses acquisitions assurément, bien qu'elles ne suffisent guère pour ce qu'il est convenu d'appeler une éducation.

Tout écolier aspire naturellement à s'élever au rang d'étudiant : il y parvient dès qu'il consacre chaque moment à l'étude car, quel que soit son degré de culture, il n'appartient 


\section{La vie des paysans chinois}

certainement à aucune des autres classes. Nous lisons dans les Analectes de Confucius que le Maître a dit : «L'étudiant accompli n'est pas un ustensile ». Les commentateurs expliquent cette sentence de la façon suivante : alors qu'un ustensile ne peut être employé qu'à un seul usage, l'étudiant accompli peut, au contraire, être utilisé de toutes sortes de manières : ad omnia paratus, suivant la paraphrase du $D^{r}$ Legge. Cette parole du philosophe est quelquefois citée en manière de plaisanterie afin d'excuser l'incapacité ordinaire du jeune Chinois lettré : lui n'est pas un ustensile ! L'étudiant, même celui qui travaille encore au village, non seulement ne laboure ni ne récolte, mais il n'aide en

rien ceux qui accomplissent ces travaux nécessaires. Il ne harnache pas une bête, il ne la nourrit pas, il ne conduit pas de chariot pas plus qu'il n'allume le feu ou ne va chercher de l'eau ; bref, en tant qu'effort physique, il ne fait pour ainsi dire rien. « L'étudiant n'est pas un ustensile », semble-t-il se répéter tout le jour, à chaque instant de son existence ; et son entourage en arrive à désirer que de temps en temps il soit un ustensile, qu'il se montre quelquefois utile. Mais il ne déplacera même pas un banc et s'abstiendra de tout geste qui pourrait faire croire à un travail quelconque de sa part. Signalons pourtant une seule exception à cette règle, exception à laquelle on ne s'attendrait guère. L'étudiant saura faire la cuisine pour peu qu'il en ait besoin dans sa vie quotidienne, car souvent, pédagogue dans un village autre que celui de ses parents, il vit généralement seul dans son école.

Nous avons déjà fait allusion à la surabondance des maîtres d'école. Beaucoup d'entre eux, faute de savoir s'adapter aux 


\section{La vie des paysans chinois}

circonstances, se trouvent continuellement à deux doigts de mourir de faim. Une très vieille maxime assure que pauvreté et fierté marchent de pair. On en trouve la preuve la plus éclatante dans le cas de l'étudiant chinois sans ressources. Il n'a rien, il ne peut et, le plus généralement, ne veut rien faire. Bref, jugé au point de vue de l'économie sociale, il n'est bon à rien.

L'auteur de ce livre eut un jour l'occasion de rencontrer un spécimen de cette classe de jeunes gens. L'étudiant avait trouvé à s'employer chez un étranger charitable dont l'industrie consistait à faire au moule des boulets de charbon, occupation qui paraissait certainement à l'étudiant et au public comme le parfait équivalent d'un travail de forçat : et cependant, au grand étonnement de son employeur, le jeune homme accepta ce travail plutôt que de mourir de faim. Un autre était si pauvre qu'il dut renvoyer sa famille chez sa belle-mère pour la préserver des souffrances de la faim. La femme, habile couturière, trouva un emploi bien rétribué dans une famille étrangère. Lorsque le mari apprit la chose, il en fut très irrité, non parce que son épouse fréquentait des étrangers qu'il voulut bien qualifier de très respectables, mais parce que c'était contraire à tous les usages que la femme d'un lettré descende au rang d'une salariée. Celle-ci eut le bon sens et le courage de répliquer que, si telle était sa manière de penser, il ferait bien de procurer à sa famille de quoi manger. A quoi celui-ci répondit par l'argument final et classique : il administra à l'épouse réfractaire une bonne raclée ! 


\section{La vie des paysans chinois}

Lorsque I'un de ces étudiants, sans argent et incapable de rien faire de ses dix doigts, vient rendre visite à un étranger qu'il n'a rencontré qu'une seule fois, qu'il n'a peut-être même jamais vu, il débutera probablement en étalant quantité de connaissances classiques pour montrer ses capacités, très grandes bien que méconnues. Il vous dira que parmi les cinq relations de prince à ministre, de mari à femme, de père à fils, de frère à frère et d'ami à ami, celle qu'il entretient en ce moment avec vous est la cinquième de cette liste; que ce serait faire violence à sa conception des devoirs qu'impose cette relation s'il vous laissait ignorer ses besoins. Il montre ses culottes et autres vêtements minces et râpés, dissimulés sous sa longue robe d'étudiant et finit par vous dire franchement que n'importe quelle contribution, petite ou grande, inspirée par une amitié telle que celle que vous lui portez, sera des plus agréables.

Tandis que l'étudiant ne trouve pas le moyen d'assurer sa subsistance de par les conditions d'existence qu'on lui fait au village, celles-ci ne sont pas moins néfastes à son développement intellectuel. Les sources principales, sinon exclusives, où il a toujours puisé pour alimenter son esprit sont les Classiques chinois, produits remarquables, sous bien des rapports, du cerveau humain et qui ont tout au moins le mérite de ne rien contenir qui tende à corrompre la morale : c'est à leur étalon élevé de moralité que I'on peut attribuer dans une large mesure leur influence illimitée et constante, influence qui a, sans aucun doute, puissamment contribué à la conservation de I'Empire. En dehors de l'action, d'une immense portée, qu'ils 


\section{La vie des paysans chinois}

exercèrent pendant plusieurs siècles sur d'innombrables millions de Chinois, il faut reconnaître que certaines de leurs pages ont une valeur intrinsèque de qualité rare.

Mais, à les prendre dans leur ensemble et si l'on considère qu'ils représentent les seuls textes appelés à former une grande nation, la critique la plus bienveillante ne peut s'empêcher de constater que ces textes sont tout à fait défectueux pour de pareilles fins. Leurs enseignements manquent de suite, leur portée est trop limitée. Maximes de morale présentées en épigrammes, fragments biographiques, incursions vagues dans les fourrés d'une économie politique encore plus vague,

morceaux d'histoire, règles d'étiquette et bien d'autres sujets se confondent sans plan, sans ordre, sans symétrie ni continuité de pensée. Les principaux défauts sont, ainsi que nous l'avons déjà signalé, la trivialité de certains sujets, la portée singulièrement limitée de cet enseignement et l'insuffisance avec laquelle les questions ont été traitées. Lorsque I'on met en parallèle les Analectes de Confucius avec les Memorabilia de Xénophon, lorsque I'on place à côté de la doctrine du Juste Milieu les écrits d'Aristote et de Platon ou que I'on compare les plates notations du Printemps et de l'Automne à I'histoire de Thucydide, ou bien encore le Livre des Odes à I'Iliade, à I'Odyssée et même à l'Énéide, il est impossible de ne pas demeurer surpris devant le succès qu'atteignit en Chine l'enseignement basé sur de pareils matériaux.

A considérer ce que, malgré leurs défectuosités, les Classiques ont fait pour la Chine, il n'est pas étonnant que ces 


\section{La vie des paysans chinois}

ouvrages y soient vénérés à un point dont l'histoire de I'Humanité offre peu d'exemples. Il nous est extrêmement difficile de comprendre les réactions que peut avoir sur le cerveau un enseignement à portée limitée parce que nous ne possédons guère d'exemple auquel l'on puisse comparer le cas des Chinois. Imaginons un instant un étudiant des pays occidentaux, pourvu d'une éducation mathématique très étendue, mais sans autre bagage intellectuel. Tout le monde tiendrait pareil esprit pour mal équilibré. Pourtant le mauvais effet d'une instruction aussi bornée serait contrebalancé par quelque autre avantage. Une certitude mathématique est une certitude absolue, infaillible ; les mathématiques mènent à l'astronomie et la connaissance approfondie de l'astronomie est en elle-même une éducation qui élargit les idées. De plus, il n'existe pas d'homme en Occident qui ne se trouvera pas un jour ou l'autre en contact intellectuel avec d'autres esprits cultivés. Il y a aussi ce que Goethe appelait « Zeitgeist » (I'esprit du siècle) lequel exerce sur I'homme une influence profonde. Mais, en Chine, celui qui a reçu une instruction bornée demeurera probablement un esprit borné, il n'y a pas de Zeitgeist chinois ou, s'il en existe, semblable aux autres fantômes, il intervient rarement dans les affaires humaines.

L'étudiant chinois moyen est, pour son plus grand malheur, très imparfaitement outillé au point de vue études. En Occident, tout étudiant digne de ce nom, sera à même, au bout de très peu de temps, de répondre à une longue série de questions avec intelligence et précision. Et il se tirera d'affaire non pas tant par ses vastes connaissances qu'à l'aide de ses livres de référence. 


\section{La vie des paysans chinois}

Les diverses théories émises quant à l'emplacement des jardins de I'Éden, aux dimensions de la grande pyramide d'Égypte, à l'auteur des Lettres de Junius, à la latitude extrême atteinte dans les explorations polaires, aux noms des généraux qui dirigèrent la quatrième guerre du Péloponnèse et mille autres questions du même genre, seraient élucidées sur-le-champ au moyen d'un dictionnaire d'antiquités, d'un manuel d'histoire ancienne et moderne, d'une biographie et d'une encyclopédie. Des références de ce genre font complètement défaut à l'étudiant chinois ordinaire lequel possède très peu de livres, car dans ce pays où fut inventée l'imprimerie, le livre est demeuré le luxe des riches.

Le dictionnaire classique de la Chine est toujours celui qui fut compilé, il y a deux siècles, sous le règne de K'ang Hsi et qui contient, dit-on, 44.449 caractères dont un nombre énorme n'est plus en usage ; d'autres, fort nombreux, ne sont que des synonymes et cette profusion de caractères ne sert qu'à embrouiller l'étudiant. Au cours des deux dernières générations, la langue chinoise a atteint un grand développement du fait d'un contact plus intime de la Chine avec ses voisins. La science moderne s'est imposée aux Célestes, mais les lettrés ne s'attachent nullement à coordonner les nouveaux enrichissements de leur langue : le dictionnaire de K'ang Hsi leur suffit amplement.

Pour s'assurer quelques succès dans un concours, il est indispensable de connaître la valeur de chaque caractère de l'écriture chinoise et, dans ce but, d'avoir en mains le dictionnaire classique. Or, il n'y a pas un étudiant sur cinquante 


\section{La vie des paysans chinois}

qui possède cet inestimable conseiller ! On le remplace généralement par un petit abrégé, véritable dictionnaire de poche, dans lequel les caractères sont ordonnés d'après leur son et non plus d'après leurs radicaux, comme c'est le cas dans le K'ang Hsi.

L'on enseigne rarement aux élèves les 214 radicaux et bien des gens qui passèrent des années sur les bancs de l'école ne savent pas se servir du K'ang Hsi. Dans une zone comprenant huit à dix villages, il peut n'exister qu'un ou deux exemplaires de ce dictionnaire ; la personne qui désire le consulter, lorsque le manuel se montre insuffisant, doit se rendre dans la localité où quelqu'un possède cet ouvrage et se renseigner sur place.

Mais il est rarement besoin d'en arriver à cette mesure extrême. L'étude incessante des Classiques fait que tous les caractères qui s'y trouvent sont familiers aux étudiants chinois et ils suffisent pour les rédactions ordinaires. Quant à ceux qui ne $s^{\prime} y$ trouvent pas, pourquoi s'en préoccuper ? L'exemplaire d'une bonne édition du K'ang Hsi, imprimé en types nets, expurgé de tout caractère faux, pourrait coûter à l'état neuf, une somme équivalente au traitement annuel d'un maître d'école de village !

Pour les examens au-dessous du second degré, la connaissance de I'histoire est, paraît-il, aussi superflue que le recours au dictionnaire. Neuf sur dix des candidats à ce concours élémentaire ne savent pas grand'chose de l'histoire de la Chine en dehors de ce qu'ils apprirent dans le Classique Trimètre ou recueillirent dans les autres Classiques. La lecture des abrégés d'histoire, bien que reconnue profitable, est reléguée aux heures 


\section{La vie des paysans chinois}

de loisirs : or, dès que s'ouvre la période de la préparation aux compositions, il n'y a plus de loisirs.

L'on voit incidemment des professeurs qui se sont spécialisés dans l'étude de I'histoire, mais ils sont rares. Des allusions historiques hantent souvent le cerveau des étudiants, tout comme des fragments de poésie, - souvenirs imprécis et sans aucune liaison entre eux. Beaucoup d'étudiants ont l'adresse de récolter ces parcelles çà et là et de se les approprier : ils acquièrent vite l'art de les glisser habilement dans leurs compositions et le succès couronne généralement ces subterfuges, alors que s'ils étaient interrogés sur le rapport des faits avec l'histoire, ils seraient incapables de répondre. Mais, tant que ces allusions sont heureusement intercalées dans la rédaction, les examinateurs ne songent pas à interroger le candidat à leur sujet et celui-ci atteint le but désiré. « Le chat qui attrape le rat est un bon chat », dit un certain adage : il importe peu que le chat soit aveugle et le rat déjà mort.

La Gazette de Pékin publie de temps à autre des articles de fonctionnaires demandant que des subsides soient réservés pour I'entretien, dans quelques villes du Centre, d'une bibliothèque qui permettrait aux étudiants pauvres de poursuivre leurs études. Si chaque ville de district était ainsi pourvue, le monde lettré y trouverait une aide précieuse et nécessaire. Mais il en est des bibliothèques comme de tout autre organisme qui vise des buts pratiques, il n'en existe pour ainsi dire pas.

La méthode chinoise d'écrire l'Histoire est, comme la qualifiait très justement Sydney Smith, antédiluvienne, c'est-à-dire que 


\section{La vie des paysans chinois}

l'écrivain procède d'après I'hypothèse que la vie du lecteur sera aussi longue que celle de Mathusalem. Conçues et réalisées sur ce plan formidable, les histoires classiques ne sont pas seulement encombrantes par leurs dimensions, mais fort coûteuses. Dans un certain district, I'on sait très bien que seule une famille riche possède une histoire de ce genre et il serait aussi impossible de « l'emprunter » que s'il s'agissait d'emprunter et d'emporter le tombeau familial. Du reste, l'étudiant y arriverait-il qu'il serait bientôt noyé dans cette mer inépuisable de renseignements. Un proverbe remarque en toute vérité que « celui qui veut connaître les choses anciennes et modernes doit compulser cinq charretées de livres ».

Mais, même après un pareil labeur, son savoir, mesuré aux étalons occidentaux, serait jugé singulièrement insuffisant. D'après les idées chinoises, I'histoire de la dynastie régnante ne peut faire l'objet d'une étude exacte, aussi les Histoires existantes s'arrêtent-elles généralement à la fin de la dynastie des Ming, il y a 250 ans environ. Le chercheur curieux de connaître ce qui se passa depuis lors devra se contenter d'attendre quelques décades, ou quelques siècles, jusqu'au prochain changement de dynastie. A ce moment, les Annales de

la Grande Pure Dynastie pourront être rédigées impartialement. Imaginez une histoire d'Angleterre qui s'arrêterait à la Maison de Hanovre !

Pour ces diverses causes, et en raison des nombreux défauts du système d'éducation, une multitude d'étudiants chinois ne savent à peu près rien des questions touchant directement à 


\section{La vie des paysans chinois}

leurs études, questions qu'il serait véritablement honteux d'ignorer chez nous. Un vénérable professeur faisait un jour remarquer à l'auteur de ce livre, avec la plus touchante naïveté, qu'il n'avait jamais compris les allusions historiques contenues dans le Classique Trimètre - ouvrage qui figure pourtant en tête des études chinoises - jusqu'au jour où, âgé de soixante ans, il eut I'occasion de lire une Histoire universelle rédigée par un missionnaire : c'était la première fois qu'il pénétrait dans I'Histoire de la Chine !

Les encyclopédies et les ouvrages de référence, compilations que les Chinois ont produites avec une extrême abondance, sont aussi inutiles à un étudiant ordinaire que les hiéroglyphes égyptiens. Il n'a jamais vu ces ouvrages, il n'en a jamais entendu parler. Des pelotons entiers d'étudiants ordinaires ne pourraient fournir les renseignements condensés dans un petit volume, tel que le manuel du lecteur chinois par Mayers. Des connaissances de ce genre, il faut que l'étudiant s'attache à les récolter tout le long de sa route, à se rappeler tout ce qu'il lit et entend. Elles dérivent souvent de petits livres bon marché, mal imprimés, conçus sans le moindre plan et ne s'appliquant à aucun sujet en particulier.

Le prix des livres chinois est, en réalité, prohibitif pour les pédagogues qui sont pauvres; pareils aux moines du Moyen Age, ils en sont réduits à copier les textes dont ils ont besoin. L'auteur connaît un maître d'école qui passait tons ses moments de loisir à copier un ouvrage en 8 volumes in- $8^{\circ}$, ce qui équivalait à noter 50.000 à 100.000 caractères. Il peina ainsi 


\section{La vie des paysans chinois}

pendant plusieurs années au plus grand détriment de sa santé et de ses yeux.

L'ensemble du plan d'études chinois a été très justement qualifié d'infanticide intellectuel. A le suivre avec soin, l'étudiant de village qui sait sur le bout de la langue tous les Classiques, qui a passé devant le Chancelier littéraire un nombre infini d'examens, peut très bien ne pas savoir distinguer le fait de la fiction, l'histoire de la mythologie. Peut-être même lui sera-t-il impossible de dire si un personnage historique marquant vivait sous la dynastie des Han ou sous celle des Ming, bien qu'il y ait entre elles un intervalle de 1.000 à 1.200 ans. Il ne prétend nullement être sûr qu'un nom donné représente un homme ayant réellement existé ou qu'il désigne simplement un personnage de comédie.

De même il ne pourra nommer les gouverneurs ou les hauts fonctionnaires de trois provinces sur les dix-huit, ni indiquer les noms des capitales d'un tiers au moins de ces circonscriptions. Il lui suffit de savoir qu'un certain endroit particulier, dont il ignore du reste la véritable situation sur le territoire chinois, se trouve « du côté Sud ». Jamais il n'a étudié la géographie ancienne ou moderne, ni examiné un vieil atlas ou une carte récente de la Chine ; en réalité, il n'en a même jamais entendu parler.

Un jeune homme élevé dans une école des missionnaires, l'auteur l'a connu personnellement, - envoya à un étudiant de son village renommé pour son ardeur au travail, un exemplaire de la géographie universelle rédigée en chinois et agrémentée de commentaires qui semblaient devoir en rendre la compréhension 


\section{La vie des paysans chinois}

facile à tout le monde. Cependant, le jeune villageois, après I'avoir longuement étudiée, n'y comprit rien. Il appela à son aide deux de ses amis dont l'un était gradué en littérature ; tous les trois se cassèrent la tête sur les cartes pendant plusieurs jours, et finalement, durent abandonner les recherches : l'énigme leur paraissait insoluble. En désespoir de cause, ils décidèrent d'attendre l'arrivée du donateur pour lui demander des explications.

Ce trait de torpeur intellectuelle n'est certes pas une exception chez les étudiants chinois. Dans une certaine classe sociale facilement reconnaissable, c'est la règle et, de plus, le résultat logique de leur mode d'éducation. Quoique l'instruction donnée à l'élève chinois soit presque uniquement consacrée à lui faire acquérir de la facilité pour ses compositions, celles-ci se réduisent à un seul genre, l'essai de concours. Observons toutefois qu'en dehors des salles d'examens, ces exercices ne jouent, même en Chine, qu'un rôle assez secondaire : une personne dont l'unique mérite consiste à produire ces essais se montrera souvent très peu à son avantage dans tout autre genre de travail. Un lettré ne saurait le plus souvent écrire une lettre sans laisser les « sept particules vides » mener tyranniquement sa plume. Il emploiera une variété de formules stéréotypées, telles que celles-ci : il a reçu votre épître et il s'est respectueusement baigné avant de se risquer à l'ouvrir. Mais il néglige très probablement de vous aviser de quel endroit il écrit, de même que, s'il vous rend compte d'un procès, il omettra sans doute plusieurs renseignements d'importance capitale pour la clarté de l'affaire. La plupart du temps, votre étudiant est 


\section{La vie des paysans chinois}

désespérément pauvre, souvent sans emploi ni perspective d'en trouver un. S'il fait la connaissance d'un étranger, vous êtes avisé, avant qu'il ait fait trois visites, qu'il cherche une situation. Vous vous informez de ce qu'il peut faire ; alors, avec une touchante simplicité, il vous assure qu'il est capable de certaines choses, qu'il n'est vraiment pas un personnage inutile. En vérité, il sait copier une lettre ou l'écrire sous la dictée, à condition qu'on ait l'œil sur lui pour l'empêcher de se tromper quand il note des caractères. Mais il ne faudra pas s'étonner si son employeur, après l'avoir mis à l'œuvre, s'aperçoit qu'il s'acquitte fort mal de sa tâche, ou qu'il est même incapable de l'assurer.

Les Occidentaux sont assez portés à formuler certaines critiques à propos des maîtres d'école chinois. D'après eux, le pédagogue indigène manque toujours d'initiative et il osera rarement agir sans instructions explicites. Il lui est difficile aussi d'arriver à des conclusions définitives, surtout lorsqu'il s'agit de ses affaires personnelles, et il tournera pendant des heures entières autour d'un point auquel il aurait dû parvenir en trois minutes si, bien entendu, son cerveau eût été façonné à la mode occidentale. On ne saurait pourtant lui contester certaines qualités intellectuelles ; la perspicacité et la justesse de ses critiques ou de ses commentaires surprennent souvent l'étranger. Mais son esprit a été préparé à un genre de travail tout spécial et souvent pour ce genre-là seulement. Chacun sait que le cerveau chinois n'est pas, par nature, analytique, pas plus, du reste, que synthétique. Le Chinois peut se figurer posséder la perception la plus claire sur la manière dont on devrait établir un rapport, mais il n'est pas rare d'apprendre 


\section{La vie des paysans chinois}

qu'une équipe entière de professeurs a pâli pendant des jours et des jours sur un compte rendu résumant quelque affaire assez compliquée, et cela pour fournir un travail dont ils ne sont pas eux-mêmes satisfaits, tandis que l'Occidental, plus mécontent encore, n'arrive pas à comprendre pourquoi cette besogne n'a pu être terminée en deux heures. Le même phénomène se voit fréquemment alors qu'un lettré s'épuise en vains efforts pour s'assimiler des ouvrages qu'il connaît peu et qui ne sont pas «géographiques ». Si un travailleur est invité à en présenter un résumé, il s'y refuse généralement en faisant remarquer qu'il ne saurait comment s'y prendre, assertion dont il fournit vite la preuve avec une certitude égale à une démonstration d’Euclide.

Le conservatisme inné de la race chinoise se montre dans le lettré moyen, quel que soit le degré de ses talents. Changer sa manière habituelle d'agir, c'est donner à ses facultés intellectuelles une entorse comparable à la dislocation physique d'un ischion. L'écriture chinoise se présente en colonnes verticales, mais, si elle est horizontale, on la lit de droite à gauche, en sens inverse de l'anglais. Il fut un jour impossible à l'auteur de ce livre de persuader à un chinois fossile, chargé de noter des phrases dans un cahier blanc bien réglé, de suivre les lignes ainsi tracées : il s'obstinait à vouloir disposer ces colonnes comme il en avait I'habitude. Lorsque I'on insista sur la supériorité de l'autre procédé, il tourna aussitôt le cahier d'un quart de cercle et écrivit sur les lignes perpendiculairement comme toujours, refusant de participer à un nouvel agencement des antiques symboles de la pensée. Pareil cerveau ressemble à une haute bicyclette démodée, très bonne si on sait la faire 


\section{La vie des paysans chinois}

rouler, mais d'un emploi assez périlleux pour le novice. On peut également rappeler à ce propos que beaucoup de Chinois jouissant d'une certaine érudition n'entendent se servir de leurs facultés intellectuelles que s'ils y sont formellement invités. Un Chinois, absent de son home pendant un temps assez long, vous dira froidement qu'il ne peut pas lire un ouvrage dont on lui demande de prendre connaissance, parce qu'il a laissé ses lunettes au logis : comment pouvait-il supposer qu'il en aurait besoin ! On ne saurait imaginer un plus grand contraste intellectuel entre I'Orient et I'Occident !

A presque tous les Chinois la forme d'un caractère écrit paraît infiniment plus importante que sa signification. Ceux qui apprennent à lire ou qui ne peuvent lire qu'imparfaitement sont en général si absorbés par la simple énonciation d'un caractère qu'ils ne veulent, et probablement ne peuvent pas, prêter la moindre attention à l'explication de ce que signifie ce caractère : un commentaire leur semble sans importance et passe même pour une interruption déplacée. Mais l'étudiant et le débutant possèdent tous deux un admirable avantage : ils savent presque toujours s'extérioriser malgré leur entourage et rester fermés à toute distraction. Cette précieuse faculté et une mémoire des mots phénoménalement développée représentent peut-être les résultats les plus enviables de la méthode d'éducation que nous décrivons. Malheureusement la mémoire des mots étouffe chez le Céleste tout jugement. L'on citera à ce propos un maître d'école de campagne - gradué en littérature - que l'auteur put un jour interviewer dans le vestibule d'un dispensaire. Il lui demanda d'expliquer les mérites respectifs de Chou, ce tyran 


\section{La vie des paysans chinois}

dont les crimes ruinèrent l'ancienne dynastie Chang, et de Pihan, un parent de Chou, auquel ce monstre fit ouvrir les entrailles par simple cruauté, afin de voir si un Sage a réellement sept ouvertures dans le cœur. Le professeur se rappelait parfaitement l'anecdote ; il cita un passage des classiques s'y rapportant, mais il refusa d'exprimer la moindre opinion sur les mérites de ces deux hommes, car il avait oublié ce que « les petits caractères » (le commentaire) disaient à ce sujet !

Nous avons déjà eu I'occasion d'attirer l'attention sur certains procédés routiniers en usage dans les écoles chinoises, mais nous ne saurions négliger le suivant. Il n'existe guère en Chine d'homme, de femme ou d'enfant qui n'aura pas passé une grande partie de son existence à manipuler de la monnaie de cuivre en quantités plus ou moins grandes. Aussi tout individu doit-il savoir compter, sinon rapidement, du moins correctement, afin de s'épargner bien des soucis et - détail beaucoup plus important - afin de ne pas perdre de l'argent. On a vraiment peine à croire que les gens n'aient aucun moyen à leur disposition pour se familiariser avec ce plus nécessaire des arts. Additionner, soustraire, multiplier, diviser, savoir employer les fractions décimales, sont des nécessités quotidiennes pour tout Céleste, et cependant personne ne les lui enseigne. Les opérations commerciales, la comptabilité doivent s'apprendre par la pratique dans les magasins et les bureaux d'affaires. Le maître d'école ne donne aucune notion de calcul à ses élèves, du reste en possède-t-il lui-même ? rien n'est moins certain. Imaginez un seul endroit en Angleterre ou aux États-Unis, où I'on n'apprendrait aux enfants aucune règle d'arithmétique, où les 


\section{La vie des paysans chinois}

élèves désireux de s'instruire seraient forcés d'aller demander à une personne complaisante de les mettre au courant des principes de l'addition, à une autre ceux des nombres composés et à une troisième résidant peut-être dans un village éloigné, les règles de l'arpentage, aucune d'elles n'étant à même de leur donner l'aide dont ils ont besoin.

La planchette à calcul des Chinois est sans doute un outil très ingénieux pour faciliter les comptes, mais il est loin d'en garantir l'exactitude. Son plus grave défaut est de ne laisser aucune trace des opérations qui ont conduit à un certain résultat, de sorte que, s'il y a eu erreur, il faut tout recommencer une fois, deux fois, etc... jusqu'à ce que la réponse obtenue soit correcte ou du moins admise comme telle. En vérité il semble étrange que la comptabilité compliquée d'un grand peuple commerçant, tel que les Chinois, soit l'esclave de procédés de calcul aussi primitifs. Un spécialiste arrive à ses conclusions avec une étonnante célérité, mais même les Célestes auxquels les calculs ordinaires sont familiers se trouvent fort embarrassés devant un problème qui est en dehors de leur routine. « Si un adulte reçoit tous les dix jours une livre de grains et un enfant la moitié seulement pour une même période, combien en faudra-t-il pour 227 adultes et 143 enfants pendant un mois et demi ? 》Sur ce problème, pourtant bien simple, nous avons vu un groupe de Chinois, dont quelques-uns avaient des prétentions à une érudition classique, se casser la tête pendant une demi-heure pour que, finalement, il ne s'en trouve pas deux qui soient d'accord sur le résultat. En réalité, plus leur savoir est grand et moins les Chinois semblent 


\section{La vie des paysans chinois}

être équipés, au point de vue mathématique, pour se défendre contre les gens qui les entourent.

L'objectif du maître est d'obliger ses élèves : $1^{\circ}$ à se rappeler, $2^{\circ}$ à se rappeler, $3^{\circ}$ toujours à se rappeler. Chaque étudiant, en effet, - nous l'avons déjà vu, - est théoriquement un candidat aux examens du district ; il devra écrire sur des thèmes donnés et choisis dans un grand nombre de livres les plus divers. Il faut donc que le candidat soit prêt à reconnaître non seulement le texte proposé, mais ce à quoi se rapporte ce passage, de même que les commentaires qui l'accompagnent dans le livre : ce n'est qu'ainsi documenté qu'il pourra se risquer à composer.

$\mathrm{Vu}$ les conditions dans lesquelles se pratiquent depuis plusieurs siècles les concours d'admission aux emplois civils, le système $d$ 'instruction scolaire que nous venons de décrire, ou tout autre susceptible de donner les mêmes résultats, est une nécessité impérieuse en Chine. Une réforme ne saurait s'attaquer à quelques points particuliers, elle doit être générale. L'on entend souvent affirmer l'excellence du système actuel et alléguer, comme preuve, le grand nombre d'hommes distingués qu'il produit. Mais, d'autre part, il faut tenir compte de la quantité innombrable de fruits secs qui n'ont retiré aucun profit - ou si peu - de cet enseignement. Rien n'est plus fréquent que de rencontrer des hommes qui, après avoir passé d'une à dix années à l'école, se trouvent embarrassés lorsqu'on les invite à lire un texte quelconque. Mis au pied du mur, ils répondent en toute vérité que depuis longtemps la connaissance des caractères a été « mise de côté ». Ce qui veut dire qu'ils ont 


\section{La vie des paysans chinois}

oublié presque tout ce qu'ils surent autrefois et sont devenus « de véritables aveugles », expression synonyme de ne savoir pas lire.

Et, fait bien significatif, les Chinois eux-mêmes reconnaissent que leurs méthodes pédagogiques tendent à engourdir les facultés mentales, transforment les professeurs en véritables machines et les élèves en perroquets. En admettant que tous les écoliers doivent poursuivre leurs études et courir la chance d'un concours, il serait peut-être difficile de suggérer un système susceptible de remplacer avantageusement celui qui est en vigueur et dans lequel la mémoire constitue l'élément essentiel du succès.

Cependant il n'est pas très hasardé d'affirmer qu'à l'école du village, il ne se trouve probablement pas un élève sur vingt même pas trois sur cent, - qui ait la perspective de poursuivre ses études jusqu'aux examens. La conséquence pratique de cet état de choses, c'est que 97 écoliers seront obligés de s'enliser dans une certaine routine scolaire pour la simple raison que telle est la seule méthode qui permettra aux trois autres de pousser leurs études jusqu'aux concours. En d'autres termes, 19 élèves sont condamnés à porter un joug de fer écrasant afin de tenir compagnie à un vingtième camarade qui se résigne à cette servitude parce qu'elle lui donne la possibilité de se faire un nom dans l'avenir ! Signalez cette étrange anomalie à des maîtres ou à des patrons de l'école, demandez-leur s'il ne vaudrait pas mieux adopter pour les dix-neuf qui n'iront jamais jusqu'aux examens un système réclamant moins de mémoire et 


\section{La vie des paysans chinois}

permettant de développer des connaissances générales pendant le temps très court que la plupart des enfants peuvent passer à l'école, ils vous répondront, ce qui est vrai pour autant qu'ils le sachent, qu'il n'y a pas d'autre système ; même si on voulait tenter l'expérience - ce qui ne sera jamais le cas - il ne se trouverait pas de professeur pour la risquer et si un maître désirait mettre en pratique une pareille réforme - ce qui n'arrivera jamais - il ne trouverait personne qui lui donnât un emploi.

La difficulté qu'éprouvent souvent des Chinois d'une certaine éducation à ne pas mourir de faim donne naissance à une classe

d'individus dénommés yu hsiao - étudiants ambulants - qui parcourent le pays en vendant du papier, des tableaux, des lithographies, des tablettes, des plumes, des pinceaux, de l'encre, etc. Il ne faut pas les confondre avec les colporteurs : ceux-ci déambulent également, ils trafiquent des mêmes articles, mais n'ont aucune prétention au savoir et transportent généralement leur pacotille sur une brouette tandis que l'étudiant ambulant n'arrive à circuler qu'avec un simple ballot sur ses épaules.

En arrivant à une école, le «yu hsiao » entre, dépose sa charge et fait un profond salut au professeur lequel, bien que fort ennuyé de voir apparaître cet intrus, doit lui rendre son salut. S'il y a des élèves adultes, l'étranger les salue également et s'adresse à eux en les appelant ses plus jeunes frères. Le maître s'enquiert alors de son nom, etc. S'il est reconnu pour un faux étudiant, le professeur laisse tomber la conversation et le 


\section{La vie des paysans chinois}

plus souvent quitte la salle. Les élèves les plus âgés comprennent à ce geste qu'ils doivent se débarrasser du visiteur. Ils déposent sur la table quelque argent - peut-être 3 ou au plus 5 cash : I'ambulant les ramasse, salue et disparaît. S'il a pu vendre quelque chose ses profits sont minimes, sans doute 3 cash sur chaque plume et 2 sur chaque petit pain d'encre. En prévision de cette sorte de demandes, les grands élèves ont toujours une réserve de quelque menue monnaie et ils obligent les jeunes à y contribuer.

Si pourtant l'étudiant ambulant est véritablement un lettré et que ses talents se manifestent, le professeur sera obligé de le traiter avec la plus grande civilité. Parmi ces savants errants quelques-uns se font une spécialité des anecdotes historiques et se plaisent à étaler des connaissances diverses. Une conversation s'engage avec le professeur et celui-ci, qui, très probablement, se sera confiné dans la routine des études classiques, se montre parfois à son désavantage. Dans ce cas I'on priera quelques autres étudiants du village de venir causer avec l'étranger auquel on demandera peut-être d'écrire deux rouleaux de papier ; enfin le professeur l'invitera à prendre un repas et, au moment de son départ, on lui remettra une petite somme d'argent.

L'on raconte qu'un étudiant ambulant de ce genre, pénétrant dans une école pendant que le maître expliquait les Classiques, se mit délibérément à enlever chaussures et chaussettes en présence de tous les élèves. Comme le professeur protestait contre cette infraction aux convenances, l'étranger répondit que 


\section{La vie des paysans chinois}

ses chaussettes sales n'avaient pas plus mauvaise « odeur » que les explications qu'il entendait. Aussitôt le maître s'empressa de lancer un défi à l'inconnu et le somma de commenter à son tour les Classiques pour que l'auditoire puisse profiter de sa science. L'étudiant ambulant, personnage d'une haute intelligence, attendait cette occasion. Reprenant alors les explications, il poursuivit la leçon dans un style si élégant - « chaque phrase ressemblait à une composition de concours »- que le professeur, stupéfait, eut honte et reçut son hôte de la façon la plus large. Si un maître s'avisait de manquer de respect envers un homme dont l'érudition est manifestement supérieure à la sienne, il s'exposerait à ce qu'on le traitât à son tour avec mépris et risquerait d'être discrédité devant ses propres élèves, accident qu'il tient avant tout à éviter.

Il existe, en Chine, une bien plus grande intimité entre maître et élève que dans les pays d'Occident. L'étudiant est supposé contracter de grandes obligations envers le professeur qui l'a sorti de son ignorance et, si celui-ci a jamais besoin d'être secouru, tout le monde considérera que c'est le simple devoir de l'élève d'agir en conséquence. Il est évidemment de I'intérêt du maître d'entretenir cette croyance. Pareille théorie a pour résultat que beaucoup de professeurs tombés dans la misère errent çà et là, ne vivant que de la générosité très aléatoire de leurs anciens élèves. 


\section{La vie des paysans chinois}

\section{$X$ \\ L'INSTRUCTION SUPÉRIEURE EN CHINE. L'ÉCOLE SUPÉRIEURE DE VILLAGE. EXAMENS. DERNIERS ÉDITS CONCERNANT L'INSTRUCTION.}

Lorsque les parents ont décidé que leur enfant poursuivra ses études jusqu'aux examens, ce lettré en puissance entre dans une école supérieure, laquelle diffère sous bien des rapports de celle où il a reçu jusqu'ici son instruction. Le professeur y est nécessairement un pédagogue possédant des talents bien audessus de la moyenne car, dans le cas contraire, il ne pourrait ni obtenir, ni tenir un pareil emploi. Les élèves sont soumis à un travail intensif, très dur, et ils doivent consacrer toutes leurs heures de veille à l'étude des compositions présentées antérieurement dans des concours. Ces modèles sont appris par cœur à la douzaine et même à la centaine. Le cerveau de l'étudiant se sature de ces matériaux, et le jour où il devra rédiger sa propre composition dans la salle des examens, il en trouvera toujours les éléments dans sa mémoire si patiemment entraînée.

Pendant les années qui précèdent son entrée à l'école supérieure, le jeune homme a déjà appris par cœur les parties les plus importantes de la littérature de son pays natal ; les commentaires traditionnels lui en sont devenus familiers. Peu à peu il s'est initié au mystère des accents et des rimes, à l'art de 


\section{La vie des paysans chinois}

construire des vers, de mettre sur pied des couplets antithétiques où I'on oppose à la hauteur du ciel la profondeur de la terre, pour continuer par l'exposé des lois embrouillées et presque inscrutables qui gouvernent la relation et la corrélation, la thèse et l'antithèse. Une étude soigneusement graduée va maintenant l'initier à un emploi judicieux de tout ce qu'il a appris auparavant, à composer l'essai littéraire qui constituera dans la suite le tissu et la trame de sa structure intellectuelle. A l'avenir, il mangera, il boira, écrira, parlera et dormira en ne pensant qu'à des essais, des essais, toujours des essais.

Mesurée à l'étalon chinois la rédaction d'un essai parfait est I'un des achèvements les plus nobles dont soit capable l'esprit humain. L'homme qui sait tout ce qui nous a été conservé de la sagesse des anciens, qui peut mettre rapidement sur pied des essais aux constructions symétriques, d'une grande élévation de sentiments, et les écrire dans une belle langue, prouvant ainsi qu'il connaît à fond le thème donné et les sujets qui s'y rapportent, cet homme là, pensent les Chinois, peut porter la tête haute non seulement devant les rois, mais devant le Fils du Ciel lui-même.

Un fonctionnaire supérieur appelé « Hsiao Yuän » chancelier littéraire provincial - est envoyé de Pékin dans les provinces pour présider aux sessions d'examens, les unes triennales, les autres se renouvelant deux fois en cinq ans. A I'occasion de l'avènement au trône d'un Empereur, de son mariage, de la naissance d'un héritier, etc., l'on accorde, à titre de faveur - ên k'o - des examens supplémentaires. Lorsque 


\section{La vie des paysans chinois}

l'étudiant de village se sent capable de produire un essai littéraire et de composer un poème susceptible de satisfaire ce terrible chancelier littéraire, il peut espérer devenir un « hsiuts'ai », c'est-à-dire un gradué. Afin de s'armer pour cette épreuve que les profanes considèrent avec effroi et qui est pour le candidat lui-même un objet tout à la fois de terreur et d'espoir, il lui faudra passer par une longue série d'examens préparatoires.

Quelques mois avant la visite du chancelier, le Gouverneur, qui en est tout d'abord avisé, I'annonce aux magistrats du district et fait procéder aux préparatifs du premier examen lequel se passe sous sa présidence et dans la capitale de la province. Il incombe à un certain nombre de membres de son personnel de propager la nouvelle de cet examen, mais, tandis que, en Occident, l'opération se ferait au moyen d'une simple annonce insérée dans la feuille officielle du district ou du comté, en Chine, le message, faute de journaux, doit être diffusé de vive voix. Toutes les écoles supérieures qui préparent à ces examens sont donc avisées de la date, et l'on en informe également les gradués en lettres du district qui vont être examinés en vue de leur passage à un grade supérieur. Les messagers du yamen espèrent toucher de 15 à 20 cents comme fiche de consolation pour « la peine » qu'ils ont prise à répandre la nouvelle. Ajoutons que, malgré une propagande aussi rudimentaire, il est rare qu'un intéressé ne soit pas mis au courant en temps utile. 


\section{La vie des paysans chinois}

Les candidats se rendent à la ville un jour ou deux avant la date d'ouverture de la session afin de louer un logis quelconque pour la quinzaine de jours qu'ils devront y passer. Si l'étudiant a la chance d'avoir des amis parmi les habitants, sans doute pourra-t-il éviter la dépense de cette location et, si son propre home se trouve près de la ville, il sera peut-être à même d'y retourner de temps à autre et de diminuer ainsi ses frais. Ces bagatelles ont beaucoup d'importance pour l'étudiant pauvre toujours talonné par le besoin d'argent. Plusieurs étudiants s'associent parfois et louent en commun une chambre ou même une maison : ils arrivent ainsi à réduire la dépense individuelle à un ou deux dollars. Chaque candidat doit se pourvoir de provisions de bouche pour quinze jours. Il existe certaines villes où se trouvent des bâtiments spéciaux en vue des examens et dans lesquels, en les entassant, on peut faire tenir de six à huit cents concurrents, tandis que d'autres centres ne possédant pas de pareils édifices ou les ayant laissé tomber en ruines, les examens se passent dans le temple confucéen ou dans le yamen du magistrat.

Le premier jour du concours, dès l'aube, I'on distribue deux thèmes : chaque candidat, déjà installé à sa place, ne doit plus en bouger. Ces thèmes ont chacun été choisis dans les Quatre Livres et l'essai à composer ne peut contenir, d'après le règlement, que 600 caractères. A 9 ou 10 heures, l'examinateur appose son sceau sur le dernier caractère tracé par l'élève : ce visa permet de contrôler tout ajoutage qui serait fait ultérieurement à un travail non terminé. Puis I'on enlève les feuilles de composition. Vers 11 heures, distribution du troisième 


\section{La vie des paysans chinois}

thème. Il s'agit cette fois d'un exercice de versification puisé dans le Livre des Odes ou dans I'œuvre de quelque autre poète classique. Le poème ne contiendra pas plus de 60 caractères, cinq par ligne. L'étudiant, suffisamment familiarisé avec l'écriture et qui sait composer rapidement, pourra remettre son travail vers 3 ou 4 heures de l'après-midi, alors que d'autres candidats auront besoin de beaucoup plus de temps. La durée de la séance peut se prolonger jusqu'à minuit et, exceptionnellement, jusqu'à I'aube du jour suivant. Un écrivain européen arriverait avec peine à s'imaginer la condition physique d'un étudiant cloué à sa chaise pendant vingt-quatre heures et s'efforçant de rédiger un essai et un poème qui devront satisfaire la critique la plus sévère.

Les deux jours suivants sont consacrés à l'examen du monceau de copies, prose et vers, fourni par la première épreuve du concours ; les malheureux concurrents profitent de ce répit pour reprendre haleine et dormir. Le matin du quatrième jour, on « suspend les tableaux », c'est-à-dire que I'on affiche la liste des lauréats. En admettant que 500 étudiants aient pris part à ces épreuves - évaluation des plus modérées pour un district de population moyenne - il y en aura bien la moitié d'évincés, ceux dont les noms figurent sur les tableaux étant seuls admis aux concours suivants. Parfois dans l'entourage du magistrat, quelques fonctionnaires, après avoir constaté le grand nombre des refusés, viendront s'agenouiller devant leur chef et, se frappant la tête, ils le supplieront d'avoir la bonté d'approuver une petite liste supplémentaire. Si ce dernier est par hasard de bonne humeur, il accueillera favorablement la requête présentée, 


\section{La vie des paysans chinois}

non pas certes parce que ses subordonnés accordent quelque intérêt aux affaires des candidats déçus, mais pour des considérations plus pratiques : en effet moins il y a de moutons et moins rémunérateur sera le produit de leur tonte.

Les frais d'examen se réduisent à 20 cents, somme payée pour l'enregistrement de l'inscription. Celle-ci comprend non seulement le nom du candidat, mais ceux de son père et de son grand-père : I'on veut s'assurer ainsi qu'aucun homme disqualifié légalement ne sera admis à concourir. Les feuilles de papier destinées aux copies des élèves - essai et poésie - sont d'un genre spécial ; elles ne se vendent qu'au yamen et coûtent chacune 10 cents environ, soit 50 cents pour les cinq examens. Le candidat doit verser les 3/5 de cette somme dès le premier concours, qu'il soit ou non admis aux suivants. S'il est reçu, on lui tiendra compte de cette provision lors de ses achats ultérieurs.

Le cinquième ou le sixième jour, les lauréats du premier examen se rendent de nouveau dans la salle des compositions pour prendre part à la deuxième épreuve ; ils se présentent dans I'ordre de classement. Encore une fois il s'agit de trois thèmes : le premier tiré des Quatre Livres, le second de l'un des cinq Classiques, quant au troisième, ce sera un sujet de versification analogue à celui de la première épreuve. La correction de ces copies demande un jour ou deux après lesquels les tableaux sont de nouveau suspendus et portent la liste des candidats reçus. Leur nombre correspond en général à la moitié des élèves ayant pris part à ce deuxième concours. 


\section{La vie des paysans chinois}

Au troisième examen, les thèmes, distribués un peu plus tard qu'aux examens précédents, sont au nombre de deux et tirés, I'un des Quatre Livres, I'autre d'une œuvre poétique. Ce même jour, vers midi, le magistrat fait servir un repas composé de vermicelle, de riz, etc. A 4 heures la salle se vide. Après un jour réservé à l'examen des copies, les tableaux sont encore une fois suspendus : ils indiquent qu'une cinquantaine seulement des candidats ayant concouru, est admise à la quatrième épreuve.

Celle-ci commence à une heure plus tardive que la troisième et, bien qu'elle impose peut-être un plus grand nombre de thèmes - tous tirés des Quatre Livres - le temps accordé ne permet de traiter complètement aucun d'eux. Aux thèmes littéraires, on en ajoute parfois un autre d'ordre philosophique. De plus, les sujets de versification doivent être traités différemment de ceux des épreuves précédentes : ils sont plus difficiles, la composition poétique étant cette fois soumise aux règles qui régissent la rédaction des couplets antithétiques.

Que le vers se compose de cinq ou de sept caractères - il n'y en a jamais ni plus ni moins - cela dépend du candidat : il a le choix. S'il est un élève brillant, sachant écrire rapidement, il traitera le même sujet des deux manières. Comme dans l'épreuve précédente, I'on sert un repas, puis vers 5 ou 6 heures, la salle se vide. Après une journée consacrée à la correction des copies, le tableau est suspendu pour la quatrième fois : la proportion des admis va toujours en diminuant et cette fois le nombre des lauréats ne dépasse guère le chiffre de 20 ou 30. 


\section{La vie des paysans chinois}

Le lendemain a lieu l'examen final. Le thème, pris dans les Quatre Livres, peut être traité en entier ou partiellement suivant les ordres donnés au début par l'examinateur. Le concours comporte avec un poème en vers de cinq caractères, une transcription de quelques-uns des «Édits Sacrés » de I'Empereur Yung Chêng, exercice qui a pour but de juger de I'habileté calligraphique des candidats et, au besoin, de faciliter le classement. De même que les jours précédents l'on sert un repas, puis, vers le milieu de l'après-midi la salle commence à se vider. Le jour suivant, suspension du tableau qui fait connaître les candidats finalement admis et dont le nombre limité, toujours fixe, est relativement le plus bas parmi les districts où la population présente la plus forte densité. Ainsi dans deux districts contigus, d'où sortent en moyenne 5 à 600 candidats, le chiffre sera par exemple de 20 pour l'un et de 18 pour l'autre. Dans un troisième, fournissant souvent 2.000 candidats, 30 seulement pourront être admis. L'on peut voir par là que les chances de l'élève de force moyenne sont extrêmement faibles.

Tout candidat à un diplôme doit avoir un « répondant », personnage choisi parmi les gradués des années précédentes qui ont passé du rang de hsiu-ts'ai au degré supérieur de lingshêng hsiu-ts'ai. Le nombre de ces répondants n'est pas nécessairement considérable, parfois quatre par district qui, pour la plupart, ne connaissent peut-être même pas les étudiants dont ils se portent ainsi garants. Ils ont cependant une double responsabilité : d'abord celle d'assurer que le nom sous lequel les personnes se font inscrire leur appartient légitimement, en second lieu, que ces candidats ne violeront au cours des 


\section{La vie des paysans chinois}

examens aucun des règlements établis. Si l'on découvrait une fraude à propos de l'une on l'autre de ces prescriptions, le lingshêng en serait tenu pour responsable et risquerait de perdre son rang de gradué. L'on exige de chaque candidat qu'il fournisse non seulement un répondant mais aussi un suppléant à ce dernier. Pour une rétribution variant de 10 cents à 5 ou 6 dollars, les lingshêng sont prêts à répondre pour tous les concurrents qui leur en feront la demande La somme fixée doit être versée d'avance, sinon le répondant interdira l'entrée de la salle au mauvais payeur.

Le premier concours ainsi achevé dans les chefs-lieux de district est suivi, après un mois de repos, d'examens similaires qui se passent dans la capitale de la circonscription, devant le Préfet (chih-fu). Là sont rassemblés les candidats de tous les districts soumis à la juridiction de la Préfecture de Fu. Le nombre des districts est fonction de la densité de la population, il varie de deux à trois jusqu'à douze et plus encore. Les candidats qui ont échoué aux concours des districts ne sont pas pour cela disqualifiés, ils peuvent se présenter aux examens de la Préfecture lesquels, tout comme les premiers, ont pour objet de passer les concurrents au crible en vue de l'épreuve finale et décisive qui a lieu devant le Chancelier littéraire. L'ordonnance du concours ne diffère pas de celle adoptée dans les districts et le temps accordé pour chaque composition est sensiblement le même. Dans une Préfecture, le nombre des concurrents s'élèvera souvent à plus de 10.000. Comme il n'existe pas de local susceptible de contenir pareille affluence, on opère par séries successives. Le Préfet dirige ces examens à la suite 


\section{La vie des paysans chinois}

desquels les premiers classés dans les districts ne se retrouveront pas nécessairement aux meilleures places. Chaque composition amène un classement nouveau, mais les candidats qui réussissent à se maintenir en tête de liste ont naturellement les plus grandes chances d'être admis à concourir devant le Chancelier.

L'auteur de ce livre a connu un Chinois qui, à un concours pour le premier grade, se trouva classé le dernier sur 17 candidats lors de l'avant-dernière épreuve ; il perdit un point à celle-ci et manqua son diplôme pour cette petite différence d'un point. Le chagrin et la colère qui s'emparèrent de lui à la suite de cet échec prirent de telles proportions qu'il devint fou et, devenu désormais inutile à lui-même et aux siens, il ne fut plus qu'un lourd fardeau pour sa femme pendant le reste de son existence.

Les lettrés parvenus au grade de hsiu-ts'ai s'examinent entre eux lorsqu'il s'agit d'avancement. La dépense d'un répondant n'est obligatoire que pour les deux dernières séries d'examens. L'épreuve finale devant le Chancelier est menée avec beaucoup plus de soin et de prudence que les précédentes dirigées par les fonctionnaires locaux. Les candidats dûment munis de répondants, régulièrement inscrits, s'installent à une place qui leur est désignée et qui a été au préalable marquée par des caractères pris dans le Classique Millénaire lequel, ainsi que nous I'avons déjà fait observer, fournit un système de notation commode, les mêmes caractères ne se répétant pas. L'on entasse les candidats par 15 ou 20 à chaque table. La première est appelée le «Ciel » d'après le premier caractère qui se 


\section{La vie des paysans chinois}

présente dans le Classique millénaire et ses occupants sont désignés par «Ciel 1 », « Ciel 2 », etc. Chaque candidat inscrit sur sa copie le caractère lui servant de désignation, car les listes finales des lauréats ne portent pas de nom, mais simplement I'indication de la place qu'ils occupaient dans la salle. A leur entrée, on fouille les concurrents méticuleusement : ils ne doivent avoir sur eux aucun livre, aucun document susceptible de les aider dans leur travail. La séance s'ouvre à une heure très matinale : le thème écrit sur une tablette en bois est promené, dès le lever du soleil, dans toutes les parties de la salle de façon à ce que chaque candidat puisse en prendre connaissance, après quoi on le lit à voix haute. A 9 ou 10 heures apparaît un autre sujet tiré des Quatre Livres ainsi qu'un thème de poésie à composer en strophes de cinq vers. Le candidat, au travail facile, peut terminer sa tâche vers 2 heures de l'après-midi. Ainsi que dans les concours précédents, chacun est admis à se retirer après avoir remis sa copie : ces sorties se font par groupes et à des heures déterminées. A 5 ou 6 heures de l'après-midi, clôture de la séance et le sceau inexorable est apposé sur le dernier caractère, que le travail soit terminé ou non. Pendant toute la durée des compositions, nul candidat, sous aucun prétexte, ne peut bouger de sa place. Si l'un d'eux était pris subitement d'un malaise grave, il irait demander au surveillant la permission de quitter la salle, mais il ne pourrait plus y rentrer. Qu'un étudiant se lève simplement de son siège et jette un regard autour de lui, il reçoit aussitôt une correction cuisante - cent coups de bâton sur les mains - et il devra, comme un simple écolier, se mettre à genoux pendant tout le reste de la séance, pour être 


\section{La vie des paysans chinois}

finalement expulsé et perdre ainsi tout droit à concourir l'année suivante.

Il y a quelques années, la salle d'examens de Chinan Fu, capitale du Shantung, était en très mauvais état. Séduit par la proximité des montagnes, le Chancelier choisit quand même cette ville pour y présider les concours d'été. On espérait que le voisinage de l'eau apporterait quelque fraîcheur. Au cours de I'une des séances, un violent orage éclata ; puis, une pluie diluvienne, traversant la toiture comme si c'était un simple tamis, inonda une partie de la salle. De malheureux candidats furent trempés jusqu'aux os et leurs copies subirent le même sort ; ils n'en durent pas moins demeurer rivés à la place qui leur avait été assignée. Ce mauvais temps provoqua beaucoup de maladies ; plusieurs candidats tombèrent gravement malades et sept ou huit d'entre eux moururent du choléra au cours de la session. Ces incidents déplorables n'ont, du reste, rien d'exceptionnel; ils se sont souvent renouvelés depuis cette époque. Pendant les examens d'automne de 1888, et dans la même ville, plus de cent personnes succombèrent, à la suite du choléra ou d'une épidémie analogue. Parmi les victimes se trouvaient des domestiques, des scribes, des étudiants et aussi quelques fonctionnaires. En outre, I'un des principaux bâtiments consacrés aux examens s'écroula au cours de cette session causant, paraît-il, la mort de plusieurs personnes. On ne saurait trop insister sur l'effet démoralisant de pareils accidents.

Deux jours après la fin du concours, on suspend les tableaux sur lesquels sont inscrits les noms des candidats reçus. Mais, 


\section{La vie des paysans chinois}

pour se garer une dernière fois de toute erreur, de tout accident, il est procédé à un examen final lequel est cette fois décisif. A la trentaine de concurrents déjà admis au concours, I'on en ajoute une quinzaine environ pris à la suite des premiers de la liste de classement, ce qui porte leur nombre à quarante environ. Pour cet examen, nouveau thème tiré des Quatre Livres et dont un fragment seulement, le commencement, le milieu ou la fin, devra être traité sous les yeux mêmes du Chancelier. Une surveillance rigoureuse peut s'exercer sans peine sur un nombre aussi restreint de concurrents, et la correction de ces compositions amène toujours quelques changements dans le classement.

Lorsque les résultats de cette dernière épreuve sont affichés, les lauréats, définitivement qualifiés de «florissants », sont enfin officiellement proclamés. Ceux qui ont échoué à un stade quelconque peuvent rentrer chez eux ; les «florissants » au contraire, « ceux qui entrent dans l'école », doivent demeurer encore en ville pour faire escorte au Chancelier lorsque celui-ci se rendra dans le prochain centre des examens qu'il doit présider.

Les frais qui incombent aux candidats évincés devant le Chancelier sont les mêmes que pour les concours précédents. Quant aux élèves reçus, ils n'en ont pas fini avec leurs débours. Ces dernières dépenses, d'ordre divers, illustrent l'aphorisme chinois d'après lequel c'est l'homme malade qui doit alimenter la transpiration. A part les honoraires dus au « lingshêng » et déjà mentionnés, il y a encore d'autres salaires et gratifications dont 


\section{La vie des paysans chinois}

le montant dépendra des ressources pécuniaires de l'étudiant, celui-ci ne pouvant d'ailleurs se soustraire à aucune d'elles. Le personnel subalterne chargé du service reçoit des cadeaux qui s'élèvent jusqu'à plusieurs dollars par tête ; ceux qui suspendent les tableaux touchent quelques centaines de cash, etc.

Dès que se répand la nouvelle du succès d'un candidat, un messager est expédié au domicile du nouveau gradué : cette mission comporte une rémunération de plusieurs milliers de cash. Des établissements spéciaux ont en boutique un assortiment de grandes proclamations dites « joyeuses nouvelles » dont les caractères sont gravés sur des planchettes ; elles se vendent aux heureux concurrents à raison de 3 à 4 cents pièce. Un étudiant pauvre n'a peut-être pas les moyens d'acquérir de pareils objets de luxe, mais ceux qui le peuvent en achètent un grand nombre qu'ils envoient de tous côtés aux parents et amis lesquels s'empressent de les exposer en bonne

place. Au reçu de ces notifications, il est d'usage que les amis fassent une visite protocolaire aux membres de l'heureuse famille ; celle-ci leur offre en échange un somptueux festin. Chaque visiteur se présente avec un cadeau en espèces dont l'importance varie suivant les conditions de fortune du donateur comme de son degré d'intimité avec la famille du lauréat. Si ce dernier possède une nombreuse parenté et un large cercle d'amis, surtout si certains d'entre eux occupent des postes officiels, il recevra probablement assez de dons de ce genre pour rentrer dans les débours qu'ont nécessités les examens et, dans quelques cas exceptionnels, les cadeaux de congratulation dépasseront peut-être le montant total de ses dépenses. 


\section{La vie des paysans chinois}

Les tablettes de notification, toutes pareilles, sont faites d'avance en réservant un blanc pour insérer le nom et le rang du nouveau gradué. Dans certaines régions on n'hésite pas à annoncer que le lauréat de la localité a été « inscrit le premier sur la liste d'admission » alors qu'en réalité il y figurait peut-être le dernier. Ce genre de fraude se pratique sans vergogne et chacun le considère comme un bon moyen de se faire un nom. Personne d'ailleurs ne s'y trompe car lorsqu'un mur blanc se couvre d'une vingtaine de pancartes proclamant chacune que son lauréat a été « inscrit le premier », il est bien évident que ce n'est qu'un subterfuge employé pour la parade.

L'on serait assez naturellement porté à croire que le résultat d'un concours aussi rigoureux et aussi long que celui qu'exige l'obtention du grade de «hsiu-ts'ai » est certifié avec soin par les autorités compétentes à l'aide, par exemple, d'un diplôme au sceau du Chancelier. Or, il n'en est rien. Les compositions des candidats reçus sont supposées être envoyées à Pékin au Conseil des Rites ; il faut espérer qu'elles moisissent et disparaissent à la longue, sinon la Capitale serait certainement un jour ensevelie sous un amoncellement de paperasses. En tout cas le gradué dont le talent est finalement reconnu « florissant » ne possède aucun document pour en témoigner. Lorsque vient le moment d'examiner les titres d'un « hsiu-ts'ai » on demande à l'intéressé en quelle année il prit ses grades, le nom des examinateurs, les sujets donnés au concours, etc. Il lui sera difficile d'inventer des réponses plausibles au point $d$ 'induire en erreur les enquêteurs. L'auteur a eu connaissance d'un cas de ce genre : un homme qui avait été examiné, sans toutefois être admis, dut un jour 


\section{La vie des paysans chinois}

répondre à de pareilles investigations ; il indiqua un nom, des thèmes, etc., lesquels appartenaient à son propre frère qui était vraiment un gradué - et I'on apprit plus tard que I'individu en question se trouvait en prison à l'époque même où il prétendait avoir conquis ses grades.

Cette absence de pièces de contrôle pour un titre si convoité donne aux étudiants sans scrupules, mais pourvus de quelque talent, la facilité de se faire passer, dans des districts éloignés de leur lieu originaire, pour des lettrés d'un rang auquel ils ne sont jamais parvenus.

Le gradué est autorisé à porter sur sa coiffure un bouton plat en cuivre qu'il préfère généralement au bouton en étain qu'on lui remet lors de la proclamation des lauréats. En cas de violation des statuts de la corporation le magistrat du district dans lequel habite le délinquant, court le risque de se voir enlever son bouton et le gradué de reprendre rang parmi le commun des mortels. Cependant, aussi longtemps que le gradué jouira de ses privilèges de classe, il ne pourra être frappé comme un vulgaire Céleste, sauf sur la paume de la main. Si un magistrat portait atteinte aux prérogatives d'un lettré, cet acte attirerait sur sa tête de tels orages qu'il n'aurait d'autre ressource que de battre en retraite ; la corporation entière des lettrés se soulèverait comme un essaim de frelons pour venger l'insulte.

En raison des exigences financières de l'État au cours des deux dernières générations, il s'est fait un véritable trafic des grades littéraires, pratique à laquelle le Gouvernement chinois a recours sur une grande échelle chaque fois qu'il lui faut des 


\section{La vie des paysans chinois}

ressources extraordinaires, comme, par exemple, la réparation des dégâts causés par le changement de lit du fleuve Jaune. Un Céleste peut parfois se procurer le grade de « hsiu-ts'ai » pour la somme de 100 dollars environ ; on fournit même à celui qui l'achète, - plus favorisé sous ce rapport que le gradué, - un certificat. Mais les diplômes que trafique l'État sont regardés avec un mépris bien mérité et leur vente, toute grande qu'elle ait été, ne semble pas avoir affecté sérieusement les concours réguliers, ni diminué le nombre de leurs candidats.

Il existe des moyens autres que l'achat du grade, par lesquels un aspirant aux honneurs littéraires disposant de moyens pécuniaires suffisants, peut essayer de faire tourner à son profit la roue de la fortune et la chance des concours. Trois procédés assez simples permettent de se procurer des essais déjà rédigés sans se donner la peine de les composer. Le premier est connu sous le nom de hsiang-tsû - plan de la boîte - : il ne s'agit pas tant de se préparer intelligemment que de se bien rembourrer. Les Quatre Livres et les cinq Classiques semblent à première vue offrir un champ presque illimité sous le rapport des thèmes et des essais, et comme le Chancelier n'annonce pas les sujets avant de pénétrer dans la salle, il est inutile d'essayer de les connaître d'avance. Mais le rusé Céleste a une connaissance empirique, sinon scientifique, de la théorie de la chance et de la probabilité des moyennes. Il sait qu'au cours des années, les mêmes thèmes reviennent sur l'eau à des intervalles plus ou moins éloignés, et que des compositions rédigées bien avant sa naissance sont tout aussi bonnes en cette présente année qu'elles le furent alors. La méthode du « rembourrage » consiste 


\section{La vie des paysans chinois}

donc à doubler ses vêtements d'un nombre énorme d'essais dont les caractères sont minuscules, aussi fins que des « yeux de mouche » et à peine déchiffrables à la loupe. Sous cette forme réduite, il est facile de ramener un essai de trois cents caractères à un bout de papier insignifiant, aussi un étudiant modérément « rembourré » peut-il se munir de huit à dix mille de ces compositions. Parfois le candidat les dissimule dans le panier qui contient ses provisions de bouche. A l'aide d'un index soigneusement établi, il vérifie très vite s'il est pourvu d'un essai sur le texte donné, mais ce qui, de prime abord, semble plus difficile, c'est d'extraire d'une pareille collection le document nécessaire : rien cependant de plus simple, pour peu que l'on ait soin de graisser suffisamment la patte aux gardes en faction devant la porte d'entrée et dans la salle. Le « rembourrage » se pratique également en recopiant les essais sur la doublure de la veste intérieure, faite de soie blanche à cette intention.

Une manière encore plus courante de se les procurer sans les écrire, c'est de les acheter. Il existe à cet effet toute une machinerie que l'on met sans peine en mouvement avec une lubrification financière appropriée.

L'acquisition d'un essai est un de ces subterfuges impossibles à dissimuler en Chine. «Il n'y a pas de haie qui arrête le vent » et le voisinage de tant de témoins rendrait en tous cas la transaction pour ainsi dire publique. Pourquoi, dès lors, les étudiants qui travaillent laborieusement et honnêtement afin de conquérir un grade ne s'entendent-ils pas pour dénoncer des fraudes qui leur sont si préjudiciables ? Il arrive parfois qu'un 


\section{La vie des paysans chinois}

candidat, quand il découvre le transfert d'essais, pousse de grands cris de façon à attirer l'attention des surveillants, mais le fait se produit rarement. La coutume de vendre des essais est comme tant d'autres abus en Chine - trop répandue et trop ancienne pour disparaître sans que plusieurs forces qu'il serait vain de vouloir réunir dans une action commune coopèrent ensemble. Le Chinois redoute avant tout de faire offense par une de ces explosions d'indignation qu'un Occidental ne pourrait, lui, réprimer. Et ainsi les choses continuent suivant le rythme des âges antérieurs. Quant à la moralité de l'affaire, si jamais quelqu'un songeait à s'en préoccuper, comment déclarer coupable le geste d'un étudiant alors qu'il passe pour légitime chez un Empereur?

Les candidats qui décrochent un grade par des procédés répréhensibles sont sans doute en grand nombre, mais il est impossible d'en tenter le relevé, même de façon approximative. Il n'y a pas deux examens semblables et la décision finale dépend en grande partie de l'humeur et de la vigilance du fonctionnaire qui préside la séance. Dans un district où vivait l'auteur de ce livre, tant d'élèves, au cours d'une session, enlevèrent par fraude leur diplôme, que la patience même des plus patients des gens fut à bout. Un candidat refusé rédigea un factum sur le tort qui en résultait pour lui et le lança en pleine salle. L'attention du Chancelier ayant été de la sorte attirée sur les conditions du concours, tous les lauréats durent subir un nouvel examen avec le résultat que onze sur quinze se montrèrent incapables de répondre puisqu'ils avaient acheté leurs essais : leur admission fut annulée. Depuis cet incident les 


\section{La vie des paysans chinois}

examinateurs se montrent beaucoup plus sévères qu'auparavant pour cet examen en particulier. Dans un autre district, un candidat que connaissait l'auteur réussit à passer le premier des deux examens du Chancelier, mais le deuxième dépassa ses moyens. L'essai et le poème furent déclarés mauvais et il reçut sur les mains cent coups de bâton. A cette époque, il était d'usage de publier les noms des candidats qui avaient le plus brillamment satisfait à la première épreuve devant le Chancelier, ce succès passait pour une sorte de garantie de l'admission ultérieure au premier grade. Or l'élève en question, qui en avait déjà avisé sa famille, eut l'extrême mortification de se voir rayé du concours alors qu'il tenait déjà presque en main la récompense de son travail. Les sous-ordre du Chancelier vinrent, dans le yamen, s'agenouiller devant Son Excellence et implorer son indulgence pour l'inconcevable stupidité du candidat : le grand homme daigna se montrer magnanime, et c'est ainsi qu'un diplôme échappa au naufrage.

Quel que soit l'examen, on constate la présence, aux abords de la salle, d'une foule de gens qui s'intronisent courtiers d'essais et intermédiaires entre ceux qui ont des copies à vendre et les camarades qui désirent en acheter. Ces opérations présupposent que vendeur et acquéreur se trouveront dans le lot des candidats admis à concourir ; mais la véritable difficulté dans ces tractations provient de l'incertitude des deux candidats quant à la place qui leur sera assignée : les compères ne peuvent savoir d'avance s'ils seront à portée de communiquer entre eux. Pour parer à cet inconvénient le courtier intervient : il présente un certain nombre de vendeurs aux acheteurs possibles 


\section{La vie des paysans chinois}

afin que s'accroissent les chances de se passer le document désiré. Le marché doit se conclure avant I'ouverture de la séance et l'acheteur signe un contrat brièvement rédigé mais très explicite. La stipulation comporte une échelle de prix appelée « premièrement deux et après deux », « premièrement cinq et après cinq », etc., ce qui signifie que le vendeur recevra, quoi qu'il arrive, un premier acompte de 20.000 ou 50.000 cash suivant le cas et, si l'acheteur décroche un diplôme, un supplément de 200.000 ou 500.000 cash selon les conditions fixées par le contrat. Ces paiements se font par l'intermédiaire des courtiers, très au fait de la situation financière des parties contractantes. Des engagements de ce genre, tout comme les dettes de jeu, ne sont passibles d'aucune poursuite légale pour non-exécution, toutefois les Chinois ne sont jamais pris de court, ils savent contraindre les récalcitrants à s'exécuter et cela par des moyens très simples, tels que celui qui consiste à ébruiter l'affaire dans des termes vexants pour l'intéressé.

Aucun candidat ne tient à ce qu'on le soupçonne d'avoir acheté un essai, quelque notoire que soit le fait, mais ce qui serait intolérable, c'est qu'on lui reprochât publiquement d'avoir acheté un essai, puis de s'être refusé à le payer. Certains vendeurs fréquentent ces concours pendant un grand nombre d'années sans intention aucune d'y prendre part personnellement : ils se contentent de récolter des bénéfices plus substantiels que ne leur vaudrait un grade de lettré : en effet, une fois qu'ils auront eux-mêmes acquis ce grade, ils ne pourront continuer leur commerce qu'en empruntant le nom de quelque candidat auquel il faudra acheter le privilège de pouvoir 


\section{La vie des paysans chinois}

se substituer à lui. Des gradués de rang élevé n'hésitent pas à pratiquer ce genre d'opérations et quelquefois usent dans ce but d'un double procédé. Ils obtiennent un diplôme pour le candidat qu'ils représentent et profitent en plus de leurs loisirs pour rédiger des essais qu'ils vendront dès qu'ils auront terminé leur composition, faisant ainsi d'une pierre deux coups. Dans I'un et l'autre cas, il est indispensable de suborner le « lingshêng » qui s'est porté garant de l'identité de l'étudiant.

La troisième méthode en usage pour se procurer contre argent quelques essais se nomme « ch'uan ti » - transmission - mais elle ne peut aboutir qu'avec la coopération des « hsün ch'ang » - surveillants - lesquels, comme tous les autres mortels, sont supposés ne pas demeurer insensibles aux avantages d'ordre matériel, du moment que I'on y met le prix. Dès la lecture du thème choisi par le Chancelier, on en prend copie et, sur un signal concerté d'avance, on lance celle-ci, pardessus le mur des locaux de l'examen, à des compères qui I'attendent. Il se peut que I'on ait engagé auparavant plusieurs étudiants du dehors pour rédiger des essais destinés à des candidats actuellement en séance. Ces essais terminés, on les empaquette avec soin et, à un signal prévu, on les lance à l'intérieur où l'homme de garde, soudoyé à cet effet, les reçoit. Le surveillant, grassement payé aussi, vérifie, d'après une marque secrète tracée sur chaque copie, quel en est le destinataire, et pendant qu'il va et vient, réussit à la remettre à I'intéressé sans attirer I'attention du Chancelier. L'on découvrit une fois que six concurrents avaient obtenu des diplômes au moyen d'essais introduits ainsi dans la salle après avoir été jetés 


\section{La vie des paysans chinois}

en un seul paquet par-dessus le mur. Quelquefois ces documents sont dissimulés dans un gâteau de pain à l'aspect inoffensif, gâteau que les candidats, d'un geste dégagé, se passent successivement au moment du déjeuner, sans doute avec la connivence des surveillants. Les magistrats du district postent de temps en temps quelques-uns de leurs secrétaires dans des coins de la salle d'examen d'où il est facile d'apercevoir tout ce qui s'y passe. Mais le plus souvent le magistrat ne prendra probablement aucun intérêt à de pareils détails.

Pour certains examens les Chanceliers se montrent très stricts quant à l'application des règlements, ils interdisent l'accès de la salle aux hommes de garde, mesure qui fait échouer les subterfuges que nous venons de décrire. Cependant cette sévérité est l'exception : fréquemment le Chancelier ne se donne même pas la peine de demeurer dans la salle, il s'en va, confiant la surveillance du concours à ses secrétaires qui, eux, ne se font pas faute de fournir aux candidats à même d'y mettre le prix tous documents utiles à leur travail. Ils circulent, s'arrêtent çà et là et, tout en examinant les copies, jettent leur feuillet sous un tabouret ou dans quelque autre endroit dissimulé : l'acheteur pourra venir l'y prendre sans se compromettre.

La Gazette de Pékin a raconté qu'il y a quelques années déjà, un vendeur d'essais, qui ne doutait de rien, réussit à faire parvenir son factum au client en l'accrochant aux vêtements mêmes du respectable Chancelier, devenu ainsi le transmetteur inconscient des documents qu'il s'efforçait d'autre part de supprimer. Pendant l'examen que préside ce haut dignitaire, les 


\section{La vie des paysans chinois}

candidats sont généralement assis, étroitement pressés les uns contre les autres, sans parler d'un tas de gens postés debout qui les enserrent : ils peuvent ainsi communiquer aisément avec, au moins, une quinzaine de personnes. La circulation des essais s'en trouve singulièrement facilitée. A la seconde épreuve, et même lorsque les candidats ne sont plus qu'une simple poignée, ils conservent I'habitude de se tasser en un groupe compact.

L'auteur connaît un étudiant que le hasard plaça un jour auprès d'un pauvre garçon qui ne savait comment se tirer de la composition donnée sur ce texte de Mencius : «Comme de grimper à un arbre pour attraper un poisson ». Un arrangement fut conclu à la hâte pour l'achat d'un essai, mais les deux jeunes gens négligèrent de confirmer l'accord par l'écrit habituel. Après en avoir rédigé le brouillon dans un style que nous pourrions appeler télégraphique, l'étudiant le passa à l'acheteur pour qu'il le recopiât. A ce moment se produisit un incident fâcheux ; le candidat confondit deux caractères avec deux autres qui leur ressemblaient beaucoup et cette erreur lui enleva toute chance de succès. Le pauvre étudiant, alléguant sa pauvreté, supplia son camarade de le tenir quitte de sa dette, dix dollars environ, mais le vendeur furieux ameuta un groupe d'étudiants contre son infortunée victime que tous ils poursuivirent jusque dans son logis où, à force de tapage, ils obtinrent du malheureux un dollar et demi environ, tout ce qu'il possédait ! Le professeur de celui qui avait vendu l'essai - lui-même candidat à cet examen affirma, avec beaucoup d'autres concurrents que la copie rédigée par le vendeur devait certainement assurer le succès de 


\section{La vie des paysans chinois}

I'étudiant, si celui-ci, en la transcrivant, n'avait pas introduit deux caractères faux.

Tout examinateur qui laisse passer à la correction des copies des fautes de ce genre encourt sa dégradation littéraire si le fait est rendu public. Il y a quelques années, la Gazette de Pékin enregistra un incident de ce genre. En 1871, lors de l'examen triennal pour le Han-lin ${ }^{1}$, et après que les compositions eurent été soumises au contrôle des examinateurs, l'on adressa les neuf copies reconnues les meilleures à l'Impératrice douairière I'Empereur était mineur à cette époque - aux fins de faire confirmer officiellement le classement des candidats : le travail noté $n^{\circ} 1$ figurait en tête. Or, la vieille dame, à la volonté de fer, désirait vivement contrecarrer les décisions des savants professeurs ; la chance voulut qu'un rayon de soleil vînt tomber sur ce manuscrit. Elle y découvrit aussitôt un défaut : le papier ne présentait pas en un certain endroit l'épaisseur normale, il y avait eu grattage à l'effet de substituer un caractère à un autre. L'Impératrice tança les examinateurs pour avoir laissé passer « un travail si malpropre » et donna la première place à un autre candidat nommé Hsiang. Cet heureux étudiant venait de la province de Kuang-tung laquelle n'avait eu qu'une fois, en 250 ans, la bonne fortune d'enregistrer pareil succès pour l'un de ses enfants. A son retour au pays natal, les autorités locales reçurent le lauréat en grande pompe. Toutes les familles portant son surnom, et assez riches pour s'offrir ce luxe, versèrent de

\footnotetext{
1 Han-Lin - Forêt de Crayons - dernier grade littéraire donnant droit à un emploi de l'État. (N. d. T.)
} 


\section{La vie des paysans chinois}

fortes sommes afin d'être admises à l'honneur de pénétrer dans la maison ancestrale de Hsiang et d'y faire leurs dévotions, ce cérémonial consacrant en quelque sorte leurs prétentions à une parenté avec le lauréat ; de plus, elles acquerraient ainsi le droit de placer à l'entrée de leurs propres demeures des tablettes portant le titre de « Chuang Yüan » - premier lauréat. - Les Cantonnais, à l'esprit superstitieux, furent persuadés que le rayon de soleil qui fit découvrir le fatal trucage était un messager tombé du Ciel.

Par l'obtention du grade « hsiu-ts'ai » un étudiant n'est pas libéré de toute étude ultérieure. Bien au contraire, ce succès s'appelle « être admis à l'école » et le gradué devra se présenter à chaque examen triennal afin de concourir pour le degré qui vient après dans l'échelle des honneurs littéraires, celui de « lingshêng hsiu-ts'ai ». Le nombre des gradués susceptibles d'être élevés annuellement au rang de lingshêng est limité. Dans un district qui enlève dix-sept places de hsiu-ts'ai, il peut ne se trouver qu'un ou deux lingshêng par examen. Il existe toutefois des concours supplémentaires - ainsi que nous l'avons déjà expliqué - lors de l'avènement d'un Empereur, par exemple ; et quand il se produit une vacance par suite de décès, pour arriver au nombre fixé on autorise un candidat supplémentaire à passer le concours. Un hsiu-ts'ai ne peut se dérober à l'examen sous le prétexte qu'il ne croit pas réussir ; tout gradué de cette classe doit, au contraire, se présenter chaque fois que s'ouvre une session. Telle est la règle en théorie ; dans la pratique, la gratification d'un dollar et demi environ donnée au subalterne du Surveillant de I'Instruction dans le district permettra au candidat 


\section{La vie des paysans chinois}

de faire noter, à côté de son nom, qu'il est « malade » ou «absent ». Mais après une série de dix échecs successifs, le gradué qui se sera montré d'une incapacité persistante est rayé définitivement. Pour ces examens, les candidats sont classés en quatre catégories d'après la valeur de leurs compositions. Tout aspirant qui ne réussit pas à figurer dans les trois premières est considéré comme n'ayant plus droit au grade de hsiu-ts'ai ; il perd son rang de classement à moins que le Chancelier ne se laisse persuader d'excuser la « déplorable instruction » de l'étudiant et qu'il permette au malheureux de tenter encore la chance une dernière fois. De là le proverbe : « Le hsiu-ts'ai

redoute le quatrième classement. » Le Gouvernement accorde une petite pension annuelle de 10 dollars au lingshêng pour lui permettre de poursuivre ses études ; mais le montant d'une pareille allocation n'est guère proportionné à la difficulté de parvenir au grade qui seul a droit à cette subvention si modeste.

Les gradués lingshêng devront concourir aux examens triennaux pour le grade qui vient ensuite, celui de kungshêng. Un seul candidat peut être admis à ce rang, sauf dans le cas d'une vacance particulières.

Il existe cinq variétés de kungshêng, lesquelles dépendent de l'époque où ceux-ci ont obtenu leur grade et des conditions dans lesquelles ils passèrent l'examen. Ces étudiants peuvent, comme les lingshêng, servir de caution aux candidats, bien qu'ils n'aient pas, comme ces derniers, droit à une pension. Ils sont autorisés à porter une robe semi-officielle, quand on s'adresse à eux, on les appelle par un titre qui marque le respect, mais, au point de 


\section{La vie des paysans chinois}

vue pécuniaire, ils n'ont rien à espérer, sauf d'obtenir la place de Surveillant de I'Instruction qu'ils ne peuvent toutefois détenir que dans un district autre que celui qu'ils habitent normalement. Les kungshêng et les hsiu-ts'ai occupent les deux points extrêmes de la longue route de l'éducation littéraire : le premier est considéré comme un écolier et le hsiu-ts'ai est traité pour la première fois comme un homme; il n'a plus besoin de passer des examens à moins qu'il ne veuille prétendre au rang de chüjên, homme de choix. Or ce concours présente des dangers et des difficultés particulières. « Le hsiu-ts'ai, dit un proverbe, doit avoir du talent, mais le chü-jên a besoin d'être favorisé par le destin »; en d'autres termes, un talent même remarquable ne suffira pas à lui seul pour conquérir cette haute situation, à moins que les dieux ne le secondent, proposition dont nous n'hésitons pas à admettre le bien-fondé d'après ce que nous avons déjà vu au sujet des grades inférieurs.

A n'importe quel stage de la longue filière littéraire que nous venons de décrire, I'on peut devenir candidat aux grades supérieurs en achetant ceux qui se trouvent au-dessous. Un homme de véritable talent, bien doué pour l'étude, pourrait, par exemple, acheter le rang de lingshêng puis, à l'aide d'un professeur particulier et en travaillant avec acharnement, devenir un kung-shêng, un chü-jên, peut-être, en fin de compte, un fonctionnaire, après avoir escamoté les grades inférieurs. Sans doute portera-t-il à tout jamais la tache d'avoir escaladé le mur au lieu de pénétrer par la voie droite et étroite, mais cette circonstance ne troublera probablement pas sa sérénité tant qu'elle ne portera pas atteinte à ses profits. Pourtant 


\section{La vie des paysans chinois}

l'expérience a démontré qu'il valait mieux acheter carrément un emploi plutôt que d'entrer en lice par la route tortueuse d'une combinaison d'achats et d'examens.

L'étudiant n'est pas toujours libre, en Chine, de décider s'il doit ou non passer un examen. Un père, résolu à faire de son fils un diplômé, eut d'abord à dompter une opposition acharnée de la part de l'intéressé, lequel finalement s'inclina devant la volonté paternelle. L'élève réussit si bien qu'à 19 ans il était bachelier, mais il découvrit alors que les ambitions de son père visaient beaucoup plus haut et qu'il devait continuer à travailler pour conquérir le grade $d^{\prime}$ « homme choisi ». Après avoir constaté qu'il ne pourrait se soustraire à cette tâche pour laquelle il ne se sentait aucun courage, le jeune homme se pendit et évita ainsi tout examen ultérieur !

La fonction de Surveillant de I'Instruction est très recherchée attendu que les devoirs de la charge sont minimes et les profits considérables. Ceux-ci proviennent en partie d'une importante étendue de terres réservée pour la subsistance des deux Surveillants ; en partie aussi des « cadeaux » de grains extorqués deux fois par an à la manière des prêtres bouddhistes, et enfin des droits d'inscription que chaque gradué a le devoir d'acquitter et dont l'importance varie, comme tout paiement en Chine, suivant la situation matérielle de la victime. Le Surveillant s'enquiert secrètement des ressources de chaque candidat et le taxe en conséquence : la décision est sans appel. Si l'intéressé refuse de verser une somme qu'il juge excessive, le Surveillant - théoriquement son précepteur - fera battre le hsiu-ts'ai sur 


\section{La vie des paysans chinois}

les mains et doublera probablement le montant de la taxation. $\mathrm{Si}$, dans un district, quelque gradué était accusé d'un crime, le magistrat saisi de l'affaire remettrait l'inculpé entre les mains du Surveillant de I'Instruction aux fins d'une enquête. Ces deux fonctionnaires peuvent prononcer ensemble la déchéance du gradué, ainsi que cela a déjà été expliqué.

Le Gouvernement désire encourager le plus possible I'instruction. A cet effet il existe dans beaucoup de villes ce que I'on pourrait appeler des Écoles Supérieures ou Collèges de l'État. L'enseignement y est donné par des professeurs de choix qui expliquent les Classiques et font passer à leurs auditeurs de fréquents examens analogues à ceux des concours officiels. Les fonds destinés à subventionner ces institutions proviennent parfois de souscriptions librement consenties par des personnes riches qui reçoivent en remercîment un titre honorifique; parfois aussi on se les procure à l'aide de taxes sur les bestiaux, etc. Lorsque ces écoles sont bien dirigées, elles produisent de bons résultats, mais, dans deux districts connus de l'auteur, elles furent discréditées au cours de ces dernières années par l'entrée en fonctions de magistrats qui, non seulement avaient acheté leur avancement, mais ne possédaient aucune instruction. En pareil cas la direction des études est abandonnée au Secrétaire de I'Instruction qui s'arrange à ce qu'elle lui donne le moins de peine possible. L'on annonce bien qu'il sera distribué des thèmes de compositions et des prix pour les meilleurs essais, mais, au lieu de présider effectivement les séances, ce fonctionnaire s'éclipse; il vaque à ses propres affaires laissant les étudiants désireux de prendre part au concours libres de rentrer chez eux 


\section{La vie des paysans chinois}

et d'y rédiger leurs essais, ou, s'ils le préfèrent, de charger une tierce personne de les composer pour eux. Dans certains cas, le même individu peut se faire inscrire sous plusieurs noms et rédiger des essais pour tous ces soi-disant personnages. Souvent aussi il écrit ses essais et les vend à d'autres et lorsque les concurrents remettront leur travail, I'on ne demandera aucune explication. Rien ne serait plus facile que de mettre un terme à de pareils abus si quelqu'un voulait bien s'en occuper ou avait quelque intérêt à le faire, mais il n'en est rien et les fraudes continuent. Un maître d'école connu de l'auteur tenait une école près de la capitale du district ; pendant plusieurs années il se fit une règle de se présenter à tous les concours. Il passa ainsi une centaine d'examens ; en quatre occasions, il reçut des prix -, une fois une somme de soixante-quinze cents et les trois autres fois, un demi-dollar environ!

Cette soif inextinguible du Chinois pour les grades et distinctions littéraires, en dépit des inconvénients et des désagréments dont nous venons de signaler un certain nombre, demeure une cause perpétuelle d'étonnement pour les Occidentaux, qui en recherchent toujours les mobiles. Ceux-ci, comme tout ce qui aiguillonne l'être humain, tiennent à plusieurs causes, mais la raison première en est sans doute un désir de célébrité et d'autorité. En Chine, le pouvoir est entre les mains des lettrés et des riches. Or, la richesse s'acquiert avec plus de peine que l'instruction et elle est incomparablement plus difficile à conserver. Depuis des temps immémoriaux, toutes les traditions de I'Empire favorisent I'homme qui consent à se 


\section{La vie des paysans chinois}

soumettre à un labeur énorme pour gagner les récompenses promises à l'étudiant.

Chaque village, comme on l'a déjà expliqué, a ses chefs, et le gradué littéraire, pour peu qu'il soit en même temps un homme pratique, prendra, sans aucun doute, la direction de ce groupe. Il se trouvera ainsi souvent en rapport avec le magistrat du district, fait qui lui vaudra une situation prépondérante parmi ses camarades. A chaque instant on l'appellera pour qu'il aide à régler des disputes et toute intervention de ce genre se termine inévitablement - privilège très prisé des Chinois - par un banquet donné aux dépens des voisins, sans parler de la satisfaction d'avoir fait de ces derniers des obligés. Aux mariages, aux funérailles qui surviennent dans le cercle étendu de ses relations, le gradué littéraire sera souvent I'hôte, et toujours à la place d'honneur due à son grade de lettré. Ce cas se présente plus spécialement aux cérémonies funéraires de ceux que I'on enterre avec le rituel le plus soigné. Dans de pareilles occasions, le gradué devra écrire la tablette ancestrale du défunt et ne pas négliger de marquer d'un point rouge le caractère signifiant roi : détail de ponctuation très important car il transforme ce symbole en celui qui indique le Seigneur. Il n'est pas rare de voir ces cérémonies funéraires se prolonger pendant plusieurs jours, chaque journée comportant, outre trois excellents festins, des provisions abondantes d'opium pour les personnes qui désirent fumer. Dans un pays tel que la Chine, participer à de pareilles jouissances c'est le bonheur suprême. Les Célestes ne sauraient concevoir de félicité plus grande. Tout étudiant désire établir avec son entourage des relations qui 


\section{La vie des paysans chinois}

feront que ces marques de déférence viendront à lui tout naturellement. S'il est très pauvre, festins et invitations pourvoiront en grande partie à sa subsistance et aussi à son bonheur.

Le gradué de village sait comment intervenir utilement dans les procès : il prépare les plaintes, il se débrouille dans les procédures tortueuses qui marquent chaque phase d'une affaire ; le prestige qu'il acquiert ainsi lui permet quelquefois de vivre aux dépens de concitoyens plus ignorants. Nul pays n'offre un meilleur champ d'activité que la Chine pour ces sortes d'entreprises. Un respect illimité pour l'instruction va de pair avec une ignorance également illimitée, et le lettré expérimenté sait comment tirer parti de chacun de ces éléments. Dans tous les pays et à toutes les époques celui qui $a$, comme on dit vulgairement, la langue bien pendue, peut faire son chemin : il réussit mieux en Chine que partout ailleurs.

L'étendue de territoire qu'un aspirant aux honneurs littéraires en Chine doit s'attendre à parcourir est, ainsi que nous l'avons vu, immense. Pour avoir quelques chances de succès, le lettré est tenu d'en connaître chaque pouce carré. Il lui faut être prêt à forer un puits artésien à n'importe quel point et à n'importe quelle profondeur. Au paysan illettré tout imprégné d'un respect aveugle pour l'instruction, respect qui va parfois jusqu'à l'idolâtrie, un pareil savoir semble presque surnaturel et lui inspire une véritable vénération. Aussi n'existe-t-il pas de plus puissant stimulant pour les étudiants ambitieux, même aux 


\section{La vie des paysans chinois}

heures de découragement, que la perspective de l'estime dans laquelle on les tiendra pendant leur vie entière.

Rien ne fournit un meilleur exemple de ce que le dicton chinois appelle « être supérieur à ceux qui sont au-dessous et inférieur à ceux qui sont au-dessus » que la situation du hsiuts'ai. Tandis que le vulgaire considère ce lettré sous un jour tel que nous venons de le décrire, les classes plus instruites qui le dominent le jugent pareil à un écolier qui n'est pas encore à l'École. Un adage populaire affirme qu'alors même que le corps entier des hsiu-ts'ai tenterait de se révolter contre ceux qui l'oppriment et qu'on le laissât libre de poursuivre ses efforts pendant trois ans, il aboutirait à un échec. L'Histoire a pourtant mis ce proverbe en défaut attendu que la Grande Rébellion n'eut d'autre origine que le mécontentement d'un étudiant exaspéré de voir que ses supérieurs refusaient avec persistance de rendre justice à ses talents. Les examens littéraires - nous l'avons suffisamment expliqué - sont pareils à une partie de tric-trac : un mélange à doses égales d'habileté et de chance, mais le jeune gradué en arrive facilement à trouver que la chance est due le plus souvent à I'habileté, l'orgueil de son intellectualité s'empare de lui, cet orgueil qui constitue l'un des plus grands obstacles au progrès national de la Chine.

Le système que quelques réformateurs ont promulgué récemment à la suite d'une agitation fomentée avec succès, diffère essentiellement de celui que nous venons de décrire, vieux de quelques millénaires. Pendant l'été de 1898, S. M. Kuang Hsü, Empereur de la Chine, rendit plusieurs décrets qui 


\section{La vie des paysans chinois}

abolissaient «l'essai soumis à huit examens » comme moyen de parvenir aux grades littéraires ; il les remplaçait par ce que I'on appela l'École pratique des lettrés et l'instruction occidentale, deux branches de connaissances qui devaient être réunies dans des Académies de provinces et de districts. Les institutions existantes allaient se modeler sur un type nouveau plus ou moins bien défini et élaboré à Pékin. Tous les temples, à l'exception des temples officiels, c'est-à-dire ceux où se rendaient les magistrats pour les services cultuels, devaient être mis à la disposition du nouvel enseignement. Les gouverneurs des provinces eurent à fournir des rapports sur l'état des locaux et sur les revenus qu'on pourrait en tirer.

Ces édits révolutionnèrent virtuellement la vie intellectuelle de la Chine. Ils reçurent des accueils très divers suivant les différentes parties du pays, mais il n'y a aucune raison de douter qu'ils eussent été admirablement accueillis par une minorité influente de lettrés qui en étaient arrivés à comprendre combien I'instruction ayant cours en Chine était insuffisante pour les besoins de la nation. Immédiatement surgirent de tous côtés des appels pressants en faveur de l'enseignement occidental. Des étudiants qui avaient toujours affecté un parfait dédain vis-à-vis des étrangers se réjouissaient maintenant de devenir leurs élèves et d'acheter en quantité leurs livres, manuels, etc. Pendant quelques semaines, les thèmes donnés aux concours s'inspirèrent de la science d'Occident, et les candidats capables de faire preuve de quelques connaissances sur ces questions furent à peu près certains d'obtenir un grade. Il paraît que toute réponse correcte à un problème élémentaire de mathématiques, 


\section{La vie des paysans chinois}

de géographie ou d'astronomie assurait le succès, I'on raconte même qu'un candidat décrocha son diplôme en reproduisant et commentant les dix Commandements de Dieu qu'il présenta comme étant le Code des lois d'Occident.

Or, vers la fin de septembre 1898 , I'Impératrice douairière prit en mains les rênes du gouvernement, après avoir supprimé I'Empereur son neveu. Du même coup disparurent presque toutes les réformes engagées en matière de politique et d'éducation. La nouvelle Université Impériale de Pékin survécut seule à I'ouragan, mais la plus grande partie du vaste et salutaire programme élaboré sous le règne bienfaisant de $\mathrm{S}$. $\mathrm{M}$. I'Empereur fut reléguée aux calendes grecques. Ce n'est plus cependant qu'une question de temps ; le vent finira par tourner et quiconque veut du bien à la Chine souhaite que l'aurore de jours meilleurs luise avant que ne soit perdue à tout jamais l'existence nationale des Chinois. 


\section{La vie des paysans chinois}

\section{XI \\ LES TEMPLES.}

Il n'est pas sans intérêt d'examiner pourquoi et comment on a élevé en Chine un nombre inimaginable de temples. Lorsque quelques personnes désirent procéder à une construction de ce genre, elles ont recours aux notables du village qui, depuis des temps immémoriaux, sont chargés de toutes les affaires intéressant la collectivité des habitants ; aussi leur confie-t-on le soin de mener à bien l'entreprise. Les participants à la dépense se voient frappés d'un impôt foncier, mais la taxe par arpent de terre n'est pas nécessairement la même pour tous : plus probablement elle sera progressive d'après l'importance de la propriété rurale ; les pauvres sont exemptés, ou tout au moins très légèrement imposés, tandis que les riches paient en raison de leur fortune terrienne. Une fois que les administrateurs ont fait rentrer les fonds, ils entreprennent la construction. Si le temple doit avoir des proportions considérables dont le coût atteindra plusieurs centaines de taels, on ouvre, pour accroître les ressources, un registre de souscriptions que l'on fait circuler dans les villages voisins, parfois sur un très grand périmètre. Cette propagande est souvent confiée à un prêtre doué d'un bagout particulièrement persuasif. Il circule, traînant après lui une chaîne ou se montrant les joues traversées par de grosses épingles : bref, il se présente comme un moine mendiant qui recueillerait des offrandes à la suite d'un vœu. Le seul mobile sur 


\section{La vie des paysans chinois}

lequel on compte dans cette chasse aux sapèques, c'est la force impulsive qui pousse tout Chinois à la «pratique de la vertu »: on en peut jouer de toutes les façons. Des listes de souscriptions se trouvent à portée dans les grands temples et les donateurs sont supposés avoir bien reçu la valeur de leur argent en voyant leurs noms inscrits, avec le montant de leur don, sur une planchette affichée en bonne place. Dans certaines régions, il est d'usage de déclarer une somme beaucoup plus forte que celle effectivement versée ; tout le monde y trouve son compte. Ainsi le donateur de 250 cash a le plaisir de voir son nom se pavaner comme souscripteur de 1.000 cash, et ainsi de suite. Ces souscriptions ne sont, en somme, qu'une sorte d'avance temporaire, car chacun des villages ayant souscrit espère bien rentrer dans ses fonds lorsque, à son tour, il fera appel à la générosité de ses voisins dans une affaire du même genre, obligation morale que n'oublieront certainement pas les premiers donateurs.

Il est presque toujours imprudent de généraliser lorsqu'il s'agit d'une question concernant la Chine, mais I'on ne risque guère de se tromper en généralisant dans ce cas-ci et en déclarant que les temples sont innombrables dans tout l'Empire. Et pourtant, même en Chine, il existe de nombreux villages qui n'en possèdent pas. Cette exception s'applique aux agglomérations en majorité musulmanes lesquelles se sont toujours refusées à participer à ces constructions. Le fait est désormais bien connu et accepté partout mais, au début, la foi monothéiste eut à passer par de dures épreuves avant de conquérir son droit de cité. 


\section{La vie des paysans chinois}

Un petit nombre d'habitants, un manque de ressources, telles sont les raisons invoquées $d$ 'habitude pour expliquer ce cas relativement rare d'un village sans temple. Incidence également possible, il ne s'est trouvé personne pourvu d'un esprit d'initiative suffisant pour mettre l'affaire en train. Or, une génération subissant assez profondément l'influence de ce que I'on a fait, comme de ce que I'on n'a pas fait au cours des générations antérieures, il pourra s'écouler cinq cents ans avant que I'on bâtisse un temple, et cela simplement parce que I'on n'en avait édifié aucun cinq siècles auparavant. Le cas extraordinaire d'un village sans temple ne prouve nullement que ses habitants ne s'intéressent pas aux dieux, car les villageois, privés de culte sur place, fréquentent souvent les sanctuaires des villages voisins et vont leur emprunter de la «lumière », tout comme un pauvre paysan dénué de ressources suffisantes pour posséder une bête de labour, s'en va emprunter un âne à son voisin plus fortuné au moment des travaux des champs.

Les deux temples qui se voient le plus fréquemment, même si tous les autres font défaut, sont ceux du dieu local et du dieu de la guerre. La dynastie actuelle attache beaucoup d'importance au culte rendu à ce dernier qui lui doit de la sorte un sérieux avancement dans le Panthéon chinois. Le dieu local est pour ses tenants une sorte d'agent de police délégué dans l'autre monde. On doit l'informer au plus tôt du décès d'un adulte afin qu'il puisse en rendre compte au « Ch'êng Huang » - dieu de la ville - lequel, à son tour, fait son rapport à « Yen Wang », le Pluton chinois. 


\section{La vie des paysans chinois}

Si le village ne possède pas de sanctuaire dédié à « T'u-ti », on communique à ce dieu local les nouvelles qui l'intéressent en gémissant bruyamment au carrefour de deux rues, point où il est supposé se tenir en embuscade.

Des villages, par dizaines de milliers, se contentent de ces deux temples qui sont tenus pour à peu près indispensables. Si le village est d'importance, composé de plusieurs quartiers s'administrant isolément, il s'y trouvera peut-être plusieurs sanctuaires élevés à la même divinité. Un dicton courant éclaire singulièrement les idées chinoises sur cette question, lorsqu'il assure que deux dieux locaux vénérés chacun à une extrémité du village, n'ont rien à voir dans les affaires l'un de l'autre.

Il arrive parfois que les promoteurs de la construction d'un temple ont récolté plus d'argent qu'ils n'en auront besoin pour le bâtir. Dans ce cas, on prélève sur cet excédent de recettes la somme que coûtera une représentation théâtrale, et I'on y invitera les donateurs - seul moyen d'assurer à leur vertu une publicité suffisante. Mais la plus grosse part sera consacrée à l'achat de terres dont le revenu subviendra aux besoins du prêtre chargé du culte. De la sorte, le temple une fois bâti est en quelque sorte doté et peut se suffire à lui-même. Les dirigeants de I'affaire choisissent l'un des donateurs qu'ils intronisent président du conseil d'administration : il est appelé shan chu maître des mérites - et c'est lui que ce conseil désigne pour surveiller la gestion des terres appartenant au temple.

Parfois ce revenu sert en plus à subventionner une école ; d'autres fois, il est entièrement gaspillé par de mauvais prêtres 


\section{La vie des paysans chinois}

qui usent de moyens sournois pour obtenir le contrôle de ces biens à l'exclusion des villageois. Lorsque l'édifice a besoin de réparations - et celles-ci sont fréquentes en raison d'une construction défectueuse - on les remet en état par le même moyen qui servit à le bâtir, car, en Chine, il y a vraiment autant de temples délabrés que de navets dans les champs.

Il n'existe pas de limite au nombre de sanctuaires que l'on peut inciter un village à construire. Certaines localités de trois cents familles en ont pour chaque dizaine de foyers, mais cette proportion doit être tenue pour exceptionnelle. Les Célestes disent couramment que plus un village a de temples, plus il est pauvre et que pire aussi est sa moralité. D'autre part, l'auteur de ce livre a entendu parler d'un village sans le moindre sanctuaire, et que I'on a surnommé le «Village de la famille de voleurs ». Il semble raisonnable de déduire des faits observés que lorsque les temples commencent à être délabrés, leur influence morale n'existe plus. Mais lorsqu'ils sont desservis par des prêtres mauvais et indolents, comme c'est trop souvent le cas, les temples sont pernicieux pour la moralité de toute communauté. Dans les districts ruraux il est relativement rare de trouver des prêtres qui y résident de façon stable, attendu qu'ils ne peuvent vivre du maigre revenu dont ils disposent, et une année de famine suffit pour les affamer et leur faire déserter de grands districts.

Les temples situés à quelque distance des villages constituent un repaire de choix pour les voleurs : nul endroit ne leur est plus favorable quand il s'agit de partager le butin. Les mendiants 


\section{La vie des paysans chinois}

viennent également y chercher asile. Pour mettre un frein à de pareils abus, les portes sont souvent closes par un mur en briques dans le haut duquel on ménage une petite ouverture afin de permettre au dieu de respirer.

L'édification d'un temple représente le premier stade d'une série interminable de dépenses car, s'il y a un prêtre, chaque service rendu par son ministère lui sera rémunéré, sans compter la taxe de grains qu'il impose à chaque villageois après les moissons de printemps et d'automne : pareil tribut constitue pour les fermiers une exaction souvent très dure. De plus, les menus frais d'entretien demandent beaucoup d'argent. La célébration annuelle du ta chiao - chant des Livres sacrés entraîne également de lourdes dépenses.

Les temples où les cérémonies sont rares offrent des locaux commodes pour y déposer les cercueils - dont le village s'approvisionne d'avance suivant une coutume générale, - ainsi que les images d'animaux en roseaux et en papier destinés à être brûlés aux funérailles afin qu'ils puissent être transportés ainsi dans le monde spirituel. Si le temple possède une ferme, il est très probable que les divinités seront cachées, pendant I'automne, par les récoltes placées tout autour d'elles ou même sur elles, car dans la campagne chinoise, avoir suffisamment d'espace pour garder les produits de la terre est chose très rare.

Les temples les plus populaires dans une région seront parfois ceux qui se voient le plus rarement dans une autre ; mais après les deux divinités indiquées ci-dessus, celles que l'on honore le plus fréquemment sont Kuan Yin $P^{\prime} u$ Sa-la Déesse de la 


\section{La vie des paysans chinois}

Miséricorde et quelques variétés de la divinité aux noms et attributs multiples connue sous le vocable de Niang Niang Mère - et Bouddha. Ce que I'on nomme San Chiao T'ang - le Palais des Trois Religions - est l'une des reliques les plus instructives d'une époque où la proposition : «les trois religions n'en font en réalité qu'une seule » n'était pas aussi implicitement reconnue que maintenant. Dans le Palais des Trois Religions, Confucius, Lao tzû (le fondateur du Taoïsme ou Rationalisme) et Bouddha se tiennent tous trois sur une même estrade ; mais Bouddha - l'étranger - est généralement installé au milieu, à la place d'honneur, montrant ainsi qu'aux Célestes eux-mêmes il a semblé que les formes natives de la foi étaient insuffisantes, qu'il y manquait quelque chose et qu'à ce quelque chose, le Bouddhisme essaye de suppléer. Cette place ne fut pourtant pas obtenue sans de longues luttes.

Une autre forme de naïf compromis entre des prétentions rivales est ce que I'on nomme Ch'üan shên miao - le Temple de tous les dieux - dans lequel une multitude de divinités diverses sont représentées sur les murs, mais sans priorité d'honneurs bien établie. Les temples dédiés à Wên Ch'ang - le dieu des Lettres - sont élevés par souscription entre les étudiants de la localité, ou bien à l'aide de taxes imposées par le magistrat du district. Il est impossible, en cette matière, d'arriver à une précision quelconque mais, probablement, l'on trouvera que, dans presque toutes les régions de la Chine, le coût actuel d'un temple représente un gros pourcentage des revenus de la population. 
La vie des paysans chinois

@ 


\section{La vie des paysans chinois}

\section{XII}

\section{LA COOPÉRATION DANS LES PRATIQUES RELIGIEUSES.}

Nulle part le génie des Chinois pour ce que I'on pourrait appeler les combinaisons ne se montre aussi clairement que dans leurs sociétés à buts religieux. Bien que ces associations soient très différentes quant aux fins qu'elles poursuivent, certains traits caractéristiques les marquent toutes, et il y en a quatre qui se retrouvent dans la plupart d'entre elles : une contribution pécuniaire très modeste que verseront à dates fixes de nombreuses personnes, la surveillance des fonds de l'association par un petit nombre d'adhérents, les prêts consentis à un taux élevé et qui se renouvellent à chaque expiration du contrat de façon à accumuler en très peu de temps des intérêts composés qui deviennent de grosses sommes, et enfin l'emploi de cet argent dans les observances religieuses pour lesquelles I'association se constitua et auxquelles il faut ajouter un certain nombre de fêtes.

Parmi les multiples sociétés ainsi organisées, citons l'une des plus caractéristiques de celles qui ont pour objet un pèlerinage à I'une des cinq montagnes sacrées de la Chine. La plus célèbre et la plus fréquentée est T'ai Shan - la Grande Montagne-dans le Shantoung. Pendant le deuxième mois de l'année chinoise, elle regorge de pèlerins venus des coins les plus lointains de I'Empire. D'après le Dr Williamson, elle représente la montagne 


\section{La vie des paysans chinois}

historique la plus ancienne du monde. Pour les gens qui habitent à une distance considérable du lieu sacré et qui désirent accomplir le voyage, les frais élevés de déplacement constituent un obstacle sérieux. Afin de parer à cette difficulté, I'on a créé des sociétés qui imposent à tous leurs adhérents une cotisation mensuelle, disons de 100 cash par exemple. S'il y a 50 membres, on arrive ainsi à constituer un premier fonds de roulement de 5.000 cash, somme que les administrateurs consentiront à prêter à celui qui voudra bien payer un intérêt mensuel de 2 à 3 . Ces avances, consenties pour de très courtes périodes, vont de préférence aux personnes ayant le pressant besoin d'une aide financière. A l'expiration du contrat, dès que I'on a fait rentrer capital et intérêts, l'opération recommence, et ainsi de suite de telle sorte que la caisse s'accroît très rapidement. Des prêts successifs à un taux élevé et pour une courte durée se renouvellent maintes et maintes fois pendant les trois ans au bout desquels prend généralement fin la période de capitalisation. Il arrive constamment que ceux qui ont emprunté dans un moment d'extrême détresse sont dans l'impossibilité de s'acquitter à la date fixée, et comme la bonté envers les malheureux ne fait pas partie, chez les organisateurs de ces sociétés, de la «pratique de la vertu», les retardataires se voient obligés de liquider leur maison ou de vendre une partie de leurs champs pour satisfaire aux exigences de la «Société de la Montagne ». Même au prix de pareils sacrifices le débiteur malheureux ne parvient pas toujours à se libérer et, parfois, désespéré, il en arrive au suicide. 


\section{La vie des paysans chinois}

Il existe deux types de «Sociétés de la Montagne »: hingshan hui - les Voyages - et tso-shan hui - les Stationnaires. La première organise les visites à la Montagne Sacrée lesquelles comprennent un certain nombre de stations aux temples les plus vénérés qui jalonnent la route. La deuxième trouve le moyen de satisfaire aux buts principaux de la Société, tout en évitant à ses clients la peine et les frais de la montée à un pic lointain, d'accès plus ou moins difficile. Les derniers débordements du Fleuve Jaune, que de nombreuses bandes de pèlerins doivent traverser au cours de leur voyage à la Grande Montagne, ont contribué à diminuer dans une large mesure le nombre des Sociétés qui « voyagent » et à augmenter la quantité de celles qui restent «stationnaires ».

A l'expiration des trois années de capitalisation, les administrateurs se font remettre la totalité des fonds, puis en avisent les sociétaires qui célèbrent alors une fête et organisent une représentation théâtrale, dépenses acquittées par un prélèvement sur cet argent. Si les intéressés appartiennent à plusieurs villages différents, I'on choisira peut-être comme lieu de spectacle un point convenablement situé pour la commodité de tous, mais non dans une de leurs localités ; d'autres fois il est fixé par un tirage au sort.

Les membres de la Société assistent à ces réjouissances artistiques lesquelles se prolongent généralement pendant trois ou quatre jours : on peut dire qu'ils y sont leurs propres hôtes et leurs propres invités. Mais la partie essentielle de la fête est toujours le banquet, sans quoi rien ne saurait progresser en 


\section{La vie des paysans chinois}

Chine. Très souvent les sociétaires s'offrent trois excellents festins par jour, et, dans les intervalles de la table et du théâtre, ils trouvent le temps de faire des dévotions plus ou moins ferventes devant l'image du dieu de la Montagne - T'ai shan niang-niang - qu'on a installée au sommet d'une petite montagne en papier considérée par les fervents comme la véritable Grande Montagne. Bien que les gens ne semblent pas absolument convaincus qu'il y ait plus de mérite à se rendre réellement au mont sacré qu'à en adorer chez soi l'image en papier, ce sentiment si naturel existe pourtant et s'exprime nettement dans le surnom donné aux sociétés stationnaires dites tun piao hui - «sociétés qui se blottissent et engraissent sur place ». Mais alors que les Chinois sentent vivement les contradictions et les absurdités de leurs coutumes et de leurs pratiques religieuses, ils sont encore bien plus sensibles au plaisir de se conformer à des rites ancestraux sans en scruter de trop près les « sévères réalités ». En Chine, les sociétés religieuses, pour autant qu'elles laissent à désirer et à quelque point de vue qu'on les envisage, satisfont du moins plusieurs instincts sociaux du peuple et elles sont le déversoir par lequel s'écoule annuellement une quantité inconcevable de richesses qui sont ainsi bien pis que gaspillées. Il est de notoriété publique que certaines de ces sociétés, celles qui possèdent les plus gros revenus et qui se livrent aux plus fortes dépenses, s'adonnent furieusement au jeu.

Plusieurs grandes foires, et plus spécialement celle du printemps, époque à laquelle les travaux des champs laissent quelques loisirs, sont fréquentées par des milliers de personnes 


\section{La vie des paysans chinois}

dont le véritable but est de jouer avec une liberté et une prodigalité qu'elles ne pourraient pas se permettre chez elles.

Dans certaines villes, sièges de ces foires, les habitants réalisent le plus clair de leurs revenus en louant leurs maisons aux étrangers qui viennent assister à ces marchés, car il n'est pas de locataire aussi facilement exploitable que celui qui joue. Ces gens ne sont pas tous cependant des professionnels du jeu ; il s'y trouve de nombreux villageois qui profitent de l'occasion pour s'abandonner à leur goût inné de tâter de la chance et risquent ainsi un argent péniblement amassé. Dans de pareilles circonstances, il est indispensable de sacrifier une certaine somme et de distribuer des gratifications aux subalternes du yamen le plus proche afin de s'assurer contre l'éventualité de difficultés avec la police ou avec la justice. Quant aux profits du tenancier de l'établissement - qui joue rarement lui-même - ils sont tellement importants qu'il peut sans peine supporter tous les risques. L'on admet généralement, et cette opinion nous semble fondée, que le mouvement des fonds qui passent de main en main entre les joueurs correspond sensiblement aux sommes que le commerce encaisse ordinairement par ses tractations courantes avec des milliers de clients. Hommes et femmes se rencontrent fréquemment dans les salles de jeu licence qui à tout autre moment de l'année ne serait guère tolérée - et la passion du jeu les étreint au point qu'ils engagent jusqu'à leurs vêtements, et que les femmes se revêtent, uniquement dans ce but, de plusieurs pantalons superposés. 


\section{La vie des paysans chinois}

Les actes coutumiers de dévotion envers le dieu local ou la divinité plus spécialement honorée sont expédiés rapidement et hommes et femmes passent le reste de leur temps dans les salles de jeu, luttant inlassablement contre le sort. On a donc pu très légitimement appeler ces foires des « foires de jeu ».

La Société des «Voyages » comme celle des «Stationnaires 》 fait rentrer ses fonds au bout de trois ans, et les personnes qui peuvent en supporter les frais, accompagnent l'expédition laquelle se met en route pour la Grande Montagne peu de temps après le Jour de l'An. L'on acquitte, en les prenant sur le fonds commun, les dépenses d'auberges, de véhicules ; quant aux achats individuels que chacun s'offre pendant le voyage, ils demeurent au compte de l'intéressé. Arrivés à destination, les pèlerins entrent dans une longue période de fêtes. Ils font emplette d'une quantité importante de simili-argent - en papier ! - qu'ils envoient d'avance à l'endroit où il sera brûlé. Sans doute trouvent-ils que les six cents marches de la montagne - le peuple les compare à une longueur de « 40 li » depuis la base jusqu'au sommet - imposent à leur chair une grande fatigue. A chaque point où l'on brûle un peu de la prétendue monnaie, est planté un drapeau pour indiquer que cette opération a été effectuée. Lorsque la bande de pèlerins atteint le foyer éteint, on l'avise aussitôt qu'il y a longtemps que le papier est consumé, les prêtres rusés ayant pris soin d'en retirer du feu la plus grande quantité possible pour le revendre à d'autres pèlerins confiants dans l'honnêteté des bonzes. 


\section{La vie des paysans chinois}

Si l'un des membres de la «Société qui voyage » ou même de toute autre association analogue, se trouve dans l'impossibilité de faire l'ascension de la montagne avec la procession, ou d'aller au temple dans lequel doivent se faire les dévotions, sa part contributive lui est rendue intégralement, sauf les intérêts : il est supposé abandonner ceux-ci aux œuvres pies de la Société, car il n'en voit jamais rien.

Les innombrables sectes secrètes existant en Chine fournissent des exemples typiques du talent qu'ont les Chinois pour coopérer dans la prétendue «pratique de la vertu ». L'organisation générale de ces sociétés ne diffère guère, du moins dans ses grandes lignes, de celle des Confréries de nos pays occidentaux, mais leur vie intérieure est autre et quelque chose d'obscur demeure à la base même de tout cet édifice religieux. Une grande discrétion entoure les séances pieuses où s'assemblent le soir maîtres et disciples - ceux-ci classés en séries graduées - pour se livrer à leurs exercices de dévotion. Les manuscrits conservateurs de la doctrine, les hymnes que I'on récite, - parfois composés par des fidèles, - les prières, les offrandes, les observances ascétiques constituent des traits communs à bien des religions autres que celle de la Chine. Ces Sociétés imposent aussi à leurs membres des contributions pécuniaires bien définies, versées à des époques fixes et sans lesquelles aucune d'elles, faute d'une force motrice suffisante, ne pourrait exister. 
La vie des paysans chinois

@

193 


\section{La vie des paysans chinois}

\section{XIII}

\section{LA COOPÉRATION DANS L'ORGANISATION DES FOIRES ET DES MARCHÉS.}

Dans plusieurs parties de la Chine l'agriculteur approche bien plus de l'indépendance, quant à ce qu'il demande à la terre pour suffire à ses besoins, que toute autre classe sociale des pays occidentaux. Cette observation s'applique plus spécialement aux zones de culture du coton et à celles où chaque famille s'ingénie à confectionner ses propres vêtements en utilisant les produits de ses champs. Mais, même avec son industrie minutieuse et infatigable, le Chinois ne réalise qu'imparfaitement de pareils objectifs. Il n'est pas de famille pauvre qui possède assez de terres pour en tirer tout ce qui lui est nécessaire, et celles qui jouissent d'une bonne aisance ont une multitude de besoins auxquels elles ne peuvent suffire qu'en se pourvoyant au dehors. De plus, quel que soit le district, la plupart des familles n'ont qu'une réserve de fonds très médiocre et pour faire face aux dépenses quotidiennes, on en est réduit à se procurer au jour le jour l'argent nécessaire. Toujours en raison de cette pauvreté relative, une partie considérable de la population se voit fréquemment forcée de disposer de l'excédent de ses produits du sol pour le transformer en moyens de subsistance. Sous l'effet combiné de ces diverses causes, le Chinois vit dans la dépendance du marché local à un point qui ne se rencontre pas en Occident. 


\section{La vie des paysans chinois}

Tout marché établi, ou même la simple réunion en un lieu donné de vendeurs et d'acheteurs, suppose une certaine somme de coopération. Cependant les marchés chinois, quoique ne différant guère matériellement de leurs similaires étrangers, dénotent, à notre connaissance, un degré de coopération poussé bien plus loin que partout ailleurs. Cette étroite collaboration apparaît déjà dans le choix des emplacements et des dates des marchés. La densité de la population est extrêmement variable selon les différentes provinces, mais il existe des zones très étendues où les villages sont distants les uns des autres d'un quart de mille à 2 ou 3 milles, et beaucoup de ces agglomérations contiennent des centaines, parfois des milliers de familles.

Nous entendons souvent parler de villes plus importantes encore que celles dites chên-tien ou villes à marchés, et dans lesquelles il se tient certainement, en plus des marchés normaux, une foire régulière. Mais les foires ne sont pas limitées aux chên-tien, sinon il serait impossible de satisfaire aux besoins de toutes les populations. Des villages moins importants ont également des jours de marché fréquentés par les gens du voisinage, dans un rayon plus ou moins grand suivant les circonstances. En règle générale, tout village se montre fier d'avoir un jour de marché : cela vaut à ses habitants d'éviter bien des déplacements car très rares sont les gens que n'attire pas une foire ou un marché.

Nous pouvons citer, à titre d'exception, une localité qui, possédant un marché, n'hésita pas à s'en déposséder en faveur 


\section{La vie des paysans chinois}

d'une agglomération voisine, sous prétexte que le public très mélangé qu'il attirait était un agent de démoralisation pour les enfants et la jeunesse locale.

Le marché fonctionne sous le contrôle de notables de l'endroit et certains marchés sont appelés « officiels » parce que les surveillants, après s'être mis en rapport avec le magistrat de la localité, ont obtenu la proclamation d'un arrêté gouvernemental établissant les conditions dans lesquelles les affaires doivent se traiter. Ces mesures facilitent la répression des délits imputables aux mauvais sujets, toujours nombreux dans des rassemblements formés en grande partie de gens étrangers à la localité. Les grands marchés attirent des milliers de personnes, - parfois plus de dix mille, - et, au milieu d'une telle foule, il ne peut manquer de se trouver nombre d'aigrefins, de voleurs, de pick-pockets, etc., aussi chacun doit-il être sur ses gardes. L'on voit parfois s'élever un conflit entre villages, par exemple lorsqu'une localité construit une digue pour se garer des inondations et détourne ainsi les eaux sur le territoire des voisins. En pareil cas il arrive souvent que les gens désertent réciproquement le marché d'un camp adverse : on en établit alors un nouveau, n'importe où, sans tenir compte des besoins des habitants, car le but unique de cette installation est de rompre avec les voisins.

Dans les régions où l'on emploie les animaux aux travaux des champs, il existe des foires spéciales pour le bétail de ferme; elles donnent lieu à de nombreuses transactions. D'ordinaire ces marchés ont une sorte de caractère officiel et les administrateurs 


\section{La vie des paysans chinois}

sont autorisés à prélever une taxe de 1 peut-être, sur les affaires traitées. Le Commissaire d'Éducation de la localité hsiao-li - réclame 10 des sommes ainsi perçues pour pourvoir à ses établissements.

Le reste demeure sous le contrôle des notables du village : cet argent doit, en théorie, subvenir à l'entretien d'une école gratuite, or très probablement, la plus grande partie disparaîtra dans l'escarcelle de ceux qui administrent les affaires publiques de la localité.

Il n'existe pas d'époques fixes pour les marchés. S'il s'agit des grandes villes, il y a marché chaque jour, mais dans les campagnes, ce serait du temps gaspillé inutilement. Parfois le marché se tient tous les deux jours ou bien encore chacun des jours dont la lettre numérale est un multiple de 3 . Plus généralement on en fixe les dates en se basant sur la division en 30 jours du mois lunaire. En ce cas, « un marché » signifie l'espace de cinq jours ou l'intervalle entre deux marchés successifs. C'est l'établissement de ces marchés qui nous fournit l'exemple le plus typique de la coopération chinoise. S'il y a marché tous les cinq jours on en comptera donc 6 par lune, car dans les mois de 29 jours, dits « petits mois », celui du 30 sera reporté au jour suivant, au $1^{\mathrm{er}} \mathrm{du}$ mois prochain. Les divers marchés sont désignés par les jours où ils ont lieu, ainsi « unsix $\gg$ indiquera celui qui se tiendra le $1^{\mathrm{er}}$, le $6^{\mathrm{e}}$, le $11^{\mathrm{e}}$, le $16^{\mathrm{e}}$, le $21^{\mathrm{e}}$ et le $26^{\mathrm{e}}$ de la lune. Pareillement «quatre-neuf » désigne ceux du $4^{\mathrm{e}}, 9^{\mathrm{e}}, 14^{\mathrm{e}}, 19^{\mathrm{e}}, 24^{\mathrm{e}}$ et $29^{\mathrm{e}}$ jours, et ainsi de suite. Tout village dispose généralement d'un marché à sa portée chaque 


\section{La vie des paysans chinois}

jour du mois, en conséquence, pour tous les jours de l'année. D'un côté on trouvera par exemple un « un-six », d'un autre un « deux-sept », etc. D'aucuns seront peu importants, d'autres davantage, mais c'est le plus grand que fréquenteront les négociants en gros de coton, de draperies, etc., venus parfois de très loin. Les Chinois n'hésitent pas à parcourir des 3, 8 et même 10 milles pour s'y rendre, car ce n'est pas seulement un marché, mais un lieu d'échanges les plus divers où tout le monde se rencontre.

Chaque village étant ainsi entouré d'une ceinture de marchés, chacun d'eux constitue du même coup la dent d'une roue tournant dans un engrenage de plusieurs autres. Les gens qui fréquentent régulièrement les marchés en arrivent à se créer des relations dans une zone très large et cela leur permet de donner satisfaction aux besoins des acheteurs et des vendeurs tout à la fois.

Le mot chi que nous traduisons par « marché » indique simplement un rassemblement de gens, et un autre caractère hui s'applique à une réunion beaucoup plus considérable d'individus, laquelle constitue à proprement parler une foire. Le nombre de personnes qu'on y rencontre s'élève fréquemment à dix ou vingt mille : cette affluence donne à l'étranger l'impression que toute la population de plusieurs provinces a été lâchée en liberté sur le champ de foire. On trouve des foires dans les plus grandes villes de la Chine comme dans les cités de moindre importance et jusque dans de simples hameaux, bien que la proportion des villes et des villages qui font vivre une 


\section{La vie des paysans chinois}

foire soit toujours petite. La majorité de ces grandes foires doit son existence aux administrateurs de quelques temples lesquels comptent en retirer des revenus importants à l'usage du sanctuaire : à cet effet, il est perçu une taxe sur toutes les tractations en même temps que sur la location du terrain. Celleci constitue un trait bien caractéristique du marché de village : le propriétaire du moindre bout de terre occupé par les marchands fait, à chaque marché, son apparition pour percevoir sur ceux-ci, soit une somme fixe, soit un pourcentage sur leurs ventes réelles ou supposées.

Dans les grands centres, il est courant de voir les foires se prolonger pendant un mois et même davantage. Certaines localités en ont plusieurs de ce genre dans l'année, constituant ainsi un centre d'activité autour duquel évolue l'existence entière des habitants. En pareil cas ces citadins retirent de gros profits car ils louent leurs immeubles à une multitude de gens qui viennent de loin pour vendre ou acheter. Pendant les intervalles où ces foires ne fonctionnent pas, la ville semble morte mais, dès l'ouverture de la foire suivante, elle reprend son animation et les rues, qui étaient presque désertes, s'emplissent à nouveau d'une foule grouillante de milliers et de milliers de personnes.

Pour qu'une foire soit prospère, il faut que ses administrateurs se montrent des hommes d'initiative, suffisamment habiles en affaires pour résoudre les nombreuses difficultés qui surgiront inévitablement. Ils exercent partout une surveillance active et sont responsables de ce qui marche de travers, mais de cette responsabilité ils s'évadent le plus 


\section{La vie des paysans chinois}

souvent. Afin d'attirer les foules, une foire de quatre jours doit généralement s'ouvrir par une représentation théâtrale qui se renouvelle pendant toute la durée du marché. Quelquefois cependant les acteurs font défaut et la foire aboutit de ce fait à un véritable fiasco. Ces grandes assises du négoce sont suivies par des marchands venus de villes situées à plusieurs centaines de milles et qui traitent de tous les articles susceptibles d'attirer les clients.

L'insuffisance des moyens de transport, la lenteur et la difficulté des déplacements obligent les marchands qui circulent, pendant plusieurs mois, d'une foire à l'autre à mener une existence peu enviable. Dès la fin des vacances de quinze jours marquant le début de l'année chinoise s'ouvre la période des grandes foires ; à partir de ce moment, elles se succèdent sans interruption pendant tout le reste de l'année, sauf un court intervalle au moment de la moisson, événement de la plus grande importance pour toutes les classes de la population. La saison des pluies provoque un autre arrêt des affaires et celui-ci est souvent si sérieux qu'il dérange tous les plans pendant deux mois et plus.

Dans les foires, le principal élément coopératif consiste à en régler les dates, de façon à ce qu'il ne se produise entre elles, aucune interruption et que les négociants ambulants perdent le moins de temps possible. Le succès des foires ne va pas sans que de nombreuses fautes soient commises, fautes qu'il faut attribuer au désir immodéré du Chinois de primer ses rivaux ; il ne se préoccupe jamais de l'intérêt d'autrui, et, dans toute 


\section{La vie des paysans chinois}

question impliquant la coopération, cette méconnaissance de l'intérêt général est souvent la cause de déboires. Ainsi il n'est pas rare de constater qu'alors que les placards annonçant une foire ont été placés dans les campagnes depuis un mois entier, personne ne saura vous dire la date véritable de son ouverture. Que le jour soit « fixé » cela ne tire pas à conséquence car, à l'exception des éclipses, rien en Chine n'est « fixé » au point de ne pas être susceptible de changements et I'on peut supposer que cette exception astronomique provient du fait que les phénomènes célestes échappent à la surveillance des Chinois. Dans des cas nombreux que nous pourrions citer, des personnes qui désiraient se rendre à une grande foire dont la date est « fixée » depuis des générations, parcoururent à plusieurs reprises, et au grand détriment de leurs affaires, des milles et des milles inutilement. A leur arrivée elles apprirent que la foire avait été retardée parce que personne ne s'était présenté au jour dit, chacun attendant sans doute que le voisin se mît en marche. Mais les malheurs de ce genre se rencontrent partout et toujours dans cette Chine où la ponctualité est un « art perdu ». 


\section{La vie des paysans chinois}

\section{XIV \\ LES SOCIÉTÉS DE PRÊTS.}

Parmi les exemples les plus caractéristiques de l'aptitude des Chinois pour les combinaisons, nous citerons les Sociétés de prêts, très nombreuses dans tout le pays. L'objet de pareilles organisations est identique à celui des institutions similaires chez d'autres peuples, mais I'on peut se demander si la façon dont procèdent les Célestes n'est pas unique en son genre. Quoique se rattachant, dans leurs grandes lignes, à un type commun, ces sociétés offrent dans les détails de telles divergences qu'il est parfois très difficile à l'habitant d'un district de comprendre les règles qui régissent deux de ces organismes même lorsqu'ils fonctionnent dans des subdivisions territoriales contiguës.

Nous avons déjà eu l'occasion d'attirer l'attention sur les raisons qui présidèrent à la constitution de ces importantes sociétés. Tout Chinois se trouve souvent dans la nécessité de disposer de sommes supérieures à ses disponibilités du moment. Le taux de l'intérêt est toujours si élevé qu'un homme obligé de contracter un emprunt important sur lequel il doit payer un intérêt mensuel de $21 / 2,3$ et même $4 \%$, succombera très probablement sous l'effort qu'il fera pour remplir ses engagements : l'expérience de chaque jour en fournit d'innombrables exemples. En échelonnant les échéances sur une 


\section{La vie des paysans chinois}

longue période et en introduisant un élément d'amitié dans des transactions purement commerciales, le Chinois réalise heureusement une double fin, celle de joindre les affaires à l'agrément. Jusqu'à quel point réussit-il ? L'étude des procédés employés à cet effet nous permettra de juger en connaissance de cause.

Le plus simple des nombreux procédés par lesquels s'effectuent les prêts mutuels est le suivant : tous les membres consentent, à tour de rôle, l'avance d'une somme déterminée à I'un d'entre eux. Une fois le cycle clos, et quand tous auront payé leur part au dernier homme inscrit sur la liste, chacun sera rentré dans ses fonds et pas davantage. Dans certaines régions une pareille société se nomme ch'i hsien hui - Club des Sept Sommités. La qualification technique d'une association de ce genre où la coopération joue le rôle essentiel est She. L'homme qui a besoin d'argent - shê-chu - invite des amis à collaborer avec lui et leur demande en même temps d'obtenir le concours de quelques-unes de leurs relations. Lorsqu'il a réuni le nombre voulu de participants, les membres de cette nouvelle société shê-yu - se réunissent et fixent I'ordre dans lequel ils pourront respectivement recourir au fonds commun. Un tirage au sort en décide généralement. Sauf le cas où la somme en jeu est insignifiante, chaque réunion pour affaires s'accompagne d'un festin auquel prennent part tous les sociétaires et dont les frais sont supportés soit par celui au profit duquel la société a été organisée, soit par celui dont c'est le tour de se servir du fonds commun. 


\section{La vie des paysans chinois}

A la première fête que donne le fondateur, chacun des membres se présente muni de la somme convenue pour le versement, par exemple 10.000 cash. Le premier inscrit touche ainsi 60.000 cash dont il conserve la libre disposition pour un temps déterminé, disons un an. L'année suivante la fête est donnée par le membre qui a tiré le $N^{\circ} 2$. Le président verse en caisse 10.000 cash, chacun de ses cinq collègues fait de même, puis ces 60.000 cash sont affectés au $N^{\circ} 3$ qui en dispose de même pour un an. Au bout de six ans tous les membres auront tour à tour bénéficié du prêt et touché individuellement 60.000 cash sans intérêts alors que, d'autre part, ils versaient également 60.000 cash sans bonification d'intérêts. De la sorte tous les participants auront pu disposer pendant un an d'une somme plus forte, et à meilleur compte qu'ils n'eussent pu le faire par n'importe quel autre procédé. A la fin ils seront rentrés intégralement dans leurs fonds et auront de plus participé à six festins plus ou moins exquis, question d'une réelle importance au point de vue chinois, quelque peu de cas qu'en fasse un Occidental.

Cette forme toute rudimentaire d'emprunt coopératif semble être cependant d'un usage moins courant que celle dont se servent les sociétés qui font payer un intérêt : I'on ne saurait s'en montrer surpris. Le Chinois est si bien accoutumé à subir un chantage pécuniaire toutes les fois qu'il doit recourir à l'argent des autres, que l'emprunteur moyen estime certainement qu'en exigeant un haut intérêt, il fait une meilleure affaire que s'il n'en avait pas reçu du tout, bien que, éventuellement, il doive verser sous forme d'intérêts, une somme égale à celle qu'il reçoit au 


\section{La vie des paysans chinois}

même titre. Point n'est besoin de démontrer qu'en tout état de cause, il se trouvera finalement dans la même situation que s'il avait emprunté et remboursé sans se préoccuper d'une question d'intérêts.

Lorsqu'il s'agit de sociétés qui exigent des intérêts, les méthodes en usage marquent de grandes différences de détail, et il n'existe pas de limites aux variations que les coutumes locales peuvent adopter. Dans certaines régions,

le nombre ordinaire des membres semble être de 16 ; dans d'autres, il s'élève à 30 et même plus. Parfois les réunions sont annuelles, parfois elles se tiennent deux fois par an, à la seconde et à la huitième lune. Parmi les sociétés qui prennent un intérêt, I'on décide par un tirage au sort ou un coup de dés de l'ordre dans lequel les membres disposeront du fonds commun, question qui se règlera très probablement lors de la première réunion, chaque intéressé prenant son tour suivant sa situation sociale ou son coup de dé. Le taux de l'intérêt est souvent soumis à une sorte d'enchère et chacun annonce à haute voix ce qu'il consent à payer. Le plus offrant se voit adjuger le droit de se servir, le premier, du capital pendant un temps déterminé, mais jamais aucun membre ne jouit d'un second tour. Si les enchères ne sont pas poussées à découvert, c'est-à-dire à haute voix, I'on adopte parfois une méthode assurément préférable, laquelle consiste à faire déposer dans une boîte, par chaque concurrent, un petit bulletin indiquant le taux offert : la priorité revient encore au plus offrant; si deux propositions sont identiques, un second tour les départage. Il est facile de se rendre compte qu'en procédant de la sorte les intérêts produits 


\section{La vie des paysans chinois}

par un même capital sont susceptibles de varier avec chaque emprunt, ce qui peut amener des complications de comptabilité. Mais les Chinois, pour la plupart, semblent se tirer avec une facilité étonnante de supputations aussi ardues, surtout si I'on considère le peu de pratique qu'ils ont acquise dans l'étude des mathématiques.

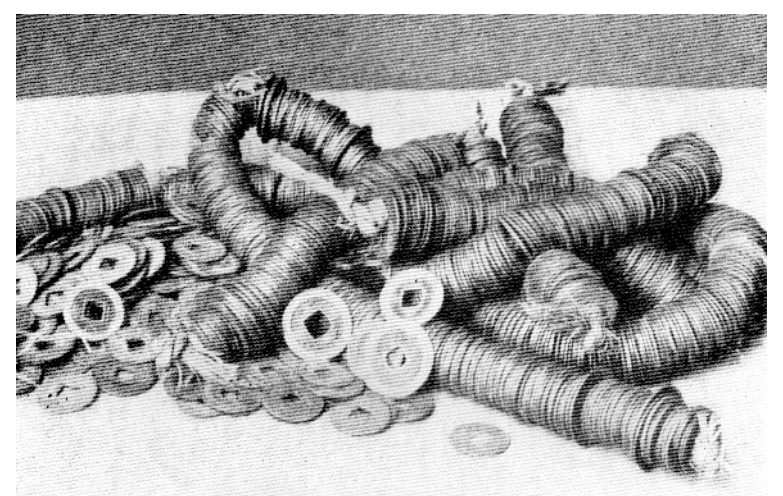

Cordons de cash

Nous allons nous expliquer plus clairement en prenant un cas concret. Supposons que l'intérêt soit pour chaque période de 1/5 du capital ; la société compte 10 membres en plus de son organisateur et la somme avancée par chacun d'eux est de 10.000 cash. Admettons enfin que le sociétaire qui, le premier, bénéficia du prêt, ne remboursera pas en espèces mais seulement en fournissant, à chaque réunion, un festin particulièrement soigné. L'intérêt est une sorte « d'escompte en banque », et il sera par conséquent encaissé à l'avance, seul moyen d'être assuré de sa rentrée intégrale. Chaque intéressé, à l'exception du premier, faisons-le observer, ne reçoit en réalité, que 8.000 cash tandis qu'il devra en rembourser 10.000 à chacun de ceux qui tirent après lui. Le tableau de tirage cidessous fera mieux voir les résultats. 


\section{La vie des paysans chinois}

(Le président donne seulement le festin mais ne rembourse pas l'avance.) 


\section{La vie des paysans chinois}

Le président reçoit de chaque membre 10.000 cash (10 ligatures), 10 ligatures $\times 10=100$.

\begin{tabular}{|c|c|c|c|c|}
\hline Le $\mathrm{n}^{\circ}$ & $\begin{array}{c}\text { reçoit } \\
-\end{array}$ & $\begin{array}{c}\text { multiplié } \\
\text { par }\end{array}$ & $=$ & $=$ \\
\hline 2 & 9 & 8 & & 72 \\
3 & 8 & 8 & $64+10$ & 74 \\
4 & 7 & 8 & $56+20$ & 76 \\
5 & 6 & 8 & $48+30$ & 78 \\
6 & 5 & 8 & $40+40$ & 80 \\
7 & 4 & 8 & $32+50$ & 82 \\
8 & 3 & 8 & $24+60$ & 84 \\
9 & 2 & 8 & $16+70$ & 86 \\
10 & 1 & 8 & $8+80$ & 88 \\
11 & 9 & 10 & & 90 \\
\hline
\end{tabular}

Dans le plan modifié suivant, le président rend la somme qu'il a empruntée, comme les autres membres et fournit aussi

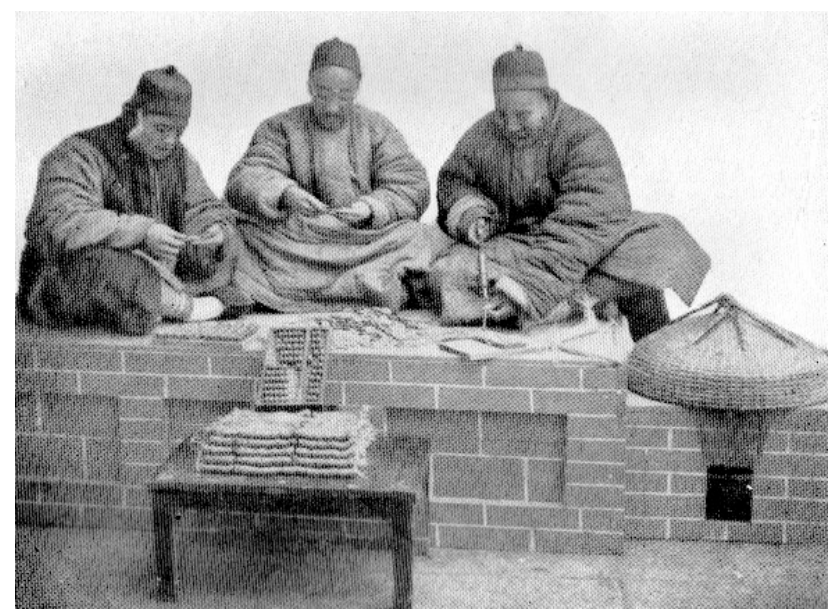

Confection des cordons

chaque festin que l'on considère comme sa part d'intérêts à payer. 


\section{La vie des paysans chinois}

Le président reçoit $10 \times 10$ ligatures $=100$.

\begin{tabular}{|c|c|c|c|c|}
\hline Le $\mathrm{n}^{\circ}$ & $\begin{array}{c}\text { reçoit } \\
-\end{array}$ & $\begin{array}{c}\text { multiplié } \\
\text { par }\end{array}$ & $=$ & $\begin{array}{c}= \\
\text { ligatures }\end{array}$ \\
\hline 2 & 9 & 8 & $72+10$ & 82 \\
3 & 8 & 8 & $64+20$ & 84 \\
4 & 7 & 8 & $56+30$ & 86 \\
5 & 6 & 8 & $48+40$ & 88 \\
6 & 5 & 8 & $40+50$ & 90 \\
7 & 4 & 8 & $32+60$ & 92 \\
8 & 3 & 8 & $24+70$ & 94 \\
9 & 2 & 8 & $16+80$ & 96 \\
10 & 1 & 8 & $8+90$ & 98 \\
11 & 10 & 10 & & 100 \\
\hline
\end{tabular}

On remarquera par ces exemples que chaque membre reçoit d'autant moins d'intérêts qu'il tire les fonds plus tard. Dans le second cas supposé, le dernier bénéficiaire qui n'a aucun intérêt à bonifier, mais par contre en touche de tous sauf du chef, reçoit tous ses fonds en bloc intérêts compris.

Pour simplifier cet exposé nous avons négligé de faire entrer en ligne de compte la durée des prêts, et indiqué un taux d'intérêt probablement très au-dessous de celui que I'on demanderait en réalité. Il est évident qu'au point de vue strictement financier, le sociétaire a grand avantage à laisser son argent travailler le plus longtemps possible ; mais les considérations d'ordre financier sont loin d'être les seules à entrer en ligne de compte. L'homme qui a besoin d'argent et qui n'est jamais sûr d'en trouver autant qu'il lui en faut dans des conditions meilleures que celles offertes par la société, 


\section{La vie des paysans chinois}

I'acceptera volontiers dès qu'il pourra l'obtenir et si, dans l'espèce, il s'agit de parer aux dépenses d'un mariage, il s'arrangera pour que cette cérémonie ait lieu au moment même du prêt.

Or, comme bien d'autres combinaisons de l'homme, les sociétés chinoises de prêts doivent être jugées d'après leurs résultats. La façon dont elles opèrent découvre souvent sur la vie des Chinois des horizons remplis d'enseignements. Celui pour le bénéfice duquel la société se réunit ne se fait aucune illusion quant à l'empressement que les autres mettront à l'obliger, à moins toutefois qu'ils ne voient clairement le moyen de faire rentrer leurs fonds, agrémentés d'un bel intérêt. Il est dès lors souvent nécessaire d'user de beaucoup de finesse pour persuader à des amis de faire partie d'une société de ce genre et surtout pour les convaincre d'en amener d'autres. Nul ne tient à faire partie de ces associations, à moins qu'il n'ait de bonnes raisons de croire que chacun de ses collègues fera rigoureusement face à ses obligations, car toute défaillance d'un associé peut faire craquer l'affaire. Pour parer à ce risque, il est d'usage de s'assurer des garanties ou des cautions et le directeur de la société se porte généralement garant pour chacun de ses collègues. S'il arrive que l'un d'eux fasse défaut à ses engagements, le directeur doit combler le déficit, opération à laquelle il répugne naturellement, bien qu'il s'y soit librement engagé. Pareilles difficultés provoquent de véritables batailles entre les intéressés. Dans le cas où l'on n'a pas recours à ces mesures extrêmes, il se peut fort bien que la personne formellement responsable essaye d'une méthode dilatoire 


\section{La vie des paysans chinois}

courante : elle demandera à être exonérée de toute sanction en s'efforçant de persuader au créditeur de se contenter d'un $k^{\prime} o-$ t'ou $^{1}$ en place de cash. Si l'on arrive à exercer une pression suffisante en faveur du mauvais payeur, ce plan peut réussir, mais parfois aussi il provoque la dissolution de la société.

Lorsque l'association compte plus d'une vingtaine de membres, ainsi que c'est le cas dans certains districts, l'éventualité que quelques-uns d'entre eux ne feront pas face à leurs obligations a plus de chances de se présenter. On objecte également, et non sans raison, que les prêts à longue échéance sont semés de dangers car, avant qu'une année entière se soit écoulée, I'on peut être assuré, moralement, que quelque événement imprévu viendra troubler la situation financière, très instable, des associés. Ainsi la rébellion des Taïpings, avec son long cortège de misères, de même que la famine persistante et les inondations dans la Chine septentrionale au cours des années qui suivirent, contribuèrent dans une large mesure à jeter le discrédit sur les sociétés de prêts. En effet des milliers de personnes qui avaient confié tout leur avoir à celles-ci ne purent jamais rentrer dans leurs fonds. Tous les Chinois que I'auteur a consultés sur cette question s'accordent à reconnaître que de nos jours ces sociétés n'ont plus aucune utilité et ne sont que duperie. Mais c'est à l'individu à se prémunir autant que possible contre les pertes financières en déployant assez de flair pour se garer des sociétés branlantes et en demeurant insensible aux sollicitations pressantes et intéressées dont il pourra être l'objet

\footnotetext{
${ }^{1} \mathrm{~K}^{\prime} \mathrm{o}-\mathrm{t}^{\prime} \mathrm{ou}$ ou bien Kotow, acte de prosternation par lequel on se frappe la tête contre le sol en signe d'hommage ou d'adoration
} 


\section{La vie des paysans chinois}

en leur faveur. Certaines personnes vous diront qu'elles furent à plusieurs reprises sociétaires et ne perdirent jamais d'argent ; d'autres, au contraire, vous serviront des preuves diamétralement opposées.

Un Chinois qui, par son caractère accommodant, était un voisin précieux pour les gens qui désiraient contracter un emprunt sans avoir le désagrément de le rembourser, raconta avoir été membre à six reprises différentes de sociétés de prêts. Une seule fois le capital fut doublé grâce à une heureuse spéculation, mais dans les cinq autres associations, il perdit presque tout l'argent qu'il y avait engagé. Un adage courant témoigne que de pareils désastres financiers sont fréquents : si un homme, affirme-t-il, a fait partie d'une société de prêts et si, à trois reprises différentes, il ne fut pas trompé, il dut pour le moins être volé !

Cet exposé sur les sociétés de coopération était déjà rédigé lorsque les journaux de Hong Kong publièrent le compte rendu d'un procès qui fait ressortir les difficultés légales auxquelles se heurtent les hommes de loi et, très vraisemblablement aussi, les membres des tribunaux. En effet, cette cause, d'abord appelée au mois de juillet, revint encore une fois, sur appel, devant la justice, au mois de janvier suivant, et ne fut tranchée qu'au mois de mars. Elle comprenait quatre plaignants et quatre défendeurs. Dans l'espèce, il s'agissait de douze individus qui avaient décidé de former une association pour prêts d'argent. L'un d'eux installé comme directeur devait rassembler les souscriptions. Chaque membre s'engageait à payer 50 dollars 


\section{La vie des paysans chinois}

par mois, soit 600 dollars en tout. Tous les membres devaient se réunir en un banquet que payait à tour de rôle chacun d'eux et, au cours de ces agapes, des offres étaient présentées pour le prêt du fonds social - 600 dollars ; le plus offrant - en intérêts - se voyait adjuger la « masse », moins l'intérêt. Après huit mois de fonctionnement, le directeur fit faillite dans ses affaires privées et disparut ; du même coup l'association se trouva dissoute.

Les quatre personnes ayant mis des fonds dans la société pendant huit mois, sans avoir touché aucun dividende, exercèrent des poursuites contre leurs quatre collègues, lesquels avaient cessé le versement de leur cotisation dès la faillite du directeur. La défense argua que seul ce dernier devait être tenu pour responsable, vu que toutes les sommes revendiquées lui avaient été versées par les défendeurs. Le président du tribunal qui entendit les parties, estima que les souscriptions qui n'avaient pas été payées étaient légalement exigibles et que le directeur n'avait à aucun moment reçu des autres membres I'autorisation de toucher d'avance des contributions. En conséquence le jugement fut rendu en faveur des plaignants.

L'affaire vint en appel : la défense déclara qu'on en appelait sur une question de droit. Elle évoqua à nouveau les circonstances de la catastrophe et maintint qu'il n'y avait jamais eu, entre l'un quelconque des plaignants et les quatre défendeurs, conjointement ou individuellement, de contrat en règle comportant pour eux l'engagement de payer 200 dollars. Le seul contrat existant et versé aux débats stipulait simplement 


\section{La vie des paysans chinois}

que chacun des membres contribuerait à alimenter un fonds commun dont le prêt ne lui serait peut-être pas concédé à sa première demande, mais dont il pourrait certainement disposer à un moment donné. En conséquence elle invoqua devant le tribunal le fait qu'il n'existait pas de contrat en bonne et due forme dont on pût faire état au procès et que, dans ces conditions, la justice ne pouvait se prononcer.

L'avocat de la partie adverse voulut bien admettre qu'il y avait, en effet, quelque difficulté à débrouiller cette affaire, mais, déclara-t-il, à moins que L. E. les Juges ne maintiennent que, dans le cas pendant, ces hommes sont responsables de la somme, les poursuivants seront pour ainsi dire privés de leur unique recours. Une pareille conception, ajouta-t-il, va à I'encontre des buts que se propose l'association laquelle prétend travailler pour des fins utiles, pour une aide mutuelle entre ses membres et en somme pour le bien de tous. Affirmer que l'on ne peut maintenir de poursuite contre l'un des associés individuellement serait offrir une prime à la malhonnêteté, car celui qui aurait touché le premier prêt s'empresserait de s'évader de la société.

Le président du tribunal fit aussitôt remarquer que pareil cas était fréquent. Puis, dans son résumé d'audience, il déclara, qu'à son avis, le procès en cours n'était rien d'autre qu'une revendication pour de l'argent prêté, tandis que les avocats s'étaient attachés à le représenter comme une instance en remboursement de 50 dollars de la part de chacun des défendeurs tenus à respecter le statut d'une association mutuelle 


\section{La vie des paysans chinois}

de prêts. Au cours des débats, les défendeurs avaient nié l'existence d'un contrat entre eux-mêmes et les plaignants, faisant allusion au fait que l'association tint plusieurs réunions et que certaines ne furent pas convoquées régulièrement conformément aux statuts de la société. Ceci prouvé, le juge maintenait qu'il n'existait pas entre les divers membres de l'association de contrat qui permit à l'un d'eux de poursuivre un collègue en justice et il concluait finalement en faveur des appelants.

Le juge assesseur fit observer que le contrat qui liait tous les tenants de l'affaire était, soit un contrat entre les défendeurs et I'un des plaignants, soit un contrat mutuel entre les défendeurs et les autres membres de l'association. Dans le premier cas, les plaignants ne pouvaient avoir gain de cause ; dans le second, une action en justice serait d'abord nécessaire pour préciser les droits des parties, et tous les membres de l'association devraient être parties en cette instance. Finalement il rendit également son jugement en faveur des appelants, avec droit aux dépens. L'argent déposé à la Cour pendant l'appel serait restitué à ses propriétaires.

Quiconque prendra la peine de suivre ces arguments et d'étudier les faits sur lesquels ils s'appuient, arrivera certainement aux conclusions suivantes : il est très facile de faire des arrangements par lesquels on accorde des prêts à des Chinois, - il est encore plus facile de ne pas rentrer dans ses avances ; - lorsqu'il survient une difficulté dans le règlement compliqué des diverses opérations de la société, il est très 


\section{La vie des paysans chinois}

probable qu'il faudra, aux avocats et aux magistrats, neuf mois au moins pour découvrir de quel côté se trouvent le droit et l'équité et une fois la chose jugée, il sera difficile à un simple mortel de juger à son tour si la décision du tribunal est bonne ou mauvaise!

(a) 


\section{La vie des paysans chinois}

\section{XV \\ SURVEILLANCE DES RÉCOLTES.}

Dans un pays où les pauvres sont en aussi forte proportion qu'en Chine par rapport à la totalité des habitants, dans des campagnes où aucune clôture ne sauvegarde les champs, il serait à souhaiter qu'il existât certaines mesures générales destinées à surveiller effectivement des propriétés aussi peu protégées. Dès que les fruits de son verger présentent le moindre signe d'une maturité prochaine, le fermier fait garder nuit et jour les arbres par quelqu'un de sa famille, et il continue ainsi jusqu'à ce que le dernier abricot, la dernière prune ou poire soient cueillis. Plus la nuit est pluvieuse, plus la garde doit être vigilante, si bien qu'une famille possédant un verger riche en fruits est complètement asservie à cette surveillance pendant une partie de l'année. Aux mois de juillet et d'août, I'on aperçoit les champs constellés de petites baraques dont quelques-unes disparaissent sous des vignes grimpantes ; aucun de ces abris fragiles n'est déserté avant l'enlèvement complet des récoltes. Dans certaines régions, le voyageur les découvre dressés sur quelque éminence de façon à commander une zone plus vaste, souvent ils dominent des champs de sorgho, produit qui ne semble pourtant pas facile à dérober. Mais ces plantes robustes montent si haut au-dessus du sol qu'elles cachent le pillard aux yeux du guetteur, aussi la surveillance en est-elle plus difficile que celle d'un champ de blé dont les tiges s'élèvent beaucoup 


\section{La vie des paysans chinois}

moins haut. En effet le sorgho atteint jusqu'à 10 et 15 pieds ; il barre entièrement l'horizon et dissimule ainsi dans la plaine tous les points de repère : le voyageur ne voit plus sa route, il pourrait se croire parfois en pleine jungle africaine. Par un temps de brume, les indigènes eux-mêmes s'égarent souvent à quelques li de leur village. Dans le Shantoung, les récoltes d'automne comprennent d'innombrables variétés de millet, du sorgho - lequel bien que dénommé « grand millet » n'a aucune affinité avec le véritable millet, - des fèves, du blé indien ou maïs, des pistaches de terre, des melons et des courges, des patates et autres produits, - ceux-ci cultivés en très petites quantités, - du chènevis, du sésame et surtout du coton, sans parler de quelques-uns de moindre importance encore.

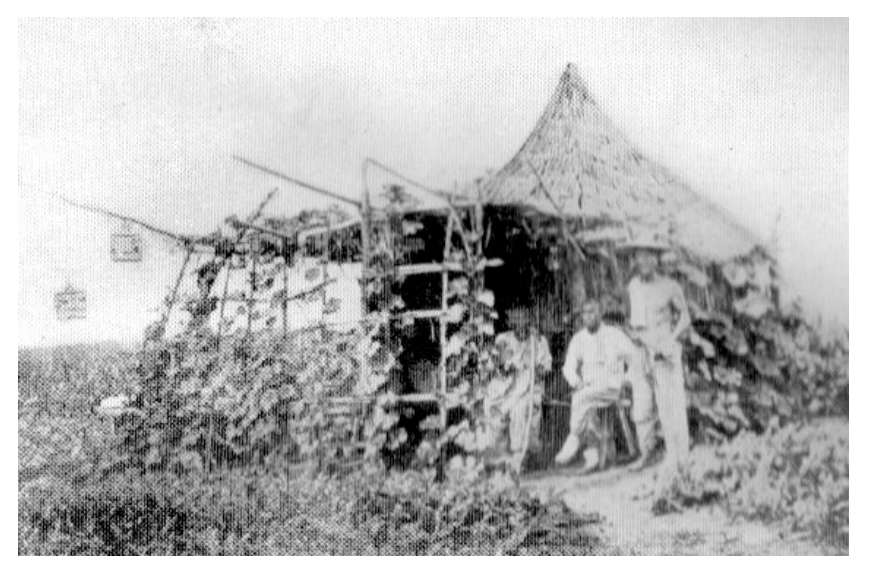

Campement de surveillant des récoltes

De tous ces divers fruits de la terre, il n'y en a guère que deux qui ne tentent pas les voleurs et ne causent dès lors aucune inquiétude aux fermiers. Par contre, les tiges du sorgho et du millet peuvent facilement être coupées et rien n'est plus simple que d'enlever rapidement la moisson d'un champ de blé ou de bêcher des patates. Celles-ci, il est vrai, ne sont pas à l'abri de l'avidité des chiens, car des siècles d'expérience ont 


\section{La vie des paysans chinois}

appris à ces animaux qu'une alimentation végétarienne vaut encore mieux qu'un manque complet de nourriture. Mais les melonnières et les arbres fruitiers réclament une vigilance de tous les instants. Les Chinois étant particulièrement friands de melons d'eau, chaque champ est pourvu d'un poste de guet établi dans le « jardin des concombres », et quelqu'un y veille nuit et jour ; de même pour les rangées de fruits appelés en langage familier hang tzû. Les insectes, les oiseaux et enfin I'homme sont les ennemis irréductibles du propriétaire de pommiers, poiriers, pêchers, cerisiers, abricotiers et ceps de vigne. Si le potager est de quelque étendue, il peut y avoir complicité entre les voleurs qui apparaîtront simultanément des deux côtés opposés : le gardien ne peut donner la chasse à deux bandes de voleurs à la fois. Les corbeaux et les geais sont les pires larrons, mais on les effraye assez facilement, un simple coup de fusil les met en fuite; on ne peut en user aussi sommairement avec leurs compères hommes. Le fermier espère toujours que la vue du guetteur arrêtera les ravisseurs et que ceux-ci s'en iront chercher fortune là où la surveillance est moins active. C'est pourquoi chacun se voit contraint à se tenir en garde partout et toujours.

Dans les endroits très peuplés on ne saurait s'imaginer jusqu'à quel point il faut veiller au grain. Le travail des champs commence à l'aube. Dès les premières lueurs de l'aurore, les gens sortent du village pour aller vaquer au dehors à leurs occupations coutumières. Le long des sentiers serpentent en foule des hommes, des femmes et même des enfants. Épars dans les champs se trouvent des sortes de lits de camp 


\section{La vie des paysans chinois}

recouverts d'une couche mince de brins de sorgho. L'on pique aussi en terre quelques longues tiges de sorgho liées ensemble au sommet, qui soutiennent un morceau de vieille natte pour vous protéger du soleil. Sous cet abri misérable loge nuit et jour une malheureuse vieille femme chargée du guet.

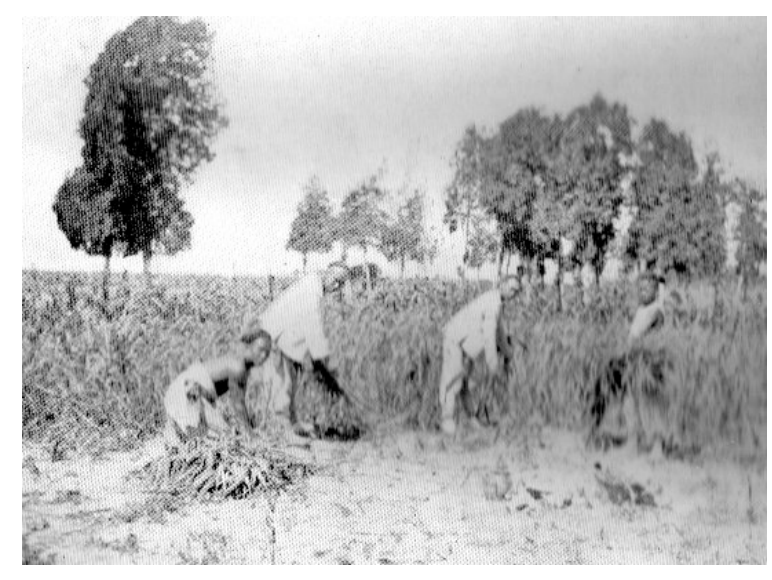

Moisson du millet

Peu de fermiers possèdent des terres d'un seul tenant. Une propriété n'ayant pas plus de 80 arpents chinois se composera peut-être de cinq à quinze parcelles situées de divers côtés. «Comment arrivez-vous à les surveiller toute la nuit ? » demande l'étranger. « Oh ! nous devons aller de l'une à I'autre ! » lui répond-on. En ce qui concerne le coton la tentation de cueillir celui d'autrui est irrésistible. Le veilleur aperçoit au bout du champ un individu qui se faufile lentement, un panier au bras, arrachant à chaque pas des tiges de coton. «Qui êtesvous ? » hurle notre garde, et la forme vague accélère sa marche, mais n'interrompt pas sa cueillette. Si le voleur disparaît dans le champ voisin, c'est un succès pour lui. Mais que le guetteur se mette en colère - ce qui arrivera certainement, qu'il se décide à poursuivre le délinquant - ce qu'il fera probablement - et qu'il le rattrape - chose encore possible - 


\section{La vie des paysans chinois}

c'est alors que commenceront ses ennuis. En admettant que le voleur ne réussisse pas à s'échapper, on devra le conduire devant les chefs du village auxquels il incombe de sévir. Pour peu qu'il soit d'un autre village, on l'attachera sans doute dans le temple de la localité, il sera probablement roué de coups et enfin relâché après paiement d'une amende. Mais voici la grosse difficulté. Bien des voleurs habitent le même village que les propriétaires du champ dont ils étaient en train de s'approprier les produits ; souvent ils sont « cousins » du fermier, parfois ses « oncles » ou même ses « grands-pères »: s'il en est ainsi l'affaire se complique singulièrement. Les idées chinoises sur le mien et le tien sont, à notre avis, aussi vagues que possible, et cela en prenant les choses au mieux. Mais ici les conditions se présentent nettement défavorables : I'unité de la famille correspond en effet à celle d'un individu qui serait composé de plusieurs entités.

C'est pour remédier, dans une certaine mesure, à ces rapines intolérables que se sont constituées des sociétés pour la surveillance des récoltes. Celles-ci ne se sont pas généralisées, mais à l'exemple de bien d'autres organisations chinoises, on en trouve dans quelques districts tandis que dans d'autres très voisins on en ignore même le fonctionnement. Nous avons connu un magistrat de district qui, ayant à juger un affaire dans laquelle I'un des défendeurs était, de profession, surveillant des récoltes, ne comprit aucunement cette appellation qu'il fallut lui expliquer tout comme à un étranger, bien qu'il fût lui-même originaire d'une province voisine. 


\section{La vie des paysans chinois}

Les villages qui sont entrés dans une association ayant pour objet la surveillance de leurs récoltes, le notifient d'habitude au public en peignant ou traçant simplement au lait de chaux sur la façade de quelque temple bien en vue les quatre caractères : kung, k'an, i, po, qui signifient que I'on surveille en commun les champs. Cette annonce comporte un sens différent suivant les lieux. Parfois elle indique qu'un certain nombre de personnes sont de garde tous les soirs : dans ce cas, l'effectif des guetteurs, qui est censé être le véritable, sera affiché sur le mur d'un temple afin de frapper de terreur les pillards en puissance - en admettant toutefois que quelqu'un d'entre eux sache lire et leur montrer combien sont nombreuses leurs chances d'être pris.

Lorsque I'on emploie un nombre fixe de gardiens, la dépense est répartie entre tous les habitants du village, elle se traduit en réalité par une taxe sur la terre, calculée en raison directe de la quantité de terrain que possède chacun des participants. Dans d'autres cas, les mesures pour protéger le blé sur pied sont prises par un seul village, mais plus généralement par un certain nombre de localités contiguës. Une réunion tenue dans un temple d'accès facile pour tous les villages, et à laquelle se rendent les représentants de chacun d'eux, en règle les détails. L'on y arrête les mesures à prendre dans le cas où un délinquant serait pris sur le fait. Question d'importance suprême, car c'est le pivot de toute la combinaison. S'il s'y trouve un point faible, tout l'édifice s'écroule. 


\section{La vie des paysans chinois}

Il ne faut pas perdre de vue que la raison d'être d'une pareille société, c'est le fait qu'il existe partout une foule de pauvres gens dont la seule ressource est le vol. Dans les consultations qui ont lieu avant I'organisation d'une ligue pour la protection du blé, les malheureux des divers villages n'ont pas voix au chapitre ; il ne faut cependant pas les tenir pour quantité négligeable, car ils sauront se rappeler à votre souvenir, et cela par plusieurs procédés assez désagréables. L'on conviendra d'abord que tout fermier de n'importe quel village faisant partie de la ligue doit signaler le maraudeur qui vole du blé sur le territoire de l'un quelconque de ces villages et s'en emparer si possible. Mais c'est précisément dans cette dernière clause que réside le point faible des accords de ce genre entre Chinois. Aussi est-il stipulé plus loin que si une personne découvre un voleur en train d'opérer et omet de signaler le délinquant, elle sera tenue - dans le cas où l'omission est prouvée - pour coupable du larcin et condamnée à une amende tout comme si elle avait été elle-même prise sur le fait.

Pour constituer un tribunal dont la compétence puisse connaître des délits de ce genre, on désigne en assemblée publique un certain nombre $d$ 'habitants choisis parmi les notabilités de chaque village, et c'est à sa barre que devront être conduits les coupables et qu'ils se verront infliger une amende. Dès que l'un d'eux est capturé, on l'amène au village, les juges sont convoqués, ils entendent le rapport de ceux qui le capturèrent et décident du taux de l'amende. Dans les cas particulièrement graves, le gong se fait entendre pour hâter la réunion du tribunal, mais il faut bien dire que la sentence 


\section{La vie des paysans chinois}

dépendra beaucoup de la position sociale du coupable et de la situation matérielle de sa famille. On rencontre des gens fort à leur aise qui n'hésitent pas à s'approprier le blé de leur prochain : ceux-là subiront une lourde amende en guise de « dommages exemplaires ». Les hommes recommandables choisis pour rendre la justice n'ont d'autre moyen de punir le délinquant que de lui infliger une amende, quoique celui-ci soit souvent attaché et fustigé par des voisins exaspérés ; I'auteur eut une fois l'occasion d'assister à des corrections de ce genre ; elles doivent pourtant être assez rares. Les amendes imposées sont payées sur l'heure; en cas de refus ou de réponses dilatoires, c'est devant le yamên du magistrat du district que l'on portera l'affaire. L'instance étant soutenue par tous les notables de la localité ou du groupe de villages intéressés, le voleur sera sans doute condamné, car le magistrat assumera certainement le bien-fondé des poursuites. L'individu le plus pauvre redouterait d'être enfermé pendant un ou deux mois dans une cangue pendant la période si affairée des moissons, à un moment où il est tout particulièrement important pour lui de jouir de sa liberté.

Un homme de couleur, résidant en Géorgie, se plaignit un jour que dans cet État le nègre n'avait vraiment pas de chance, attendu «qu'il était obligé de travailler durement pendant le jour et de voler toute la nuit afin de gagner honnêtement sa vie ». Or cet homme appartenait à une catégorie de gens que l'on rencontre dans toutes les parties de la Chine et dont il faut toujours tenir compte. Partout où il existe des mesures pour la protection des blés contre les voleurs, les fermiers doivent se 


\section{La vie des paysans chinois}

souvenir des recommandations faites jadis par Booz dans l'ancienne Bethléem, lorsqu'il prescrivait à ses moissonneurs de ne pas se montrer trop regardants et de négliger quelques épis de leurs gerbes afin que les malheureux ne glanent pas en vain. Des questions de ce genre, poussées même jusqu'à déterminer la quantité d'éteule qui sera laissée dans les champs, font souvent le sujet d'accords et de réglementations particulières : elles revêtent une grande importance pour beaucoup de pauvres gens.

Dans les districts à culture de kao-liang - sorgho - il est d'usage d'arracher quelques-unes des feuilles de la partie inférieure de la tige afin, disent les gens, de permettre aux grandes pousses de « respirer plus librement » et de faciliter la maturité du grain. Dans les régions où prévaut cette coutume, un accord fixe parfois le jour où commencera le dépouillement et personne, pas plus le riche que le pauvre, n'est autorisé à anticiper sur cette date. Mais, au jour dit, chacun est libre d'enlever les feuilles dans n'importe quel champ, pourvu qu'il ne s'aventure pas au-dessus de la hauteur stipulée pour l'émondage. Ces feuilles sont très appréciées comme nourriture des animaux. La veille du jour désigné pour l'opération, le son du gong en avise le village, et le lendemain, tout le monde se livre à ce travail qui constitue l'occupation essentielle du moment.

Plus important encore que les mesures prises pour l'élagage du sorgho, est le règlement établi pour la glane du coton. Dans plusieurs parties de la Chine, le coton est le produit le plus précieux du sol et il jouit du privilège d'être le seul produit 


\section{La vie des paysans chinois}

cultivé dans l'Empire qui corresponde à une nécessité absolue pour tous, hommes, femmes et enfants. Dès qu'arrive la saison de la cueillette, les femmes et les enfants, dans les zones où le coton représente la principale culture, sont absorbés par ce travail fatigant d'une façon presque exclusive. Avec les premières gelées la période la plus propice a passé, bien que les graines continuent à s'ouvrir pendant quelque temps encore. On admet, comme une prérogative des pauvres, que la glane est libre partout après une certaine date, toujours incertaine du reste ; dans plusieurs districts elle sera fixée par une proclamation du magistrat lui-même, car l'on n'observerait pas un ordre émanant d'une autorité de moindre importance. Dans certaines régions, l'affaire dépend, comme tant d'autres, d'un accord local ou d'une entente entre plusieurs localités. Le jour où il devient légal de glaner n'importe où - jour d'allégresse pour les pauvres gens - est appelé « relâchement des punitions 》 parce qu'on ne court plus le risque d'une amende. Les champs se couvrent alors de monde ; d'aucuns poussent jusqu'à de grandes distances de chez eux parce que la récolte y est plus abondante. Une personne connue de l'auteur fit la remarque que sa femme était demeurée loin de son home pendant plus de dix jours, occupée à glaner dans des champs plus fructueux qu'autour de son village ; elle prenait ses heures de sommeil dans une embrasure de porte ou sous quelque hangar lorsqu'on voulait bien I'y autoriser.

Il arrive parfois que de riches propriétaires essayent d'interdire l'accès de leurs grands domaines aux pauvres gens, mais ils y réussissent rarement, et une mesure de ce genre ne 


\section{La vie des paysans chinois}

sera jamais de la bonne politique. L'auteur de ce livre assista un

jour à une discussion entre l'un de ces gros tenanciers de terres et plusieurs centaines de pauvres, femmes et enfants, au moment où ces derniers allaient se précipiter à la recherche des résidus de la moisson. Pendant que se poursuivait le conflit, un grand nombre des glaneuses que le coton intéressait beaucoup plus que la légitimité de leur intrusion dans le domaine, s'étaient hâtées de faire leur cueillette, abandonnant à d'autres le soin de régler au mieux la question abstraite du droit.

A plusieurs reprises déjà nous avons eu l'occasion de faire allusion aux amendes imposées pour violation des arrêtés ou accords entre villages : là gît le point délicat des mesures prises en vue de la protection des récoltes. Il est d'usage d'employer I'argent ainsi recueilli à louer une compagnie théâtrale, méthode très dispendieuse de jouir d'un supplément de recettes, les faux frais que provoque la présence d'une troupe d'artistes, tels que les réceptions d'invités, etc., représentant parfois jusqu'à dix fois la somme payée à l'impresario.

A passer ainsi des nuits dans les champs pendant la période de la moisson, alors que le sol est généralement saturé d'humidité, les habitants contractent la malaria, des rhumatismes, de la pneumonie et bien d'autres maladies encore. Mais il faut braver tous les risques si l'on veut avoir de quoi manger jusqu'à la prochaine moisson. Les querelles, inévitables conséquences des larcins de blé et autres incidents qui accompagnent les récoltes d'automne, suscitent de profondes inimitiés, elles conduisent parfois à des procès ruineux dont le 


\section{La vie des paysans chinois}

coût peut revenir à mille fois la valeur du bien en litige. Telles sont néanmoins les conditions dans lesquelles se récolte le blé chinois ; elles se renouvellent d'année en année, toujours identiques, et il en est ainsi depuis les origines les plus lointaines de la Chine.

(a) 


\section{La vie des paysans chinois}

\section{XVI \\ INCANTATION DE LA PLUIE.}

Par un de ces paradoxes tout à fait caractéristiques des Chinois, et bien qu'ils aient produit des systèmes philosophiques très profonds, aucun de ces systèmes ne les a conduits à accorder quelque créance à la fixité des lois de la Nature. Le polythéisme ne s'appuie pas sur une pareille manière de voir. C'est ainsi que dans un Empire qui est l'un des exemples les plus frappants d'homogénéité, le peuple, comme ses dirigeants, ignore complètement les causes de la pluie. Dans la province du Shantoung, I'on adore une grande variété d'êtres réels et imaginaires afin qu'ils règlent les chutes de pluie conformément aux besoins des fermiers. Parmi les divinités ainsi honorées se trouvent la Déesse de la Miséricorde, considérée dans la Chine méridionale comme un mâle ; le Dieu de la Guerre ; le Dieu Dragon ou Lung Wang ; et un Tai Wang que la croyance populaire incarne dans un serpent, souvent un serpent d'eau, mais, à son défaut, un ophidien de terre qui fera tout aussi bien I'affaire. Lorsque I'on découvre I'un de ces Tai Wang, il est d'usage de notifier la trouvaille au magistrat le plus proche, et I'on s'attend à ce qu'il vienne aussitôt faire ses dévotions devant la divinité. Il y a plusieurs années Li Hung Chang s'acquitta de ce culte à Tien-Tsin où se trouve un sanctuaire très important consacré à Tai Wang. 


\section{La vie des paysans chinois}

Comme si ces auxiliaires incongrus de la Nature ne suffisaient pas, il est des gens qui adorent Yu Huang Shang $\mathrm{Ti}$ ou l'Empereur Perlé Suprême, tandis que certains offrent des sacrifices à «Sun Ta Shêng » qui n'est autre qu'un personnage imaginaire du roman « Voyage en Occident ». Sun était à l'origine un singe né d'une pierre par un processus d'évolutions, mais ses exploits sont si nombreux et si impressionnants que l'esprit populaire l'a choisi comme l'être propre à régler les chutes de pluie. Cependant son culte semble assez limité et, comme celui de toutes les divinités déjà mentionnées, très irrégulier. Le même village qui adore aujourd'hui le Dieu de la Guerre honorera peut-être prochainement la Déesse de la Miséricorde, sans doute d'après le principe qu'il doit se faire un judicieux roulement dans le panthéon de ses dieux.

En plus de tous ces cultes, il en existe un autre très différent et particulièrement en faveur. Dans I'ancienne ville de Han Tan Hsien, au Chih-li occidental, s'élève un temple dont les dépendances contiennent un puits célèbre par la multitude de tablettes en fer qui y ont été déposées. Chaque fois que la pluie se fait rare et après que le magistrat a fait sans succès sa tournée de dévotions dans tous les temples de la ville et des environs, on expédie, comme suprême espoir, un messager officiel à Han Tan Hsien-voyage qui dure généralement plusieurs jours - pour en rapporter une tablette de fer tirée du puits. Le courrier emporte à son départ une tablette semblable sur laquelle est inscrite, avec la date du voyage, le nom du district

qui adresse la supplique, et dès son arrivée, il se rend au temple taoïste : là, on lui remet, contre une certaine somme, la tablette 


\section{La vie des paysans chinois}

tirée précédemment du puits dans lequel est aussitôt lancée celle qu'il vient d'apporter.

Pendant son voyage de retour le messager est supposé ne manger que du son et voyager nuit et jour à toute vitesse : I'on attend son arrivée avec la plus vive anxiété. Ici se place un incident particulièrement caractéristique de la mentalité chinoise. Très probablement les régions traversées par le courrier ont autant besoin d'eau que le district qui fit les frais du voyage : les habitants le guettent au passage, ils le retiennent, lui « empruntent » son talisman qui est ainsi « invité » à arroser leurs champs et la pluie tombera sur ces terres au lieu d'aller féconder celles du village auquel appartient la tablette.

De prime abord, il paraît certainement singulier qu'un peuple aussi pratique que les Chinois puisse accorder le moindre crédit à de pareilles mômeries mais, à dire vrai, il s'agit fort peu de la question foi dans cette affaire et I'on ne s'adonne à ces superstitions que faute de connaître les lois qui régissent la météorologie de l'Empire. En outre, les mois pendant lesquels se renouvellent le plus fréquemment ces étranges pratiques sont le $5^{\mathrm{e}}$ et le $6^{\mathrm{e}}$, et c'est précisément à ce moment-là qu'a lieu l'époque des pluies. La période assignée pour l'efficacité de ces pétitions étant d'habitude limitée à dix jours, il est plus que probable que le terme en coïncidera avec une chute d'eau que I'on attribuera à la pétition, tandis que si celle-ci ne produit pas d'effet en temps voulu, on expliquera l'échec par quelque raison absolument différente. 


\section{La vie des paysans chinois}

Un incident qui eut pour théâtre une région à l'ouest du Shantoung montrera clairement, même à l'intellect chinois le plus obtus, les inconvénients que produit une compréhension erronée des phénomènes de l'univers. Une bande de villageois porteurs de drapeaux et précédés d'un tambour se rendait à un temple pour implorer une chute de pluie. Ils rencontrèrent un homme coiffé d'un grand chapeau de paille, qui conduisait un cheval sur lequel était assise une femme mariée. Celle-ci revenait d'une de ces visites classiques à la famille de sa mère et portait un enfant dans les bras.

Or, les mêmes gens qui adressent en faveur de la pluie des supplications absurdes aux singes et aux serpents, nourrissent des idées tout aussi erronées quant aux causes qui empêchent l'eau du ciel de tomber. Des étrangers porteurs de parapluies se sont vus houspillés par la foule parce qu'elle les considérait comme la cause efficiente de la sécheresse. L'on s'est plaint également des gouttières d'un nouveau consulat construit dans un port à Traités parce qu'elles retenaient l'eau à laquelle avait droit la province entière. Dans le cas qui nous occupe, la foule s'indigna contre le vaste couvre-chef du rustaud, contre-indiqué, - ainsi que s'expriment les docteurs, - à un moment où I'on faisait des prières pour la pluie. Le paysan fut invectivé ; un long bâton bouscula le chapeau qui tomba sur la tête du cheval et la bête effrayée, prenant le mors aux dents, s'enfuit dans une course éperdue. La femme perdit l'équilibre, laissa échapper son enfant qui fut tué dans la chute, puis son pied se prit dans l'étrier et la malheureuse fut traînée ainsi sur une assez grande distance. Lorsque l'on parvint à maîtriser la monture, la pauvre 


\section{La vie des paysans chinois}

femme avait aussi cessé de vivre. Elle était enceinte, de sorte que l'accident brisa trois existences. Le paysan convoyeur courut jusqu'à la maison de la victime pour raconter l'histoire. Les hommes de la famille se trouvaient justement chez eux : s'armant en toute hâte des outils qui leur tombèrent sous la main, ils coururent à la poursuite des auteurs de cette catastrophe; une terrible bataille s'ensuivit et quatre ou cinq pèlerins demeurèrent sur le carreau. L'affaire fut portée devant le yamen du district, mais nous ignorons comment elle se termina.

Une autre excentricité ayant pour but d'amener la pluie consiste à emprunter le dieu d'un village afin de s'en servir dans un autre. Si l'artifice réussit, l'idole est réintégrée chez elle avec tous les honneurs possibles mais, en cas d'échec, on la laisse à I'endroit où elle fut déposée pour être adorée, les villageois étant uniquement influencés par les « résultats », tels les correcteurs de composition dans un concours. D'autres fois, si le dieu ne paraît pas se rendre compte que la terre a besoin de pluie, on le placera en plein champ où il cuira au soleil jusqu'à ce qu'il se décide à sortir de sa torpeur pour faire son devoir. Il a dans les mains un bouquet de tiges de saule parce que cet arbre est sensible à la moindre humidité. On répète couramment en Chine que «lorsque les inondations emportent le temple de Lung Wang - le roi Dragon - c'est que ce dieu ne connaît pas sa propre race ». Et cependant cela arrive continuellement.

Il y a plus de quarante ans que le fleuve Jaune changea son cours pour s'installer dans le lit d'une petite rivière appelée « le 


\section{La vie des paysans chinois}

fleuve Clair ». Ses flots torrentiels, bourbeux semèrent partout la dévastation et la ruine. Pendant plus d'une génération, le Shantoung central a subi la malédiction du « malheur de la Chine » et même lorsque, en 1887 , le fleuve se décida à modifier encore une fois son itinéraire, le Gouvernement dépensa des sommes fabuleuses et il réussit à le ramener dans son lit primitif, œuvre gigantesque dont la réalisation paraissait impossible à la plupart des gens qui connaissent l'état des lieux.

L'année suivante un groupe d'ingénieurs hollandais visita la région : après un examen approfondi de la situation, ils publièrent un rapport remarquablement documenté sur les travaux susceptibles de stabiliser le fleuve, rapport auquel le Gouvernement ne prêta du reste aucune attention. A cette époque le manque d'argent passait pour une excuse suffisante ; cependant on aurait pu trouver les fonds nécessaires si l'on avait voulu en confier l'emploi à des ingénieurs étrangers, or ces Hollandais étaient on ne peut mieux qualifiés pour exécuter ces travaux. Mais au moment où le « Directeur général du fleuve Jaune » - titre pompeux dont le côté humoristique échappe aux Chinois - adressait un mémoire au Trône en insistant sur la nécessité d'utiliser la technique étrangère dans une tâche très au-dessus des compétences indigènes, sa proposition fut repoussée par l'Impératrice douairière comme « prématurée et prétentieuse »!

D’après les idées chinoises, les «Trois Harmonies » sont «le Ciel, la Terre et I'Homme ». Ces trois éléments se trouvent à I'heure actuelle en délicatesse les uns avec les autres. Il faut 


\section{La vie des paysans chinois}

absolument qu'ils se réconcilient, mais leur entente ne pourra être rétablie avant que les Chinois en arrivent à une conception plus exacte de la limite assignée aux pouvoirs respectifs de cette triade. Un nouveau groupe d'hommes ferait bientôt une nouvelle Terre, et sans doute se contenterait-on alors des Cieux tels qu'ils sont aujourd'hui ; au cours d'une décade d'années il tombe certes assez d'eau pour satisfaire aux besoins de tous et l'excédent n'est pas tel que I'on ne puisse s'en rendre maître ; mais il faut que l'homme apprenne à diriger cette eau : avant qu'il y réussisse, « le Ciel, la Terre et l'Homme » ne seront jamais en bons termes. 


\section{La vie des paysans chinois}

\section{XVII}

\section{LA CHASSE.}

Dans certaines zones de la grande province du Shantoung il existe d'importantes nappes d'une eau claire et profonde, particulièrement recherchée par les poules d'eau, surtout à I'automne et en hiver. En tout pays d'Occident ces sites seraient un paradis pour les chasseurs, mais en Chine les oies et les canards sauvages peuvent s'ébattre en «paix et en tranquillité le long de la route »: jamais un coup de feu ne trouble leur quiétude ; ils ignorent le chasseur malfaisant et en voici la raison. Au yamên de la Préfecture voisine des principaux marais, une ancienne coutume consiste à lever un « squeeze » sur les produits de la chasse : cette taxe, très forte, est devenue prohibitive, aussi ne trouve-t-on presque plus de poules d'eau sur les marchés.

Le Dr Medhurst, I'un des plus admirables missionnaires de la Chine, père de Sir Walter Medhurst, à un moment consul général de S. M. à Shanghaï, nous fait, dans I'histoire de sa vie, le récit d'une excursion qu'il entreprit avec un compagnon de route au nord de Shanghai, le long des côtes du Shantoung. Voici comment ils procédaient : ils débarquaient de la jonque de pêche où ils avaient pris passage, puis après avoir battu le terrain environnant, ils rejoignaient leur bord pour recommencer le même procédé plus loin. Ils réussirent ainsi à pénétrer dans quelques villages côtiers et à causer avec un certain nombre de 


\section{La vie des paysans chinois}

pêcheurs. Avec une charmante franchise, I'historiographe de cette expédition mentionne qu'ils ne virent nulle part d'animaux sauvages. Nous le croyons sans peine car, même à cette phase avancée des grandes explorations, le seul animal sauvage que le plus fin limier aurait quelque chance de rencontrer, c'est le lièvre. Ajoutons pourtant qu'il en existe quelques autres, la belette, une certaine espèce de renard, etc.., lesquels se gardent généralement d'importuner le public.

Nous avons ouï-dire que, dans le petit royaume de Danemark, l'un des sports d'hiver en faveur consiste en une chasse au lièvre, soigneusement organisée et réglementée, qui se fait sur de grands espaces et à laquelle prend part toute la population mâle. La chasse se clôture par une grande fête où tout le monde est invité et que les jeunes attendent avec la plus vive impatience. Chose curieuse, on rencontre la même coutume en Chine. Dans le Shantoung se trouve un district anciennement appelé « P'ing-yuên »- plaines de niveau ; - les habitants s'y livrent à un sport analogue qui, toutefois, ne se termine pas, comme au Danemark, par une fête brillante. Où trouver en effet un Chinois assez osé, du moins assez fortuné, pour offrir aux nuées de personnes qui s'empresseraient d'accourir, le plaisir de manger aux dépens de quelqu'un d'autre?

L'organisation de cette chasse est monopolisée par quelques gaillards sans sou ni maille qui s'arrogent encore un autre monopole, celui de «protéger » les marchands aux grandes foires de la région, en les frappant d'une sorte de taxe, sous prétexte de les mettre à l'abri des exactions d'autres coureurs de 


\section{La vie des paysans chinois}

routes. Un homme au crâne absolument rasé passe de long en large dans les ruelles encombrées du marché et annonce à haute voix que tel ou tel jour, les gens du district Nord, par exemple, se réuniront pour chasser le lièvre. L'avis est répété nombre de fois jusqu'à ce que tout le monde ait bien compris, puis chacun retourne chez soi et le communique aux autres habitants. Au jour dit, la population entière est prête pour la mêlée. Si I'on choisit un homme chauve comme crieur, c'est pour une raison bien chinoise. Dans le dialecte mandarin en effet, le mot chauve - T'u - et celui du lièvre ont le même son. Cette circonstance provoqua un jour une erreur singulière chez le petit enfant, fort intelligent, d'une famille étrangère en résidence au Shantoung. L'un des employés de la maison était parti en course sur un âne, et, tandis qu'il reprenait le chemin du logis, la bête s'emballa, désarçonna son cavalier et s'enfuit au galop. Un jeune garçon en train de couper de I'herbe aperçut l'animal, courut après lui, s'en rendit maître et le maintint jusqu'à l'arrivée de son cavalier. De retour à la maison, l'employé fit un dramatique récit de sa mésaventure en présence de l'enfant et attribua I'honneur d'avoir capturé l'âne à un petit « T'u-tzû », ou « enfant chauve ». Notre jeune étranger écouta ce récit palpitant et le soir, à la table de ses parents, il le répéta dans ses moindres détails, mais en traduisant « T'u-tzû » par lièvre, le seul genre de « T’u-tzû » dont il eût jamais entendu parler !

$\mathrm{Au}$ jour fixé pour la chasse, toute la population qu'on a pu rassembler arrive, curieuse de prendre part au sport. Le nombre des amateurs est parfois si considérable qu'ils se tiennent en rangs serrés comme une troupe de soldats. Les lièvres affolés 


\section{La vie des paysans chinois}

courent d'un côté à l'autre de la foule qui s'étend en un cercle immense, mais chacun des assaillants étant armé d'un bâton, sinon de deux, le gibier a peu de chances d'échapper au massacre. D'après une règle du jeu, tout lièvre pris doit être tenu en l'air par l'heureux chasseur qui s'écrie à tue-tête : « chû » - je le lève. - Après quoi l'animal lui appartient et nul n'a le droit de le lui ravir. Néanmoins, comme les Chinois sont bien de la même espèce que les autres mortels, à quelque pays qu'ils appartiennent, des querelles parfois sérieuses s'élèvent à propos du butin de la chasse, des têtes sont mises à mal, des membres sont cassés et tout finit souvent par un procès. Mais, avec cette intelligence pratique qui distingue le fonctionnaire chinois, les magistrats se refusent à prendre en considération des plaintes de ce genre, de sorte que le conflit doit être réglé, comme tant d'autres causes où la loi devrait intervenir, hors du tribunal, par les « pacificateurs ».

Un incident qui se produisit il y a quelques années et dont les principaux acteurs sont bien connus de l'auteur, fait ressortir combien facilement une dispute surgit, même chez un peuple aussi pacifique que le Chinois, avec ou sans chasse au lièvre.

Quelques villageois revenaient un soir, assez tard, par une nuit de lune, d'un enterrement qui avait eu lieu dans un village des environs. En approchant de leur hameau ils surprirent deux jeunes gens occupés à abattre de petits arbres de l'espèce jujubiers ou rhamnus : ils préparaient des gourdins pour la chasse au lièvre du lendemain. En s'entendant interpeller, les jouvenceaux qui violaient ainsi le bien d'un village voisin, prirent 


\section{La vie des paysans chinois}

la fuite, poursuivis par les gens qui les avaient aperçus. Arrivés chez eux, ces derniers répandirent méchamment le bruit que les jeunes gens étaient en train de couper des pins sur la sépulture de leur famille. Aussitôt, en dépit de I'heure tardive, une foule se rassemble et se met en marche vers l'autre village, à 1 mille environ, afin de demander satisfaction. Ils trouvent la population endormie, mais quelques notables, enfin réveillés par le bruit, sortent de leurs demeures et invitent les assaillants à remettre au lendemain, dès le lever du jour, le règlement de l'affaire. A ce moment le cas serait examiné, les coupables punis et I'on accorderait aux plaignants tonte satisfaction.

Cette proposition, pour aussi raisonnable qu'elle fût, n'eut pas I'heur de plaire aux énergumènes qui ripostèrent par des injures ; puis la bande retourna à son village. On frappa le gong, tous les hommes ainsi réveillés durent accompagner la populace armés de massues, de perches, etc., pour participer à l'attaque de l'autre village, lequel était clos par un mur en pisé dont les portes demeuraient fermées pendant la nuit. Les assaillants menaient grand bruit devant cet obstacle et s'acharnaient à exaspérer l'adversaire en lui criant toutes sortes d'injures. Les anciens s'efforçaient bien de tenir les portes closes, mais ils furent débordés par une jeunesse ardente, qui, devant l'insistance de l'ennemi, résolut de lui donner, quoique d'une autre façon, la satisfaction qu'il demandait. Dès les portes ouvertes, une bataille furieuse s'engagea et les femmes, juchées sur les terrasses des maisons pour tâcher de voir ce qui se passait, entendirent le bruit sourd de coups violemment échangés par les combattants. Plusieurs hommes frappés 


\section{La vie des paysans chinois}

s'évanouirent, I'on cria qu'ils avaient été tués, aussi le combat reprit-il de plus belle jusqu'au moment où la défense dut se replier derrière ses murailles. Dans chaque camp il y eut de nombreux blessés, dont quelques-uns gravement atteints. Un homme âgé eut le crâne troué par une perche : transporté chez lui sans connaissance il demeura pendant deux semaines dans un état voisin de la mort.

Le lendemain matin, les assaillants coururent couper trois petits pins qui poussaient dans leur propre cimetière, comme preuve du dommage causé par les jeunes gens, puis allèrent au chef-lieu du district porter plainte. Bien entendu l'autre village se rendit également au yamên. Ses adversaires traînèrent avec eux le vieillard mis à mal, à l'aspect moribond très vraisemblablement. Chaque parti dut verser au magistrat la part des frais qui lui incombait avant d'engager une instance et, le cas étant sérieux, ceux-ci furent lourds. Le tribunal ne voulut opiner en faveur ni de l'un ni de l'autre des villages avant de s'être rendu compte de l'état des blessés. Un garçon épileptique,

à moitié idiot, fait prisonnier par l'une des bandes et effrayé par des menaces de mort, avoua sa part de responsabilité dans tous ces agissements ; il fut aussitôt roué de coups et resta à moitié mort sur le carreau. L'affaire traîna en longueur, finalement un jugement intervint, la décision du magistrat ne s'appuyait pas, du reste, sur le moindre principe de droit ou d'équité : tel est le cas en Chine, dans la plupart des procès. Chaque village dut régler ses propres dettes et aucun d'eux n'eut gain de cause. Le village attaqué avait englouti 300 cordons de cash dans la caisse 


\section{La vie des paysans chinois}

du yamên, l'adversaire 500 ! Le vieillard finit par se rétablir. L'ordre régna de nouveau à Varsovie et dans ses alentours.

Or, quel était le mobile de tout ce drame ? Existait-il déjà une inimitié entre ces deux villages ? Nullement, ils entretenaient au contraire les relations les plus cordiales, six ou huit familles se trouvant alliées par des mariages. $Y$ eut-il une provocation particulière ? Pas la moindre. La plus simple raison conseillait que la paix continuât comme par devant et cependant la guerre éclata quand même et il y eut du sang versé. L'emportement des Chinois explique bien des choses, mais comment la colère peutelle surgir ainsi brusquement sans aucun motif réel ? Il est d'usage de justifier les phénomènes, célestes comme terrestres, par la théorie de l'évolution. Étant donné I'hérédité, l'éducation, le milieu, vous avez I'homme et la société. Cependant on a le droit de se demander si cette classification est aussi complète qu'elle le semble au premier abord. Ne voit-on pas à certains moments un autre facteur intervenir ? Edgar Poe l'appelait le Démon de la perversité. 


\section{La vie des paysans chinois}

\section{XVIII \\ MARIAGES ET FUNÉRAILLES.}

Les Chinois partagent avec le reste de la race humaine le désir de faire de la cérémonie d'un mariage une occasion de réjouissances. L'une des périphrases les plus courantes pour annoncer un mariage est en effet : « joyeux événement ! 》 Or, il n'y a pas de doute qu'en Chine la forme la plus parfaite de la « joie » se traduit par le repas. Alors que chez tous les peuples et dans tous les temps on a offert des banquets de noces, ce protocole est plus spécialement le fait des Orientaux et l'une des caractéristiques des Chinois.

En raison des ramifications étendues et compliquées des alliances, le nombre est grand des personnes qu'il faut inviter à un mariage. Dans certaines régions, la coutume veut que seules les femmes contribuent pour une «part » - fên-tzû - aux frais d'une noce, tandis que les hommes offrent leur cadeau à ce moment de la cérémonie où le marié salue successivement les invités en se prosternant. Appelé pour recevoir cette marque de déférence, chaque invité tend alors le montant de son offrande. Dans d'autres endroits, hommes et femmes contribuent aux dépenses du mariage pareillement. En tout cas, I'on peut être assuré de deux choses : presque tous les invités seront présents, à moins qu'ils n'aient dû se faire représenter par un délégué, de plus, la plupart des femmes seront accompagnées 


\section{La vie des paysans chinois}

de leurs enfants qui ne contribuent en rien à la recette, mais ajoutent énormément aux dépenses du festin.

En Chine, les coutumes concernant le mariage varient certes beaucoup selon les régions, mais nous n'avons jamais entendu dire que quelqu'un puisse être présent à la « cérémonie » et non au « déjeuner » qui l'accompagne. En vérité I'on peut à peine dire qu'il existe une « cérémonie » dans le sens que nous donnons à ce mot : l'essence du mariage entre Célestes consiste

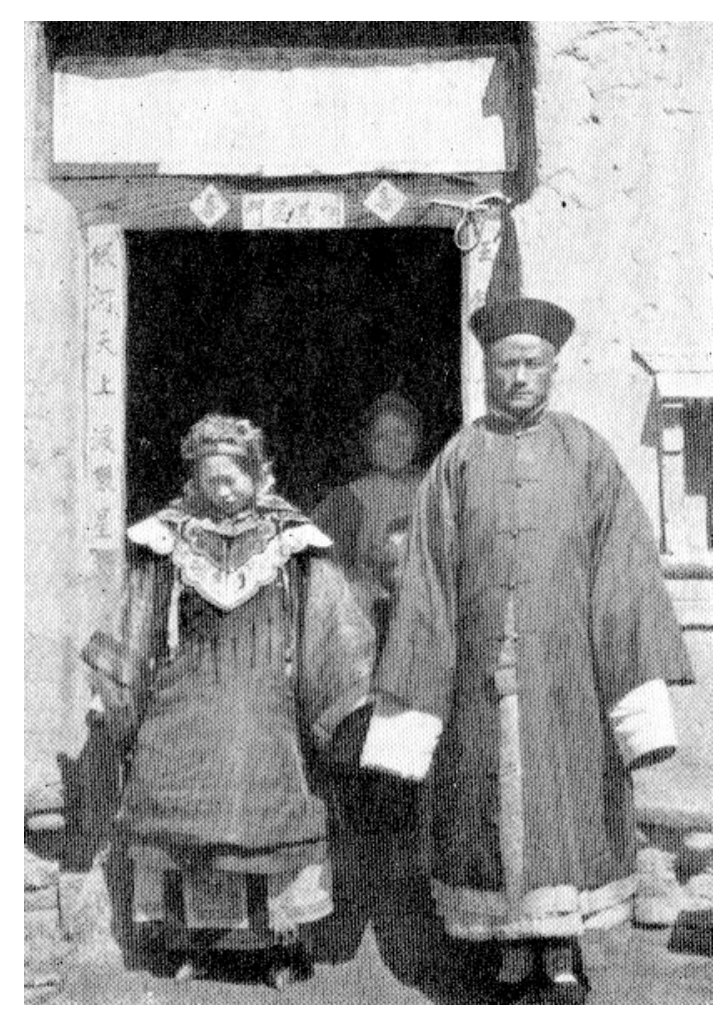

Couple de jeunes mariés

dans l'arrivée de la mariée à son futur home; quant au festin, il est le clou de la fête. Parfois les parents ne sont pas invités le jour du mariage, mais l'un des jours suivants. Il n'en reste pas moins que lorsque les invités font acte de présence, le festin est le centre et l'âme de toutes les réjouissances. 


\section{La vie des paysans chinois}

S'il y a quelque chose que le Chinois ait ramené à une science exacte, c'est bien l'acte de manger. L'on ne saurait donner à un homme une preuve d'amitié plus certaine qu'en l'invitant à un repas, et certain dicton très populaire nous apprend que celui qui vient avec une barrique de vin sur son épaule et un mouton au bout d'une laisse est un homme qui comprend vraiment I'hospitalité, car il montre par des actes la réalité de ses intentions. La grande masse des Chinois vit dans des conditions matérielles qui ne sont rien moins que l'opulence, mais les frais qu'entraîne un mariage ou des funérailles, au seul point de vue de I'achat des victuailles, sont énormes. En conséquence, étant donné l'importance des sommes à débourser à ces moments-là et le nombre des occasions où il faut ainsi faire appel à sa dernière sapèque, il est impossible que toute famille, à l'exception des gens très fortunés, n'en soit pas réduite à l'absolue pauvreté

Sous la pression de ces circonstances inexorables, les Chinois ont depuis longtemps découvert une heureuse manière d'appliquer le principe de la participation qui leur permet de ramener les frais des mariages et des enterrements à un taux abordable aux petites bourses. Il est généralement difficile de

prévoir le nombre de personnes qui viendront assister à l'une ou l'autre de ces deux cérémonies, mais la quantité des approvisionnements sera calculée d'après le chiffre maximum des invités. Un code rigoureux d'étiquette sociale exige que chacun d'eux - ou plutôt chaque famille - contribue pour « une part » aux dépenses que nécessite la circonstance. Cette « part » peut se traduire par un apport de victuailles, mais il est 


\section{La vie des paysans chinois}

plus usité de fournir sa contribution en espèces dont l'importance suit une gradation parfaitement comprise de chacun. Le montant en varie beaucoup suivant les localités et va de la somme insignifiante de 5 ou 6 cents jusqu'à $1 / 4$ de dollar et plus, suivant le degré d'intimité des familles et la capacité de chaque invité à participer pour une somme plus ou moins forte. Dans certaines régions, le montant de cette contribution varie du simple au double. Parfois l'étalon est si bien compris que l'expression « une part » revêt une signification locale aussi précise que si l'on indiquait une certaine somme, 250 cash par exemple.

Dans quelques endroits le taux $d^{\prime} \ll$ une part » pour des mariages équivaut au double de celle admise pour des funérailles. Cette différence résulte du fait que dans ce dernier cas la nourriture est modeste $-s u-$ tandis que dans le premier cas on sert de la viande - hun - et d'autres mets coûteux. L'on constate souvent que la «part» de la personne venant d'une autre ville ou d'un autre district s'élève au double ou au triple de celle d'un habitant de la localité où se sert le festin. Un étranger perdrait sa «face » à donner la même somme qu'un natif de l'endroit.

Mais nous devons observer, à titre d'exemple caractéristique de la façon de procéder des Chinois, qu'en des occasions de ce genre, les sommes recueillies correspondent rarement à ce qu'elles prétendent être. Si, d'après les coutumes du lieu, 96 ou 98 cash équivalent à 100 cash, la tentation de verser une contribution plus faible est trop forte pour qu'un Céleste y 


\section{La vie des paysans chinois}

résiste, d'autant plus que dans la confusion qui accompagne la remise de nombreuses cotisations, il sera difficile de dire par qui fut donné tel ou tel cordon de cash, bien que le montant de chaque don soit porté sur un « compte » destiné à être vérifié.

Les chefs de famille soucieux de conserver un indice exact de I'honnêteté relative des contribuants, se munissent parfois d'une longue corde à laquelle sera attachée successivement par son cordon chaque somme de cash après avoir été portée en compte. L'opération terminée, le maître de maison pourra vérifier cette série de cordons et s'assurer de ce qui manque à chacun d'eux, puis se basant sur le rang qu'ils occupent et qui doit correspondre à l'ordre dans lequel les donateurs sont inscrits, il pourra ainsi retrouver le nom de chacun de ces derniers. Les invités ne voient pas d'un bon œil cette façon de procéder, peu usitée du reste parce qu'elle cause trop d'ennuis. Mais le chef de famille y trouve l'avantage de pouvoir payer la famille qui n'a pas donné honnêtement sa part, de la même monnaie lorsqu'il devra, à son tour, assister à l'une de ces cérémonies. Dans certains endroits, il est bien entendu qu'alors que la « part » individuelle comporte 250 cash, il en faudra 5 pour faire 1.000 cash, puisque chaque centaine de cash n'est en réalité que 80 cash.

Il appartient à un comité constitué pour la circonstance de centraliser les recettes et de garder un compte du montant versé par les invités pris individuellement. Ce détail est de grande importance attendu que chaque contribution joue un double rôle. Elle satisfait d'abord aux obligations des participants à la fête, de 


\section{La vie des paysans chinois}

plus, elle sert de barème pour la quotité du cadeau que devra faire à son tour la famille aujourd'hui bénéficiaire à celle des donateurs actuels. Le montant de la somme offerte par chaque personne dépend des relations qu'ont les familles entre elles et surtout de ce qu'elles auront reçu précédemment en pareille occasion. Ne pas tenir compte du code traditionnel, qui demande aux invités des contributions proportionnées à celles données par d'autres, est considéré comme une offense grave contre le décorum, car la famille intéressée peut avoir à supporter de grosses répercussions pécuniaires du fait de la diminution de ses recettes.

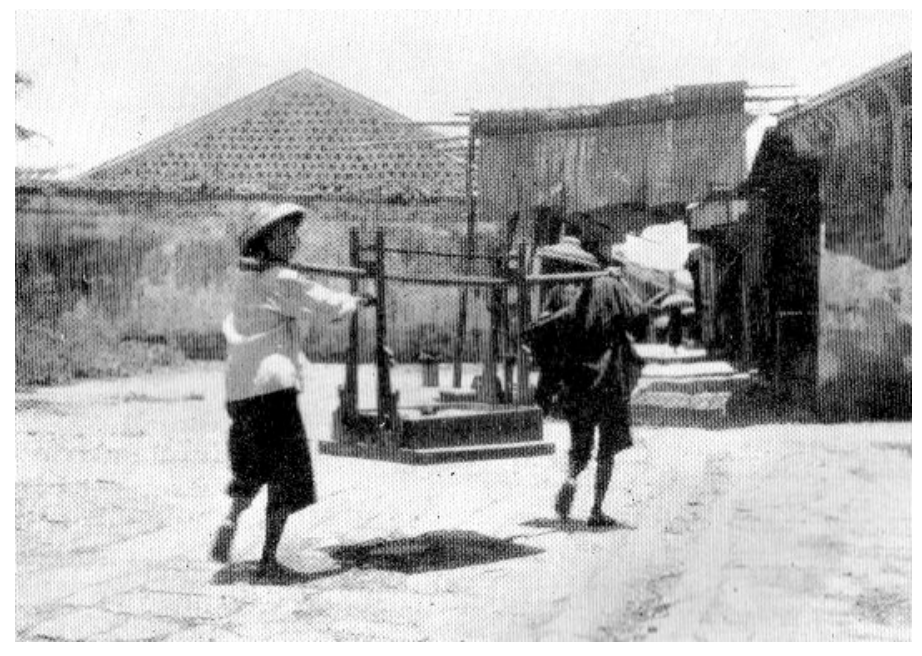

En route pour le festin

Assister à un festin et n'apporter aucun don en espèces ou en nature, voilà une chose dont on n'a pour ainsi dire jamais entendu parler, bien qu'il arrive fréquemment que la quantité de vivres qu'en de certaines occasions l'on substitue à l'argent ne corresponde pas même à la moitié de ce que mangera le donateur. Tel est tout spécialement le cas de la femme qui se fait suivre-ainsi que nous l'avons déjà mentionné - d'une bande d'enfants voraces qu'on ne pourra tenir tranquilles qu'en les 


\section{La vie des paysans chinois}

gorgeant d'aliments pendant toute la durée de la fête, leurs capacités d'absorption étant du reste illimitées.

Dans les petites comme dans les grandes villes, l'ordonnance d'un festin de noces ou d'enterrement se pratique sensiblement de la même manière que dans les pays d'Occident. Un magasin d'approvisionnements s'engagera à livrer un nombre déterminé de bols contenant des aliments d'une qualité définie et à un prix fixé d'avance. L'on prévoit aussi des fournitures supplémentaires dans le cas où l'affluence des invités dépasserait le nombre prévu. Mais si la fête doit être donnée sur une grande échelle, il est probable que la cuisine se fera sur les lieux mêmes à l'aide d'un maître queux de profession. L'on dit couramment d'une cérémonie de cette classe qu'elle comprend tel nombre de « festins », le mot « festin » ne s'appliquant pas à un seul individu, ainsi qu'on pourrait le supposer, mais au groupe de convives qui viendront prendre place autour d'une table. Groupe à nombre naturellement variable suivant les localités. Parfois il est de huit et l'expression « huit tables de fées » sert à désigner les articles alimentaires demandés dans ce but.

Ces tables ont partout les mêmes dimensions, mais dans certains endroits l'un des grands côtés du rectangle n'est pas occupé afin de faciliter le service et un « festin » n'indique alors que six convives. Lorsque les « festins » sont servis d'après un contrat passé d'avance, la convention comporte des serviteurs qui présentent les plats et touchent à la fin de la fête une petite gratification. 


\section{La vie des paysans chinois}

Le nombre des familles en situation de s'accorder de pareilles facilités de service est relativement minime par rapport à toutes celles qui sont obligées de préparer des festins de noces ou de funérailles. Lorsqu'elles n'ont pas cette ressource à leur disposition, il n'y a d'autre moyen que de remettre l'ordonnance du banquet entre les mains de certains individus experts en la matière, classe de gens qui se trouve partout. Chaque village ou groupe de villages peut toujours fournir un cuisinier de métier qui s'est spécialisé dans ce genre de festins. S'il jouit d'une haute réputation professionnelle et s'il est employé par des familles riches, il se fait accompagner d'une équipe d'aides et de marmitons qui travaillent sous sa direction : tous recevront à la fin des gratifications convenables.

Le personnel auquel est confiée l'organisation d'un festin se divise en trois services : les maîtres d'hôtel - chih fang, - le département culinaire - chu fang - et le département des finances - chang fang. Chacun d'eux sert de frein pour les deux autres ; mais dans les entreprises de mince envergure et peu dispendieuses, ces trois comités se fondent en un seul sous la direction d'un chef unique. Les maîtres d'hôtel achètent les provisions qu'ils estiment nécessaires et choisissent ce qu'ils trouvent de mieux sur le marché local.

Dans la région septentrionale de la Chine, les articles les plus chers sont les gâteaux de froment - mant'ou - et le vin. Si la distribution intérieure du logis le permet, l'on dépose les provisions destinées au festin dans des locaux séparés sous la responsabilité exclusive de l'un des maîtres d'hôtel : c'est 


\section{La vie des paysans chinois}

seulement sur son ordre exprès que I'on passe au cuisinier les fournitures dont il a besoin. Mais, dans la pratique, ces opérations donnent toujours prise à un sérieux coulage, car un grand nombre des parents et des voisins de la famille qui offre la fête envoient leurs enfants marauder autour de la chambre aux provisions où ils trouvent moyen « d'emprunter » quelques gâteaux de froment ou des verres de vin. Si le maître d'hôtel refuse - ainsi que le ferait sans aucun doute un étranger - il encourra la mauvaise humeur des gens qui désirent « emprunter » et, finalement, ce gardien trop zélé ne récoltera que des injures, chose qu'aucun Chinois ne trouve de son goût. En pratique il est donc admis de « donner à celui qui demande » et de ne pas se détourner de qui voudrait « emprunter » même si, comme l'assure un vieil aphorisme anglais, « de longues lanières sont coupées dans le cuir des autres personnes ».

Il arrive souvent que les maîtres d'hôtel chargés de la réception des approvisionnements fument l'opium : en pareil cas les dépenses ne peuvent qu'augmenter. Dans certaines régions, il est également passé dans les usages de mettre de l'opium à la disposition des invités, générosité qui entraîne de nombreux abus. De plus, un homme qui fume la drogue se trouve naturellement incapable de veiller avec soin sur les provisions confiées à sa garde. S'il est fumeur et si l'opium fait partie des articles fournis pour le repas de noce, tous les camarades adonnés au même vice profiteront de la circonstance et lui rendront visite : bien entendu on leur offrira une pipe aux frais du patron. Le vin, les gâteaux de froment disparaissent, en de pareilles fêtes, avant même que I'on ait déposé devant un invité 


\section{La vie des paysans chinois}

le premier bol de vivres : I'on dirait de l'eau qui s'évapore par une chaude journée d'été. L'auteur de ce livre a entendu raconter qu'à l'occasion d'un enterrement dans une famille du voisinage, six « catty » de vin environ disparurent sans laisser de traces.

De pareils incidents, connus de tous, ne proviennent pas de l'incapacité des maîtres d'hôtel à exercer leurs fonctions, pas plus que de leur indifférence à sauvegarder les intérêts des gens qui les emploient. La raison est tout autre. En effet, chaque famille à même d'offrir de grandes fêtes est entourée d'une multitude de parents pauvres qui, n'ayant aucune autre occasion de profiter de leurs belles alliances, entendent bien ne pas être oubliés sur la liste des invités. Une famille dans la gêne, qui porte le même surnom que I'hôte, se tiendra, bols en mains, à la porte de la maison où se prépare une cérémonie et réclamera sa part des bonnes choses qui vont être servies aux convives. $\mathrm{Si}$, par extraordinaire, le maître de maison refuse catégoriquement d'y consentir et que les maîtres d'hôtel exécutent ses ordres à la lettre, cela ne servira à rien, car la famille pauvre se livrera alors à des manifestations tapageuses, au point de jeter le trouble dans les réjouissances et tous les invités, prenant son parti, exhorteront l'hôte à se montrer plus accommodant.

La coutume de lever un tribut sur les assistants en état de le payer est, ainsi que nous l'avons déjà fait remarquer, profondément enracinée chez les Chinois. L'on se rendra compte jusqu'où peut mener cette pratique en lisant l'incident suivant, cas sérieux raconté à l'auteur de ce livre par celui qui en souffrit 


\section{La vie des paysans chinois}

le plus. Un homme eut une discussion avec I'un de ses oncles au sujet d'un arbre qui ne valait certainement pas plus d'un dollar. D'une insigne faiblesse de caractère et incapable de faire valoir ses droits, il dut «avaler la perte ». Sa femme en conçut une si violente irritation qu'elle se pendit. Il ne restait au mari d'autre issue que d'entamer des poursuites en accusant l'autre partie « d'avoir harcelé sa femme au point que mort s'ensuivit » ( $p i$ ssû). Ce procédé eût peut-être réussi si les « prêcheurs de paix » n'étaient intervenus afin de persuader au pauvre veuf de transiger contre une somme d'argent. L'adversaire avait comme conseil un de ses parents, avocat très retors, fort connu pour ses escroqueries. Cependant, malgré toutes ses roueries, les experts chargés de régler le litige, décidèrent que l'oncle verserait 30.000 cash à la famille de la femme comme contribution aux frais des funérailles. Et ainsi fut fait.

Il n'est pas dans les usages de donner grand éclat aux enterrements des suicidés, à moins que la somme nécessaire pour rehausser la cérémonie ne soit extorquée aux gens supposés avoir poussé la victime à se donner la mort. Dans le cas que nous venons de citer, la moitié de l'argent versé aurait suffi amplement pour des funérailles convenables. Les « amis de la famille » du mari, les oncles, les cousins, les neveux, etc., se chargèrent des démarches qu'ils firent traîner pendant plus d'une semaine, et lorsque les cérémonies funèbres eurent pris fin, le mari, dont les récoltes de l'année avaient été détruites par des inondations, constata que, grâce aux « amis de la famille », non seulement ces 30.000 cash étaient engloutis, mais qu'il lui restait en plus une dette criarde de 20.000 autres cash. Celle-ci 


\section{La vie des paysans chinois}

provenait des gâteaux de froment et du vin consommés par les « amis de la famille », - comme ils le prétendirent - au cours des interminables négociations. L'on ne put jamais tirer au clair ces dépenses : la seule chose dont l'infortuné veuf ne pouvait pas douter, c'est que les « amis de la famille » l'avaient pour ainsi dire ruiné.

Tout Chinois admet comme chose très naturelle qu'une famille assez riche pour supporter les frais de coûteuses funérailles à la mort d'un parent, sera impitoyablement pillée à cette occasion. La raison en est que le maître de maison, déprimé par le chagrin - du moins en théorie - et les convenances exigeant qu'il ne s'occupe de rien à ce moment-là, tout son temps devra être exclusivement consacré à l'accomplissement des rites funéraires. Même s'apercevrait-il que tout va à la débandade chez lui, il faut qu'il se comporte comme s'il était sourd, aveugle et muet. Une longue pratique a rendu les Chinois très habiles dans ce genre de dissimulation : inutile de faire observer qu'il serait très difficile, ou même impossible, à un Occidental d'agir de la sorte. Lorsque le chef de famille est, pour une raison quelconque, généralement peu aimé, il sera dans l'occurrence encore plus saigné à blanc, ainsi que le montrera I'histoire suivante, racontée à l'auteur par un Chinois qui habitait à 2 milles du village dans lequel se déroulèrent ces faits.

Un homme riche qui avait perdu son père se prépara à lui faire de somptueuses funérailles. Il plaça cent cordons de cash dans un grand chariot de ferme et se rendit au marché pour y acheter quelques porcs destinés au festin. En route, une bande 


\section{La vie des paysans chinois}

de ses propres parents le guettant au passage, le dépouilla de tout son argent, et cela de telle façon qu'il n'eut plus aucun espoir de le recouvrer.

La victime n'en acheta pas moins quatre porcs et même un bœuf, se montrant ainsi particulièrement généreux pour ses invités. Suivant l'usage, des tsung-li - agents spéciaux - se chargèrent de faire les arrangements nécessaires, mais ils furent incapables d'empêcher les raids entrepris par des «amis», des voisins, etc., pour s'emparer des provisions et, la veille de l'enterrement, des voleurs ayant fait irruption dans les locaux où se trouvaient les victuailles, emportèrent jusqu'au moindre article comestible : il ne resta rien des vivres destinés au festin. Les agents, pris de peur, se hâtèrent de fuir. Le repas, et pour cause, ne se composa que de légumes, ce dont le maître de maison ressentit une grande honte. Il n'osa plus préparer de nouvelles funérailles et, depuis lors, deux cercueils gisent à découvert dans sa propriété. Ils attendent d'être ensevelis ; peut-être attendront-ils jusqu'à la génération suivante !

Une fois toutes les «parts » remises et le total fait, l'on apprend alors pour quelle somme I'hôte y est de sa poche. Loin d'en faire mystère, les invités sont tout de suite avertis du montant de la somme et si celle-ci est forte, l'honneur en rejaillit sur le maître du logis qui acquiert ainsi la réputation de bien faire les choses sans regarder à la dépense. Un pareil renom le rehausse auprès des voisins, genre de prestige particulièrement prisé. Chez les familles pauvres où la « face »n'a pas autant d'importance que le cash, l'on voit souvent les festins établis sur 


\section{La vie des paysans chinois}

un tel pied de parcimonie que le coût en est insignifiant, bien que le nombre des « parts » soit aussi considérable qu'aux réceptions plus luxueuses. Il arrive parfois qu'une famille réussit à restreindre ses dépenses au point qu'elles sont couvertes par les contributions dont le total laisse même un bénéfice. L'homme qui mène à bien une pareille opération est jugé digne d'une certaine admiration, et non sans raison, car cet exploit implique une tactique qui n'est pas ordinaire.

L'organisation des équipes chargées de transporter un cercueil de dimensions spécifiées illustre également la manière dont sont appliqués les principes coopératifs. Chaque groupe s'avance sous la direction de son chef. Lorsqu'un enterrement doit avoir lieu, le chef de la brigade de porteurs dont c'est le tour de marcher en est avisé, celui-ci prévient ses hommes et si l'un d'eux ne répond pas immédiatement à l'appel, il s'expose à une amende.

Dans les districts ruraux le catafalque, avec son attirail compliqué de perches laquées qui servent à le porter, est souvent la propriété d'un groupe de fermiers habitant la localité. Convoqués pour assurer les funérailles, ils accomplissent parfois ce service à titre gracieux s'il s'agit de leurs concitoyens, mais ils font payer la location du matériel qui représente dans certains cas une mise de fonds très importante. Les sièges pour les noces se louent de la même façon. Les capitaux engagés dans l'acquisition de toutes ces fournitures sont d'un excellent rapport ; mais les sommes à débourser dépassant en général les possibilités d'un seul individu, c'est une collectivité plus ou moins nombreuse qui engage l'opération : ses membres reçoivent un 


\section{La vie des paysans chinois}

léger dividende sur le cash déboursé ainsi que quelques allocations en vivres, en cadeaux, etc., pour le travail manuel qu'ils ont fourni.

Le principe de la coopération peut se développer à l'infini. L'auteur de ce livre habita pendant quelque temps un village dans lequel fonctionnait une «société de bols»: elle en possédait de 100 à 200 qu'elle louait aux particuliers à l'occasion de festins et dont elle tirait ainsi un joli revenu. Le maître de maison y trouvait également son compte puisque cette faculté de location lui évitait les dépenses d'achat d'un matériel considérable, sans utilité dans le courant ordinaire de sa vie familiale.

Les sociétés créées pour venir en aide aux familles à l'occasion de funérailles existent en grand nombre et procèdent suivant des modalités diverses. Une raison spéciale détermine le fonctionnement de ces organisations appelées pai shê. En effet, alors qu'une noce peut être retardée jusqu'à ce que I'on ait terminé tous les arrangements nécessaires, il est généralement difficile, sinon impossible, d'agir de même pour des funérailles.

Parfois les familles qui font partie de la société versent à sa caisse une cotisation mensuelle de 100 cash. Chacune d'elles possède ainsi le droit - en cas de décès de l'un de ses membres adultes (ou peut-être seulement de la génération la plus ancienne) - de puiser dans ce fonds 6.000 cash, par exemple qui défraieront les dépenses. Si la réserve ne contient pas la somme suffisante pour payer le cérémonial prévu en cas de mort dans la famille de l'un des membres de l'association, le déficit 


\section{La vie des paysans chinois}

est comblé par une taxe spéciale imposée à chacun des sociétaires. En conséquence de ces dispositions, tout souscripteur qui, pendant une période de cinq années, n'aurait pas eu à faire appel à cette caisse, se trouverait dans la situation de I'individu qui alimente une cagnotte sans jamais recevoir quelque chose en retour. L'on est sans doute poussé à entrer dans ces sortes de sociétés d'assurances en raison des difficultés sérieuses qu'éprouvent les familles chinoises à se procurer d'un seul coup de l'argent comptant. Au point de vue financier I'on ne tire peut-être aucun avantage de ces contributions mais, dans la pratique, il est plus facile d'ôter chaque mois de sa bourse une centaine de cash que d'en trouver d'emblée 6.000 à un moment donné.

Voici une autre forme d'aide mutuelle pour les frais de funérailles. Un homme, dont les parents sont déjà d'un âge avancé, n'ignore pas qu'un jour ou l'autre il devra parer aux frais de leurs funérailles et débourser une somme qu'il lui sera peutêtre difficile de se procurer instantanément. En conséquence il « invite une association » - ch'inghui - dont chaque membre s'engage à contribuer aux funérailles d'un parent pour 2.000 cash par exemple. Les participants seront exclusivement choisis dans les familles qui ont des ascendants âgés. Leur nombre pourra s'élever jusqu'à 40 et les fonds en réserve atteindront de la sorte 80.000 cash, somme au moyen de laquelle un Chinois peut s'offrir des funérailles somptueuses. La coutume est de spécifier dans le contrat signé par tous les sociétaires que les dépenses ne dépasseront pas un chiffre fixé à l'avance et que, 


\section{La vie des paysans chinois}

d'autre part, les fonds en caisse ne pourront être utilisés que pour des enterrements.

Lorsqu'un membre désire, à l'occasion d'un décès dans sa famille, puiser dans la caisse commune, il lui faut d'abord trouver deux cautions garantissant qu'il continuera à payer sa cotisation, car sa carence pourrait laisser dans l'embarras les autres souscripteurs. Seules les personnes que I'on sait en état de faire face à cette charge pécuniaire ont quelque chance de pouvoir entrer dans l'association et si, pour une raison ou une autre, un membre vient à défaillir, il sera frappé d'une forte amende.

Tous les sociétaires doivent assister d'office aux funérailles d'un de leurs collègues, mais ils ne sont pas tenus de contribuer aux dépenses autrement que par les 2.000 cash de leur cotisation réglementaire. Chacun d'eux se présente en costume de deuil, il pousse des gémissements comme s'il était l'un des proches parents du défunt. La présence d'un si grand nombre de personnes venant s'ajouter au cortège des membres de la famille donne beaucoup de «face » à l'individu qui vient de perdre l'un des siens, et cet aspect de l'affaire est peut-être un stimulant aussi actif que l'assurance d'une aide financière.

Lorsque, pendant un certain temps, aucun décès ne survient dans les familles ayant souscrit aux fonds funéraires, I'on jugera peut-être bon de convoquer les membres de la société à un festin et de profiter de la circonstance pour risquer un appel de fonds, ceci en vue d'une participation destinée aux frais d'un mariage ou de quelque autre cas en dehors des buts statutaires 


\section{La vie des paysans chinois}

de la société. Pour lancer une affaire de cette nature, le festin est l'accompagnement indispensable des pourparlers : sans victuailles rien ne peut commencer, rien ne peut se terminer.

Le plus grand nombre des sociétés de ce genre visent beaucoup plus les funérailles que les mariages, cependant il en existe quelques-unes qui s'appliquent également à ces derniers. Ainsi une famille désire célébrer le mariage d'un fils avec une pompe très au-dessus des ressources dont elle dispose : elle recourt aussitôt à un expédient dénommé « attirer des amis au moyen d'autres amis ». Supposons que I'on veuille trouver 100.000 cash. Aussitôt préparation d'une centaine de cartes d'invitation dont dix seront envoyées à dix amis de la famille qu'on invitera à un festin préliminaire. Ces amis reçoivent des cartes supplémentaires et chacun d'eux en remet une à neuf autres de ses «amis » qui consentent à assister au mariage en question et à donner chacun, pour leur part, un cordon de cash. De la sorte, une famille peu fortunée et à relations restreintes est à même de se trouver du jour au lendemain en état de se pavaner à un mariage qui comptera une centaine d'invités dont beaucoup d'ailleurs ne connaissent pas leurs hôtes - et la libérale contribution des «amis » et des «amis des amis 》 pourvoira aux dépenses de la fête.

Le seul mobile qui pousse les « amis » à ce geste généreux, c'est l'amitié et aussi la perspective de déguster un festin de noces. Ces deux considérations expliquent également la générosité des «amis des amis ». Inutile de faire observer que les 100.000 cash si rapidement cueillis sont en réalité une dette 


\section{La vie des paysans chinois}

d'honneur que la famille, aujourd'hui bénéficiaire, devra revaloir aux donateurs par de futures contributions du même genre.

Un Occidental jugera sans doute absurde de faire endosser à toute une famille une responsabilité de ce genre, simplement pour étaler quelque faste passager. Il est vrai que l'amour de la parade n'est pas seulement l'apanage de la race chinoise, bien qu'elle trouve à certaines de ces manifestations des satisfactions qui n'auraient pour nous aucun attrait. Les Jaunes se caractérisent dans la conduite de leurs affaires par un penchant irrésistible à tirer de lourdes traites sur l'avenir afin de satisfaire aux besoins du moment. Plus d'une famille vendra la totalité de ses terres et abattra même sa maison afin de pourvoir aux funérailles d'un parent : enterrer un mort sans une pompe convenable serait perdre sa «face ». Et cette façon irrationnelle de procéder s'exécute avec un air de bonne humeur, comme si I'on avait conscience de sa vertu, et qui semble dire : Regardezmoi bien ! Je fais ce qui se doit, quelles qu'en soient les conséquences!

L'on peut évaluer à peu près d'avance l'ordonnance compliquée du cérémonial funéraire en calculant le produit de deux facteurs : I'âge du défunt (et plus spécialement le rang qu'il occupe dans l'échelle des générations encore vivantes) et la situation sociale de la famille. Dès le décès, les pleurs commencent à couler et l'on se rend tout de suite, ou au coucher du soleil, dans le temple du dieu local pour lui faire part de la fin, toujours avec accompagnement de pleurs. Des rites de ce genre se renouvellent le «troisième jour » qui, dans certaines régions, 


\section{La vie des paysans chinois}

est en réalité le deuxième, bien qu'il soit tenu pour le « troisième »! Pour peu que la famille exige un grand cérémonial, on célèbrera des solennités spéciales tous les 7 jours, c'est-à-dire 7 fois, puisque l'enterrement n'a lieu que le $49^{\mathrm{e}}$ jour. On peut voir dans ces détails une survivance bizarre de la divisibilité par 7 du mois lunaire. Dans ce long intervalle, il n'y a plus de repos pour la famille éplorée. Peut-être des prêtres bouddhistes chanteront-ils, en même temps que des prêtres taoïstes, leurs Livres Sacrés dans des pavillons improvisés

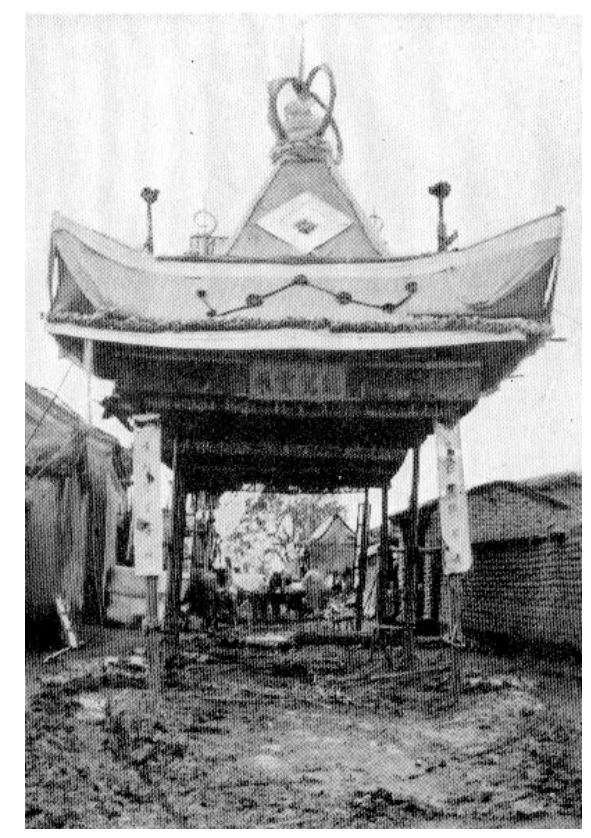

Pavillon funéraire provisoire

couverts de nattes aux colorations criardes ; car l'on considère souvent plus prudent, étant donné l'incertitude qui plane sur la meilleure voie à suivre pour parvenir aux régions bienheureuses, de se frayer un passage par ces deux chemins de la religion. Une musique insupportable à des oreilles étrangères déchire l'air du matin au soir et des bombes détonent à intervalles rapprochés afin de terrifier les esprits malins, au plus grand amusement des 


\section{La vie des paysans chinois}

garçons du village qui ne se tiennent pas de joie pendant toute cette période funèbre.

On a parfois reproché aux peuples de langue anglaise de prendre leurs plaisirs tristement. Les Chinois, au contraire, trouvent souvent le moyen de se divertir pendant la période de deuil. Ils n'ont en aucune autre circonstance mondaine I'occasion de s'asseoir à des tables aussi copieusement servies et dans des conditions si faciles. L'adage dit, et c'est vrai, que :

Lorsque meurent les vieilles gens, les survivants se nourrissent bien.

Grand est l'affairement dans cet étroit espace d'une cour ou même d'une suite de cours, quand il faut préparer d'un seul coup les aliments pour des invités qui se comptent souvent par centaines. Cependant tous se résignent sans peine à l'inévitable entassement, à l'attente, au tumulte, au manque de confort, toutes incommodités que l'on subit sans irritation et sans proférer la dixième partie des plaintes qu'exhaleraient certainement les lecteurs de ces lignes s'ils devaient supporter la dixième partie des mêmes ennuis. En Chine, il n'existe et n'a jamais existé d'autre manière d'enterrer les morts. La pompe, c'est la vie même de la race chinoise et, en nulle occasion, le cérémonial n'est aussi triomphalement tyrannique que lors des funérailles. Pourtant, au faste le plus éclatant se mêle souvent un élément d'inexprimable mesquinerie. En effet, dans ces cortèges qui se déroulent le long des rues d'une ville, l'on portera en grand nombre devant et derrière le cercueil des bannières, drapeaux, parasols, écrans, belles tablettes de bois 


\section{La vie des paysans chinois}

reluisantes de laque, aux dorures éblouissantes, mais ceux qui les porteront seront fréquemment des mendiants minables, sales, déguenillés, s'avançant en désordre. Cette pompe ne se voit pas dans les districts ruraux, quoique la confusion et le désordre soient partout omnipotents et inévitables. La langue chinoise ne possède aucune expression correspondant au mot solennel, car il n'existe rien qui ressemble, dans l'Empire chinois, à ce que nous appelons de la solennité lors d'une cérémonie.

Le blanc étant la couleur de deuil, des foules de gens, quand ils assistent à un enterrement, portent, les uns un simple bandeau blanc autour de la tête, d'autres un bonnet carré tandis que d'autres encore font étalage de vêtements de teinte protocolaire. Quant aux parents les plus proches du défunt, ils

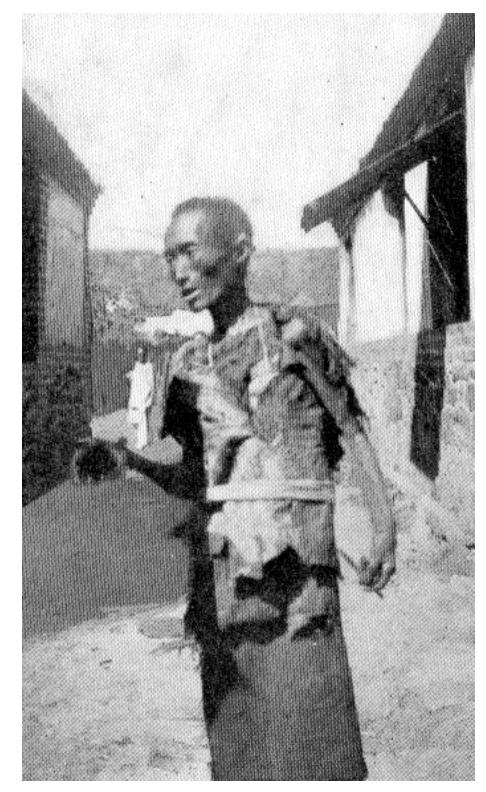

Une plaie de la Chine : le mendiant

doivent s'enfouir sous un tissu grossier, témoignage de la douleur la plus profonde, leurs pas chancelants sont soutenus par une courte canne de saule sur laquelle ils s'appuient avec ostentation, tout particulièrement aux nombreux moments où les 


\section{La vie des paysans chinois}

gémissements doivent redoubler d'intensité. En général les gens vêtus de blanc appartiennent à l'un des « cinq degrés de parenté »-wu fu - c'est-à-dire les descendants en ligne directe du grand-père de son grand-père. En chinois, ces degrés sont indiqués pour chaque génération par des noms particuliers, à savoir kao, tsêng, tsu, fu et shên, c'est-à-dire trois générations de « grands-pères », mon père et moi-même. La famille en deuil fournit des étoffes à la nuée de gens également en deuil, mais quand les filles mariées reçoivent aussi de la famille du mari une provision de tissus, il faut y voir une marque d'honneur toute spéciale. Parfois des femmes défilent portant orgueilleusement un énorme ballot d'étoffes, charge bien inutile, qui témoigne cependant devant le public que leurs maris ou leurs beaux-pères ont agi correctement et donné ainsi à la belle-fille une forte dose de « face .

Les sépultures de famille se trouvent généralement au milieu des champs cultivés. Dès lors, si un enterrement a lieu au printemps ou au début de l'été, I'on ne peut éviter que le piétinement de tant de personnes cause de grands dommages aux récoltes en pleine pousse. Les porteurs du catafalque auraient besoin d'une piste large de vingt pieds pour pouvoir avancer ; de plus, si la cérémonie est importante, le cortège des assistants sera suivi d'une foule très dense. Les malheureux propriétaires des terrains adjacents se postent parfois sur le bord de leur bien et, munis de pelles, ils lancent en l'air et sans répit de la terre afin que celle-ci retombe sur la tête des gens qui écrasent leurs cultures : et cela en signe de protestation - futile 


\section{La vie des paysans chinois}

comme toute protestation chinoise - contre la violation de leurs droits.

Des paroles de colère, des injures sont souvent I'accompagnement des funérailles chinoises, pour peu que la provocation soit par trop irritante et difficile à supporter. Intervenir dans un enterrement constitue une offense grave envers la famille du défunt, mais il s'élève aussi parfois des disputes, même parmi ceux qui participent à la cérémonie. L'auteur de ce livre vit une fois un cercueil qui resta abandonné pendant plusieurs jours au bord d'une route parce que les porteurs de deux défunts qui devaient être enterrés ensemble n'étaient pas d'accord sur l'ordre de préséance de leurs charges respectives lorsqu'elles quitteraient le village. Le différend se termina par une rixe ; un procès s'ensuivit pendant lequel l'on n'eut pas le droit de déplacer le mort.

Le moment où, les interminables festins enfin terminés, I'on crie : «Enlevez le cercueil ! » est le point culminant de la cérémonie. Seize porteurs - ou un multiple de seize (plus il y en a mieux cela vaut) - s'efforcent de soulever le pesant cercueil et l'immense catafalque qui le supporte. Seuls les porteurs en tête peuvent voir où ils posent les pieds, de sorte qu'il faut un maître de cérémonies pour régler les mouvements de l'équipe; ce dernier s'en acquitte en poussant d'une voix de fausset des cris stridents qui se terminent par un hurlement plus perçant encore, assez semblable à celui du jaguar. Les clameurs sauvages mêlées aux gémissements ostentatoires des personnes en deuil que I'on a empilées dans une vraie caravane de chariots de 


\section{La vie des paysans chinois}

ferme, contribuent à produire un effet bien différent du recueillement qui, d'après nous, doit présider à une cérémonie de ce genre. Lorsque par une lente et pénible marche I'on est enfin arrivé au lieu de la sépulture, la descente du cercueil dans la tombe marque le dernier acte de nombreuses journées d'excitation. Les cris du maître de cérémonies deviennent cette fois de véritables hurlements, les répliques des assistants sont tumultueuses et discordantes, chacun les criant suivant son point de vue personnel, sans s'inquiéter le moins du monde de ce que pense ou clame son voisin. Ainsi, au milieu des explosions de pétards et de bombes, parmi les gémissements encore plus violents des parents affligés, les cris des porteurs et des fossoyeurs, le bourdonnement de spectateurs curieux, le Chinois est enfin déposé dans sa demeure dernière. 


\section{La vie des paysans chinois}

\section{XIX \\ LE JOUR DE L'AN.}

Si l'étranger qui a vécu assez longtemps en Chine pour en comprendre les phénomènes apparents sans cependant pouvoir encore en pénétrer les causes, voulait expliquer à quelqu'un moins au courant des us et coutumes des Célestes les traits principaux qui caractérisent chez eux le passage d'une année à I'autre, tels qu'ils apparaissent dans l'existence chinoise, il citerait non sans raison, une ou plusieurs des particularités suivantes :

Chaussons.

Les coutumes varient certainement d'une région à une autre de la Chine, mais il ne s'y trouve sans doute pas un seul coin dans lequel le chausson ou quelque pâtisserie similaire ne soit intimement associé au Jour de l'An au même titre que le plumpudding du Noël anglais ou la dinde rôtie du Thanksgiving Day de la Nouvelle-Angleterre. Comparé aux nations occidentales, bien faible est le nombre de Célestes qui ne soient pas obligés de pratiquer le renoncement soit dans la quantité, soit dans la qualité de leur nourriture ou plus souvent encore dans l'une et l'autre à la fois. Le régime alimentaire de la grande masse des gens est systématiquement et nécessairement fait d'abstinence. 


\section{La vie des paysans chinois}

Même parmi les familles de fermiers jouissant d'une aisance suffisante pour pouvoir s'offrir au cours de l'année entière une nourriture saine et abondante, nous n'en voyons pas souvent se permettre un tel luxe. Si même les doyens d'âge succombent à la tentation, les femmes et les enfants des générations suivantes n'y sont pas autorisés. Une économie atavique sur le chapitre de la nourriture est un trait chinois particulièrement marqué. L'expression « manger de bonnes choses » indique un mariage, un enterrement ou quelque autre occasion dans laquelle on ne peut se passer de «bonnes choses ». Manger des gâteaux ordinaires le Jour de I'An et devoir se priver de chaussons est considéré comme pire encore que de n'avoir pas de Jour de l'An du tout.

De plus, l'immense joie d'une famille devant la perspective des copieuses victuailles qu'elle va absorber le Jour de I'An, l'allégresse plus vive encore que chacun de ses membres apporte à dévorer toutes les bonnes choses qui s'offrent à lui, enfin la satisfaction à peine moins grande qu'il éprouve quand il se remémore chaque détail du menu une fois que la famille est de nouveau réduite à l'indigence habituelle, sont des traits caractéristiques pleins de suggestions et d'enseignements pour un Occidental. Celui-ci n'a-t-il pas habituellement une table si abondante que bien rarement il doit se préoccuper de calmer une faim vorace et que, vraisemblablement, il sera plus ennuyé que flatté d'être invité à un festin composé d'un nombre indéfini de plats ? L'imagination la plus fertile ne pourrait concevoir un Chinois qui partagerait cette manière de voir. Il y a donc bien des 


\section{La vie des paysans chinois}

raisons de placer le chausson au premier rang dans les rites de la nouvelle année chinoise.

Réunions de famille.

Aucun jour de fête en pays occidental ne peut se comparer, même de loin, au Jour de l'An chinois en ce qui concerne faculté de déplacement et puissance d'attraction. Nous tenons pour un événement théoriquement désirable et réellement utile qu'une famille réunisse tous les siens en certaines circonstances ; mais, à ce point de vue, nous sommes desservis par les exigences de nos vies. Nos familles se divisent et se dispersent, souvent jusqu'au bout du monde : un nouveau « home » ne tarde pas à se créer. Des familles entières ne peuvent se transporter à de longues distances, surtout dans les saisons inclémentes, et le plus souvent la maison qui les attire ne serait pas à même d'en hospitaliser tous les membres.

Mais en Chine la famille est sur place. Seuls sont absents les représentants du sexe fort ; et ils reviennent au logis ancestral avec l'instinct infaillible des oiseaux migrateurs qui savent retrouver leurs habitats méridionaux. Parfois de trop grandes distances s'opposent à ce retour annuel - tel le cas des innombrables shan-hsi dispersés dans tout I'Empire où ils se livrent au commerce de l'argent comme banquiers, prêteurs sur gages, etc. - ainsi que beaucoup de Chinois natifs des provinces du Nord qui vont « en dehors de la Grande Muraille », mais tous ils vivent dans l'espoir de revoir, au moins tous les trois ans, le 


\section{La vie des paysans chinois}

home familial et ils choisissent toujours la fin de l'année pour revenir.

Un chat claustré dans un grenier inconnu, un oiseau immobilisé par une aile cassée, un poisson hors de l'eau ne sont pas plus inquiets et malheureux que le Chinois moyen qui ne peut rentrer chez lui au moment du Jour de I'An. Non seulement il est privé de nombreuses satisfactions personnelles, mais il a en outre la certitude de se voir ridiculisé, et par les personnes avec lesquelles il est obligé de rester et par les gens de son propre village Iorsqu'il rentrera enfin chez lui. Le Chinois redoute le ridicule encore plus que la perte d'un bon repas, et l'on peut être bien certain qu'un Céleste ne saurait demeurer loin de son home au Jour de I'An à moins de circonstances exceptionnelles et indépendantes de sa volonté. Nous avons donc d'excellentes raisons de considérer ces réunions de famille comme l'un des traits caractéristiques du Jour de l'An chinois.

Vêtements neufs.

En jetant un coup d'œil, même superficiel, sur les habitants des villes et des villages pendant la période qui s'écoule entre le premier jour de la première lune et le quinzième jour de cette même lune, l'étranger sera frappé du déploiement de vêtements neufs aux couleurs éclatantes sous lesquels se pavanent les gens. Les articles d'habillement, aussi bien ceux des hommes que des femmes, et encore plus ceux des enfants, se parent de toutes les couleurs de l'arc-en-ciel. Aux yeux de l'étranger, les 


\section{La vie des paysans chinois}

Chinois ne brillent pas par ce que nous appelons le bon goût ; parfois ils semblent vouloir égaler les divagations vestimentaires des sauvages africains, et ces extravagances ne se manifestent jamais avec plus d'intensité qu'à l'époque des vacances, période d'exhibitions. Des combinaisons de couleurs devant lesquelles une femme d'occident frissonnerait d'horreur se recommandent aux goûts des Chinois comme étant de bon ton et d'une grande correction. Du vert éclatant, du bleu, accompagnés d'un rouge violent, de pourpre, de violet et d'orange ne semblent pas «se tuer », ainsi que ne manqueraient pas de l'affirmer en frémissant nos couturières. Mais ce mélange de couleurs fait évidemment tant de plaisir à ceux qui s'en parent aussi bien qu'aux gens qui le contemplent que l'étranger le plus prévenu s'aperçoit bien que ses principes d'esthétique vestimentaire ne sauraient convenir ici. En raison de l'importance que les Chinois attachent à ce trait de leur grand anniversaire, nous nous croyons dans le vrai en disant que les beaux vêtements sont, eux aussi, l'une des caractéristiques du Jour de l'An.

Cérémonies religieuses.

Le premier aspect sous lequel se présente le nouvel An chinois, quel que soit le coin du monde où il nous arrive d'y assister, c'est le bruit. Toute la nuit l'on entend le vacarme, bang ! bang ! bang ! des pétards, petits et gros, qui, à l'exemple de tant d'autres calamités, viennent non pas discrètement, un par un, mais au grand jour, par bataillons. Cette fête tient 


\section{La vie des paysans chinois}

indubitablement à la religion par des attaches profondes, ainsi qu'il en est des cérémonies analogues dans le monde entier. Mais, quoique les explosions de poudre occupent une place d'honneur, elles sont loin de constituer l'acte le plus important, en ce qui concerne le culte du nouvel An : il y a le renvoi de celui qui fut le dieu de la cuisine pendant l'année écoulée, renvoi qui a généralement lieu le 23 de la douzième lune, et l'intronisation de son successeur. Le dernier soir de l'année, la famille se réunit, soit au temple ancestral, soit, à son défaut, dans le home familial pour l'adoration des tablettes appartenant aux générations antérieures. Dans certaines parties de la Chine, les tablettes ancestrales sont relativement rares chez les ouvriers et les gens de fermes. La veille de la nouvelle année, on les remplace, en ce qui concerne les manifestations pieuses, par un grand rouleau contenant une partie de la généalogie de la famille, rouleau qui sera suspendu au mur et qu'on honore en se prosternant devant lui et en brûlant de l'encens. Le matin du second jour de la première lune - peut-être aussi à d'autres moments - tous les hommes d'âge mûr se rendent à la sépulture de la famille ou du clan et y déposent les offrandes coutumières aux esprits des disparus. Les savants spécialisés dans les études chinoises ne sont pas d'accord sur la valeur véritable de ces rites au point de vue religieux, mais personne ne met en doute qu'ils constituent un élément essentiel de la célébration du nouvel An chinois et que, vu les dispositions d'esprit actuelles de la race jaune, un nouvel An sans pareils rites serait à la fois inconcevable et inadmissible. Nous sommes 


\section{La vie des paysans chinois}

donc justifiés de présenter les manifestations religieuses en bonne place dans notre exposé.

Cérémonies sociales.

Point n'est besoin d'être très au courant des faits pour constater qu'alors que les cérémonies destinées à honorer les morts, quelque importantes qu'elles soient, se liquident en bloc et n'entrent pas dans le cadre permanent du nouvel An, il en est tout autrement des cérémonies sociales se rapportant aux vivants. La coutume des visites de nouvel An, telles qu'elles se pratiquent dans certains pays occidentaux, n'est qu'une pâle parodie des usages chinois. Nous allons rendre visite à qui il nous plaît et à l'heure qui nous agrée. Les Chinois présentent leurs respects aux gens qu'ils doivent honorer, au moment où il est de leur devoir de le faire, et il est impossible d'y surseoir. Ainsi, afin de ne pas paraître généraliser des usages locaux variant d'après les régions, nous dirons qu'il est assez habituel que la maisonnée entière soit levée ce jour-là longtemps avant l'aube. Après que I'on a échangé les congratulations de famille, chacun, à l'exception de la génération masculine la plus âgée, va faire sa tournée dans le village : les représentants de chaque famille pénètrent dans la cour des autres maisons et se prosternent devant les vieillards restés chez eux pour les recevoir. Cette marque de respect se fait par priorité, c'est-à-dire par ancienneté sur la tablette généalogique, comme cela se pratique dans la marine et dans l'armée où les officiers prennent 


\section{La vie des paysans chinois}

rang d'après la date de leur nomination. Des mariages entre très jeunes enfants appartenant à une branche collatérale, des unions plus tardives parmi les membres d'autres branches, l'adoption d'héritiers à n'importe quel moment, et bien d'autres incidences encore ont pour conséquence courante que des hommes beaucoup plus âgés ne figurent pas à leur rang d'âge dans la liste de la génération à laquelle ils appartiennent. Ainsi nous assistons à l'absurde spectacle d'un homme de 70 ans qui est «le neveu », ou, dans un cas extrême, « le petit-fils » d'un simple jouvenceau. L'on entend souvent un homme d'âge mûr se plaindre des fatigues que lui impose le Jour de l'An car, se trouvant faire partie d'une «dernière génération », il est obligé de « se prosterner - « kotow » - devant chaque enfant long de deux pieds » qu'il rencontre, et qui est, en effet, « plus vieux » que lui ; en conséquence de cette intervention des « devoirs de parenté », les enfants sont frais comme une rose, tandis que I'homme d'âge mûr a les genoux courbaturés souvent pendant une ou deux semaines!

Si le premier jour est consacré aux devoirs à remplir dans la ville natale, les suivants sont employés aux visites de cérémonie chez des parents habitant d'autres villes ou villages. La série commence par la famille de la mère et s'étend jusqu'à des alliances dont peu d'étrangers pourraient se rappeler les noms et que la plupart, du reste, ne peuvent comprendre. De pareilles démonstrations familiales ont sans doute leur bon côté : elles empêchent bien des brouilles et, en maintes occasions, elles améliorent des rapports qui n'en sont encore qu'à leur premier degré de tension. Cependant une routine à ce point 


\section{La vie des paysans chinois}

cérémonieuse et monotone nous semblerait, à nous, insupportable.

Pour les Chinois, ces visites ne sont pas seulement I'un des rites importants du Jour de l'An, elles résument en réalité l'année nouvelle. Chacune d'elles comporte un « vrai repas » et, d'après le point de vue chinois, un peu de bon temps. Les négliger serait non seulement se priver de beaucoup de plaisir, mais on commettrait par cette omission un véritable crime social, omission que beaucoup de gens considéreraient comme une grave offense.

Loisirs du peuple.

A mesure que I'on pénètre plus avant dans les conditions et les détails de l'existence des Chinois, I'on s'étonne toujours davantage qu'un peuple si laborieux trouve le temps de se livrer à de pareilles bombances et au futile étalage de ses plaisirs. Mais nous cessons d'en être surpris lorsque nous avons bien saisi le fait que la race chinoise presque en entier s'est mise d'accord pour retrancher des douze mois de l'année toute une moitié de lune depuis le Jour de I'An jusqu'à la Fête des Lanternes afin de la consacrer à ses plaisirs. Pendant la $24^{e}$ partie de l'année, ce que I'on peut éviter de faire ne se fera pas. La perte en sera portée au compte des dépenses de l'année : ne s'agit-il pas avant tout de se donner du bon temps ! Cette période devient ainsi une soupape de sûreté pour le peuple chinois, lequel sans pareil dérivatif, risquerait de devenir fou à travailler sans répit 


\section{La vie des paysans chinois}

tout le long de l'année. Si le Chinois n'était pas, de façon générale, soumis à un labeur épuisant, ces longues vacances ne lui causeraient pas une aussi ardente satisfaction. Et s'il ne jouissait pas avec une telle allégresse de ces longues vacances, il ne pourrait pas travailler si bien pendant le reste de I'année. Par conséquent nous sommes autorisés, en dressant notre table des matières du nouvel An chinois, à donner une large place à cet arrêt presque complet des industries productives. C'est l'époque du loisir national.

Le jeu.

Une vieille maxime prétend que « Satan ne se trouve jamais à court de méchantes inventions s'il s'agit d'occuper les gens désœuvrés ». Il est certain qu'aucune race ne pourrait résister à la rupture d'équilibre que provoque la transition si brusque, de passer d'un labeur ininterrompu pendant presque toute une année, à un demi-mois d'une oisiveté absolue, puis de reprendre au bout de ce demi-mois la vieille routine, c'est-à-dire de longs mois d'esclavage. Une pareille tension physique amènerait une inéluctable réaction. Les Chinois n'y font pas exception. Il n'est pas dans la nature humaine de jouir de plaisirs dans l'ordre de ceux que nous venons d'indiquer sans désirer en augmenter la dose et obtenir encore plus de jouissances. Voilà précisément ce à quoi aspirent les Célestes et ils y réussissent par l'excitation que procure le jeu. Or le jeu et la fumerie d'opium sont les deux vices capitaux et la cause de tant de ruines en Chine. 


\section{La vie des paysans chinois}

Cependant, pour autant que nous en sachions, il semble qu'à prendre les districts dans leur ensemble, la proportion des joueurs parmi les classes laborieuses est en somme assez limitée, bien que de très grosses sommes soient dilapidées annuellement par cette passion du jeu. Chose curieuse, à l'époque de la nouvelle année toutes les restrictions paraissent abolies, et hommes et femmes se donnent entièrement à l'excitation absorbante des cartes, des dominos, etc. Les enjeux varient en importance et la crainte ou même la pensée d'une prochaine récolte pouvant être mauvaise n'effleure personne. En théorie, le jeu est évidemment, et de l'aveu unanime, une faute à laquelle nul ne doit s'abandonner, car elle ouvre la voie à bien des malheurs. Mais, au moment du Jour de I'An de pareilles considérations n'entrent pas en ligne de compte : « tout le monde joue », « ce n'est que pour s'amuser », d'ailleurs « il n'y a rien d'autre à faire ». Cette dernière allégation est à retenir à un moment où l'on prépare souvent d'avance, et autant que possible, jusqu'aux mets des repas. Les marchands ne baissent pas les volets de leurs devantures, mais l'on peut entendre les commis jouer bruyamment à l'intérieur. Les aubergistes s'abstiennent d'ouvrir leurs portes de devant tandis que patrons et serviteurs jouent tous ensemble; ils refusent même d'interrompre la partie pour donner la pâture aux bêtes de l'étable on servir un repas au passant. Ce n'est pas, déclarentils, le temps des voyages. Les affaires sont les affaires et les plaisirs sont les plaisirs ! 


\section{La vie des paysans chinois}

Jeunes et vieilles, accroupies sur leurs nattes ou sur le h'ang, battent fiévreusement les cartes et règlent leurs modestes différences. Elles se donnent toutes du bon temps.

Il est bien évident que cet état de choses ne cesse pas brusquement au lendemain de la Fête des Lanternes. Souvent il continue, prolongeant la voie qui aboutit à la ruine, ne s'arrêtant même pas à la tombe, car les conséquences s'en font parfois sentir jusqu'à la troisième ou quatrième génération. N'avonsnous donc pas raison de dire que le jeu constitue l'un des traits caractéristiques du Jour de l'An ? Et cependant, nous ne sommes peut-être pas allés jusqu'au fond de la question.

\section{Règlement des dettes.}

Pour aussi peu d'attention que prête l'étranger au calendrier chinois, les Célestes auront bien soin de lui rappeler que la fin de I'année approche et cela d'une manière qui ne lui permettra pas de I'oublier, longtemps même avant que l'aube du nouvel An pointe à I'horizon. A un moment quelconque de la douzième lune, le boy fait son apparition et, avec une animation qui tranche sur l'impassibilité ordinaire de son visage, il explique que, par suite d'un concours de circonstances que nous devons renoncer très vite à élucider, il se voit dans la nécessité de demander l'avance de ses gages du mois courant ainsi que ceux du mois suivant. 


\section{La vie des paysans chinois}

Cela peut être contraire à la règle, et c'est même plus que probable, mais en raison du concours de circonstances mentionné ci-dessus, il y a nécessité impérative si l'on veut éviter une ruine imminente. Un peu plus tard, le cuisinier présente une demande identique appuyée sur des raisons semblables, puis les divers coolies, jusqu'au dernier, en font autant. Dans chacun des cas I'on en arrive, après enquête, à reconnaître que la nécessité est si réelle et l'insistance sur le concours de circonstances si fortement étayée que nous nous trouvons en quelque sorte obligés d'aller à l'encontre de notre propre jugement afin de détourner la ruine immanente qui menace des gens à notre service et auxquels nous portons peutêtre quelque intérêt. Mais ce n'est que longtemps après qu'il nous vient à l'esprit d'approfondir la question, et nous constatons ce que tout le monde a toujours su, à savoir que le nouvel An chinois est précédé d'une période pendant laquelle chacun, sans exception, paie ses dettes, obligation à laquelle nul ne peut se soustraire. Si nous voulons absolument remonter par un examen minutieux jusqu'aux causes les plus lointaines d'un cas particulier, nous apprenons bientôt, de la bouche même des intéressés, certains faits qui semblent justifier leurs assertions, à savoir qu'il y a urgence, que tel ou tel cas n'est pas unique, mais que bien d'autres personnes se trouvent dans des situations analogues. Si I'on pousse encore plus loin les investigations et que l'on aille jusqu'au fond des choses, notre enquête mettra au

jour les sept péchés capitaux qui réagissent fâcheusement sur la manière dont les Chinois conduisent leurs opérations financières privées. 


\section{La vie des paysans chinois}

I. - Un Chinois a toujours besoin d'emprunter. - Que pour les affaires du monde on ait besoin, même dans les pays d'Occident, de recourir à l'argent des autres, que le crédit soit le plus grand moteur des affaires, nous ne l'ignorons pas. Mais la méthode d'emprunt, d'usage courant entre Chinois, est d'un type très différent de celui qui nous est devenu familier en raison de la grande expansion du commerce moderne. Nous n'irons pas jusqu'à prétendre qu'il n'existe pas de Chinois qui puisse se passer de recourir à l'argent du voisin pour faire marcher ses affaires, nous dirons simplement que de pareilles gens sont si rares qu'il n'y a pas lieu d'en tenir compte. L'existence des Chinois, leur système entier de gestion financière sont tels que la marge laissée aux disponibilités ou aux réserves est extrêmement étroite. $\mathrm{Vu}$ l'esprit pratique et l'habileté incomparable des Chinois dans leurs affaires, l'étranger s'étonne constamment que si peu d'entre eux aient de quoi faire face à une difficulté subite. Plusieurs causes y contribuent. D'abord, il est très difficile au Chinois d'accumuler des réserves, puis il n'a aucun moyen sûr de faire fructifier son argent. La caisse d'épargne n'existe pas en Chine et il n'y a pas de placements offrant quelque sécurité. La seule opération que I'on puisse risquer avec de l'argent comptant c'est de prêter des fonds à ceux qui en ont besoin, opération à laquelle le Céleste ne se résignera qu'avec répugnance : il craint, non sans raison, de ne jamais toucher ni intérêts ni capital. Lorsqu'il y a un mariage à célébrer dans une famille, celle-ci peut se trouver forcée d'emprunter pour les frais de la cérémonie; en cas de 


\section{La vie des paysans chinois}

funérailles, la nécessité en est plus impérative et plus urgente encore. Le Céleste a besoin d'argent pour débuter dans les affaires et il lui en faut aussi pour régler ses fins d'année. Car, si I'on doit ajouter foi à leurs propres comptes, neuf négociants chinois sur dix, qui débutent modestement trouvent toujours qu'ils « ont perdu de l'argent », alors qu'il faut souvent entendre par là que les bénéfices n'ont pas été aussi forts qu'ils I'espéraient. En résumé, il est difficile de rencontrer un Chinois auquel le prêt d'une somme d'argent à n'importe quel moment ne serait pas le bienvenu, tout comme de « l'eau à un poisson dans une mare desséchée ». Cette nécessité impérative chez tous les Jaunes, prépare « le sol au milieu duquel le puits doit être creusé ».

II. Chacun est obligé de prêter de l'argent. - Nous avons fait observer que tout homme qui a la bonne fortune de posséder quelques cash en réserve, n'aime pas à les prêter dans la crainte de ne jamais les revoir. Or il existe diverses méthodes et divers degrés de pression à l'aide desquels on peut agir sur un capitaliste. L'un d'eux est fondé sur la solidarité de la famille chinoise ou du clan. Si l'un de ses membres a de l'argent disponible et qu'un autre en ait un besoin particulièrement urgent, ce dernier obtiendra d'un représentant de la génération au-dessus de celle à laquelle appartient le capitaliste d'intercéder pour lui. On le fera à contre-cœur sans doute, mais la démarche sera certainement tentée. Si la pression de l'ancêtre est jugée suffisante, le rentier peut trouver bon de céder, bien qu'il s'y 


\section{La vie des paysans chinois}

décide souvent à l'encontre de sa propre opinion au point de vue financier. Le Chinois, depuis son enfance, n'est-il pas accoutumé à l'idée que I'on peut rarement faire en toutes choses ce que l'on veut, et que, lorsque I'on ne peut agir à son gré, il faut agir comme I'on y est forcé ! Pour peu que l'emprunteur n'appartienne pas à la même famille ou au même clan que le prêteur, la difficulté sera d'autant plus grande, mais I'on trouvera peut-être moyen de la surmonter à l'aide d'amis essayant du même genre de pression. Un homme en quête d'argent est souvent obligé à bien des « kotows » avant de pouvoir se procurer la faveur d'un prêt - à un taux du reste exorbitant, mais ce qui le soutient c'est la notion bien chinoise que toute demande qu'accompagnera un certain degré de pression doit être accordée, tout comme l'un des plateaux de la balance s'abaisse fatalement si vous y mettez des poids suffisants. Il arrive de la sorte que, parmi les Chinois, et quel que soit le rang social, l'homme qui possède est celui qui se contente de permettre au prochain de participer à sa richesse (pour une belle rémunération).

III.- En Chine, chaque personne pour ainsi dire doit de l'argent à quelqu'un. - Telle est la conséquence normale des considérations précédentes. Il n'existe pas de raison de demander à un Chinois s'il doit de l'argent. La formule qui convient en pareille circonstance est la suivante : «Combien devez-vous ? A qui ? Quel est le taux de l'intérêt ? » 


\section{La vie des paysans chinois}

IV. - Aucun Chinois ne paie comptant à moins d'y être contraint. - Pareilles mœurs nous paraissent incroyables; en Chine, elles ont presque force de loi. Des siècles d'expérience ont appris au Céleste qu'à peine emploie-t-il de l'argent à éteindre une dette, qu'il a besoin de cette même somme pour en liquider une autre. Pour s'exprimer dans sa langue imagée, on a besoin d'un verre d'eau en même temps à quatre ou cinq endroits et la provision d'eau est toujours aussi insuffisante qu'est la classique « coupe d'eau pour éteindre le feu dans une charretée de combustible ». Tout Chinois sait cela et il y songe avec une appréhension dont il nous est difficile d'apprécier l'intensité ; aussi se refuse-t-il énergiquement à lâcher son argent avant que sa bourse ne lui soit arrachée par une force supérieure à celle qu'il emploie pour la retenir.

V. - Aucun Chinois ne paie une dette à moins d'y être forcé par les tracasseries qu'on lui inflige. - Pareille pratique nous paraît également fort étrange. Nous avons grandi pour la plupart avec l'idée fixe que toute dette devant être remboursée, il est bon de s'en acquitter au plus vite. Le cerveau d'un Chinois travaille de tout autre manière. Voici son point de vue : «S'il faut y arriver, mieux vaut s'exécuter le plus tard possible. »

VI. - Aucun Chinois ne paiera ses dettes s'il n'y est brutalement invité un grand nombre de fois. - Telle est la 


\section{La vie des paysans chinois}

règle courante. Ici encore, nous sommes placés à des pôles opposés. Nous n'aimons pas à être importunés, aussi ferionsnous de grands sacrifices plutôt que de nous voir pourchassés par des gens dans le besoin qui nous réclament une créance que nous leur devons honnêtement et qu'il nous faudra toujours payer : le fait de ne pas s'arranger à payer sur-lechamp nous semble être plus ou moins une honte. Par « nous », il faut entendre naturellement la moyenne des étrangers, car on ne saurait oublier que les pays occidentaux sont infestés de gredins impudents et sans sou vaillant qui savent vivre de leurs dettes et volent qui ils peuvent. Mais le Chinois dont nous parlons n'a rien de commun avec cette catégorie d'aigrefins. A notre avis, la masse des Chinois est honnête, ils ont la ferme intention de payer tout ce qu'ils doivent, seulement aucun d'eux ne songe à s'exécuter avant qu'il ne se sente prêt à le faire, et ni les dieux ni les hommes ne sauraient dire à quel moment cette heure sonnera. Un dicton populaire assure que lorsque une personne a beaucoup de dettes, elle cesse de s'en préoccuper, tout comme l'individu couvert de parasites n'éprouve plus le besoin de se gratter.

VII. - Le Chinois qui paie une dette s'acquitte rarement du tout à la fois. - La coutume est presque générale. Le débiteur essaiera de trouver le reste de la somme à payer «le $3^{e}$, le $6^{e}$ mois » ou encore « à la fin de l'année ». Le résultat de ces trois dernières particularités, $c^{\prime}$ est que la $12^{\mathrm{e}}$ lune de l'année est 


\section{La vie des paysans chinois}

l'époque où règne dans tout l'Empire la plus grande activité. Que personne n'aille pourtant s'imaginer que l'on accomplit une somme énorme de travail : la réalité est tout autre. Et cela vous fait penser à la sorcière dans « Alice behind the Looking-Glass », où l'enfant est enlevée précipitamment sur un manche à balai, avec une vitesse telle qu'elle en perd le souffle. Elle croit parcourir des espaces infinis, mais lorsqu'elle fait part de cette impression à la sorcière, celle-ci se met à rire et lui répond que leur allure n'a rien d'anormal, car il faut qu'elles cheminent à cette vitesse vertigineuse si elles veulent « marcher de pair avec le cours des choses »; et que si elles tiennent vraiment à devancer le temps, il leur faudra encore accélérer énormément leur course ! Or les Chinois courent à bride abattue pendant ce dernier mois de la lune, parce que eux aussi veulent « aller de pair avec le cours des choses ». Chaque magasin, quelque insignifiant que soit son chiffre d'affaires, dépêche au dehors son armée de commis : ceux-ci présentent leurs créances aux débiteurs et tâchent de faire rentrer les fonds ; mais y réussir n'est pas chose facile. Si le débiteur est lui-même créancier de quelqu'un, il s'efforce aussi de récupérer son dû. Tout individu, pris isolément, est absorbé par le souci de donner la chasse aux gens qui lui doivent de l'argent et, pendant qu'il cherche à faire rendre gorge à un client, il essaye d'éviter la rencontre des personnes qui le poursuivent, lui, pour le faire tirer de sa bourse l'argent qu'il leur doit. Les subterfuges, les ruses auxquels chacun a recours se compliquent, s'accroissent à mesure que se rapproche la fin de l'année et, les derniers jours du mois, l'activité nationale devient absolument fiévreuse. Car toute 


\section{La vie des paysans chinois}

créance qui n'est pas rentrée avant le premier jour de l'an sera reportée à l'année suivante ; et que deviendra une réclamation qui a trouvé le moyen de flouer le jour annuel du jugement ! En dépit de l'excellente coutume qui fait d'une fin d'année le grand comptoir servant au règlement des dettes, la nature même du Jaune est réfractaire à tout ce qui est impératif et nombre de ces créances ajournées sont un souci constant pour plus d'un créancier chinois.

Les Chinois sont à la fois le peuple le plus pratique et le plus sentimental du monde entier. Le Jour de I'An ne saurait être profané par des tracasseries pour dettes, mais la créance n'en doit pas moins être acquittée en ce jour de liesse. C'est ainsi que I'on aperçoit souvent, dès l'aube, un créancier sortir de son logis d'un pas pressé, le premier jour de l'année : muni d'une lanterne, il cherche son débiteur. L'éclairage artificiel dont il s'accompagne indique, par une douce fiction, que le soleil n'est pas encore levé, que la journée d'hier n'a pas pris fin, et qu'il est encore temps de réclamer sa dette.

Appliquons les principes que nous venons d'énumérer à I'Empire tout entier et nous projetterons une nouvelle lumière sur la nature des fêtes du Jour de l'An chinois. La nation entre dans une période de réjouissances, mais personne n'en éprouve d'aussi vives que le débiteur aux abois lorsqu'il réussit, par d'habiles subterfuges, à éviter les plus impitoyables de ses créanciers et qu'il voit ainsi sa ruine différée d'une année au moins. Car une fois passée l'heure critique de la fin de l'année, le 


\section{La vie des paysans chinois}

débiteur vogue de nouveau sur des eaux paisibles que rien ne peut troubler.

Alors même que, le Jour de l'An, il se rencontrerait face à face avec ses créanciers, ceux-ci n'auraient plus le droit de faire allusion aux incidents de la veille, à la fuite honteuse du débiteur qui leur échappa, ni de glisser le moindre mot d'affaires. Ces reproches ne seraient plus de «bon ton » et pour les Chinois, le « bon ton » - autrement dit la coutume - est la première divinité nationale.

Les associations, dites «Sociétés de la Nouvelle Année », offrent un système ingénieux pour se procurer le résultat souhaité, c'est-à-dire assurer à une famille une provision de vivres suffisante pour bien traiter ses invités pendant les fêtes du nouvel An. Chacun de leurs membres fournit une contribution de quelques centaines, peut-être même d'un millier de cash, versés mensuellement pendant les cinq premiers mois de l'année, en réalité jusqu'à la moisson de juin, alors que le blé passe par ses cours les plus bas, par exemple 1.200 cash pour 100 catties. Pendant les cinq mois écoulés, les sommes fournies par les cotisations ont été placées et, en leur ajoutant les intérêts accumulés, on arrive à un total très intéressant. Dès que le nouveau blé apparaît sur le marché, tout l'argent placé rentre dans la caisse, puis, avec la somme entière appartenant à la société, le trésorier achète du grain. Il le conserve en magasin jusqu'à la fin de l'année, époque à laquelle le prix du blé a parfois doublé. Il l'échange alors, au cours du jour, contre des gâteaux de froment - man-t'ou - qui sont distribués aux 


\section{La vie des paysans chinois}

actionnaires. De cette façon chaque membre reçoit, non seulement sa part des bénéfices réalisés par le placement des fonds pendant cinq mois, mais en plus, près du double de la valeur du blé acheté au moment de la moisson. Parfois les versements mensuels se continuent jusqu'à la fin de l'année, et la somme recueillie est alors entièrement affectée à l'achat de gâteaux de froment, de blé, coton et tous autres articles que réclament les familles à l'occasion du nouvel An. Les sociétés de ce genre imposent le taux de 3 au moins, peut-être même de 4 , par mois. Les sommes ainsi prêtées sont généralement peu importantes pour chaque individu, tout emprunteur n'en doit pas moins offrir des garanties à la société. Si le remboursement n'a pas lieu à la date fixée, le créancier procède d'abord à l'intimidation en faisant un gros vacarme, puis, au besoin, il emploiera la force pour rentrer dans ses fonds. L'aléa qui partout et toujours accompagne fatalement la rentrée de tout prêt d'argent, confirme en Chine peut-être mieux qu'ailleurs, la sagesse du vieil adage : «plus grand est le profit, plus grand est le risque ».

Pour aussi usuraire que soit le taux habituel des intérêts en Chine - de 24 à 48 et plus, par an - il existe d'autres moyens permettant, mieux encore que les prêts directs, de récolter de gros profits. La passion du jeu semble empoisonner jusqu'aux dernières classes sociales; elle constitue peut-être l'obstacle le plus sérieux à la prospérité des gens de condition moyenne. Bien des singularités de la coopération chinoise sont la conséquence directe de pratiques de jeu dont les administrateurs tirent les plus grands profits. Partout où il y a de l'argent à prêter, il peut 


\section{La vie des paysans chinois}

être employé à des opérations de jeu par l'intermédiaire des tenanciers ou de certains banquiers. Ceux qui sont adonnés à ce vice ne s'arrêtent pas, même lorsqu'ils ont perdu toutes leurs disponibilités ; ils empruntent à une banque de prêts à des conditions fixées d'avance, mais variant dans la pratique suivant les circonstances. Dans un cas urgent, il peut arriver qu'un individu à court d'argent soit obligé de demander à la banque 800 cash par exemple, et cet emprunt, toujours à court terme, devra être réglé par un versement de 1.000 cash. Lorsque, à la fin de l'année, les comptes sont arrêtés et toutes les avances rentrées, le total disponible est réparti entre les actionnaires de la société, qu'ils aient eu, ou non, recours à ce capital pour jouer. Dans le cas où ayant eux-mêmes emprunté à la caisse, ils ne peuvent rembourser l'argent, ils perdent, pour compenser leur dette, la somme totale qu'ils ont engagée dans l'association. 


\section{La vie des paysans chinois}

\section{$\mathrm{XX}$ \\ LE MATAMORE.}

L'on ne saurait se faire une idée exacte de la vie des Chinois sans posséder quelques notions sur la place qu'y tient le matamore et, réciproquement, il ne semble pas exagéré de dire qu'une juste conception du caractère et du rôle de cet individu équivaut à une compréhension plus claire de la société chinoise.

Pour autant que nous en sachions, le matamore chinois est un personnage spécial à la Chine. Bien entendu l'on ne prétend pas par là que d'autres peuples n'ont pas ou n'ont pas eu toujours leurs fanfarons, nous voulons simplement dire que la manière dont le matamore chinois exerce son pouvoir est unique en son genre. Elle est surtout fonction de certaines caractéristiques de la race jaune amie par-dessus tout de la paix et répugnant à s'engager dans une querelle. Les traits distinctifs d'un fanfaron qui s'agite au milieu d'un peuple barbare et guerrier, tel que furent nos ancêtres, ou, au contraire, parmi des gens aussi paisibles que des Chinois, sont, dans leur essence même, différents.

Les Célestes disposent de plusieurs termes pour désigner l'individu que nous avons nommé un matamore : l'un d'eux est kuang-kun - littéralement «bâton nu » par allusion au fait que de pareilles gens n'ont, en général, rien à perdre. Mais cette qualification s'applique couramment à quiconque prétend en 


\section{La vie des paysans chinois}

jouer le rôle, quelle que soit sa condition sociale, et c'est dans ce sens que nous allons l'employer.

En considérant le rôle social du matamore, il est bon d'établir une distinction entre plusieurs catégories de personnes, il appartiendra peut-être à l'une d'elles, comme il pourrait aussi en différer tout à fait. Ce classement comporte quatre catégories : d'abord les notables du village, nous avons déjà vu qu'on les désigne sous plusieurs autres vocables ; $2^{\circ}$ les intermédiaires, non dans notre sens technique du mot, car je veux dire par là les gens qui, au titre de «pacificateurs », interviennent dans les affaires de leurs concitoyens $; 3^{\circ}$ les mendiants $; 4^{\circ}$ les voleurs.

En Chine, après la division des êtres en deux sexes, il existe une autre classification presque aussi importante et que le Chinois adopte en quelque sorte instinctivement. Elle consiste à coter tous les membres de la société d'après la manière dont probablement ils se comporteront si on les maltraite; tout comme le chimiste considère les corps d'après leurs affinités et leur propension à entrer en combinaison les uns avec les autres.

Dans le langage populaire, chaque villageois est ou n'est pas «lao-shih ». Ces deux caractères signifient « vieux » et « solide » et, par extension, aimable, maniable, d'où surgit une troisième signification, stupide et crédule. Pour souligner le plus haut degré de cette qualification, I'on emploiera la périphrase «ssû-lao-shih », littéralement l'être qui est incurablement stupide, celui auquel on peut en faire accroire au delà de toute limite. Un adage courant compare ce genre d'individus aux orteils des pieds d'une vieille femme lesquels ont été comprimés 


\section{La vie des paysans chinois}

pendant toute leur existence et ne peuvent plus revendiquer leurs droits naturels de supports.

Le matamore de village est simple, composé ou complexe. Le fanfaron simple est par lui-même une individualité ; il dirige personnellement ses affaires avec ses propres ressources. Le fanfaron composé appelle à son aide la puissance du nombre et ce talent de la combinaison, mystérieux, presque irrésistible, inhérent au caractère chinois. Le complexe n'est pas un simple matamore ; il a une profession ou dirige quelque affaire et, dans I'une comme dans l'autre de ces situations, la crainte qu'il inspire le seconde.

Sous sa forme la plus simple, le matamore chinois est un homme au caractère plus ou moins violent et aux passions fortes, bien résolu à ne jamais « avaler d'échec » et prêt en toute circonstance à rendre, en bien comme en mal, tout ce qu'il reçoit. Fort heureusement pour la paix sociale, l'énorme majorité des Chinois est lao-shih. Afin de s'assurer la réputation de ne pas être lao-shih, un villageois rusé adoptera parfois l'expédient - la Chine n'en a pas le monopole - de porter des vêtements négligés, mal ajustés, de parler fort, en s'irritant de la moindre contradiction ou en invectivant quiconque n'acquiesce pas immédiatement à sa manière de voir.

Il met avec intention sa casquette de travers, sa robe de dessus pend négligemment sur ses flancs au lieu d'être attachée avec recherche, les cheveux abondants tombent en une natte trop lâche aussi grosse que le bras ; elle ne commence qu'à plusieurs pouces du crâne et son extrémité est généralement 


\section{La vie des paysans chinois}

enroulée autour du cou ou sur le sommet de la tête - graves infractions à l'étiquette chinoise - comme pour montrer que son esprit batailleur cherche une querelle. Ses molletières seront sans doute peu serrées dans le haut afin de laisser apercevoir une doublure plus riche que l'extérieur ; enfin ses chaussures étaleront des talons usés, peut-être pour bien montrer le talon de soie brodée d'un bas de coton, trait prétentieux d'une splendeur affectée qui a pour but de frapper de respect le spectateur rustique. A l'époque où de prétendus enlèvements d'enfants soulevaient partout une violente agitation, nous apprîmes qu'un homme avait été appréhendé en plein tribunal et soupçonné d'être un mauvais sujet à cause de la couleur extraordinaire de ses vêtements.

En persistant dans cette façon d'agir, le matamore réussira probablement à donner partout l'impression qu'il est un être dangereux, qu'il vaut mieux par prudence ne pas s'immiscer dans ses affaires, et ainsi tout le monde le laissera tranquille. Un chat, même pourvu d'une faible expérience, hésitera avant d'essayer d'avaler un lézard. D'où il ressort que si un petit reptile est forcé de fréquenter des chats, l'art de se faire passer pour un lézard aura bien son prix. Le genre de matamore que nous venons de décrire est trop répandu dans toute la société chinoise pour attirer beaucoup l'attention et on peut l'éviter en le laissant tranquille. Ses armes, à l'exemple des murs d'enceinte des agglomérations chinoises, ne sont que défensives.

Bien plus à redouter est le matamore qui ne veut pas laisser ses concitoyens en paix et s'immisce toujours dans leurs affaires 


\section{La vie des paysans chinois}

avec le secret espoir d'en retirer quelque profit pour lui-même. Le plus à craindre des individus de cette espèce est celui qui fait peu de bruit, mais dont les interventions sont néfastes pour les gens auxquels il désire nuire, tel un chien qui mord sans montrer les dents.

La tactique qu'il adopte dans le but d'établir ses prétentions au rang de « roi du village » ne diffère guère de celle que nous ne connaissons que trop bien dans d'autres pays : notre civilisation, en dépit de ses progrès, n'a pas encore réussi à lui enlever toute efficacité. S'il ne voit pas le moyen de se livrer à quelque acte qui le mette en vue, il peut toujours chercher noise en injuriant quelqu'un, ce qui équivaut à jeter son gant comme défi. Ne pas répondre à une pareille provocation est, du point de vue chinois, chose presque impossible. Être injurié et n'en pas souffrir leur semble le comble de la honte. Rien de plus rare que de voir un Céleste, lorsqu'il a été injurié et qu'il est assez fort pour exiger des excuses, laisser tomber l'affaire.

Vu l'organisation compliquée de la société chinoise, bien des actes, tout en n'étant peut-être pas absolument hostiles, doivent être tenus pour une provocation. $\mathrm{Si}$, par exemple, un matamore a laissé répandre le bruit qu'il compte donner à l'automne suivant une représentation théâtrale dans son village, le fait que quelqu'un s'y oppose équivaudra à un acte d'hostilité à l'égal d'un défi. Dès lors, le matamore doit immédiatement engager une troupe d'acteurs, sinon il perd sa «face », ce qui ne lui arrivera jamais, on peut en être sûr, tant qu'il sera à même de l'empêcher. 


\section{La vie des paysans chinois}

Il plane toujours autour de ces fanfarons de village une atmosphère de menace comme s'ils avaient soif de trouver l'occasion de lancer un défi. Et c'est ce qu'ils font souvent d'une manière assez vague, mais dont le sens ne saurait échapper à personne. Si A est le matamore et qu'au vu et su de tout le monde, $B$ soit en concurrence avec $A$, celui-ci raconte à tous les échos que si $B$ se permet telle ou telle chose, il ne le supportera pas : pu suan t'a - littéralement « n'empêchera pas l'affaire » et, du même coup, il fera quelque louche allusion aux conséquences que $B$ pourrait avoir à supporter. Si B comprend à demi-mot et bat tranquillement en retraite, c'est la paix ; sinon ce sera la guerre.

La force physique, sans être absolument indispensable, assure au matamore de village de précieux avantages. Au nombre des titres qu'on lui donne nous avons cité celui de roi du village. Parmi les fanfarons dont la violence est le point fort, le roi devra jouir d'une supériorité musculaire incontestée, « être I'homme qui peut », car l'on ne saurait prévoir à quel moment il aura besoin de toute sa vigueur pour soutenir un combat.

C'est sous la hantise de ces considérations que les jeunes gens désireux de se distinguer devant leurs camarades étudient l'art du coup de pied et du coup de poing et s'adonnent à la gymnastique. Une supériorité dans la lutte corps à corps, une adresse particulière à arracher, d'un coup de poing bien asséné, une brique dans un mur d'un pied d'épaisseur, sont en maintes circonstances des talents précieux. 


\section{La vie des paysans chinois}

L'auteur connaît un jeune homme qui passait dans son village pour être le plus fort. Envoyé en course dans une ville éloignée, il dut traverser une petite localité située à 40 li de son home et où il n'était pas connu. Quelques bravaches du cru devisaient par hasard devant le yamen, quand frappés de son air rustaud, ils I'interpellèrent et lui demandèrent qui il était et où il allait. Ses réponses vagues ne les ayant pas satisfaits, plusieurs d'entre eux lui tombèrent dessus simultanément. Et c'est à ce momentlà que sa science du pied et du poing lui fut d'un grand secours. Bien qu'aux prises avec deux adversaires, il réussit à saisir la cheville de l'un d'eux et la tordit si violemment que la jointure se trouva presque disloquée, sur quoi ses assaillants, déjà tous mis à mal, ne furent que trop heureux d'abandonner la lutte. Plus tard, on s'occupa de l'incident et le groupe batailleur dut, en guise d'excuses, offrir un festin à son vainqueur. L'un d'eux clopinait encore douloureusement et il n'hésita pas à avouer qu'en cette affaire, il s'était trompé sur son homme !

Dans les nombreuses occasions où un matamore trouve moyen d'en imposer à certaines personnes qui ne sont pas de taille à se mesurer avec lui, celles-ci commenceront par se demander comment s'y prendre pour rassembler une bande d'hommes spécialisés dans la pratique de la boxe et la lancer sur l'agresseur afin de le terrasser. Un jour l'auteur rencontra un Chinois qui habitait un village coté comme le refuge d'un groupe de voleurs audacieux et sans scrupules. Dépouillé par ces malandrins et n'espérant obtenir aucune réparation par les moyens légaux, il rassembla une bande d'athlètes qui réussirent à attaquer les voleurs en dehors du village dont ils avaient fait 


\section{La vie des paysans chinois}

leur quartier général. Toute la bande reçut une telle correction qu'elle transporta aussitôt son centre d'opérations dans un autre endroit.

C'est un avantage pour le matamore, mais nullement une nécessité, que d'être pauvre, de n'avoir rien à perdre. La pauvreté est généralement en Chine synonyme d'une abjecte misère. Des multitudes de gens ont pour toute fortune cinq dollars à peine, et des milliers de personnes ne savent pas comment elles pourvoiront à leur prochain repas. En Europe ces miséreux constitueraient ce que I'on nomme les «classes dangereuses ». En Chine, à moins que leur détresse ne soit extrême, ils ne se groupent pas et ils livrent rarement bataille à la société. Mais parmi ces déshérités, ceux qui possèdent les talents requis peuvent devenir des « rois de village » et régler le cours des événements dans leur rayon d'action, à peu près au gré de leur volonté.

Les Chinois, dans leur langage imagé, les appellent les « hommes aux pieds nus » par allusion à leur dénûment ; I'on dit couramment que «I'homme aux pieds nus » - nommé aussi « jambes boueuses »- ne craint pas celui qui a des bas aux pieds, car le premier peut au besoin battre en retraite dans la boue, là où l'autre n'osera pas le suivre. En d'autres termes, « I'homme aux pieds nus » peut terroriser l'individu qui a des biens à perdre, par une menace de vengeance, ouverte ou déguisée, menace contre laquelle I'homme aisé n'a aucun moyen de se garer. 


\section{La vie des paysans chinois}

Les procédés à l'aide desquels s'exerce une vengeance varient avec les circonstances. L'un des plus courants est l'incendie par malveillance. Les villages à population dense où sont accumulés, en gros tas, des approvisionnements de combustible, se prêtent on ne peut mieux à ce mode d'attaque particulièrement redoutée. Il est toujours facile de mettre le feu, et souvent impossible de l'éteindre. Nous avons connu d'innombrables cas de ce genre et, malgré les investigations les plus actives, l'on ne réussit jamais à mettre la main sur les incendiaires. Cette terreur du feu est si grande que I'homme soupçonné capable d'un pareil méfait peut se trouver, pour cette seule raison, mis en quarantaine dans son propre village ; on le redoute et on craint encore plus de l'aider à éteindre l'incendie. Dans une circonstance semblable, un même individu fut victime de plusieurs incendies allumés par la malveillance : le dernier détruisit toutes ses charrettes, on ne retrouva que les jantes métalliques. L'on découvrit par la suite que tous ses véhicules remisés dans un hangar avaient été liés ensemble ce qui mit, bien entendu, obstacle à toute tentative de les sortir de l'abri en feu.

Une autre méthode dont se sert le matamore pour manifester son irritation contre un ennemi consiste à ravager ses récoltes. Dans un pays où les propriétés terriennes sont morcelées en une infinité de parcelles, chacune d'elles se trouve confiner à celles de beaucoup d'autres fermiers. Ainsi que nous avons déjà eu l'occasion de le faire remarquer, une grande ferme pourra comprendre une vingtaine de lopins de terre achetés çà et là et successivement au hasard des circonstances. Les terres cultivées 


\section{La vie des paysans chinois}

fournissent d'excellents prétextes de disputes dès que la moisson est terminée, les petites haies qui délimitent souvent les propriétés voisines dans les régions où la pose de bornes en pierre serait trop coûteuse étant facilement arrachées et enlevées ; du reste, elles ne constituent que des limites assez vagues et l'on peut aisément ergoter sur la position exacte de la ligne idéale de partage.

En pareille occurrence, le matamore sera tout à son affaire. Il est bien entendu que lui ne souffrira aucune perte de terrain et que quiconque se trouve être son voisin aura de durs moments à passer. Or, il y a certains coins de terre, tels que des espaces d'utilité publique, les berges des cours d'eau, l'enclave de certains temples et autres parcelles encore que, seul, le matamore peut se risquer à cultiver parce que les produits de pareilles surfaces doivent être protégés contre les empiètements des voisins et que seul aussi un matamore possède assez d'astuce et de férocité pour se protéger lui-même.

Dans son Essai sur lord Clive, Macaulay rappelle un incident dont on se souvient encore dans le Shropshire. Pendant ses années de jeunesse ce grand soldat des Indes « rassemblait tous les gamins désœuvrés de la ville pour les former en une sorte de bataillon de pillards et il forçait les boutiquiers à se soumettre à une sorte de tribut - des pommes et des pennies - contre lequel il leur garantissait la sécurité de leurs fenêtres ». Le jeune Robert Clive avait précisément imaginé le principe sur lequel repose la force incontestée du matamore chinois, principe aussi vieux en vérité que la race humaine : 


\section{La vie des paysans chinois}

La bonne vieille règle, le simple plan c'est :

Que ceux qui en ont le pouvoir prennent,

Que ceux qui le peuvent gardent.

Le moyen de commettre ces exactions est toujours à portée de tous ; il s'exprime par le mot décisif : procès. Le matamore qui entend bien son affaire, entretient de nombreuses relations dans le personnel du yamen et, en réalité, il est I'un de ses meilleurs clients ou plus exactement celui qui lui apporte le plus de clientèle. Le yamen représente la toile d'araignée, et le matamore le gros insecte qui attire les mouches dans un filet où il leur en cuira avant de pouvoir s'échapper de ses mailles.

Si l'adversaire a de la fortune, le matamore déposera peul être un sac de sel de contrebande devant sa porte, non sans s'assurer en même temps la connivence d'un inspecteur du sel prêt à saisir le corps du délit au bon moment et à dénoncer I'homme qui, tout en ayant de la fortune, ose braver la loi. Les « inspecteurs du sel » se recrutent généralement parmi des contrebandiers passés maîtres dans la pratique de cette fraude et, de même que les autres agents subalternes de I'Administration chinoise, ils sont complètement dépourvus de tout scrupule de conscience. Il est peu vraisemblable qu'un homme riche puisse se tirer de poursuites de ce genre sans débourser plusieurs milliers de cordons de cash, forcé qu'il sera probablement de fournir les fonds nécessaires pour réparer le mur d'une ville, rebâtir un temple ou quelque autre édifice public. L'art de mener avec succès un procès est aujourd'hui en Chine ce qu'il devait être à Bagdad au temps du calife Haroun al 


\section{La vie des paysans chinois}

Raschid : s'envelopper de mystère et s'armer de vitesse. De telles officines bravent tous les adversaires à l'exception de ceux qui sont équipés pareillement. Et, de même que les Récits des « Nuits » arabes fourmillent d'histoires de magiciens en lutte avec d'autres magiciens qui opposent enchantements à enchantements, de même lorsque les matamores chinois s'affrontent au yamen, le public assiste à un combat de géants.

Le plus habile dans cette catégorie de gens si redoutés est le matamore qui se double d'un lettré, peut-être un hsiu-ts'ai ou un bachelier des Arts. Il dispose de la sorte d'un prestige tout particulier qui lui assure non seulement le privilège d'être écouté alors que d'autres plaideurs le seraient moins, mais encore l'immunité contre la fustigation en plein tribunal, punition à laquelle les plaignants sont exposés. De plus, il est à même de préparer des chefs d'accusation pour sa propre cause comme aussi pour celles d'autres demandeurs, et il sait que ses dires auront une grande portée.

Les avantages que vaut à un tel homme sa situation de matamore sont importants, aussi n'est-il pas rare de rencontrer des Célestes déclarant sans ambages que s'ils s'astreignent au travail écrasant qu'exige l'obtention du grade littéraire le plus bas, c'est pour que celui-ci leur serve, pendant le reste de leur vie, d'abord à s'élever, puis à nuire à leurs voisins. Le matamore chinois est toujours à craindre, mais aucun n'inspire une méfiance aussi justifiée que le matamore lettré.

Nous devons mentionner un autre type de matamore, unique en son genre, à savoir le matamore femme. Ses traits 


\section{La vie des paysans chinois}

caractéristiques sont les mêmes, mutatis mutandis, que ceux que nous avons déjà étudiés, mais le fait seul qu'elle existe semble si en dehors de notre conception de la vie sociale des Chinois, qu'il est nécessaire d'entrer dans quelques explications. Ce type féminin a simplement évolué hors de son milieu. Habileté dans la parole, violence physique dans l'action, talent d'exécution, tels sont ses dons, et cette femme est à ce point utile aux «loups et tigres » perpétuellement affamés du yamen qu'on l'a surnommée le cheval de trait qui traîne les victimes à leurs pieds. A l'exemple de ses congénères du sexe masculin, elle est capable - du fait des services importants qu'elle rend aux subalternes du yamen - de mener un procès personnel sans avoir à supporter aucune des innombrables dépenses, aucune des vexations qui, telles des sangsues, sucent le sang des victimes ordinaires. Pour toutes ces raisons une femme pareille est un ennemi terrible, sinon invulnérable, et sages sont ceux qui se méfient d'elle. Ainsi que l'affirme un proverbe chinois, une femme est plus à craindre en de semblables cas qu'un gradué du second degré. Un certain philosophe a dit, non sans humour, $q^{\prime}$ '« un seul frelon peut mettre en fuite une armée entière lorsqu'il est en pleine vigueur ». Il serait impossible de supporter tout le mal que peut accomplir un matamore chinois au cours d'une existence de durée moyenne.

Bien que le gouvernement chinois semble s'appuyer sur des éléments d'une grande stabilité, il est parfois réellement faible dans des questions où il aurait le plus besoin de force, du fait de ne pas savoir fournir, à une heure critique, un effort prompt et puissant. Chaque fois que se produit, un soulèvement populaire, 


\section{La vie des paysans chinois}

rien n'empêche généralement celui-ci de s'étendre et de grossir, vu l'incapacité des autorités locales à le réprimer dès sa naissance. On peut constater le même phénomène dans toute rixe entre deux individus. Il n'y a pas de police pour arrêter quiconque trouble l'ordre public, et seule l'intervention d'un tiers, d'un ami de la paix, réussit à ramener le calme. Mais si l'un des combattants est à même de rassembler un fort groupe de partisans pour foncer sur son adversaire, celui-ci court de gros risques d'être mis à mal.

C'est dans des cas pareils que la bande de séides du matamore se montre un ennemi formidable pour la paix sociale. Supposons que deux hommes se soient violemment querellés. Le moment le plus favorable pour liquider l'affaire sera celui d'une grande foire, telle qu'il s'en tient en Chine durant presque toutes les saisons de l'année. L'un des deux adversaires a d'excellentes relations avec quelque matamore professionnel qui dispose, même à simple portée de voix, d'une équipe de compères sur lesquels il peut compter dans un cas urgent. Notre homme va trouver ce bravache, il lui explique son cas, fait appel à son concours. Le matamore laisse entendre à ses camarades qu'un de ses amis a besoin qu'on vienne à son aide ; aussitôt le groupe se rendra dans le coin de la foire où se rassemblent les marchands de petites perches qui servent à soutenir les bâches au-dessus des comptoirs ; chacun « emprunte » alors un solide bâton qu'il s'engage à rendre un peu plus tard. A la tête de cette bande désordonnée, assez pareille aux troupes de Robin Hood, le matamore fond sur sa victime et remporte en un clin d'œil une victoire facile, car aucun des spectateurs n'intervient dans ces 


\section{La vie des paysans chinois}

querelles, les conséquences pouvant être sérieuses. Mais il ne faudrait pas croire qu'il existe la moindre organisation entre ces gens de sac et de corde si vite rassemblés. Cette lie dangereuse de la population va à celui qui lui promet les joies de la bataille ainsi qu'une récompense sous la forme probable d'un festin.

Des cas de ce genre, très nombreux, font ressortir la faiblesse du Gouvernement chinois, ils en montrent aussi la force. Si les Célestes qui se comptent par millions, n'étaient pas satisfaits de leurs gouvernants, rien ne leur serait plus facile que de s'unir et de les renverser. Mais la sécurité du Gouvernement repose avant tout sur le fait bien établi et constaté que le peuple, pris dans son ensemble, n'a aucune envie de bouleverser le régime sous lequel il vit, et sur ce second fait, également incontestable, qu'une coalition efficace entre Chinois est une opération extrêmement difficile.

La réunion de bandes d'hommes sous la direction virtuelle d'un chef constitue une menace permanente pour la tranquillité publique de toute la région qu'ils occupent, et il n'est guère étonnant que les magistrats des districts en question mènent une existence peu enviable. Le pillage étant le véritable objectif de ces associations, le yamen du magistrat se trouve être fréquemment le point d'attaque, aussi le fonctionnaire est-il dans la nécessité de s'entourer d'athlètes bien entraînés, en état de

soutenir un assaut nocturne et de pouvoir le repousser. On lit parfois dans la Gazelle de Pékin que des voleurs ont visité tel ou tel yamen en dépit de toutes les mesures de précaution prises par l'autorité et que le sceau du magistrat a disparu causant 


\section{La vie des paysans chinois}

ainsi sa propre ruine. La vengeance est souvent le mobile de ces vols.

Il est certain que l'existence de pareilles bandes irrégulières au milieu de la vie sociale des Chinois, toute tranquille et ordonnée qu'elle soit habituellement, ne peut manquer de produire de fréquentes émeutes. Mais ces attaques ne viennent pas toutes du même côté. La littérature chinoise abonde en phrases proverbiales qui font allusion au tigre : bien qu'elles soient rédigées sous forme de métaphores, il est facile de reconnaître le matamore, considéré comme un tigre social. D'après l'un de ces aphorismes, le tigre qui a blessé un grand nombre de personnes est exposé à tomber dans un ravin : en d'autres termes, le matamore qui a soulevé contre lui trop de haines finira, lui aussi, par s'attirer des désagréments; ses ennemis prendront un jour leur revanche.

Les incidents de ce genre se produisent fréquemment et ont souvent pour conséquence un ou plusieurs meurtres dont le magistrat doit rendre compte et que la Gazette de Pékin publie quelquefois avec force détails. De temps à autre I'on raconte que des matamores furent attaqués par de fortes bandes de gens armés dont la plupart avaient eu précédemment à souffrir de ces bravaches ; souvent on les enlève, parfois on les tue. Les méthodes employées dans les provinces de Fu Kien et de Kuangtung pour les guerres entre villages ou les luttes de clans, ont probablement beaucoup d'analogie avec les procédés de justice sommaire que nous venons de décrire. On dirait des joutes auxquelles se livreraient des voisins rivaux pour éprouver leur 


\section{La vie des paysans chinois}

force, joutes conduites d'après le système de guerre en usage au Moyen Age sous le régime féodal. Les magistrats locaux se gardent d'intervenir trop tôt et de pousser l'affaire trop avant, car il pourrait leur en cuire. Lorsque la lutte est terminée, les officiers de justice se montrent, des arrestations ont lieu et la machinerie gouvernementale sort de sa paralysie momentanée.

Nous avons signalé le matamore lettré comme l'un des plus à redouter parmi ses congénères, mais il existe un autre avantage social qu'un individu de ce genre peut posséder, avec ou sans celui de l'instruction, et qui fait de lui un adversaire presque irrésistible. En effet, si le matamore appartient à une famille dont quelques membres sont investis de situations officielles et jouissent d'une certaine influence dans le monde des fonctionnaires, un pareil homme est un ennemi dangereux. Les rapports publiés par la Gazette de Pékin signalent des cas nombreux qui prouvent combien il est difficile, sinon impossible, de lutter avec quelques chances de succès contre des êtres pareils. Même s'il s'agit d'un meurtre perpétré sans le moindre motif I'on trouvera toujours un biais pour arranger l'affaire et rien ne saurait garantir que le coupable recevra son châtiment.

L'incident suivant, qui remonte à plus d'une génération et eut pour théâtre un district voisin de celui où vécut longtemps l'auteur de ce livre, en dit long sur les procédés auxquels il vient d'être fait allusion.

$\mathrm{Au} \mathrm{XVIII}^{\mathrm{e}}$ siècle vivait dans la région une famille du nom de Lu dont l'un des membres occupait la haute situation de Ko Lao ou Grand Secrétaire. Une famille de cette classe, surtout si elle 


\section{La vie des paysans chinois}

est seule de son espèce dans le district, jouit toujours d'une grande autorité, et le magistrat local fera bien d'agir avec circonspection pour peu qu'il ne veuille pas encourir les rancunes de gens aussi puissants. Il a déjà lieu de se féliciter s'il arrive à se faire payer par eux le simple impôt foncier que toute terre chinoise est supposée verser.

Or, I'on raconte au sujet de cette famille que l'agent de police de la localité ayant reçu du magistrat du district l'ordre d'aller percevoir la taxe à domicile, notre homme ne put arriver à toucher un seul cash. A plusieurs reprises fustigé au yamen pour ses insuccès, il résolut de se présenter une dernière fois chez le riche récalcitrant. Après s'être arrêté devant la porte d'entrée, il supplia le portier, non sans se prosterner jusqu'à terre, d'intercéder en sa faveur et d'obtenir de son maître le versement de la taxe.

La maîtresse de céans, veuve d'un certain âge, fut avisée de la requête. Sans hésiter un instant elle fit atteler sa voiture et se rendit au yamen où elle demanda audience au magistrat. Peutêtre ce dernier conçut-il le fol espoir que la dame venait régler son arriéré, peut-être même se proposait-il de lui emprunter quelque argent. Toujours est-il qu'il dut en déchanter, car la visiteuse lui déclara sans ambages qu'elle-même avait besoin d'un prêt de quelques milliers de lads ; à quoi le magistrat répondit avec empressement qu'il s'efforcerait de les lui procurer au plus tôt. Puis, se levant pour prendre congé, la dame fit incidemment la remarque que certains agents du yamen s'étaient permis d'importuner le portier de sa propriété et de 


\section{La vie des paysans chinois}

venir réclamer plusieurs fois le paiement de l'impôt foncier ; elle espérait bien qu'à l'avenir on n'userait plus de pareils procédés à son égard!

Dans une autre circonstance, alors que le Ko Lao lui-même était encore de ce monde, le magistrat fut saisi d'une plainte ; on accusait I'un des fils du Ko Lao de séquestrer dans le domaine familial une jeune servante. Cette fille était fiancée au moment de son entrée en service, mais lorsque vint la date du mariage, son maître se refusa à la laisser partir. Le magistrat convoqua le jeune homme, il l'informa de l'accusation portée contre lui et exigea la mise en liberté de la servante. Il alla jusqu'à faire battre I'intendant de la famille Lu, qui avait accompagné son maître, ce dernier étant d'un rang trop élevé pour subir pareil châtiment. Le fils rentra au logis en proie à une rage folle ; il écrivit à son père, alors à Pékin, et lui raconta toute I'histoire. Peu de temps après le magistrat apprenait sa promotion : de sous-préfet il passait au grade de préfet dans la province de Ssûch'uan.

Le voyage qu'impose à un fonctionnaire un changement de résidence est une affaire des plus sérieuses et lorsqu'il s'agit de traverser l'Empire entier - comme tel était le cas ici - un pareil déplacement coûte beaucoup d'argent et de peine. A peine avaitil pris possession de ce poste lointain qu'il fut avisé qu'on l'affectait ailleurs et qu'on l'envoyait dans la province de Yünnan. Nouveau voyage également long et coûteux. Enfin lorsqu'il se fut, à la longue, installé dans ces dernières fonctions, il apprit sa promotion au rang élevé de Tao-t’ai dans une région au delà 


\section{La vie des paysans chinois}

de la Grande Muraille. Commençant à comprendre le sens de cette étrange succession d'événements, incapable d'autre part de supporter plus longtemps les maux qu'on lui infligeait, il recula devant la perspective d'en subir peut-être de plus grands encore et « avala de l'or », moyen le plus sûr d'échapper à une nouvelle promotion ainsi qu'à la ruine !

(a) 


\section{La vie des paysans chinois}

\section{XXI \\ LES ADMINISTRATEURS COMMUNAUX.}

Plusieurs des particularités de la vie au village, que nous allons avoir l'occasion de signaler, illustrent bien les aptitudes des Chinois pour la coopération.

Rien peut-être, dans la société chinoise, ne met ce principe plus en évidence que les règles qui président au self-government des petites communautés rurales dont se compose la majeure partie de I'Empire. L'administration du village se trouve entre les mains des villageois eux-mêmes. De prime abord, un pareil régime pourrait être considéré comme de la pure démocratie, cependant à y regarder de plus près, I'on découvre qu'alors que les affaires d'intérêt local sont, en théorie, traitées par le peuple, en pratique ce n'est pas sur l'ensemble de la population que retombe le fardeau administratif, mais sur les épaules de quelques personnes connues sous des appellations diverses suivant les régions et dont les attributions sont aussi différentes que leurs désignations. Il est facile de constater que sous cette uniformité apparente, la Chine est sujette à d'étonnantes variations, non seulement dans les régions séparées par de grandes distances, mais même dans d'autres qui sont voisines ou à peu près. Dès lors il devient difficile de généraliser lorsqu'il est question du mode administratif des villages; il faut se contenter de décrire quelques cas concrets en expliquant qu'ailleurs I'on peut atteindre aux mêmes résultats par des 


\section{La vie des paysans chinois}

moyens légèrement différents, ou par les mêmes moyens sous d'autres désignations.

Chaque village constitue par lui-même une petite entité administrative distincte. Cependant il arrive parfois que deux ou plusieurs de ces agglomérations situées dans le voisinage les unes des autres ou unies par d'autres liens, dirigent leurs affaires en commun et souvent à l'aide d'un même groupe de personnes appelées quelquefois hsiang chang ou hsiang lao anciens du village - et aussi plus simplement shou shih jên administrateurs. En principe, ces agents sont choisis ou plutôt proposés par leurs concitoyens et confirmés dans leur emploi par le magistrat du district. Dans certaines régions, les choses se passent vraiment ainsi et, pour s'assurer de la bonne gestion de ces administrateurs, I'on demande aux principaux propriétaires terriens d'être leur caution.

L'expression « anciens du village » pourrait faire supposer que ces fonctions sont dévolues aux hommes les plus âgés de la localité, mais ce n'est pas forcément le cas. De même les plus riches n'en seront pas nécessairement investis, quoique, d'habitude, toute famille jouissant d'une certaine aisance soit représentée dans ces conseils d'une manière ou d'une autre. Enfin, ces hommes n'auront pas toujours des connaissances littéraires, bien qu'il puisse se trouver parmi eux quelques lettrés.

Dans ces régions la méthode de sélection est très élastique et le nombre des administrateurs ne correspond pas toujours à l'importance de la localité. Leur fonction n'est pas héréditaire, 


\section{La vie des paysans chinois}

pas plus qu'elle n'a une durée fixe. Après une certaine période, un homme pourra se récuser ou parfois négliger son service tout en demeurant en fonctions. Dans les endroits où prévaut ce système, les anciens ne sont ni formellement nommés, ni formellement déposés. Ils se trouvent en place par une sorte de sélection naturelle à moins toutefois qu'ils ne s'adjugent la situation de leur propre autorité. Les qualités nécessaires à un villageois pour diriger une administration rurale sont les mêmes que celles qui permettent à un homme de réussir dans tout autre emploi. Il lui faut un esprit pratique secondé par une habileté native et une certaine expérience de I'humanité. L'Ancien devra, à I'occasion, consacrer une somme indéfinie de temps et de travail aux affaires qui peuvent lui être confiées et y consentir volontiers.

Les fonctions des Anciens sont multiples. Elles s'appliquent à tout ce qui intéresse l'administration publique de même qu'à ce qui concerne la vie ou les intérêts privés des individus. C'est aux Anciens que I'on s'adresse pour toutes ces affaires parce que I'on considère que nul mieux qu'eux ne saura les mener à bien.

La question la plus importante parmi celles qui intéressent le Gouvernement est l'assiette. de l'impôt impérial, c'est-à-dire la taxe des grains dont la fixation ainsi que la manière de procéder pour la percevoir varient beaucoup suivant les régions. Les agents du Gouvernement demandent à chaque instant des moyens de transport, des approvisionnements nécessités par les réceptions offertes aux fonctionnaires qui viennent en missions officielles ; ils réquisitionnent des matériaux pour réparer les 


\section{La vie des paysans chinois}

berges des fleuves et régulariser les lits des cours d'eau, pour l'entretien des routes impériales pendant la période de l'année où la circulation est le plus active et pour bien d'autres travaux encore.

Le magistrat du district communique avec le village par I'intermédiaire du ti-fang ou ti pao - agent de police local - et cet individu a forcément des relations étroites avec les Anciens qui constituent le Conseil exécutif, seul appelé à prendre des mesures décisives.

Parmi les affaires qui intéressent exclusivement le village, nous citerons la construction et l'entretien des murs d'enceinte - s'il en existe - et le bon fonctionnement de leurs portes - si on les ferme la nuit -, l'établissement et l'inspection des foires et marchés, les engagements des compagnies théâtrales, la surveillance des récoltes, la répression des délits relatifs aux mesures de protection prises à cet effet, la construction et la réparation des temples, le creusement des puits publics et le curage de ceux qui sont déjà en service ainsi que quantité d'autres travaux similaires, suivant la situation du village et ses coutumes traditionnelles.

Il est à remarquer que le Gouvernement chinois, bien que plus ou moins despotique en théorie, n'oppose pas de restrictions formelles à la liberté de réunion des gens désireux d'étudier les affaires de leur communauté : les habitants d'un village peuvent, s'ils le veulent, s'assembler chaque jour de l'année, aucun censeur officiel n'assiste à ces réunions et les débats se poursuivent librement. L'on peut dire ce que I'on veut, 


\section{La vie des paysans chinois}

le magistrat local ignore les choses que I'on discute et ne tient, du reste, aucunement à le savoir. Le Gouvernement a d'autres moyens de garantir sa sécurité que l'espionnage : un système de responsabilités savamment étagées lui permet de maintenir tous ses sujets sous un contrôle étroit. Mais qu'une insurrection vienne à éclater et aussitôt ces droits populaires s'évanouiront : tout le monde le sait.

Les méthodes administratives chinoises étant ce qu'elles sont, il n'est pas étonnant que ceux qui dirigent les affaires de la communauté trouvent leur avantage à cette situation ou plutôt s'arrangent pour en tirer profit. Les moyens utilisés à cet effet sont nombreux.

Dans chaque village affluent nombre d'affaires qui n'intéressent pas la collectivité mais doivent être réglées par des hommes de métier connaissant le fond des questions et les moyens de les traiter. Il ne manque pas de Chinois qui aiment à se lancer dans ce genre d'affaires : rajuster des querelles domestiques, des disputes entre voisins, etc. Les Anciens du village sont fréquemment appelés à régler de pareils litiges.

Cependant ce labeur, tout onéreux qu'il soit souvent pour celui qui l'assume, ne sera reconnu que par les remercîments des intéressés et par une invitation à la fête qui clôt inévitablement le moindre différend. Il en est autrement lorsqu'il s'agit de questions d'ordre général, telles que la réquisition et le rassemblement de matériel pour cause d'utilité publique. Chaque village a de nombreuses entreprises qui impliquent des 


\section{La vie des paysans chinois}

maniements de fonds; elles doivent rester entre les mains de ceux ayant la compétence voulue pour les mener à bien.

Il est à remarquer qu'en pareil cas, l'on ne connaît pas cette lutte permanente entre I'homme pourvu d'une fonction et celui qui n'en a pas, lutte dont les pays où l'esprit démocratique est plus accentué qu'en Chine fournissent le spectacle constant. Cependant, même en Chine, de pareilles contestations se produisent quelquefois. Nous connaissons un village où la gestion des affaires publiques se trouvait depuis longtemps monopolisée par un groupe d'hommes dont les procédés administratifs avaient soulevé des critiques chez quelques-uns de leurs concitoyens plus jeunes, ces derniers étant convaincus qu'en dépit de leur âge ils ne seraient pas moins capables. Ils firent tant et si bien que les anciens se retirèrent abandonnant la place à ceux qui les critiquaient, manière d'arranger les choses connue pour être souvent pratiquée dans le gouvernement de I’Empire.

Mais les cas où I'on obtient une victoire si facile doivent être relativement rares pour la raison que les beati possidentes comme on dit en Occident - ont toutes facilités de se maintenir dans leurs fonctions ; ils ne sont, pour la plupart, aucunement sensibles à la critique et se contentent de récolter les bénéfices substantiels de l'emploi et de laisser jaser le public. En ce qui concerne les questions ordinaires courantes, il est facile de trouver de nombreux précédents justifiant à peu près toutes les irrégularités, et pour le Chinois, le précédent est chose précieuse en ce qu'il fixe la limite naturelle de l'action humaine. 


\section{La vie des paysans chinois}

Dans beaucoup de villages, seule une minorité d'habitants sait lire suffisamment pour examiner les comptes et parmi les gens dont le savoir permettrait ce contrôle, rares sont ceux qui possèdent quelques connaissances au sujet des questions administratives, n'ayant jamais eu l'occasion de se familiariser avec les affaires publiques.

La plupart des personnes qui reconnaissent les défauts des méthodes usitées dans l'administration de leur village s'abstiennent de protester pour deux raisons excellentes. D'abord, agir ainsi serait attirer l'orage sur leurs têtes et elles n'ont pas la moindre envie d'affronter la tempête. En second lieu, si le mouvement protestataire avait plein succès et provoquait la retraite de tous les administrateurs, il serait difficile, pour ne pas dire impossible, de leur trouver des remplaçants capables de mettre en œuvre des méthodes administratives entièrement nouvelles. Dès lors, un changement équivaudrait simplement à chasser l'essaim de mouches bien nourries pour le remplacer par d'autres plus affamées : substitution contre laquelle le renard de la fable risqua de sages remontrances. Les Chinois sont tout a fait d'accord avec la judicieuse logique du renard.

Un cas connu de l'auteur va fournir un heureux commentaire de la tournure que prennent les choses lorsque I'on se plaint sérieusement. A la suite de l'un des derniers débordements du Fleuve Jaune qui ravagea le Shantoung central, ordre fut donné dans toutes les subdivisions administratives dont les territoires touchaient au fleuve, de fournir une certaine quantité de tiges de 


\section{La vie des paysans chinois}

millet pour la réparation des berges et des digues. Les agents du Gouvernement devaient payer les fournitures argent comptant. Mais certaines zones soumises à cette réquisition se trouvant à plus de deux journées de marche des chantiers, il en résulta que la somme touchée en paiement du millet ne couvrit même pas les frais de transport - nourriture des convoyeurs et de leurs attelages - et du retour à domicile. De plus, les agents impériaux possédaient un moyen facile d'exercer leur pression sur les fournisseurs de tiges en refusant de prendre en charge le matériel dès son arrivée à pied d'œuvre ou bien en retardant arbitrairement la pesée. De cette façon les charrettes étaient immobilisées aux frais de leurs propriétaires et ceux-ci en désespoir de cause n'étaient que trop heureux de pouvoir regagner leurs villages sans recevoir le moindre paiement pour les fournitures qu'ils avaient apportées.

Il paraît qu'à cette époque les abus de ce genre se renouvelaient fréquemment ; toutefois I'on nous a assuré que par la suite, dans des cas analogues, les fonctionnaires réglèrent exactement et en bon argent le prix des livraisons. Dans le village auquel nous faisons allusion, le magistrat du district chargea un gradué en lettres, d'âge respectable, de procurer et de livrer les tiges de millet. Cet homme appela naturellement auprès de lui quelques-uns de ses anciens élèves et leur confia la partie matérielle du travail. A trois reprises ils apportèrent les tiges à l'endroit indiqué et touchèrent 70.000 cash. Profitant de l'incertitude qui régnait sur le mode des paiements, ils ne fournirent au village aucune comptabilité et s'approprièrent une certaine partie des recettes. 


\section{La vie des paysans chinois}

Cette gabegie se prolongea pendant plus d'une année, jusqu'au moment où quelques fermiers mécontents provoquèrent une réunion publique dans l'un des temples du village et exigèrent communication du relevé des recettes et des dépenses ; naturellement on ne put le leur fournir. Le gradué, comprenant enfin que l'affaire prenait une mauvaise tournure, persuada à quelques notables de la localité d'aller « parler paix » dans les villages afin de calmer l'agitation générale. Si nous poussons I'affaire plus avant, dirent les Anciens, et que nous la portions devant le magistrat du district, le vieux gradué, qui n'a pas trempé personnellement dans ces tripotages, perdra son bouton et sera déshonoré ; ses subordonnés, engagés dans I'affaire seront battus et, de toute cette histoire, il ne résultera que des haines et des inimitiés dont plusieurs générations auront sans doute à supporter les conséquences. Les pacificateurs proposèrent alors un arrangement. Le gradué offrirait un festin auquel assisterait un représentant de chaque groupe de familles portant le même surnom. Le compromis fut accepté, faute de trouver une autre solution ; I'affaire, enterrée, tomba dans I'oubli qui couvre généralement de pareils incidents. Cette aventure est un exemple typique d'une nombreuse catégorie d'affaires chinoises.

Dans beaucoup de villages, I'on rencontre des gens qui ne se sentent jamais aussi heureux que lorsqu'ils se querellent avec leurs voisins et de pareils chicaniers deviennent une véritable plaie pour les Conseils des Anciens dont les réunions du reste ne sont pas publiques. On entend fréquemment parler de procès soulevés à propos de temples de villages et tout porte à croire 


\section{La vie des paysans chinois}

qu'il est exceptionnel de trouver un grand temple ancestral n'ayant suscité ni querelles, ni procès.

L'on bâtit des temples dans certains districts plutôt en raison de ce sentiment impulsif qui vous porte à imiter le voisin que par un besoin véritable de pareils édifices. Ces constructions deviennent une taxe à perpétuité sur les revenus des habitants, et, à la longue, une source de disputes. Dans de pareilles régions, I'on voit fréquemment des temples dont les prêtres furent supplantés ou délogés, à moins qu'ils ne les aient volontairement abandonnés parce que leur situation y devenait trop désagréable.

Dans une circonstance de ce genre - cela se passait près du « home » de l'auteur - un certain notable, homme très en vue, commença un procès qui provoqua le départ du plusieurs prêtres attachés au service d'un temple bouddhiste : un seul demeura en fonctions. Les prêtres partis, le notable en question consentit à se charger des terres dépendant du temple ; il s'adjugea la totalité des revenus au détriment du prêtre et se dispensa de rendre aucun compte. La charrette et le harnachement même, qui appartiennent au temple, sont remisés dans la cour de cet homme, comme s'ils étaient son propre bien.

Lorsque I'on demande aux hommes intelligents du village pourquoi ils ne protestent pas contre une pareille usurpation, ils vous servent tous la même réponse : «Qui donc consentirait à soulever un procès dont il ne retirerait que des pertes ? Ce n'est certainement pas mon affaire ! » Cette localité ne représente pas absolument le type de la moyenne des villages, mais elle offre 


\section{La vie des paysans chinois}

un assez juste échantillon des cas les plus flagrants dans lesquels un petit noyau d'individus se cramponne à une collectivité chinoise et l'exploite tout comme, il y a bien des années, la coterie Tweed s'imposa à la ville de New-York. Si l'on élève quelques objections contre ces procédés, la bande demande dédaigneusement, à la manière de $M$. Tweed : «Eh bien! Qu'allez-vous faire ? » Et les gens de répondre : «Oh ! rien, certes. C'est très bien comme cela ! »

Citons en exemple de la facilité avec laquelle des difficultés surgissent dans les affaires d'un village, un fait qui se produisit dans cette même localité pendant l'une des années où de grosses pluies furent une menace constante pour les terres. Quelques-uns de ces terrains se trouvaient situés au milieu d'une dépression exposée aux inondations tandis que les autres étaient à une altitude plus rassurante. Dès que les eaux menacèrent les récoltes, les Anciens donnèrent I'ordre de former des équipes de travailleurs qui élèveraient sans relâche une digue de protection et le millet sur pied fut partout arraché pour consolider les remblais. Les propriétaires perdirent ainsi leur récolte, mais ne touchèrent pourtant aucune indemnité. L'on assure que le cas de force majeure justifie de pareils sacrifices et que les gens qui en profitent ne sont jamais disposés à compenser les pertes causées ainsi à quelques-uns de leurs concitoyens. Peu de jours après cet incident, les Anciens entreprirent de lever une taxe dans le village afin de payer les frais de main-d'œuvre de la digue. Ils arrivèrent chez l'un des fermiers qui avait perdu son millet à un moment où celui-ci était absent de chez lui ; ils furent reçus par son fils. Non seulement ce dernier ne manifesta 


\section{La vie des paysans chinois}

aucune appréhension devant les autorités du village, mais il donna cours à son indignation et leur reprocha avec véhémence la destruction des récoltes paternelles ; il ajouta qu'au lieu de I'inviter à contribuer aux frais qui causaient la ruine des siens, on devrait d'abord rembourser à son père ses propres pertes. Pour autant qu'un pareil point de vue puisse paraître compatible avec la justice abstraite, cette façon d'envisager le cas n'était rien moins, aux yeux des Anciens, qu'une trahison de la forme la plus dangereuse.

A son retour, le chef de famille apprit que les notables venaient de partir au chef-lieu du district afin de porter plainte contre lui comme refusant de payer sa juste quote-part pour la protection du village. Or, cette procédure engagée sur une pareille base d'accusation constituait pour le malheureux une calamité pire encore que les méfaits des eaux. Le père affolé courut à la poursuite des Anciens proposant qu'une tierce personne s'entremette et arrange l'affaire. Devant son insistance, toute la bande retourna au village sans avoir été déposer de plainte au yamen.

Le père du jeune homme coupable en appela à quelques amis qui habitaient un village voisin. Il les supplia de venir intercéder en sa faveur auprès des gardiens de la prospérité publique, lesquels venaient d'être outragés dans l'exercice de leurs fonctions. Le lendemain matin, les personnes qui avaient accepté cette mission délicate se mirent en route. Elles eurent des entrevues avec quelques-uns des Anciens mais, de toute la journée, ne purent réussir à les voir tous ensemble : il fallut se 


\section{La vie des paysans chinois}

contenter d'entretiens isolés, d'abord avec un groupe, puis avec un autre, jusqu'à ce que la question eût été discutée sous tous ses aspects. Ces conférences, y compris les projets d'arrangements proposés, modifiés, rejetés, amendés, puis présentés à nouveau et à plusieurs reprises, absorbèrent la journée entière, se prolongèrent même pendant la nuit suivante et ne prirent fin qu'au moment où le chant du coq annonça l'aube prochaine. Le second jour luisait déjà lorsque les « intermédiaires »las et écœurés, revinrent chez eux, non sans avoir réussi à obtenir une réduction de l'amende, laquelle devait d'abord être très forte à titre d'exemple et qui finalement se réduisit à une somme insignifiante.

Cet incident est typique des cas innombrables dans lesquels les forces mauvaises de la société chinoise coopèrent en une action commune, modifiant sérieusement tous les autres phénomènes sociaux et conduisant à des résultats d'une grande portée. 
La vie des paysans chinois

\section{DEUXIÈME PARTIE}

\section{LA VIE DE FAMILLE AU VILLAGE}




\section{La vie des paysans chinois}

\section{XXII \\ GARÇONS ET HOMMES.}

Dans le Livre des Odes, I'un des plus anciens classiques chinois, nous lisons la description du palais d'un roi : elle jette un jour saisissant sur la valeur relative attribuée en ces temps reculés aux garçons et aux filles. Après avoir parlé des rêves du roi, le poète ajoute quelques stances que le $D^{r}$ Legge traduit de la façon suivante :

Des fils naîtront de lui. On les fera reposer sur des lits ; Habillés somptueusement ils auront des sceptres pour jouets ;

Leurs voix retentiront avec force.

Plus tard, le (futur) roi, les princes du royaume,

Resplendiront sous la parure de leurs jambières rouges.

Des filles naîtront de lui. On les couchera par terre.

Vêtues de simples robes, elle auront des tuiles pour jouets ;

Il leur appartiendra..., de ne faire ni le bien, ni le mal,

Leurs pensées ne porteront que sur les boissons et la nourriture ;

Leur seule préoccupation sera de ne causer aucune peine à leurs parents. 


\section{La vie des paysans chinois}

Ce poème, à lui seul, suffit pour montrer que le Chinois contemporain est bien de la même lignée que ses lointains ancêtres.

S'il en juge dans le simple recul de ses dix premières années, le jeune Chinois doit considérer sa petite enfance comme une période de félicité suprême. Il est accueilli dans la maison paternelle avec une joie folle, telle qu'aucun Occidental ne saurait imaginer. Il commence sa vie d'après ce principe que tout ce qu'il demande doit lui être accordé, principe qu'adopteront aussi tous ceux qui sont chargés de s'occuper de lui, et cela à un point qui nous semble stupéfiant, bien que nous cherchions à nous montrer impartial dans notre critique. La mère chinoise est littéralement l'esclave de ses enfants. S'ils pleurent, elle les dorlote et, au besoin, les promène dans ses bras, quelque peine qu'il lui en coûte, car il faut à tout prix faire cesser cette chose lamentable, les cris d'un enfant. Impossible de laisser se prolonger une crise de larmes ! Sous ce rapport, du moins, il ne semble pas exister de différence sensible entre la façon de traiter les garçons et celle dont on traite les filles.

Le choix des noms donnés aux enfants chinois est souvent déterminé, comme chez les Indiens de l'Amérique du Nord, par un objet quelconque que le hasard fait tomber sous les yeux du père : panier, carriole, etc. Chacune des années d'un cycle de douze ans s'écoule sous le signe d'un animal « qui lui est propre », tel que chien, chat, poule, tigre, cheval, singe, etc., et toutes ces dénominations sont d'un usage courant. Si à la naissance d'un enfant une vieille grand'mère vient d'atteindre 


\section{La vie des paysans chinois}

sept décades d'âge, il n'est pas rare que l'enfant reçoive le nom de «Soixante-dix ». Beaucoup de nouveau-nés n'ont d'autre appellation qu'un nombre : Trois, Cinq, Six... ce qui complique singulièrement la tâche de celui qui cherche à se renseigner à leur sujet. Si l'enfant paraît avoir une constitution robuste, il recevra peut-être le nom de Pierre ou de Solide ; s'il est dodu, on I'appellera le Petit Gros ; si de couleur foncée, le Petit Noir. Mauvais Caractère, Petit Idiot sont d'un emploi fréquent, et pour peu que tous les enfants nés antérieurement aient disparu, le dernier arrivé sera nommé Grand Dédommagement.

Lorsque les parents appréhendent tout particulièrement que de mauvais génies fassent disparaître leur fils unique, ils donnent parfois à ce dernier un nom féminin afin de tromper les puissances du mal et les vaincre ainsi par leurs propres armes. Un autre moyen pour mettre également en défaut de pareilles tentatives consiste à faire adopter nominalement les enfants par une autre famille chez laquelle ils passent une partie de leur temps. Les esprits ainsi déroutés ne savent plus à quels parents attribuer I'enfant. Les noms de Fille Esclave, Vieille Femme, sont dans cette occurrence souvent donnés à des garçons. Un homme possédant plus de filles qu'il n'en eût souhaité, appela I'une d'elles Assez de Faucons - Kou Ying - tandis qu'une autre recevait le nom peu flatteur « Aurait dû être un garçon »-Kai Tzû. Par contre, pour les filles, les noms d'oiseaux, de fruits, de fleurs, sont assez prisés.

Toutes les dénominations que nous venons de citer sont des « noms de lait » ou « petits noms » et un étranger, alors même 


\section{La vie des paysans chinois}

qu'il les connaîtrait, doit se garder d'en faire usage. On ne saurait infliger de plus grande insulte à un Chinois adulte que de l'interpeller en public par son « petit nom » - et cela arrive souvent - car pareille liberté semble impliquer que celui qui l'outrage est au courant de ses antécédents et qu'il a pour lui un absolu mépris.

Pour permettre de s'orienter à travers le réseau complexe de la parenté chinoise, nombre de familles donnent à chaque membre d'une même génération - en se limitant à certains degrés bien définis de cousinage - un nom qui fournit un indice de sa parenté avec les autres. C'est ainsi que lorsqu'un homme porte le surnom de Wang, son nom de famille - qu'il soit composé de deux caractères ou d'un seul - peut être composé avec le caractère qui désigne le printemps. Dans ce cas, l'un des frères pourrait s'appeler Wang-Fleurs de printemps ; le suivant, Wang-Effluves de printemps, un troisième, Wang-Prairies du printemps et ainsi de suite pour toute cette génération aussi loin que l'influence printanière a encore droit de cité parmi les cousins. Ces noms de famille se trouvent, en théorie, relevés dans des registres soigneusement tenus et ne doivent pas se répéter au cours des générations suivantes ou tout au moins avant l'extinction de plusieurs d'entre elles. La Gazette de Pékin publie fréquemment des insertions émanant de hautes personnalités officielles qui demandent l'autorisation de changer leur nom de famille, un titre déjà existant ayant été pris par inadvertance. 


\section{La vie des paysans chinois}

L'emploi des mêmes caractères dans les noms de famille chinois a souvent été comparé à l'habitude assez répandue chez les Anglo-Saxons d'octroyer aux frères des noms où revient constamment la même syllabe : Edward, Edwin, Edmund, Edgar, etc.

En dehors du nom, il y a «le titre » souvent plus employé que toute autre désignation et qui peut être donné par un ami. Un préfixe, né d'une familiarité respectueuse, s'ajoute au premier caractère du titre, I'expression honorifique «Vieux »Lao - formant un autre titre supplémentaire. Donc, à supposer que M. Wang Effluves de Printemps ait pour titre Illustre Vertu, on pourra I'appeler habituellement Wang Vieil Illustre, tout en le désignant de temps en temps par ses autres noms. Il en résulte qu'un seul Chinois paraît souvent représenter trois ou quatre personnes différentes, car les étudiants sont aussi dotés de leurs noms d'examens lesquels, par une étrange anomalie, diffèrent de tous ceux qu'ils ont portés jusque-là. Et lorsqu'il s'agit d'adresser des lettres, des complications se produisent qu'aucun Occidental ne pourrait tolérer.

En dehors des ambiguïtés déjà signalées, il arrive encore qu'un correspondant trouve bon d'ajouter un titre au revers de la lettre. N'étant connue que de lui-même et du destinataire, cette addition contribue à augmenter l'effarement des personnes entre les mains desquelles doit passer la missive. Nous avons vu un instituteur chinois invité à examiner une adresse ainsi libellée : il ne parvint, pas plus que d'autres, du reste, à identifier le destinataire. Or, il se trouva en fin de compte que celui-ci était 


\section{La vie des paysans chinois}

son propre fils ! Mais de ce labyrinthe qui prépare tant de complications le villageois ne se soucie guère et toute sa vie s'écoulera peut-être sans qu'il ait possédé un véritable nom pour désigner sa personne.

Dans ces conditions, il est assez naturel qu'un étranger se trouve fort embarrassé lorsqu'il lui faut s'adresser à un Céleste. La langue chinoise ne possède pas d'expression correspondant à Monsieur. Le terme qui s'en rapprocherait le plus serait Premier Né ou Seigneur - Hsien-Shêng - bien que, à dire vrai, ces expressions dénomment plutôt un professeur, soit par courtoisie, soit parce que ce dernier jouit véritablement de cette qualité ; de plus, comme on les applique sans discernement à des hommes obscurs, seraient-ils même des mendiants, elles ne peuvent être d'un usage général. Certes les termes honorifiques abondent, mais on n'en a guère l'emploi dans les districts ruraux où ils ne seraient d'ailleurs qu'assez mal compris.

En raison de ce principe que « tous les Chinois sont frères dans la périphérie des quatre mers », I'habitude chinoise est de supposer l'existence d'une parenté, ce qui autorise un passant qui n'est pas du village à interpeller quelqu'un qu'il n'aura jamais vu auparavant par une phrase telle que celle-ci : «Cher frère aîné, puis-je recourir à vos lumières et vous demander si c'est bien là le chemin qui mène à Pékin ? » Pour peu que la personne à laquelle on s'adresse soit un vieillard, I'on changera le titre de frère en celui d'oncle ou de grand-père.

Le fait que le terme diffère suivant que l'on s'adresse à un individu plus âgé ou plus jeune que soi est une cause d'embarras 


\section{La vie des paysans chinois}

pour l'étranger, lequel se voit forcé de décider laquelle des deux appellations il devra choisir, et cela sans avoir les moindres données à cet effet.

Une jeune mariée ne possède littéralement aucun nom qui lui soit propre ; elle n'a que deux surnoms, celui de son mari et celui de son père, de sorte que s'il s'agit de noms très répandus, il est à peu près impossible de distinguer une femme d'une autre. Dans le cas assez rare où un étranger serait obligé d'adresser la parole à une Chinoise, il éprouvera encore plus de difficultés qu'à interpeller un homme. Dans certaines régions, le terme Sao-Tzû - Belle-Sœur Aînée - s'applique à n'importe quelle femme, mais dans d'autres, Tante - Ta-Niang - est de rigueur, alors qu'ailleurs encore le seul qui convienne est NaïNaï, expression équivalant en d'autres villages à Vieille Grand'Maman.

Il arrive parfois qu'une même famille contienne trois générations de femmes et qu'on leur donne à toutes le titre de «Grand-Mère ». C'est proprement absurde, surtout s'il y a parmi elles une jeune personne ayant à peine vingt ans qui vient de se marier. Cependant qu'à d'autres portes les mendiants implorent de leurs «Tantes » un peu de nourriture, I'appellation Vieille Dame (lao T'ai t'ai) est d'un usage courant lorsque l'on s'adresse à une femme qui a dépassé l'âge moyen.

L'âge auquel un enfant est jugé trop grand pour être porté sur les bras varie beaucoup. L'on rencontre parfois des mères affolées, titubant sur leurs petits pieds sous la charge d'un enfant qui pèse souvent la moitié de leur propre poids, et cela 


\section{La vie des paysans chinois}

sous le prétexte spécieux que le bambin « ne souffrirait pas d'être posé à terre ». Une pareille discipline ne prépare certes pas les enfants à savoir se conduire par eux-mêmes et à se dominer ; elle ne leur donne aucune leçon utile. Et le résultat peu brillant de cette première éducation n'est pas pour nous surprendre. Mais l'enfant chinois est un petit être éminemment pratique ; I'expérience lui démontre bien vite que là où il y a une demi-douzaine d'enfants plus petits que lui, l'ère de son règne omnipotent touche à sa fin, qu'elle s'est enfuie pour ne plus jamais revenir, et il apprend sans beaucoup de peine à s'adapter à ces nouvelles conditions.

De cette sympathie pour l'enfance qui joue un rôle si prépondérant dans notre civilisation moderne, le père chinois de situation moyenne n'a pas la moindre idée. Non qu'il n'aime pas ses enfants, I'on ne peut mettre en doute son affection pour eux, mais il est incapable de partager la vie de l'enfant, encore moins de la comprendre. Sa tendresse pour sa progéniture découle de son instinct paternel, elle n'émane aucunement d'une compréhension intelligente et sympathique de la mentalité des petits. Non seulement la possibilité d'une pareille sympathie ne lui vient pas à l'esprit, mais il ne la comprendrait même pas si on attirait son attention sur ce point. Toute suggestion à ce propos émanant d'un étranger le pousserait à répondre : « Mais ce n'est qu'un enfant ! » Le père compte uniquement sur l'action lente et progressive de la vie pour que l'enfant apprenne les leçons de I'existence, et ces leçons, il doit les apprendre dans une large mesure - quoique pas entièrement - par lui-même. 


\section{La vie des paysans chinois}

Pour la plupart des enfants chinois, le home familial n'a rien d'attrayant. Un mouvement instinctif de préservation le pousse bien entendu à y chercher refuge chaque fois qu'il rencontre au dehors de la malveillance, mais cet instinct, il le partage avec les animaux.

Les cours intérieures des maisons chinoises sont généralement peu spacieuses, aussi la jeunesse turbulente n'y trouve-t-elle pas le champ nécessaire pour se livrer à des ébats autres que des amusements rudimentaires. L'enfant chinois ne dispose d'habitude que de quelques jouets de confection grossière. A I'occasion de certaines fêtes, surtout dans les villes, I'on voit des enfants surchargés des jouets les plus divers, objets de pacotille et peu coûteux.

On peut observer ce même phénomène dans les villages à l'époque de chaque grande foire : la part attribuée à l'enfant y est toujours préparée de façon à ce qu'elle corresponde à ses besoins. Mais de tous ces objets confectionnés avec de l'argile, du papier, des morceaux de drap, des herbes, du sucre et d'autres substances périssables, rien ne restera à la prochaine lune. Dans les régions où pousse le bambou, on fabrique à I'usage des enfants des objets plus utiles, moins fragiles et sans doute destinés à une plus longue durée.

A en juger d'après ce que nous avons observé, jamais les parents chinois ne prennent part aux jeux de leurs enfants : c'est une éventualité qui ne leur vient même pas à l'esprit. Il y a fort peu de jeux auxquels les enfants puissent se livrer à l'intérieur de la maison et cette heure bénie entre toutes chez 


\section{La vie des paysans chinois}

nous par nos petits, celle qui les réunit autour de la lampe familiale, est pour le Céleste I'heure de I'obscurité sans joie. On vaque tant bien que mal aux occupations de la soirée, à la faible lueur d'une mèche mal taillée trempée dans quelques cuillerées d'huile végétale brute ; mais pour l'étranger la maison chinoise constitue à pareille heure un asile dépourvu de tout confort, surtout en hiver. Il n'est donc pas surprenant que ceux des membres de la famille qui en ont la possibilité, se traînent sur le k'ang plus ou moins bien chauffé, après s'être enroulés dans leurs vêtements de nuit ouatés. Pendant le moment de son existence où les parents laissent avec plaisir l'enfant chinois livré à lui-même, celui-ci trouve un refuge dans les bras accueillants du dieu Morphée.

Les jeux en plein air des enfants chinois sont d'un type anodin, peu intéressants. Lancer des mottes de terre sur un but, jouer au volant avec leurs doigts de pied et leurs talons, frapper sur un morceau de bois effilé à un bout de façon à le faire sauter dans l'enceinte d'une «ville » tracée sur le sol, pratiquer un certain jeu d'oie et de renard, etc., tels sont les amusements les plus populaires dans les régions rurales que nous connaissons. Les villes chinoises ont des attraits d'une autre nature et dont quelques-uns ne diffèrent pas beaucoup de ceux qui se rencontrent dans le reste du monde. Mais, même à la campagne où ils peuvent se mouvoir librement, les jeunes gens chinois ne paraissent avoir aucun goût pour les jeux qui les obligent à beaucoup d'exercice. On ne les voit guère se livrer à des courses comme le font en Occident les enfants de cet âge. Leur manière de sauter, de grimper dénote une ignorance complète des sports. 


\section{La vie des paysans chinois}

Nous n'avons jamais connu de corbeau assez imprévoyant pour bâtir son nid en un endroit susceptible d'attirer l'attention d'un garçon anglo-saxon. Le corbeau chinois n'a pas de ces méfiances : il édifie son nid sur un arbre quelconque à l'intérieur et autour des villages chinois. Il n'est pas rare de voir un vieux peuplier qui porte une douzaine de ces énormes amas de tiges entrelacées, et qui, d'année en année, sont utilisés successivement par les générations ailées.

L'auteur de ce livre se souvient d'avoir compté un jour vingtquatre nids sur un orme de grandeur moyenne, et cela dans le faubourg d'une ville chinoise. Les enseignements de Bouddha sur le respect religieux dû aux animaux ne suffisent pas pour expliquer l'inviolabilité dont jouissent les nids de corbeaux dans toutes les régions de la Chine. Au printemps, il arrive parfois qu'on les protège en disant : «Aimeriez-vous que votre maison soit détruite ? » Mais, dans les zones où le moindre brin de combustible est précieux, quelle peut être la raison qui fait que l'on respecte le nid alors que le volatile a cessé d'en faire usage ? Inutile de chercher à l'expliquer par la croyance superstitieuse que sa démolition porte malheur, bien que, à première vue, I'on soit tenté d'admettre cette hypothèse. Des enquêtes portant loin nous ont fait découvrir que le petit Chinois a tout simplement peur de grimper sur un arbre jusqu'à hauteur d'un nid de corbeaux. « S'il allait tomber ! 》 vous réplique invariablement toute personne interrogée à ce sujet. Et c'est cette question laissée sans réponse et à laquelle personne ne peut répondre, qui semble protéger les petits corbeaux chinois à travers les âges. 


\section{La vie des paysans chinois}

L'eau courante est rarement accessible aux garçons chinois, c'est-à-dire que la proportion de ceux qui ont un cours d'eau quelconque à leur portée est infinitésimale. Ils n'ont généralement ni lacs, ni rivières, ni étangs dans lesquels ils pourraient se plonger, apprendre à nager ou se livrer au plaisir de la pêche. La mare communale, excavation d'ou I'on extrait depuis des temps immémoriaux les matériaux nécessaires à la construction des maisons, voilà ce qui procure très approximativement aux enfants les joies, qu'ils ne connaîtront jamais, d'une ville d'eaux. Pendant l'été, ces trous - dont quelques-uns ont les dimensions d'un bassin de radoub débordent d'une eau sale et, à ces moments-là, ils sont en général fréquentés par des bandes d'enfants qui, dans le costume primitif du Paradis terrestre, s'adonnent à I'un des rares plaisirs de leur vie mondaine. Lorsque les gamins sont devenus trop grands pour se livrer à ce genre d'ébats, il existe plus d'une raison de craindre que beaucoup d'entre eux aient pris leur dernier bain, quel que soit le nombre des années qu'il leur reste à vivre!

Si le garçon chinois ne peut connaître les plaisirs de la pêche, il ne lui est pas davantage loisible d'aller à la chasse, car même dans les parties les plus fertiles des plaines dont se composent les immenses régions de l'Empire, il n'y a rien à chasser. Quelques oiseaux de petite taille et le lièvre ordinaire semblent être les victimes les plus habituelles des villageois. Mais, en dehors du nombre restreint des gens qui cherchent à tirer profit de leur chasse comme moyen de subsistance, peu de personnes dépensent leur énergie dans ce genre de sport et l'instinct qui, 


\section{La vie des paysans chinois}

dit-on, pousse l'Anglais moyen à s'écrier : « Le temps est beau, allons tuer quelque chose ! » fait totalement défaut au Chinois.

Dans les zones de l'Empire, relativement limitées, où la glace devient en hiver d'une épaisseur suffisante pour supporter le poids de l'homme, l'on voit beaucoup de personnes prendre leurs ébats sur les rivières et les étangs gelés. Mais la circulation des traîneaux avec passagers est l'affaire des bateliers qui, pendant la saison où la navigation est arrêtée, ne possèdent nul autre moyen de gagner leur vie. Les petits Chinois ne s'adonnent pas à ce divertissement comme nos enfants, et, le voudraient-ils, que les parents ne songeraient jamais à leur fournir de pareils véhicules dans un simple but d'amusement. Quant à chercher à les gagner comme s'y emploierait un garçon de chez nous qui, désireux de posséder un traîneau ou une paire de patins, ferait dans ce but des travaux supplémentaires en ramassant de la ferraille ou par d'autres expédients analogues, un jeune Céleste serait incapable même $d^{\prime} y$ songer.

Si les amusements de l'enfant chinois sont plutôt rares et peu intéressants, il est, par contre, un fait bien établi, à savoir que rien ne doit entraver son travail. La quantité d'enfants, dans n'importe quelle région de la Chine, est littéralement incalculable ; or il est permis d'affirmer que l'on oblige le plus grand nombre de ces enfants à consacrer la majeure partie de leur temps à quelque occupation utile. Il n'y a presque aucune main-d'œuvre qui ne puisse utiliser jusqu'aux plus jeunes, et c'est bien pour cette raison que I'on voit fréquemment certains métiers devenir héréditaires dans les familles. L'enfant, habitué à 


\section{La vie des paysans chinois}

un certain genre d'activité physique, est apte à l'exercer, même $s^{\prime}$ il se montre incapable d'aucun autre travail. S'il est fils de fermier, rares sont les périodes de l'année où il ne trouve pas à s'occuper aux travaux agricoles. Sans doute en est-il de même dans d'autres pays ; toutefois l'assiduité inlassable des Chinois au travail, aiguillonnée par la pauvreté générale, donne à ce fait une importance qui ne se manifeste nulle part ailleurs avec autant d'acuité qu'en Chine.

Mais alors même que les travaux des champs fourniraient quelque répit, ce qui n'est du reste jamais le cas avant que I'hiver se soit tout à fait installé, il y a deux occupations qui conviennent à l'enfant en toute saison et qui sont pratiquées ici par des milliers de garçons et de filles : récolter le combustible et ramasser le fumier. Dans un pays où les frais de transport ne permettent pas d'utiliser le charbon à plus de quelques milles de la mine, il est indispensable de recourir aux produits du sol

spéciaux à chaque région, afin d'assurer tant bien que mal la cuisson des aliments et le chauffage du logis. On ne gâche ni une branche, ni une feuille, ni un brin d'herbe. Même pendant les périodes les plus prospères, les produits du champ familial ne suffisent guère pour les besoins en combustible de la maisonnée. La coutume chinoise d'absorber fréquemment de l'eau chaude qu'il faut renouveler chaque fois qu'elle se refroidit afin de satisfaire à la soif de tout nouvel arrivant, consomme une quantité de combustible très supérieure à celle que réclamerait la cuisson seule des aliments. La cueillette et l'emmagasinement de tout ce qui peut se brûler est d'une importance presque aussi grande que la récolte du blé. Toutefois, il existe dans chaque 


\section{La vie des paysans chinois}

village, un nombre considérable, bien que variable, de gens qui ne possèdent aucune terre. Gagnant une subsistance précaire en travaillant pour les propriétaires fonciers, ils sont mal rémunérés et leur gain est souvent insuffisant pour nourrir au logis les nombreuses bouches qui réclament leur pitance.

Dans le Shantung, on peut louer à l'année un ouvrier agricole pour une somme équivalant à cinq dollars-or, nourriture comprise, mais sans casuel. Si l'année a un mois intercalaire, cet homme n'arrive pas à gagner plus de deux « cents » par jour. Lorsque le fleuve Jaune déborde et chasse les paysans de leurs habitations, on peut avoir un laboureur à un taux pour ainsi dire nominal.

L'auteur a connu un garçon bien constitué qui avait été engagé à raison d'une somme annuelle équivalant à 1 dollar 1/2or. Dans un autre cas, I'on n'offrit au jeune gars, pour un an également, qu'un dollar environ, et encore lui demandait-on qu'une personne honorable se portât caution et garantît qu'il ne déserterait pas la ferme!

En ce qui concerne le combustible indispensable pour cuire les misérables aliments qui composent une nourriture insuffisante, la maisonnée dépend entièrement de ce que les enfants ont pu ramasser. Tout relâchement dans ce travail causerait un tort presque aussi grave à l'entretien de la famille que le chômage du gagne-pain lui-même. Dans cette lutte ingrate autour d'un panier de feuilles sèches et de mauvaises herbes, les enfants de Chine donnent le long de l'année une somme de travail absolument incalculable. 


\section{La vie des paysans chinois}

Au milieu du désert véritable dans lequel s'écoule l'existence de la plupart d'entre eux, tout événement qui interrompt la désespérante monotonie de leurs journées est accueilli avec joie. Les jours fériés, les foires annuelles ou semi-annuelles de quelque ville des environs, parfois une représentation théâtrale ou même l'humble guignol, l'arrivée imprévue du conteur ambulant, l'inéluctable succession de mariages et d'enterrements et, par-dessus tout, les quinze jours de vacances du nouvel an, sont autant d'entr'actes reposants dans ce dur et incessant labeur.

Il est dans l'existence du jeune Chinois un événement qui revêt à ses yeux une importance que ne soupçonnent pas les jouvenceaux d'Occident. C'est la cérémonie de « l'imposition du bonnet » : du jour où il arbore la coiffure masculine nationale, le jeune Chinois est un homme, il peut se marier.

L'âge requis pour le mariage n'a rien d'absolu, mais le plus souvent il a lieu vers la seizième année de l'intéressé. Le protocole en est très variable : dans certaines localités rurales il consiste en une sérénade donnée par des musiciens la veille de la cérémonie et le jeune homme, de son côté, fait une visite à chaque famille du village où il s'acquitte de ses prosternations à peu près comme lors du jour de l'an. Il est désormais considéré comme ayant atteint sa maturité, ce qui le met, dans une certaine mesure, à l'abri des rebuffades qu'on lui prodiguait alors qu'il était « seulement un enfant ».

Le mariage même constitue la partie la plus curieuse de I'affaire. La façon de procéder repose sur des principes si 


\section{La vie des paysans chinois}

différents des nôtres qu'il est difficile à un Occidental de se réconcilier, soit avec la théorie, soit avec la pratique des Chinois en pareille matière. A nos yeux un mariage semble normal entre personnes ayant atteint non seulement l'âge de puberté, mais aussi une certaine maturité d'esprit compatible avec les relations nouvelles qui vont s'établir entre les deux conjoints. Nous concevons I'homme et la femme comme la base et le centre d'une nouvelle famille et nous nous inclinons devant l'ancienne théorie qui veut qu'à cette occasion l'on quitte père et mère. Il en est tout autrement en Chine. Le garçon et la fille qui se marient ne forment pas une nouvelle famille, mais simplement un rameau de plus du grand arbre familial, indépendamment duquel ces nouveaux ménages n'ont aucune existence personnelle.

Le mariage d'un garçon de dix ans n'est pas chose rare bien qu'il soit tenu pour légèrement prématuré. Le développement physique, intellectuel ou moral des parties contractantes n'a rien à voir dans l'affaire, laquelle est dominée par des considérations très différentes. Parfois I'on hâte le mariage parce qu'une vieille grand'mère dont les forces déclinent veut, avant sa mort, voir s'accomplir cet acte, le plus important dans l'existence de tout Céleste. Quelquefois, c'est afin de régler le partage d'une propriété de telle façon que les héritiers les plus anciens n'aient pas la faculté de récuser les arrangements familiaux. Mais très souvent aussi il faut chercher la raison véritable de ces mariages hâtifs dans le fait que la famille du jeune homme, ayant besoin

d'une servante de plus, estime pratique de la prendre dans la personne de la nouvelle bru. C'est ce qui explique qu'il se trouve 


\section{La vie des paysans chinois}

en Chine tant de femmes plus âgées que leurs maris. Plus les fiancées sont musclées et plus on les recherche, elles pourront d'autant plus travailler.

Aux yeux des Chinois, il n'y a pas plus d'incongruité dans le fait d'épouser un tout petit bout d'homme, très jeune et dont la taille atteint à peine la moitié de celle de sa future femme, qu'il n'y en a à jouer aux dames avec des boutons et à couronner le premier qui parvient à la rangée des rois. Quelle importance peut-il y avoir à ce que le bouton soit petit ou gros une fois qu'il est parvenu au dernier rang du damier et qu'il peut se mouvoir en toute indépendance, fait que I'on reconnaît en doublant ce premier bouton d'un autre ? Il en est de même du jeune marié chinois. Est-il, à vrai dire, autre chose qu'un double bouton, mais qui reste toujours un bouton, et de petite taille, un élément insignifiant dans le jeu large et compliqué de la vie familiale ?

L'étranger qui assiste à un mariage chinois n'a pas l'impression que l'intérêt général est concentré sur le fiancé. Quant à la fiancée, son prestige, essentiellement fugitif, repose sur la curiosité que chacun éprouve a évaluer le genre du marché qu'a fait la famille en la choisissant. Le fiancé reçoit l'ordre de quitter l'appartement où, d'après la coutume de certaines régions, il était consigné, tel un bœuf prêt pour le sacrifice. Il doit ensuite s'agenouiller, faire kotow, successivement devant des quantités de personnes, tant et tant que ses genoux deviennent raides et ses jambes engourdies. Les

yeux baissés en signe d'une profonde humilité, le plus gauche des jouvenceaux chinois s'acquittera des détails de cette pénible 


\section{La vie des paysans chinois}

cérémonie avec une aisance naturelle que le jeune Occidental le mieux éduqué ne pourrait guère égaler et certes jamais dépasser.

Ce rituel compliqué et qui se prolonge indéfiniment, une fois terminé, notre jeune héros est, il est vrai, un homme marié, mais non pour cela le « chef d'une famille », pas même de la sienne. Il demeure sous le contrôle de son père tout comme avant et sa femme est soumise à l'autorité de sa belle-mère à un degré qui dépasse notre entendement. Si le jeune époux apprenait, avant son mariage, à composer des « essais », le lien conjugal n'interrompra nullement le cours de ses études. Aussitôt la fête terminée, il s'y remet comme par le passé. Pour peu qu'il soit de compréhension lente et qu'il ne puisse faire pénétrer dans sa cervelle les « sept particules vides » - cette terreur de l'étudiant chinois encore inexpérimenté - de façon à satisfaire le professeur, il lui arrivera de recevoir encore des coups de bâton sur la tête pour son manque de sens critique. Peut-être rentrera-t-il alors en pleurant au logis et demandera-til à sa femme de recouvrir d'un emplâtre noir la partie de son crâne endommagée par le châtiment du pédagogue. Nous avons connu un garçon chinois hydropique, à un stade déjà très avancé du mal, qui refusait obstinément d'avaler le moindre médicament de goût amer. Si la mère, dans sa tendresse, insistait en essayant de la persuasion, il entrait dans une colère folle ou fondait en larmes. Lorsqu'on lui refusait les deux melons d'eau entiers qu'il réclamait, il usait de la même tactique, d'où crises violentes d'irritation et cris éperdus. Ce jouvenceau ne faisait en 


\section{La vie des paysans chinois}

somme que prolonger jusqu'à un âge plus avancé les procédés universellement adoptés par l'enfance chinoise.

Cependant ce garçon de dix-sept ans, si douillet, était marié depuis quelques années déjà et il a laissé une veuve pour déplorer que la conjonction inopportune de I'hydropisie, des drogues et des melons ait brisé sa vie.

Il n'est pas rare de rencontrer des jeunes gens qui, mariés tôt, courent en pleurant chez leur mère épancher quelque chagrin et chercher consolation, comme ils en avaient coutume peu de temps auparavant, mais ils sont rabroués sans pitié par cette phrase :

- Pourquoi venir chez moi ? Si tu as besoin de quelque chose va chez elle!

Par une étrange exception à la pruderie qui caractérise presque uniformément les coutumes chinoises, il est fréquent mais pas absolument général - qu'à l'occasion d'un mariage, les invités prennent la liberté de pénétrer dans l'appartement particulier des mariés pour se livrer à une minutieuse inspection de la mariée, - telle la bête que I'on examine au marché avant de l'acheter, - et d'exprimer ouvertement toutes les critiques que la jeune femme leur suggère. En cela comme en tout, les coutumes varient avec les lieux, mais la phrase : faire des niches dans la chambre nuptiale - nao tung-fang - témoigne de la fréquence de pareils procédés. En 1893, un journal de Canton signalait le cas d'une jeune mariée qui avait trouvé la mort à la suite d'une inspection de ce genre : on l'avait inondée d'eau froide. Les coupables furent condamnés à payer 200 dollars à 


\section{La vie des paysans chinois}

titre de « monnaie de consolation » et à supporter tous les frais d'un nouveau mariage.

Un postulat de l'éthique chinoise prescrit qu'aucune branche d'une famille ne doit demeurer sans son représentant vivant afin que les rites ancestraux puissent s'accomplir en bonne et due forme. Or il arrive souvent que l'une des branches n'a pas de fils. Force est alors d'adopter ceux des autres frères ou, à leur défaut, le petit-fils d'un oncle ou l'arrière-petit-fils d'un grandoncle. Les fils ainsi adoptés jouissent des mêmes prérogatives que s'ils étaient les véritables enfants de la maison et ils ne peuvent en être dépossédés par ceux qui naîtront peut-être ultérieurement. En raison de la fréquence de ces adoptions, il est souvent difficile de préciser la parenté exacte d'un homme avec les autres membres de la famille. Quelquefois il continue à appeler père celui qui l'est véritablement ; par contre, il lui arrive souvent de donner ce titre à l'oncle qui l'adopta et d'appeler oncle son propre père. Il se peut également qu'il soit adopté nominalement par un oncle tout en continuant à vivre chez ses parents comme par le passé. Le fait d'adopter des parents, qui s'exprime par le terme : « passer de l'autre côté » - kuo -, joue un rôle suffisamment important dans la vie chinoise pour faire l'objet d'un véritable traité plutôt que d'un simple paragraphe. En Chine l'adoption se mêle à la trame de toute l'existence familiale, laquelle ne peut se comprendre si l'on ne tient pas compte du substratum sur lequel repose cette pratique universelle. Bien qu'elle prenne racine dans le culte des ancêtres,

elle se maintient jusque parmi les classes les plus pauvres de l'échelle sociale, et cela en raison de leur pauvreté même. 


\section{La vie des paysans chinois}

Lorsqu'un homme n'a pas d'héritier, il peut se voir obligé d'adopter I'un ou l'autre des nombreux candidats qui se présentent, avides de s'assurer ainsi la possession éventuelle de biens, même insignifiants. Mais celui qui est adopté dans ces conditions devient responsable des frais des funérailles de I'homme qui l'adopta. D'innombrables procès sont nés de la complexité de ces transactions.

S'il ne se trouve personne dans la famille ou dans le clan de l'adoptant qui convienne à ce but, il faut alors qu'il se contente du fils d'une sœur ou même du petit-fils d'une tante. Pour nous, un « neveu » en vaut un autre ; mais, aux yeux d'un Céleste, les enfants d'une sœur - portant un nom de famille différent - lui paraissent beaucoup plus éloignés que ceux d'un frère. De plus, au moment du décès de l'adoptant, la position du fils d'une sœur peut devenir très incertaine. Aussi, plutôt que de prendre un pareil héritier, beaucoup de Chinois préfèrent-ils porter leur choix sur un simple étranger dont on pourra facilement se débarrasser si l'on s'aperçoit qu'il ne fait pas l'affaire. Des « outsiders » de ce genre, bien qu'ils puissent faire preuve de sentiments filiaux à l'égal des enfants véritables et donner entière satisfaction en toutes choses, n'arrivent jamais à effacer le stigmate d'avoir été « ramassés », et cette tare persistera à travers de multiples générations. L'auteur a reçu à ce sujet les confidences d'un homme qui se plaignait d'être sans influence dans son village natal parce que son grand-père avait jadis été adopté comme étranger. 


\section{La vie des paysans chinois}

Il existe une autre méthode permettant de s'assurer un fils, méthode bien moins répandue d'ailleurs qu'on ne le supposerait. Elle consiste à chercher un mari pour une fille et à l'adopter ensuite comme fils. Par ce moyen, les parents sont à même d'avoir, leur vie durant, les services de leur propre fille privilège très rare en Chine - et un héritier adopté dans ces conditions est certes plus attaché à sa nouvelle famille que n'aurait chance de l'être un fils choisi dans une autre famille. Mais bien rares sont les clans qui ne pourraient fournir un certain nombre de candidats aptes à remplir le rôle de fils adoptif. Il faudrait pour se concilier le personnage quelconque qui brigue I'adoption faire avec lui le partage de ses biens, ce qui pour une famille sans beaucoup de ressources, équivaudrait à une complète pauvreté. C'est pour cette raison que « l'appel à un gendre » n'est guère pratiqué que dans les familles où il n'y a ni fils de frères, ni cousins disponibles.

En règle générale, le Chinois se montre aussi habile à saisir l'occasion d'établir des droits sur la propriété d'autrui que l'est un chat qui simulerait le sommeil pour happer l'oiseau imprudemment perché à portée de ses griffes.

L'auteur de ce livre connaît un Chinois qui avait adopté un gendre dans les formes légales, mais le jour où l'on enterrait son propre père, l'adoptant fut très surpris de voir une bande d'étrangers en deuil venir dans la cour de sa maison et faire entendre un chœur de gémissements sur la mort de leur «oncle », « grand-père », etc., selon la parenté qu'ils s'attribuaient avec le défunt. Renseignement pris, notre homme 


\section{La vie des paysans chinois}

apprit que ces gens arrivaient d'un village assez éloigné et que, possédant le même nom que le décédé, ils avaient décidé de se réclamer de leur parenté avec lui pour faire valoir des droits à ses biens, biens si modestes d'ailleurs qu'ils suffisaient à peine pour subvenir aux besoins d'une famille peu nombreuse. Il en résulta un procès que ces prétendants perdirent n'ayant pu fournir aucun document authentique qui justifiât leurs droits ; ils furent, de plus, sévèrement bâtonnés par ordre du magistrat du district pour les punir d'avoir émis des prétentions illicites.

En Chine, on est souvent surpris d'apprendre qu'un autochtone qui, de tout temps, fut connu sous un certain nom, a pris brusquement un surnom absolument différent. C'est ainsi que M. Wang-Fleur de printemps apparaît du jour au lendemain sous le vocable de Ma Vertu Illustre. Cela s'appelle « revenir à son nom originaire »; les raisons en sont multiples. Au moment même où l'auteur écrit ces lignes, un de ses amis lui raconte les expériences par lesquelles il a passé dernièrement et dont le résumé jettera peut-être quelque clarté sur les théories et les pratiques des Chinois en fait d'adoption. Cet homme est le deuxième de quatre frères dont l'aîné avait été adopté par une branche de la famille un peu éloignée ; il a lui-même trois fils. Son frère $\mathrm{N}^{\circ} 1$ en a deux dont le plus jeune a été adopté par le $N^{\circ} 3$ qui n'a pas d'enfants. Le № 4 mourut récemment sans progéniture, mais ses obsèques n'ont jamais eu lieu. Le corps, mis en bière, attend le moment favorable, c'est-à-dire une période de prospérité matérielle, pour être enseveli. Ce $N^{\circ} 1$ devait de l'argent à un marchand de grains chez lequel les $N^{\circ} 2$ et 3 ont des intérêts, quelques centaines de cordons de 


\section{La vie des paysans chinois}

sapèques. Pour pouvoir acquitter cette dette et payer les frais d'un enterrement convenable, il aurait fallu vendre les quarante arpents de terre composant la propriété commune, de sorte que personne ne voulut se risquer à contester le droit d'adoption. Mais, tout dernièrement, un fils du $\mathrm{N}^{\circ} 1$ a voulu faire valoir ses droits à I'héritage et, depuis douze jours, on se dispute sur cette question. Afin de régler le différend, on a fait appel à près de trente-huit «prêcheurs de paix » dont plusieurs sont des gradués littéraires. De graves discussions ont éclaté entre eux et les membres de la famille, une bataille même. Les « prêcheurs de paix » furent injuriés et ils se vengèrent en rouant de coups le fils du $\mathrm{N}^{\circ} 1$ qui s'était mis dans son tort. De nouvelles complications surgirent qui, finalement, viennent de se régler autour d'un beau festin.

Au cours de ces controverses embrouillées, les 38 hommes ne s'étaient pas privés de boire et de manger : telles sont du reste les prérogatives les plus marquantes des «prêcheurs de paix » et pour l'avantage desquelles beaucoup de disputes sont avivées à plaisir et nombre d'autres laissées en suspens pendant de longues périodes. Dans le cas qui nous occupe, la bande consomma 78 « catties » de vin, une centaine de gâteaux de farine, etc. Le coût total incombant au $N^{\circ} 2$ se monte à 230 cordons de sapèques dont une centaine sera versée par le $\mathrm{N}^{\circ} 2$ à la famille du $\mathrm{N}^{\circ} 1$ à titre de «monnaie de consolation ». Et cependant le $N^{\circ} 2$ n'a aucun intérêt d'ordre pécuniaire dans cette affaire. 


\section{La vie des paysans chinois}

Un autre des nombreux moyens imaginés par les Chinois pour perpétuer une branche familiale menacée d'extinction consiste à faire représenter deux branches par un seul individu. Donc, à supposer que sur deux frères un seul ait un fils, ce rejeton pourra prendre deux femmes, une pour chaque branche. Chacune de ces épouses aura son installation particulière : le mari devra sans doute partager également son temps entre ses deux habitations, et aller même changer de vêtements en se rendant d'un logis dans un autre. Inutile de dire que les jalousies provoquées par une pareille organisation suffiraient à détruire n'importe quel ménage.

Si la question de sentiment joue un rôle assez effacé lors de I'introduction d'une bru dans une famille, il en est souvent de même lors de sa mort. Ce décès cause pourtant quelques regrets, ne fût-ce qu'en raison des soucis et des dépenses qu'il entraîne. Rien ne fait peut-être mieux ressortir le contraste entre les mœurs d'Orient et celles d'Occident que l'absolue indifférence que professent les Orientaux pour leur tranquillité et pour ce que nous entendons par vie privée. A la vérité, ils ressentent quelquefois vaguement ce manque de quiétude, mais comme celle-ci est un bienfait éprouvé seulement par la faculté imaginative et ne provenant jamais de l'expérience, son absence n'assume pas ici le caractère intolérable qu'elle revêtirait à nos yeux. Dès qu'un Chinois tombe malade, I'on s'empresse d'en aviser tous les parents proches ou éloignés, et nombreux sont ceux qui estimeront que le strict devoir les oblige à quitter leurs occupations, fussent-elles même très importantes, et à aller « jeter un coup d'œil ». Cette inspection se prolonge parfois 


\section{La vie des paysans chinois}

pendant des jours, des semaines, sans que la présence de ces visiteurs contribue le moins du monde aux soins donnés au malade ; elle lui serait plutôt nuisible en augmentant le nombre de gens qui papillonnent autour du patient et le fatiguent par des questions incessantes sur l'état de sa santé : chacun est fertile en suggestions, en conseils tous plus saugrenus les uns que les autres, quant à ce qu'il est bon de prendre en pareil cas. Rares seraient ceux d'entre nous qui n'aspireraient pas à la mort plutôt que de subir de pareilles pratiques, inséparables chez les Célestes de toute maladie grave, et ce sont cependant tous ces usages immuables qui règlent la naissance, la vie et la mort des Chinois.

Lorsque l'état du malade est considéré comme désespéré, on s'empresse de lui « mettre les vêtements », c'est-à-dire ceux qui doivent servir à son ensevelissement, tâche extrêmement pénible à regarder et à laquelle on procède en tirant la victime dans tous les sens. Quand il s'agit d'un vieillard, des disputes violentes pour des questions d'intérêt ont souvent lieu autour de son lit de mort. Si c'est une épouse qui va disparaître - surtout une jeune - et que la fortune soit considérable, il ne faudra pas s'étonner que, dans la maison mortuaire, il y ait des visites d'intermédiaires qui se relayent sans relâche, acharnés à proposer une autre femme pour remplacer celle qui est sur le point de mourir et de prévenir ainsi d'autres offres. Ces

négociations peuvent avoir lieu en présence même de la mourante, deux ou plusieurs étrangers s'efforçant en même temps de faire écouter leurs propositions. 


\section{La vie des paysans chinois}

L'auteur a personnellement connu une famille où s'était produit un incident de ce genre et qui aboutit au choix d'une remplaçante ; mais, finalement, la malade trouva le moyen de ne pas trépasser ; cependant le pacte conclu demeurait valable, et le mari qui devait être si cruellement frappé fut ainsi pourvu de deux femmes légitimes lesquelles lui donnèrent chacune des fils. Chose étrange, la vie de famille est, dans le cas qui nous occupe, relativement paisible. Après le décès d'une femme mariée, la période de temps qui s'écoule avant un nouveau mariage dure souvent très peu et ce ne sont nullement des questions de sentiment qui la prolongent plus ou moins, mais la difficulté de se procurer les fonds nécessaires pour la nouvelle noce. Il arrive même que les obsèques de l'épouse défunte ne sont célébrées qu'après le second mariage.

Le jeune Chinois atteint théoriquement sa majorité à l'âge de seize ans ; pourtant, dans la pratique, il ne jouira de son indépendance que lorsque la génération précédente (limitée à cinq degrés de parenté) aura disparu de la scène du monde. Jusque-là à quel point ses parents se mêleront-ils de ses affaires ? Cela dépendra en grande partie de leur tempérament, beaucoup aussi du sien. Dans certaines familles il règne une assez grande liberté, alors que dans d'autres, la vie, fort pénible, est une source intarissable de vexations - et cela parce que, en Chine, le statut social va à l'encontre des desseins de la nature qui prétend accorder à chaque être humain une personnalité propre tandis que la famille chinoise s'attache à la fondre dans le stock commun, ne laissant à l'individu qu'une indépendance purement nominale. 


\section{La vie des paysans chinois}

En regardant tout autour de soi, I'on peut conclure que la vie d'un jeune garçon au village n'a rien d'enviable. Ainsi que nous avons pu le voir, il apprend à fond deux leçons : l'obéissance et le respect de l'autorité. Elles ont certes leur valeur, et il s'en pénètre si complètement que la haute morale ainsi inculquée contribue dans une large mesure à compenser les grosses lacunes de cette éducation à d'autres égards. Il apprend également à devenir un travailleur. Dans la plupart des cas, cette dernière qualité est la condition essentielle de son existence, et ceux qui refusent de s'incliner devant la loi inexorable du travail disparaissent du fait même de cette loi, au grand avantage des survivants. Pour ce qui est de l'indépendance intellectuelle, il n'en a aucune, il est même incapable de la comprendre. Il fait ce que font ses camarades et ne connaît, ni ne peut imaginer aucune autre voie. Si le jeune Chinois a reçu une bonne éducation, son esprit peut assez justement se comparer au conduit souterrain où viennent se condenser les matières qui filtrent à travers le sol. Parmi toutes celles qui remplissent son cerveau, beaucoup, à l'origine, s'inspirèrent, il est vrai, de la pure doctrine de Confucius, mais, depuis lors, les éléments qui les constituèrent ont passé par de multiples avatars : la plus grande partie de ces matières a subi l'empreinte humaine et manque, hélas ! de sa pureté originelle. Or, c'est d'elles et d'elles seules que son esprit est formé.

Si d'autre part, le Chinois n'a reçu aucune éducation, son cerveau est semblable à un fossé, vide en partie, et, en partie rempli de tout ce qui coule ou vole sur la surface. Le Chinois ne manque pas d'humilité, il en possède même une dose qui ne 


\section{La vie des paysans chinois}

peut exercer sur lui qu'une action déprimante. Il sait qu'il ne sait rien, qu'il n'a jamais rien su, ni ne saura jamais rien et que du reste ce qu'il sait, ne lui sert guère. L'instruction lui inspire un respect aveugle, quoiqu'il n'ait pas l'idée d'en recueillir quelques miettes à son profit. Ses jours sont obscurcis par l'ombre longue, profonde et sans espoir de la doctrine de Confucius. Celle-ci signifie un haut degré de culture pour le petit nombre - qui est fatalement d'esprit étroit et souvent fanatique, - et, pour la masse, une vie entière de stagnation intellectuelle. 


\section{La vie des paysans chinois}

\section{XXIII \\ JEUNES FILLES ET FEMMES.}

Le peuple chinois possède un esprit pratique qui ne le cède en rien à celui des autres nations, et nous n'avons aucune raison de supposer que le Céleste ait jamais douté que l'égalité des sexes, tout au moins sous le rapport du nombre de leurs représentants respectifs, soit l'une des conditions de la propagation de la race. Il est de fait qu'aucune autre famille ethnique ne prit plus de soin à entretenir la continuité de la procréation et que nulle part ce zèle attentif ne fut couronné de plus de succès. Pourtant, les Chinois qui se vantent de posséder une civilisation ancienne et très développée, méprisent leurs propres filles mariées dans d'autres familles, parce qu'elles sortent ainsi du giron ancestral et ne pourront plus, conformément à de très vieilles coutumes, offrir les sacrifices rituels aux mânes des parents décédés. C'est pour cette raison que le dicton populaire affirme que la fille la plus idéalement parfaite, c'est-à-dire celle qui possède les vertus des dix-huit Lo-hans, n'est même pas l'égale d'un fils aux pieds bots. Tout Chinois fait montre, sciemment ou simplement d'instinct, de ce sentiment, au point que I'on ne peut douter qu'il est amalgamé à toutes les fibres de son être. L'égoïsme pur et simple, telle en est la source, comme du reste celle de tant d'autres sentiments humains.

L'entrée dans ce monde d'une petite Chinoise sera vraisemblablement accueillie sans joie, quoique cela ne soit pas 


\section{La vie des paysans chinois}

toujours le cas. Les diseurs de bonne aventure dispensent généralement la chance dans les familles au prorata de cinq garçons pour deux filles. « Tout ce qui dépasserait cette proportion proviendrait de l'esprit du mal. » Avec de pareilles théories proclamant l'incapacité des filles à accomplir les rites ancestraux, étant donné d'autre part la mentalité chinoise telle que nous la connaissons, nous ne saurions nous étonner que, sous l'emprise angoissante de la pauvreté, l'infanticide se pratique sur une aussi grande échelle ; et il semble qu'il a dû toujours en être ainsi. Il ne faudrait pas pour cela se figurer que la conscience chinoise méconnaît que la suppression d'un nouveau-né du sexe féminin est une mauvaise action, mais l'impulsion qui pousse au meurtre plus spécialement les mères déçues et souvent injuriées est trop forte pour que, malgré tous les motifs invoqués, elles puissent y résister.

Des personnes en situation de constater souvent de pareils actes se sont efforcées d'exposer les vraies pratiques des Chinois en ce qui concerne les infanticides féminins. Or, tout ce que I'on peut affirmer c'est que ce crime se commet couramment sur tout le territoire de l'Empire et qu'il est si fréquent dans certaines régions, qu'il compromet sérieusement le maintien d'une proportion rationnelle des sexes. Ces pratiques sévissent avec le plus d'intensité dans les provinces maritimes de la Chine méridionale ; dans quelques districts, les Chinois eux-mêmes les considèrent comme une calamité terrible et menaçante pour l'avenir de la race. Des sociétés chinoises ont beau répandre des tracts et des livres afin d'exhorter le peuple à lutter contre de pareils errements et les magistrats lancer de temps à autre des 


\section{La vie des paysans chinois}

proclamations pour les flétrir, il n'en reste pas moins que, par leur nature même, ces forfaits échappent à la répression légale, et seule une transformation radicale de la mentalité des mères pourrait avoir des effets durables sur cette plaie sociale que constitue l'infanticide des filles chinoises.

A côté de la suppression des enfants femelles, il existe en Chine une autre pratique tout aussi révoltante à notre point de vue occidental, c'est la vente des filles à n'importe quelle période de leur existence, depuis le premier âge jusqu'à celui où elles sont à même d'être mariées. Sous ce rapport, les usages varient beaucoup selon les contrées de l'Empire, mais la coutume de vendre des filles semble, comme l'infanticide, fleurir plus spécialement dans les provinces maritimes du Sud où ce commerce est pratiqué aussi ouvertement que tout autre négoce. Nous voulons bien croire que les parents sont souvent amenés à cette extrémité sous la seule pression de la pauvreté, cependant la certitude que la fille devra se séparer de sa famille à un moment quelconque de son existence et que cette séparation sera irrévocable, contribue sans doute à accoutumer, par anticipation, beaucoup de parents chinois à l'inévitable. Nous n'entrerons pas dans le détail des misères que sont appelées à endurer les pauvres filles ainsi vendues : ce que l'on sait à ce sujet ne peut que nous amener à considérer ces pratiques avec horreur. Lorsque les parents ne sont pas assez riches pour garder leur fille jusqu'à l'époque de son mariage et qu'ils reculent cependant devant l'alternative de la vendre, l'astuce chinoise a imaginé un autre expédient, une sorte de compromis entre les deux. C'est ce que les Chinois appellent le «mariage 


\section{La vie des paysans chinois}

d'élevage », par lequel l'on cède la fille à la famille dans laquelle elle se mariera plus tard. Dès lors le soin d'élever l'enfant et de la marier tôt ou tard au gré de sa convenance incombera à cette famille. Bien que de graves objections puissent être soulevées contre une pareille coutume, il n'y a pas de doute qu'elle est encore préférable au système des mariages dont la pratique cause tant de misères aux Indes. Dans certains cas, toute relation est rompue avec la famille de la jeune fille lorsque celleci a été cédée en vue d'un «mariage d'élevage ». En tout état de cause, une union de ce genre est une sorte d'aveu de pauvreté et d'impuissance matérielle qui place cette famille dans un état d'infériorité plus grand encore que celui dans lequel elle se trouvait auparavant. Lorsqu'une jeune fille est ainsi élevée dans la famille dont le fils va devenir son mari, les deux intéressés ont naturellement toutes facilités pour apprendre à se connaître, il se peut toutefois qu'on leur interdise de causer ensemble par respect pour les usages reçus. Le sentiment ne joue et ne peut jouer qu'un rôle secondaire dans les mariages chinois, mais tout ce qui tend à rendre les parties contractant un mariage de ce genre plus capables de s'adapter aux inévitables frictions de leur future existence en commun ne peut manquer d'avoir ses avantages. Un « mariage d'élevage » procure-t-il en fin de compte aux jeunes époux plus ou moins de bonheur que le mariage usuel ? Jamais un Chinois ne se posera une pareille question pour la simple raison qu'il ne saurait associer l'idée de mariage avec la notion de bonheur, bien au contraire, et s'il arrive à un étranger d'interroger là-dessus un Céleste, les 


\section{La vie des paysans chinois}

réponses qu'il en obtiendra ne seront certainement pas de nature à l'éclairer.

La coutume qui consiste à enserrer dans un bandage les pieds des petites Chinoises est connue de tous les gens possédant quelques notions sur les mœurs de la Chine; inutile de nous y arrêter longuement. Elle est d'usage à peu près général, à quelques exceptions près cependant, tels les Hakkas dans le Sud de I'Empire, exceptions dont on donnerait difficilement une raison. Cette coutume illustre d'une manière frappante certains des traits innés qui caractérisent la race chinoise, entre autres une étrange complaisance à endurer de longues souffrances en vue d'atteindre un certain degré de perfection, rien que pour rehausser son prestige. Il n'existe pas d'autre pratique particulière aux Chinois, parmi celles que la religion n'impose pas, qui soit aussi foncièrement contraire aux instincts naturels de l'être humain, à laquelle le Céleste demeure pourtant plus attaché et qu'il abandonnerait avec plus de regrets.

Nul n'ignore que le plus grand Empereur qui ait occupé le trône de la Chine n'osa jamais risquer sa couronne en essayant d'abolir cette coutume alors que son père avait su imposer à la nation le port de la natte de cheveux en signe d'asservissement. Pendant les 250 ans que dura la domination tartare, il semble que I'on n'ait également rien tenté - sauf à un degré très limité dans Pékin même - pour abolir l'enserrement des pieds et lui substituer les habitudes plus rationnelles de la race qui détenait alors le pouvoir. Mais à quelques li à peine de la Capitale, les vieux usages maintiennent leurs règles barbares. Seuls les 


\section{La vie des paysans chinois}

étrangers habitant la Chine peuvent revendiquer I'honneur d'avoir lutté les premiers pour la réforme de coutumes aussi cruelles qu'inutiles. Leurs efforts demeurés longtemps sans effet commencent enfin à se faire sentir, surtout dans les régions du centre de I'Empire.

Toutes les observations qui ont été faites quant à l'assiduité au travail du garçon chinois s'appliquent également - mutatis mutandis - aux jeunes filles chinoises. En tout pays, et sous tous les climats, « les femmes n'en ont jamais fini avec leur travail », et cette remarque n'est nulle part aussi exacte qu'en

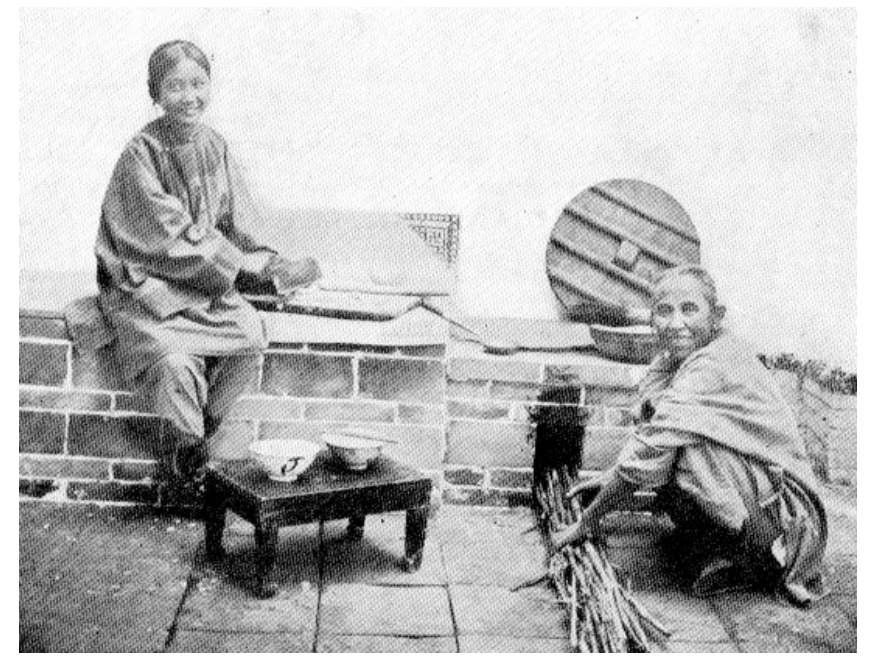

Femmes préparant le repas

Chine où la machine n'a pas encore remplacé les procédés primitifs de ce qui constitue, au sens littéral du mot, la manufacture ou travail à la main. Le soin d'élever les vers à soie, de cueillir, filer et tisser le coton est en grande partie réservé aux femmes et les jeunes filles sont dressées à ce labeur dès l'âge le plus tendre. Les travaux de couture jouent dans la famille chinoise un rôle capital, d'autant plus que le nombre de gens qui peuvent se payer des ouvrières à gages est extrêmement 


\section{La vie des paysans chinois}

restreint. Mais, en dehors de la couture pour laquelle la jeune fille désireuse de se faire accepter par la famille de sa future belle-mère doit se montrer très experte, les jeunes filles peuvent encore rendre des services en ce qui concerne presque tous les travaux d'intérieur auxquels s'adonnera le père. Dans les districts ruraux de l'Empire, garçons et filles sont envoyés au dehors afin de grapiller tout ce qui peut servir de combustible pour la préparation des repas et les filles continuent ce genre d'occupation jusqu'à ce que, devenues trop grandes, elles n'aient plus la permission de s'éloigner, même à courte distance, du toit paternel. Ce n'est pas sans raison que la jeune fille est habituellement désignée par l'appellation de « fille esclave »Ya t'ou -, tout comme nous dirions « notre fille ». A l'étranger cette désignation fait l'effet de celle de « nègre » appliquée à un noir ; mais les Chinois admirent la justesse de l'expression et ne voudraient pas y renoncer.

A l'exception des déplacements, en nombre très limité, qu'elles peuvent accomplir dans leur première enfance et de quelques visites aux parents, la plupart des jeunes filles chinoises ne vont nulle part : elles mènent littéralement l'existence d'une grenouille confinée dans un puits ${ }^{1}$. Des dizaines de milliers d'entre elles ne sont jamais allées à plus de 2 milles de leur village natal en dehors des visites, déjà

1 Une jeune Chinoise employée pendant des années dans la famille de l'auteur racontait que, longtemps après son mariage, on ne lui avait pas encore permis de mettre le pied au dehors de la cour très exiguë de sa maison. La femme d'un Tao-t'ai déclara à une dame étrangère qu'elle espérait bien renaître chien dans la vie future afin de pouvoir aller où il lui plairait. 


\section{La vie des paysans chinois}

mentionnées, à la famille de leur mère où elles sont d'ailleurs très probablement considérées comme des êtres malfaisants, impossibles à exterminer, mais qu'il faut le plus possible tenir en laisse. Lorsque du côté maternel les nièces sont nombreuses, comme il arrive fréquemment, les chefs de famille redoutent ces visites véritablement ruineuses pour eux. On ne peut en effet séparer la mère chinoise de son troupeau d'enfants; or ceux-ci jouissent d'une capacité d'absorption inimaginable et ils éprouvent, tout comme leurs aînés, une joie particulière à se gaver aux dépens du prochain.

C'est lorsque les filles mariées appartenant à une nombreuse famille viennent passer quelques jours, ou quelques semaines, dans la maison maternelle qu'il se passe des scènes dramatiques. Jamais I'on n'a enseigné la discipline de soi-même ou l'abnégation à cette nuée de cousins dont la réunion en masse ressemble souvent à l'intérieur d'une ruche en effervescence. Chacun des membres de la jeune génération est poussé par le désir instinctif de s'adjuger ce qu'il y a de meilleur dans la réserve des vivres et d'en emporter la plus grosse part. Cette course à la victuaille provoque entre les compétiteurs des « scènes de confusion agrémentées de plaintes et de pleurs », dans lesquelles chaque petit participant explique à sa façon les incidents de la lutte ; les cris perçants qu'il fait entendre attirent bientôt la maisonnée entière sur le théâtre du drame. Des parents quelque peu judicieux auraient vite fait de punir tous ces

enfants pour avoir pris part à une querelle qui repose le plus souvent sur des inégalités, vraies ou imaginaires, dans la part d'aliments assignée à chacun d'eux. Mais les parents chinois sont 


\section{La vie des paysans chinois}

rarement judicieux ; tout ce que l'on peut attendre en l'occurrence d'une mère, c'est qu'elle rappelle son ou ses enfants et qu'elle crie après eux. « Yelling » une personne littéralement hurler - c'est l'acte par lequel le « Yeller » sur un ton perçant proclame qu'il désapprouve la conduite du «Yellée ». Cette manifestation se corse le plus souvent d'un langage injurieux et souvent aussi de menaces contre tout fauteur d'une nouvelle provocation : il sera « tué » ou pour le moins « roué de coups ». Le «Yellee » conclut de cet orage qu'il est temps d'en finir, et tout rentre dans l'ordre après une succession de récriminations plus ou moins convulsives.

Mais dans le cas assez fréquent où la mère croit devoir prendre fait et cause pour les droits de son rejeton, la situation se complique. Chaque mère, épousant la cause des siens, se mettra à vociférer avec accompagnement de plaintes, de hurlements et d'insultes de la part des représentants de sa postérité. Enfin, dominant la clameur générale, se feront entendre les cris aigus de la grand'mère dont la volonté, quelque difficulté qu'elle ait à l'imposer, prévaudra finalement, lorsque la paix sera rétablie autour de la bouillotte à thé. Après l'un de ces cyclones, l'atmosphère retrouve peu à peu son calme, la vie ordinaire reprend son cours. Nous avons pourtant connu une jeune femme au tempérament particulièrement fougueux qui refusa d'accepter le règlement à l'amiable d'une dispute de ce genre et qui, pendant plusieurs jours, s'obstina à ne pas dire un mot à ses sœurs. 


\section{La vie des paysans chinois}

Avec le traintrain quotidien de la vie familiale, rompu de temps à autre par quelques visites chez des parents, par une grande foire ou une représentation théâtrale, la petite fille chinoise arrive à un stade que nous appellerons celui de I'« écolière ». A ce moment de son existence, l'enfant commence à préoccuper tous ses amis : quel sera son sort ? A peine avonsnous besoin de faire remarquer que ce souci ne porte aucunement sur son développement intellectuel lequel, en tant qu'il s'agit de la culture qu'elle reçoit, est tout à fait inexistant. A moins que son père ne soit maître d'école et, faute d'emploi au dehors, ne demeure au logis, nul ne songera un instant à donner à la fille de la maison quelques rudiments de lecture. S'agît-il même de garçons, pareil soin serait exceptionnel, en dehors des habitudes, mais, dans le cas d'une fille, on le jugerait absurde. «Et pourquoi donc ? » s'empresse de demander l'étranger sceptique. Le Chinois mettra beaucoup de temps à expliquer la nature de ses objections et, quelque copieux que soient ses commentaires, il n'aura pas abordé toutes les faces de la question, ni touché au fond même du problème. En voici la véritable raison. L'éducation d'une fille équivaudrait à sarcler dans le champ du voisin, ce serait mettre une chaîne d'or au cou d'un jeune chien appartenant à quelqu'un d'autre et susceptible d'être à tout moment rappelé par son propriétaire : alors que deviendra la chaîne ? Le père qui marie sa fille et exige le remboursement de toute la nourriture qu'il lui a prodiguée depuis sa naissance, est en Chine le type proverbial de I'homme mesquin. Mais cette maxime illustre bien l'une des croyances fondamentales de la société chinoise, à savoir que les parents 


\section{La vie des paysans chinois}

sont responsables du corps de la fille et non de son esprit. Il n'existe guère de Céleste qui n'estime que dépenser son temps, de la peine et surtout son argent pour éduquer la bru en puissance du voisin, c'est du simple gaspillage.

- Mais, objecterez-vous, n'est-elle pas votre fille?

- Pas une fois qu'elle sera mariée ! répondra-t-il, elle leur appartient! Qu'ils la fassent éduquer s'ils en voient la nécessité ! Pourquoi lui apprendre à lire, à compter alors que je n'en retirerai jamais aucun profit !

Et voilà comment, pour cette simple question utilitaire, l'éducation de la plupart des jeunes filles chinoises, depuis des milliers et milliers d'années, n'est jamais entrée en ligne de compte dans les préoccupations du Céleste.

Le souci qu'inspire à ses amis la petite Chinoise dès qu'elle commence à grandir se manifeste par la manière dont on cherche à se renseigner sur elle chaque fois que son nom est prononcé. Les points d'interrogation ne concernent ni son caractère, ni ses talents domestiques, moins encore le degré de ses capacités intellectuelles qui sont à peu près nulles. Elles se résumeront toutes dans cette seule phrase : «Est-elle dite ?» ce qui signifie : «Est-elle fiancée ? » Une réponse négative sera accueillie à peu près de la même façon que nous accueillerions la nouvelle qu'un enfant de chez nous a atteint l'âge de seize ans sans qu'on lui ait rien enseigné. «Pourquoi ? 》 demanderonsnous. «Quel est le motif d'une si étrange négligence ? 》 Le sentiment instinctif des Chinois c'est qu'une jeune fille doit être fiancée le plus tôt possible. Voilà l'un des nombreux points sur 


\section{La vie des paysans chinois}

lesquels Chinois et Anglo-Saxons n'arriveront jamais à se comprendre. Pour nous, Occidentaux, le mariage d'une enfant à peine sortie de nourrice équivaut à un acte d'absolue barbarie.

Dès qu'une Chinoise est fiancée sa situation vis-à-vis du monde change du tout au tout. Elle n'a plus la même liberté qu'auparavant, pour si minime qu'ait été cette liberté. Elle ne peut aller nulle part : ce serait « inconvenant», attendu que quelque membre de sa future belle-famille pourrait la rencontrer et le Céleste ne saurait imaginer rien de plus affreux.

- Pourquoi donc ? demande l'étranger dont la curiosité n'est jamais satisfaite.

- Parce que ce ne serait pas convenable !

Le risque que court la jeune fille d'être vue à un moment inopportun par la famille de sa future belle-mère a pour conséquence que très peu de fiançailles se font dans la ville même où vit la jeune fille, alors que le contraire serait beaucoup plus commode pour les deux familles intéressées. En effet, l'on mettrait ainsi fin à beaucoup de manœuvres louches auxquelles se livrent les intermédiaires ou faiseuses de mariage professionnelles lesquelles n'ont d'autre but que de mener à bien n'importe quelle union proposée afin de toucher la commission promise. On éviterait aussi les pertes d'argent et de temps résultant du déplacement des fiancées d'une ville à l'autre et l'échange de menues politesses entre les deux familles se trouverait également facilité. Mais de tous ces avantages le Chinois n'a cure et à toute modification des usages reçus, il opposera toujours la même objection, à savoir le risque déjà 


\section{La vie des paysans chinois}

mentionné. Lorsqu'il y a quelque chance que ces deux groupes familiaux se rencontrent dans le cours ordinaire de la vie, rien n'est plus divertissant pour l'étranger que d'observer les efforts déployés par chacun d'eux pour éviter pareille catastrophe. Cette véritable partie de cache-cache nous rappelle certain jeu de notre enfance dans lequel les uns figuraient «le poison», les autres, ceux qui risquant d'être « empoisonnés » doivent s'efforcer de n'être pas atteints par les premiers. La seule différence entre ces deux jeux, c'est que dans celui des Chinois, chaque camp a peur du « poison » et luttera pour s'en défendre. Il se présente pourtant certain concours de circonstances dans lequel malgré tous les subterfuges des uns et des autres, le sort se prononce à la fois contre empoisonneurs et empoisonnés. Ainsi, lorsque pendant la période des fiançailles une personne âgée vient à décéder dans la famille de la future belle-mère, les bienséances prescrivent que la jeune fille, qui est considérée comme «appartenant » déjà à cette famille, soit présente, et apporte à la défunte son respectueux tribut. Ainsi ferait-elle si elle était déjà mariée. Théoriquement, elle est la fille de la maison; pourquoi ne viendrait-elle pas se lamenter avec les autres parents ? 1 Toutefois, si la chose est possible, l'on s'arrangera pour hâter le mariage dans l'éventualité du décès de quelque personne appartenant à une génération plus ancienne, alors même qu'une date postérieure avait déjà été fixée.

\footnotetext{
1 Nous avons eu connaissance de plusieurs cas dans lesquels la fiancée ne fut pas requise d'assister aux funérailles de sa future belle-mère ou de son futur beau-père. Combien dut-elle se féliciter d'esquiver cette corvée pénible ! Si, parfois, elle doit être présente, elle se contente de s'agenouiller auprès du cercueil sans se livrer aux lamentations rituelles, car les usages sont, dans ce cas comme dans beaucoup d'autres, extrêmement capricieux.
} 


\section{La vie des paysans chinois}

L'étranger cherche vainement une excuse valable à cette coutume de fiançailles prématurées : elle cause de grands embarras aux deux familles sans aucun avantage en échange, en admettant qu'il puisse y avoir des avantages. Elle présuppose et rien n'est moins certain, ni même vraisemblable - que les situations relatives des deux familles resteront les mêmes. L'expérience de tous les jours infirme ce postulat. Le temps apporte des changements pour tous et l'insécurité des affaires humaines n'est nulle part aussi manifeste que dans le cas de la propriété chinoise. Les familles s'élèvent et déchoient sans cesse. D'après un principe bien établi en Chine, les mariages doivent se faire entre gens de conditions égales. Déroger à cette règle serait s'exposer à une infinité de déboires. Mais, lorsqu'il y a fiançailles prématurées, les risques de changements matériels dans la situation de chacune des familles se trouvent singulièrement accrus. A ce moment, le caractère du jouvenceau sur qui repose pour une si grande part la félicité de la prochaine épouse, n'est peut-être pas encore formé et, le serait-il, que la famille de la jeune fille ne peut généralement pas se procurer sur le compte du futur mari des renseignements qu'on devrait cependant obtenir facilement en $s$ 'y prenant d'une manière détournée. Or il semble que d'habitude les parents se préoccupent peu de ces détails une fois les fiançailles proposées et acceptées et, qu'en tous les cas, ils ne se livrent pas à la centième partie des investigations qu'exigerait un pareil acte. Si le jeune fiancé devient brusquement joueur, dissipé, mauvais sujet, la famille de la jeune fille ne peut se rétracter, alors même qu'elle serait poussée à bout. La façon dont les Chinois violent 


\section{La vie des paysans chinois}

les règles les plus élémentaires de la prudence et du bon sens, en ce qui concerne les fiançailles de leurs filles, paraît a priori incompréhensible à un homme d'Occident.

Les accordailles chinoises entrent en vigueur du jour où les cartes rouges - qui attestent les engagements réciproques ont été échangées. Documents d'une ampleur formidable et ayant dans certains districts une grande importance comme témoignages en cas de désagréments futurs. Mais on apprend rarement en Chine la rupture de fiançailles, bien que le cas se produise de temps à autre. En une circonstance de ce genre, la carte de la famille du jeune homme avait été transmise aux parents de la fiancée, ce qui constitue généralement l'acte final de la transaction. Cependant un oncle de la fiancée, bien que plus jeune que le père, souleva des difficultés et refusa de reconnaître l'accord. L'affaire devenait sérieuse ; mais le frère plus jeune tenant bon, il fallut se résigner à renvoyer la carte rouge par l'intermédiaire de celui qui l'avait apportée, opération fort délicate. Or un Chinois est rarement à court d'expédients lorsqu'il se trouve en face d'un acte difficile à accomplir. Celui-ci choisit donc l'instant où tous les membres masculins de la famille du jeune homme se trouvaient aux champs et il jeta la carte dénonçant l'accord dans la cour de la maison familiale du fiancé ; puis il se sauva. Comme aucune des femmes présentes ne savait lire, ce ne fut qu'au retour des travailleurs que l'on apprit ce dont il s'agissait. D'où grand procès, action intentée contre le père de la jeune fille et contre l'intermédiaire. Le différend fut tranché à l'aide d'un versement en argent au profit des demandeurs. 


\section{La vie des paysans chinois}

Nous avons déjà fait remarquer que la remise des cartes rouges établit le point initial des fiançailles, le point culminant étant celui de l'arrivée, dans sa chaise à porteurs, de la fiancée au domicile conjugal. La date de l'événement dépend en général du bon plaisir de la famille du marié. Quelles que soient les cérémonies accessoires de la noce, cette arrivée constitue ipso facto l'accomplissement du contrat, fait qui revêt plus d'importance encore lorsqu'il s'agit de secondes noces pour lesquelles aucun apparat ne semble être en usage. Le calendrier impérial désigne les jours les plus favorables à la célébration des mariages et il arrive souvent qu'il y ait ces jours-là des «festivités rouges », suivant l'expression en usage dans presque tous les villages. Nous avons ici une nouvelle preuve de ce que coûtent aux Chinois nombre de leurs superstitions. Aux dates de bon augure, le prix de location d'une chaise à porteurs augmente selon la loi de l'offre et de la demande, tandis que les gens qui défient courageusement la chance sont, à d'autres dates, mieux servis et à plus bas prix. On raconte qu'en plein hiver, par l'un de ces « jours fortunés » - le fait remonte au commencement du siècle - nombre de fiancées furent transportées dans leurs nouveaux foyers par une terrible tourmente de neige qui aveugla les porteurs et couvrit les chemins ; beaucoup d'entre elles moururent de froid en cours de route, I'on dut en hospitaliser d'autres dans des maisons qui ne leur étaient pas destinées. Par contre, lors d'un été brûlant, l'on connaît des cas où la fiancée fut trouvée morte de chaleur en arrivant au logis du mari. La même chaise à porteurs peut être utilisée plusieurs fois. Dans les régions où il est d'usage de célébrer tous les mariages le matin, 


\section{La vie des paysans chinois}

les secondes noces sont remises à l'après-midi ou même au soir afin de souligner leur peu d'importance.

Le seul acte essentiel du mariage est, en général, l'arrivée de la fiancée dans la demeure du mari, fait que confirment des cas assez fréquents où le Chinois se trouve marié sans avoir été présent à la cérémonie. L'on considère habituellement comme un mauvais augure de changer la date fixée pour un mariage, surtout de la retarder. Il arrive parfois que le fiancé étant, à ce moment, trop éloigné de son domicile n'a pu revenir à temps ; ou bien encore que le jeune homme faisant des études, la date d'un examen important coïncide avec celle fixée pour son mariage. Il n'hésitera pas en pareil cas, à faire passer « les affaires avant le plaisir »; d'autres membres de la famille, plus âgés, se chargeront de prendre livraison de la fiancée afin de ne pas entraver les ambitions de l'époux en ce qui concerne sa culture littéraire.

Nous n'avons pas l'intention d'entrer dans le détail des noces chinoises. Elles sont soumises à des usages très variables bien que l'ordonnance générale en soit la même partout. Ce n'est pas seulement les cérémonies du mariage qui diffèrent, mais la façon dont on procède depuis le commencement jusqu'à la fin. Ces variantes singulières, et en apparence inexplicables, que I'on rencontre partout en Chine proviennent sans doute de coutumes qui se sont toujours transmises depuis l'époque où la Chine était divisée en royaumes distincts. Cependant des différences profondes d'us et de coutumes se rencontrent aussi dans des zones peu distantes les unes des autres et qui jadis firent partie 


\section{La vie des paysans chinois}

d'un même royaume. Selon un dicton populaire, « les usages varient à chaque dizaine de $l i \gg$, ce qui semble être parfois la vérité.

Dans le sud de la Chine, ainsi que nous l'avons déjà remarqué, la coutume qui veut que les parents du fiancé remettent des espèces sonnantes à ceux de la jeune fille à I'occasion des fiançailles de celle-ci, prend l'aspect d'un achat et c'est bien là très souvent le cas. Il est d'autres régions où nous n'avons jamais entendu parler de transactions de ce genre, mais simplement d'une dot apportée par la famille de la fiancée, ainsi que cela se pratique parfois en Occident. Il est hors de doute que les riches Chinois gaspillent de grosses sommes d'argent à l'occasion du mariage de leurs filles et on a coutume de dire que ces dépenses somptuaires ne connaissent pas de limites. Toutefois l'étranger curieux d'observer les faits de près en assistant à un mariage dans cette classe moyenne à laquelle appartient la majeure partie du peuple, gardera l'impression d'un luxe de pacotille, d'un léger vernis d'élégance sous lequel se devine la structure véritable.

Ici, comme en tout ce qui a trait aux usages chinois, I'on ne saurait émettre des opinions qui soient générales en même temps qu'exactes. Dans certaines régions du nord de la Chine, la somme d'argent exigée par la famille du mari est tellement considérable que le reliquat de compte, défalcation faite des frais du trousseau, constitue un profit très appréciable pour le père. Dans d'autres districts, les coutumes locales n'imposent qu'une contribution minime à la famille du fiancé ; parfois même elle 


\section{La vie des paysans chinois}

s'en tire sans bourse délier mais, par contre, la famille de la fiancée doit faire de lourds sacrifices. On réclame une garderobe bien fournie, de la literie. Même dans sa propre maison, la jeune femme devra accomplir des travaux de couture pour la famille du mari et la famille de la fiancée se voit soumise à d'incessantes exigences.

La chaise à porteurs nuptiale est par elle-même l'emblème d'une noce chinoise. Vue avec un certain recul, elle prend l'aspect d'un objet véritablement fastueux, mais à l'examiner de près, I'on constate souvent qu'elle est faite d'un châssis grossièrement monté et recouvert de draperies voyantes très usagées. Dans certains cas, cette sorte de caisse est englobée dans un second châssis que l'on peut enlever à volonté pour pénétrer dans la cour de la maison. La chaise intérieure a des dimensions qui lui permettent de franchir les portes étroites donnant accès aux cours intérieures et, au besoin, à celles de la maison elle-même.

A peine la fiancée est-elle sortie de sa chaise qu'on procède comme chose toute naturelle - au démontage du châssis en présence même des invités. La question de sentiment n'existe pas pour le Chinois, aussi ne conçoit-il pas l'incongruité d'une pareille façon d'agir. La robe resplendissante de la fiancée n'est souvent qu'un vêtement d'apparat loué pour la cérémonie, fait que n'ignorent probablement pas les invités. C'est ainsi qu'un jour la robe que la mariée venait de quitter fut sous nos propres yeux remise au chef d'équipe des porteurs de la chaise. Après l'avoir soigneusement examinée en tous sens pour se rendre 


\section{La vie des paysans chinois}

compte de l'état dans lequel elle lui était rendue, notre homme aperçut - ou feignit d'apercevoir - une tache de graisse qui excita sa colère. Il se mit à déblatérer sur un ton aigu et en arriva à un tel degré de fureur que les invités accoururent de tous côtés pour assister à la dispute. Seul sans doute le spectateur étranger apprécia l'inconvenance du procédé, si peu en harmonie avec les circonstances.

L'arrivée d'un premier né est, dans la vie de la femme chinoise, un événement bien différent de ce qu'il est chez l'épouse des pays d'Occident. S'il s'agit d'un garçon, la joie de la famille est grande, mais, pour peu que ce soit une fille, personne dans la maisonnée ne cache sa déception. La jeune mère sera traitée avec froideur, parfois avec dureté, si même on ne va pas jusqu'à la frapper, - le cas se produit de temps à autre, - pour la punir de son manque de sagesse en privant les siens d'un rejeton mâle. Qu'elle donne le jour à une série de filles et qu'elle ne réussisse pas à avoir un garçon, son existence au logis deviendra un enfer.

Un lord anglais possédait, paraît-il, plus de filles que n'importe quel autre membre de l'aristocratie britannique. Se promenant un jour sur le Continent avec six d'entre elles, il entendit un passant dire à son camarade :

- Pauvre homme !

Et le noble lord se retournant vers la personne qui s'apitoyait ainsi sur son sort, répliqua :

- Pas si pauvre que vous croyez! J'en ai encore six à la maison! 


\section{La vie des paysans chinois}

Il est probable que tout Chinois approuverait le promeneur compatissant et réserverait son mépris au père prolifique. Nous ne croyons pas trop nous avancer en affirmant que sur les millions et les millions de Célestes, il ne s'en trouvera pas un seul ayant douze filles vivantes.

La femme chinoise est autorisée à fréquenter la maison maternelle (dans certaines régions, les coutumes locales sont à ce sujet très libérales). Mais le protocole mondain veut en Chine que tout enfant vienne au monde sous le toit du mari. Cette règle est inflexible et l'on considérerait comme une honte de l'enfreindre. Aussi, pour éviter ce déshonneur, les femmes chinoises se résignent-elles à subir bien des incommodités et à courir les plus grands risques, s'exposant à des accidents aussi pénibles qu'humiliants. Lorsque les étrangers cherchent à savoir les raisons pour lesquelles il est interdit à une femme d'accoucher dans la maison de sa mère, les Chinois se contentent d'affirmer que si pareil événement se produisait, il faudrait s'attendre à ce que la famille de la mère devienne très pauvre. Cette superstition est si vivace que, dans certaines localités, lorsque un tel accident survient, la coutume veut que la famille du mari attelle deux chevaux à une charrue et se rende au logis des parents maternels où elle laboure la cour. Le gendre doit, pour sa part, faire bouillir du millet ou du riz à l'intention de sa belle-mère afin de lui éviter les tourments d'une pauvreté extrême. Toutes ces coutumes bizarres sont peut-être issues d'une seule et même idée, à savoir que si une fille mariée et sa progéniture font appel à la famille maternelle pour subvenir à 


\section{La vie des paysans chinois}

leurs besoins, elles la réduiront à la misère, opinion qui, du reste, a quelque raison d'être.

Il faudrait des volumes entiers pour décrire le cérémonial superstitieux auquel donne lieu la naissance d'un enfant, surtout d'un fils, et plus particulièrement s'il s'agit d'un premier-né. Ces usages sont respectés dans le sud de l'Empire plus rigoureusement encore que dans le nord, dans les villes mieux que dans les agglomérations rurales où souvent l'on ignore entièrement ces coutumes.

A s'en rapporter aux plus hautes autorités classiques chinoises, lorsqu'une mère est véritablement animée du désir de faire de son mieux pour élever son enfant, elle réalise généralement assez bien ses fins, alors même qu'elle n'y arrive pas complètement. D'autre part, le témoignage fourni par de hautes autorités médicales étrangères, affirme que cette présomption en faveur de la mère chinoise est absolument erronée. On ne peut mettre en doute que la superstition détruit, directement ou indirectement, l'existence de nombre d'enfants. Toutefois cette cause aux résultantes complexes, est beaucoup moins néfaste que l'incapacité des parents chinois à se conformer aux lois les plus évidentes de la nature.

L'enfant nouveau-né, déposé sur le k'ang, est parfois chaudement emmitouflé, mais par contre il y demeure exposé à de formidables variations de température. Nombreux sont les enfants qui prennent le sein pendant plusieurs années; on ne connaît pas en Chine d'autre procédé d'apaisement s'ils pleurent, fallût-il à cet effet le leur offrir cent fois par jour. Lorsque le bébé 


\section{La vie des paysans chinois}

est assez fort pour supporter une nourriture variée, I'on n'apporte pour ainsi dire aucune restriction à la nature et à la quantité de ses aliments : fruits verts, melons en nombre illimité, etc. ; on voit même de tout petits enfants occupés à mâchonner des patates crues ou des navets.

Dès qu'il commence à courir, l'enfant ne cesse de grignoter quelque chose ; parfois il suce la pipe paternelle imprégnée de nicotine, distraction qui n'est pas sans provoquer dans l'organisme une faiblesse générale allant jusqu'à l'atrophie. A San-hsi, de tous petits bambins s'exercent à fumer de l'opium : jeu qui devient une habitude indéracinable.

En tenant compte des conditions matérielles de leur première enfance, il est plus que probable que la moitié des enfants chinois disparaissent avant d'avoir atteint la deuxième année ; ce résultat est imputable en majeure partie à beaucoup de ces superstitions qui ont plus que force de loi. C'est ainsi que dans certaines régions, il est absolument interdit de voir la mère ou I'enfant pendant les quarante jours qui suivent les couches. Au cours de cette période critique, des milliers de jeunes existences sont détruites sans que les voisins les plus immédiats en aient même connaissance. Pareille interdiction s'applique dans les cas de maladies fort répandues telles que rougeole, petite vérole, diphtérie ; aussi la mortalité qui en résulte est-elle énorme.

Des quantités d'enfants chinois meurent dans des convulsions dont les causes sont évidentes pour les étrangers à même de constater le manque total d'hygiène infantile qui sévit partout. Nous avons vu une mère chinoise, sous le coup d'un mouvement 


\section{La vie des paysans chinois}

de dépit, jeter son jeune enfant tout nu sur un tas de neige devant la porte de sa maison. Une autre coupa le doigt de son bébé avec des cisailles ébréchées pour préserver l'enfant d'une attaque; elle en fut récompensée en le voyant mourir dans des convulsions. Il paraît que pareilles pratiques sont loin d'être rares.

- Qui aurait pu supposer que ceci produirait cela ?

dit la mère à un étranger. Mais, même une mère douée d'un excellent jugement serait dans l'impossibilité de donner à son enfant des soins éclairés pour la simple raison qu'elle n'est elle aussi qu'une « enfant 1 », et que, pour élever sa progéniture, tout comme pour d'autres choses, elle est entièrement soumise aux ordres de sa belle-mère, aussi bien qu'aux caprices d'une nuée de tantes, de grand'mères, etc., qui pullulent dans les cours intérieures des habitations chinoises.

Le rude labeur imposé aux femmes dans le but de subvenir aux besoins d'une famille nombreuse, d'aider à la rentrée des récoltes et à tant d'autres travaux de plein air, sans parler de la dépense de vitalité physique consécutive à la maternité et à l'allaitement d'une nombreuse progéniture, suffit amplement à expliquer la vieillesse précoce de la femme chinoise, ainsi qu'on peut le constater d'un bout à l'autre de l'Empire. Une fiancée, belle à dix-huit ans de la beauté de sa race, sera fanée à trente

\footnotetext{
1 La femme chinoise dont les parents sont vivants s'entendra fréquemment appeler non seulement « jeune fille », mais aussi « jeune fille non mariée » Ku-niang - alors même qu'elle serait déjà à la tête d'une demi-douzaine d'enfants.
} 


\section{La vie des paysans chinois}

et, avant la cinquantaine, elle n'aura plus que des rides, sans trace aucune de ce qu'elle fut dans sa jeunesse.

En Chine, ainsi qu'il a déjà été constaté, l'existence de la femme au village illustre d'une manière frappante ce fait qu'il est impossible que sa tâche soit jamais terminée. Avant le moment où ses propres enfants cessent d'être pour elle une source inépuisable d'occupations le jour comme la nuit, des petitsenfants auront déjà surgi ne laissant à la grand'mère ni trêve, ni repos. La nourriture nécessaire pour tant de bouches et qui doit être préparée dans I'unique marmite servant encore aux usages les plus divers, constitue, à elle seule, une lourde tâche indéfiniment renouvelée. Les objets d'habillement, sans en excepter les chaussures, sont exclusivement confectionnés au logis y compris la literie, les couvertures, les vêtements ouatés que l'on doit défaire de temps à autre pour les nettoyer et les remettre en état.

Femmes et jeunes filles surveillent à tour de rôle les vergers et les plants de melons, etc., pendant le jour et parfois aussi de nuit. Au moment de la moisson toutes les femmes disponibles de la famille prennent part à ce travail et, lors des récoltes d'automne, les granges regorgent de femmes et de leurs innombrables enfants. Dans les régions qui produisent le coton, les femmes et les filles passent la plus grande partie de leur temps aux champs : c'est souvent en travaillant pour les voisins qu'elles arrivent à gagner les seules épingles qui leur tomberont jamais entre les mains. 


\section{La vie des paysans chinois}

La préparation du coton, ce produit de première nécessité pour les Chinois, occupe des millions de femmes depuis sa cueillette dans les champs - travail pénible en raison de la faible hauteur de la plante - jusqu'au moment où il se transforme en vêtements, puis finalement en couches minces dans les semelles des chaussures. L'égrenage, le teillage des tiges, le filage, le cordage, le dévidage, l'étirage et surtout le tissage sont autant de travaux durs et fastidieux dont il est impossible d'envisager la fin au cours d'une existence. Dans certaines régions, chaque famille possède un métier, machine rudimentaire rejetée depuis un siècle par les pays d'Occident. Il arrive souvent que les membres de la famille se relayent au métier, le mari tissant jusqu'à minuit, la femme lui succédant jusqu'au lever du jour, et cela dans des locaux enfouis aux deux tiers sous le sol, humides, non ventilés, malsains ; il est même parfois difficile d'en tenir les loups éloignés. Au cours de ces dernières années, la concurrence des cotons cordonnés mécaniquement eut des répercussions très graves dans les régions cotonnières de la Chine et bien des gens qui arrivaient péniblement à se suffire avec l'ancien système se trouvent aujourd'hui menacés de mourir de faim. Voilà le revers de la médaille du « progrès ».

Le fait que les jeunes filles chinoises, mariées très jeunes, ne savent exercer aucun empire sur elles-mêmes - maîtrise qu'on ne leur a pas enseignée, mais qui a dans la vie une importance capitale - suffit à démontrer combien est nécessaire la présence d'une belle-mère en tant que facteur dirigeant de la vie familiale. La jeune femme doit appeler sa belle-mère « mère », mais afin de préciser la nature du lien de famille, on lui permet de dire en 


\section{La vie des paysans chinois}

parlant d'elle : «belle-mère mère ». Une femme chinoise en visite chez une étrangère l'interrogea - en présence du mari de cette dernière - sur ses parents d'Europe. La dame mentionna, entre autres personnes, une belle-mère ; et la Chinoise de demander à mi-voix tout en jetant un regard du côté du monsieur étranger : «Ne va-t-il pas nous battre pour avoir dit cela ?»

L'on raconte bien des histoires sur la tyrannie et la cruauté des belles-mères chinoises. Il existe incontestablement dans tous ces bruits un certain fonds de vérité, mais il ne faut pas perdre de vue que, sans elles, la famille chinoise courrait sûrement à sa ruine. Le beau-père n'est pas seulement inapte à exercer le contrôle qui revient à sa femme alors même qu'il ne quitterait jamais son logis - ce qui est rarement le cas - mais les simples convenances l'empêchent d'agir de la sorte, posséderait-il toutes les aptitudes voulues pour remplir cet office. Dans les familles où manque la belle-mère I'on souffrira peut-être de maux bien plus grands que de la pire des bellesmères. Maltraiter sa belle-fille est un incident tellement courant qu'il n'attire guère l'attention des voisins, à moins d'être trop flagrant.

Si l'on ne saurait présenter cet état de choses comme la condition normale et fatale à laquelle sont réduites les jeunes mariées chinoises, on peut du moins affirmer sans exagération qu'aucune d'elles n'est garantie contre de pareils traitements. Ceux-ci prennent des formes variées depuis la réprimande incessante jusqu'aux sévices les plus cruels. Si ceux-ci dépassent 


\section{La vie des paysans chinois}

les bornes, la famille maternelle intervient, non par la voie légale car elle n'en a pas le pouvoir, mais par la force brutale. Dans un cas de cette nature où la belle-fille avait été maintes fois honteusement insultée par la famille de son mari, non sans protestations réitérées de ses propres parents, ceux-ci se décidèrent à mobiliser des forces importantes. Pénétrant dans la maison de la belle-mère, la troupe saccagea le mobilier, roua de coups la famille et finit par traîner la vieille belle-mère jusque dans la rue où on l'abandonna couverte de sang et usant ses dernières forces à hurler tant et plus. Des étrangers l'aperçurent dans cet état. L'on use de ces procédés sommaires en signe de protestation contre la tyrannie domestique et ils illustrent d'une façon typique le dicton que « la sauce qui sert de condiment pour une jeune oie peut aussi en assaisonner une vieille ». L'on pourrait supposer que la seule issue possible à des excès de ce genre fût un long et pénible procès à la suite duquel les deux parties n'auraient eu d'autre perspective que la ruine; mais l'esprit pratique des Chinois ne perdant jamais ses droits, la jeune femme fut ramenée dans la maison de ses parents, des « prêcheurs de paix » intervinrent et la victime regagna le domicile conjugal sur la promesse d'y être traitée plus équitablement. L'on atteindrait sans doute toujours ce résultat si les familles des jeunes mariées faisaient preuve de I'habileté nécessaire à cet effet.

L'auteur connaît un autre cas qui se termina de façon plus tragique. La jeune femme, ayant été ramenée à son mari après que les «prêcheurs de paix » eurent rétabli l'ordre, fut enfermée à clef par sa belle-mère dans une petite pièce où on lui servait 


\section{La vie des paysans chinois}

un seul repas par jour. Au bout d'une année de ce régime, la malheureuse se pendit.

Ce ne sont pas seulement les ignorants et les gens sans éducation qui prennent eux-mêmes la loi en main pour protéger leurs filles malheureuses. Nous connaissons un père, gradué littéraire, dont la fille s'était jetée à l'eau. Il recruta une bande de gens avec lesquels il se rendit à la maison de son gendre, fit démolir la porte d'entrée et jeter à bas une partie des bâtiments. Au cours du procès qui s'ensuivit, il fut sévèrement réprimandé par le magistrat du district. Il n'avait pas le droit, lui dit ce dernier, de se venger lui-même, et n'eût été son rang littéraire, il aurait été condamné à recevoir la bastonnade devant le tribunal.

Un exemple plus frappant encore nous est fourni par un fonctionnaire de troisième rang. Ce père, indigné des mauvais traitements subis par sa fille, alla, fortement accompagné lui aussi, tenter une attaque en règle contre la maison de son gendre ; la bâtisse, solidement construite ne se laissa pas entamer. Le Tao t'ai furieux exhala sa colère en insultant toute la famille d'une voix tonitruante avec un vocabulaire qu'aurait pu lui envier le dernier des coolies. Des torts qui ne peuvent être réprimés que par des actes de ce genre devant lesquels n’hésitent pas même des personnes appartenant à la société la plus conservatrice de la Chine, doivent être très réels, très graves. Dans les nombreux cas où la jeune belle-fille se voit poussée au suicide pour échapper à d'intolérables sévices, les mesures prises ultérieurement dépendent en général du nombre de ses parents et de leur position sociale. Le premier acte 


\section{La vie des paysans chinois}

consistera à faire part à la famille de la morte du décès de son enfant, car l'enterrement ne peut avoir lieu hors de sa présence, et, si l'on passait outre, il y aurait lieu de procéder à une exhumation pour convaincre les amis de la défunte que sa mort fut naturelle et non pas causée par la violence, ainsi qu'on le suppose habituellement en pareil cas. Un Chinois, employé par l'auteur de ce livre, fut un jour appelé auprès de sa fille mariée habitant un village voisin et qu'on disait être « un peu souffrante ». Lorsque le père arriva, il la trouva suspendue par sa ceinture à une poutre.

Dans les cas de ce genre, il y a rarement procès. De nombreuses et puissantes considérations entrent en jeu pour que l'on ne coure pas le risque de poursuites judiciaires. Il est presque toujours impossible de faire la preuve des mauvais procédés dont la famille de la jeune femme se prétend victime, pour la simple raison que celle du mari n'hésite jamais à présenter les faits de façon à jeter le blâme sur la jeune femme elle-même. Nous citerons à ce propos un cas où le mari exhiba devant le tribunal un soulier de très petite pointure et expliqua qu'il avait reproché à sa femme de se chausser tellement à l'étroit qu'elle était incapable d'accomplir son travail. Il prétendit que I'intéressée riposta à ses observations par des injures, sur quoi le mari la roua de coups (on en constata les traces) et elle finit par courir se noyer. La famille de la victime se trouve tout à fait désarmée devant de pareils systèmes de défense. L'action n'est pas intentée au mari, mais au beau-père car, en réalité, la loi $n$ 'intervient pas dans les différends entre mari et femme. Il suffit donc à un homme d'admettre qu'il a battu sa femme et de 


\section{La vie des paysans chinois}

donner comme prétexte qu'elle a manqué à son « devoir filial » envers ses parents à lui, pour qu'il soit à l'abri de toute poursuite. Nous avons eu connaissance d'un procès où, en réponse à une prétention de ce genre, le frère de la victime témoigna qu'elle avait été battue avant l'acte soi-disant « non filial » qu'on lui reprochait. Cette déclaration parut exaspérer le magistrat qui condamna le frère à quelques centaines de coups de rotin en raison de son témoignage et décida que la famille du marié ne serait tenue qu'à fournir une bière peu coûteuse, en bois de saule, pour le corps de la défunte.

Une autre raison encore plus probante, qui incite à renoncer à ce genre de procès, résulte de l'obligation de soumettre le corps de la jeune femme à un examen post mortem, sorte d'autopsie qui revêt une grande publicité, attendu que les usages d'Orient veulent que le public ait toute liberté de venir se rendre compte par lui-même du cas litigieux. Une grange est transformée en laboratoire officiel; on y dresse des clôtures faites de paillassons et le village voit accourir aussitôt tous les habitués du yamen, friands d'affaires sensationnelles. Le corps nu de la défunte, placé sur une natte, est exposé aux yeux de tous avant et pendant l'enquête. Afin d'éviter la honte d'une pareille exhibition et les grandes dépenses qu'elle entraîne, les ennemis les plus irréconciliables préfèrent souvent avoir recours aux bons offices des « prêcheurs de paix ». Ceux-ci doivent être choisis dans les villages respectifs des parties en cause et ils cherchent d'abord à se mettre d'accord sur les termes de l'arrangement. Les conditions dépendront exclusivement du degré de prospérité de la famille de la belle-mère. Si celle-ci est riche, la partie adverse 


\section{La vie des paysans chinois}

s'efforcera de la saigner à blanc, et encore davantage si c'est possible. Chaque détail des obsèques sera taxé au prix le plus fort ; on choisira un cercueil en bois de cyprès en en spécifiant l'épaisseur et la taille; les vêtements funéraires destinés à la morte seront en telle quantité qu'ils excéderont parfois la capacité disponible dans la bière ; il y en aura en soie et en satin. L'on exigera une somme également fixée d'avance pour engager des prêtres bouddhistes ou taoïstes, ou les deux à la fois, qui assureront le cérémonial religieux des funérailles. Toute transaction avec la famille de la belle-mère par laquelle on accepterait un paiement en argent au lieu d'exiger toute cette pompe est considérée comme chose honteuse ; mais très certainement il doit parfois se conclure en secret des arrangements de ce genre. A un point de vue strictement commercial, il serait de l'intérêt des deux parties de verser aux parents de la jeune femme 200 cordons de sapèques, par exemple, au lieu d'en gaspiller plus d'un millier dans une cérémonie funèbre qui ne peut profiter à personne. Mais l'épiderme chinois est extrêmement sensible à I'opinion publique, de sorte que de pareils règlements par un simple transfert d'argent comptant doivent être relativement rares.

Le trousseau d'une fiancée est souvent fort important, toutefois, en cas de suicide, sa famille n'en revoit jamais rien. Des témoins oculaires nous ont affirmé que dans plusieurs circonstances analogues d'énormes quantités de vêtements réclamées à la famille de la belle-mère pour servir aux funérailles à l'occasion d'un suicide de ce genre furent brûlées en masse sur la tombe. Nous connaissons un cas où le trousseau de 


\section{La vie des paysans chinois}

mariage qui avait été considérable et comprenait des armoires, des tables, des glaces et autres accessoires somptuaires fut jeté tout entier dans la rue et détruit en présence des parents de la mariée. Ces procédés sont forcément inspirés par un désir de vengeance, mais ils agissent ultérieurement comme une sorte de frein sur la conduite de la belle-mère et de sa famille à l'égard de la belle-fille que, de son vivant, les lois du pays sont impuissantes à protéger.

Lorsque les funérailles ont lieu dans des conditions telles que celles que nous venons de décrire, on court toujours le risque qu'en dépit des efforts des «prêcheurs de paix », la dispute n'éclate à nouveau. A la vue du masque livide de la jeune femme - résultat de la mort par strangulation - on ne peut s'étonner que la famille, au comble de l'indignation, s'écrie : «Vengeance! Vengeance ! » Maintenir la tranquillité, en pareille occurrence, parmi les femmes du côté maternel est certainement au-dessus des forces de n'importe quelle collection de «prêcheurs de paix », pour aussi nombreux et respectables que soient ces gens. Si les cérémonies de l'enterrement se terminent sans que les deux familles se soient réciproquement injuriées ou même battues, I'on estime que tout s'est bien passé. La famille de la défunte trouve naturellement à critiquer en gros et en détail le cercueil, I'habillement, les ornements, en un mot toutes les dispositions prises. Mais elle se calme à la pensée réconfortante que les morts sont bien morts, que rien ne peut les rappeler à la vie et que les ressources de la belle-mère sont épuisées au point que la dernière parcelle de terre a été hypothéquée pour parer 


\section{La vie des paysans chinois}

aux frais de l'enterrement, enfin que cette famille entière est écrasée sous le poids de ses dettes.

L'on a depuis longtemps fait la remarque que la moitié de I'humanité ignore la façon de vivre de l'autre moitié. Un étranger peut passer de longues années au milieu des Chinois sans connaître réellement la manière dont ils résolvent certaines difficultés auxquelles ils sont exposés de par la forme même de leur civilisation.

La meilleure manière d'étudier des phénomènes de cet ordre consiste à recourir à l'examen de cas concrets. Un seul, bien considéré sous tous ses aspects, peut nous mieux éclairer que ne le ferait un volume entier de dissertations spéculatives. Quiconque est disposé à entreprendre des études de ce genre trouvera toujours en Chine les matériaux à portée de sa main ; il ne sera même pas étonnant que ces matériaux s'imposent bon gré mal gré à son attention comme tel fut le cas dans les circonstances très caractéristiques que voici. Il y a de longues années, un professeur chinois employé par l'auteur de ces lignes obtint un congé d'une durée limitée. A l'expiration de cette période, on ne le vit pas revenir. En Chine, pareil incident est tellement courant - même général, pourrait-on dire - qu'il aurait passé presque inaperçu, si l'intéressé n'en avait fourni plus tard une curieuse explication, laquelle parut d'ailleurs si bizarre qu'il fut prié de la mettre par écrit. En voici le résumé :

Une sœur aînée du professeur était mariée à un homme très pauvre dans un village appelé « Tour de la famille Li », hameau insignifiant ne comprenant que quatre familles. Au cours d'une 


\section{La vie des paysans chinois}

grande famine - en 1878 - la dite sœur et son mari moururent laissant trois fils tous mariés. L'un d'eux, le second, mourut à son tour et sa veuve se remaria.. La femme de l'aîné des neveux du professeur étant également décédée, le veuf épousa en secondes noces une veuve, mère d'une fille de douze ans. Cette personne jouissait d'une réputation peu rassurante : elle passait pour avoir battu sa première belle-mère et même occasionné la mort de son premier mari. La femme du troisième frère, ayant un naturel plutôt querelleur, les deux belles-sœurs étaient toujours à couteaux tirés, d'autant plus que les deux ménages et leurs quatre enfants vivaient sous le même toit et possédaient un bien indivis.

Au mois d'août de l'année en cours, le troisième neveu se rendit à un marché assez éloigné avec un bateau chargé de melons d'eau. Au moment de s'en aller, il ordonna à sa femme de lui apporter ses vêtements d'hiver, ce à quoi elle se refusa, d'où querelle. Puis il partit. Le lendemain le temps se mit au froid et à la pluie. L'aîné des neveux, assis dans la maison d'un voisin, entendit sa femme se disputer violemment avec sa belle-sœur, mais il ne songea pas un instant à aller s'enquérir de ce qui causait l'altercation et aucun voisin n'eut l'idée d'intervenir pour ramener le calme au logis. Furieuse, la plus jeune belle-sœur quitta la maison et, à partir de ce moment, on ne la revit plus. Vers midi cette absence prolongée commença à inquiéter le frère aîné qui, jusqu'à la tombée du jour, fouilla en vain les environs. Il fit aussitôt prévenir la famille de la mère, celle-ci habitait à deux lieues de distance, un village appelé « le petit camp ». En apprenant la disparition de leur fille, les parents rassemblèrent 


\section{La vie des paysans chinois}

une dizaine de personnes et se mirent en route vers « la Tour de la famille $\mathrm{Li} \gg$. Ils pénétrèrent dans la cour du logis en question, brisant les jarres à eau et tous les objets de poterie qui leur tombèrent sous la main. Des «prêcheurs de paix » se hâtèrent d'intervenir ; ils réussirent à empêcher les assaillants de pénétrer à l'intérieur de la maison, ce qui eût encore augmenté les dégâts.

Lorsque la bande se fut retirée, le « Seigneur de l'amertume », autrement dit le frère aîné, pria ses amis d'agir à leur tour et de « prêcher la paix », car, résidant dans un modeste village, il ne pouvait songer à se mesurer avec les gens du « petit camp », agglomération beaucoup plus importante. Les hommes de cette dernière localité appartenaient à l'une des nombreuses petites sectes appelées « portes noires » ou sociétés secrètes. Ces associations comprennent souvent une catégorie d'individus dénommés «Voyants» ou « Yeux clairs » - ming-yen - qui prétendent pouvoir faire connaître les progrès qu'ont accomplis les élèves en étudiant la doctrine. Parfois, comme dans le cas actuel, ils assument également le rôle de diseurs de bonne aventure. C'est à un « œil clair » de leur secte que les hommes du « petit camp » s'adressèrent pour savoir ce qu'était devenue la jeune disparue. « L'đFil clair » répondit que la femme avait été battue jusqu'à ce que mort s'ensuive, puis enterrée dans la cour du «Seigneur de l'amertume ». A cette nouvelle, la famille de la victime alla frapper à toutes les portes du village, faisant « kotow » devant chacune d'elles, procédé général et bien connu pour implorer aide et assistance. Ainsi se forma un groupe important qui se rendit à la « Tour de la famille 


\section{La vie des paysans chinois}

Li » muni de bêches pour déterrer le corps. Prévenus de leur arrivée, tous les habitants mâles de ce dernier village s'empressèrent de déguerpir et la famille du «Seigneur de l'amertume » se réfugia dans la maison de l'agent de police local chargé de la surveillance de plusieurs villages. Le professeur en question, en sa qualité de proche parent du «Seigneur de l'amertume » et, de plus, homme intelligent et de manières amènes, fut prié de veiller sur la maison de son neveu, ce qu'il fit. Grâce à sa présence et à son affabilité, le logis n'eut pas à subir de nouveaux dommages, mais toute la cour fut éventrée pour retrouver le cadavre, et en vain. Devant l'échec de ses prédictions, «l'đil clair » modifia son oracle et révéla que le corps se trouvait en dehors de la cour, à une distance de trente pas seulement. Les recherches se poursuivirent à coups de bêches et de pioches pendant une semaine entière. Après avoir vainement essayé d'arranger l'affaire, et devant le refus de la partie adverse, d'écouter toute offre de conciliation, le «Seigneur de l'amertume » se décida à introduire une instance au yamen du magistrat du district. Celui-ci se fit, à deux reprises, exposer les faits, mais à chaque déposition, la famille de la femme disparue se livra à des manifestations si violentes, si déraisonnables, que le juge finit par rayer l'affaire du rôle ; il se borna à charger l'agent de police de la localité de recruter encore plus de «prêcheurs de paix » et de s'arranger pour que les deux parties en arrivent à quelque compromis.

Un autre cas analogue se présenta à peu près à la même époque non loin de ce village : il s'agissait d'une femme soupçonnée de s'être donné la mort en se noyant. Aussitôt une 


\section{La vie des paysans chinois}

étroite surveillance fut exercée sur les barrages de la rivière jusqu'à quelques milles de distance afin de repêcher tout cadavre qui flotterait à la dérive.

Le magistrat venait à peine de prendre cette décision qu'un corps de femme fut trouvé contre une digue et identifié pour celui de la personne disparue de «la Tour de la famille Li ». Le juge ordonna une enquête pendant laquelle I'on s'efforça des deux côtés de découvrir des blessures sur le corps de la noyée, mais il n'y en avait pas trace : le magistrat obligea alors la famille de la femme à reconnaître ce fait en apposant l'empreinte de ses pouces sur un papier. Il ordonna au « Seigneur de l'amertume »d'acheter un bon cercueil, des vêtements, de prendre toutes dispositions utiles pour faire un enterrement pompeux, y compris des chants par les prêtres bouddhistes, et de faire transporter le corps dans sa maison. Il prescrivit d'autre part à l'agent de police de fournir une fois de plus des « prêcheurs de paix », de veiller à tous les détails et de régler l'ordonnance des funérailles.

Cependant les gens du « petit camp » ne l'entendaient pas ainsi. Faisant preuve d'un entêtement inimaginable, ils ne voulurent pas entendre raison et allèrent jusqu'à chasser de leur village les «prêcheurs de paix » qu'ils couvrirent d'insultes. Jamais un langage injurieux n'exaspère autant les Chinois que lorsqu'il s'adresse à des gens qui sacrifient leurs intérêts particuliers à ceux du public. Sur ces entrefaites, le mari de la disparue revint du marché aux melons d'eau. Il se rendit immédiatement à la maison de sa femme défunte, harangua la 


\section{La vie des paysans chinois}

famille et fit également conseiller la paix par un tiers. Mais les gens du « petit camp » persistèrent à réclamer des funérailles pompeuses dont le coût se serait élevé à dix mille cordons de sapèques.

Le professeur qui gardait la maison du « Seigneur de l'amertume », voulut faire une dernière tentative pour arriver à un compromis avec les gens du « petit camp ». Grâce à son entremise, ceux-ci renoncèrent à certaines de leurs exigences contre versement de 800 cordons de sapèques, somme qui après de nombreux marchandages. fut réduite de moitié. Le «Seigneur de l'amertume » en offrit 250, proposition que la partie adverse accueillit avec mépris.

Devant l'échec de tant de négociations laborieuses, l'agent de police se rendit au yamen où il déposa une nouvelle plainte, celle-ci basée sur les refus répétés de la famille de la femme de vouloir bien transiger. Le magistrat reconnaissant là un de ces cas où les parents sont résolus à tirer d'une morte le plus d'argent possible, envoya le jour même six hommes de son personnel pour assister aux obsèques et veiller à ce que tout $s^{\prime} y$ passât avec ordre. Ces « courriers du yamen », fidèles aux traditions chinoises et comptant se faire acheter leur obéissance, ne se rendirent pas tout de suite sur les lieux. Le «Seigneur de l'amertume » et son entourage demeurèrent donc seuls mais, dans l'intervalle, le parti du « petit camp » rassembla encore une fois ses troupes, il opéra quatre incursions successives à la «Tour de la famille Li » et saccagea tout ce qui lui tomba sous la main. Le jour suivant, les agents du magistrat firent leur 


\section{La vie des paysans chinois}

apparition. Le «Seigneur de l'amertume » dont l'exaspération ne connaissait plus de bornes, forma un groupe de plusieurs centaines d'hommes ramassés dans les villages des environs et résolut à tout hasard de célébrer les obsèques, dût-il engager une lutte générale avec les gens du « petit camp ». Mais cette fois, ceux-ci s'abstinrent de paraître et les obsèques purent enfin avoir lieu. Les partisans de la femme se refusèrent cependant à considérer l'affaire comme définitivement réglée. Là se termine le récit, non sans laisser entrevoir une série de procès, de batailles et de ruines.

Le lecteur que les secrets rouages de la vie chinoise intéressent suffisamment pour vouloir suivre, sans en perdre le fil, les méandres d'une histoire de ce genre, en est récompensé par la mise en lumière de plusieurs faits importants. En Chine, la famille d'une fille mariée baisse la tête pendant que celle de I'homme qui l'épouse la lève : fait passé à l'état d'axiome. Mais dans le cas où l'épouse meurt de mort violente, les rôles sont renversés et, sous le processus naturel de la réaction, la famille de la victime devient un ennemi féroce et intraitable.

Il suffit que de pareils principes soient mis en question, entre deux gros villages ou entre deux familles, et nous avons l'explication de la pérennité bien connue des luttes de clans qui se poursuivent avec âpreté dans le sud de la Chine. L'une des plus grandes faiblesses de l'organisme social chinois est précisément cette insécurité de l'existence et du bonheur de la femme, mais n'existe-t-il pas un fait d'ordre général, à savoir que, dans tout organisme, rien n'est plus résistant que la partie 


\section{La vie des paysans chinois}

la plus faible ? la société chinoise ne fait pas exception à cette règle. Tous les ans, des milliers et des milliers de jeunes femmes se suicident causant par là de graves embarras à des dizaines de mille de personnes, sans compter les centaines de mille autres, qui se trouvent mêlées de gré ou de force à ces incidents, et les millions de dollars qui s'engloutissent en funérailles extravagantes et en procès ruineux. Pareil état de choses est le résultat fatal de la théorie de Confucius lequel déclare que la femme ne possède aucun droit que le mari soit tenu de respecter. La loi n'accorde à l'épouse aucune protection de son vivant, et la part minime de justice qu'elle peut exiger avec difficulté est strictement une concession post mortem.

Les maux très réels qu'engendre le système matrimonial chinois sont mis en lumière par les expédients extraordinaires auxquels ont recours les jeunes filles encore célibataires pour se soustraire au mariage. Les journaux chinois contiennent souvent des allusions a certaines confréries de jeunes filles dont les membres s'engagent solennellement à ne jamais prendre un époux. Les extraits suivants sont traduits du journal, le Shih Pao :

Le suicide, une vertu.

Dans un district nommé Shun-tê, de la province de Canton, il existe une coutume parmi certaines femmes de la société, celle de constituer des sortes de confréries, telles que «les Sœurs toutes pures», «les 


\section{La vie des paysans chinois}

Sœurs qui ne doivent jamais se marier », etc. Chacune d'elles comprend une dizaine de jeunes filles qui jurent devant le Ciel de ne jamais prendre mari ; elles considèrent le mariage comme une chose horrible et sont convaincues que l'existence matrimoniale est impie et ne peut être que malheureuse : les parents ne parviennent pas à briser leur résistance.

Un cas fort triste vient de se présenter. Plusieurs jeunes filles se sont jetées dans la rivière du Dragon et ont ainsi mis fin à leurs jours parce que les parents voulaient forcer l'une d'entre elles à se marier. On I'avait fiancée lorsqu'elle était encore toute jeune et avant son entrée dans la confrérie. Après que ses parents eurent fait tous les arrangements nécessaires pour la noce, I'intéressée porta la question devant les autres membres de la confrérie qui, sans hésiter, décidèrent de se donner la mort pour la défense de sa cause, si ellemême s'engageait à demeurer fidèle à son vœu de virginité. Dans le cas où elle violerait les lois de l'association en cédant à ses parents, ses sœurs lui rendraient la vie impossible et elle serait stigmatisée comme une créature indigne. La jeune fille leur demanda alors conseil quant au meilleur moyen d'échapper à ce mariage et toutes ses camarades s'engagèrent à mourir avec elle si elle réussissait à s'enfuir de la maison paternelle le soir des noces. 


\section{La vie des paysans chinois}

Mais des amis nombreux de la famille la surveillaient étroitement : elle ne put s'évader. Elle essaya de mettre fin à ses jours en avalant un anneau d'or ; un émétique violent eut raison de cette tentative de suicide. Finalement, elle fut prise de force et, à son grand désespoir, livrée à son époux. Selon les coutumes courantes elle eut la permission de revenir chez ses parents : au cours de ses visites elle ne cessait de songer au moyen d'aller retrouver secrètement ses sœurs. Finalement, en soudoyant des servantes, elle obtint de celles-ci d'être conduite un soir auprès de ses compagnes. C'est alors qu'elles prirent la résolution d'aller toutes ensemble se jeter dans la rivière du Dragon où le courant rapide les fit disparaître.

Ce genre de tragédie se renouvelle assez souvent dans la région. Les pouvoirs publics ont tenté parfois d'empêcher la formation des dites confréries; ils n'y ont pas réussi. Les jeunes filles doivent être poussées par des raisons vraiment impérieuses pour former de pareilles associations. Sans doute, la vie conjugale a-t-elle dû, pour beaucoup de leurs amies, être une suite ininterrompue de tribulations. La loi n'en a pas moins le devoir de combattre ces suicides en masse, si les parents n'ont plus assez d'autorité sur leurs enfants pour empêcher d'aussi tristes dénoûments.

\# On sait que la législation chinoise reconnaît sept cas de divorce : la stérilité, le manque d'égards pour les parents du mari, la débauche, le bavardage, - togen, - le penchant au vol, 


\section{La vie des paysans chinois}

la jalousie et la fièvre maligne. L'homme n'a généralement pas de grandes prétentions quant aux qualités qu'il réclame chez la femme qu'il va épouser. Un Chinois, employé chez l'auteur de ce livre et qui semblait vouloir renoncer au célibat, ayant été interrogé sur le genre de femme qu'il préférait, répondit simplement :

- Il me suffit qu'elle ne soit ni chauve, ni idiote.

Dans un pays où la fin avouée du mariage est la procréation d'enfants qui puissent un jour brûler de l'encens sur les tombes des ancêtres, il n'est pas étrange que la « stérilité » figure au premier rang des causes de divorce, mais ce serait une erreur de croire que, simplement parce qu'il est désigné dans le code impérial, ce motif ou l'un des autres ci-dessus mentionnés soit d'ordinaire une raison de divorce.

Il est toujours difficile d'arriver à des conclusions exactes en ce qui touche à des faits très complexes, surtout quand il s'agit des Chinois. Mais, pour autant que nous puissions en juger, il semblerait que le divorce n'est pas aussi fréquent en Chine que le laisserait croire la loi dont nous venons de rappeler les termes. L'adultère est sans aucun doute le motif de divorce le plus répandu pour la simple raison qu'il constitue l'atteinte la plus grave à l'existence de la famille.

Mais, et nous devons insister sur ce point, dans tous les cas de divorce se retrouve un facteur dont on devrait tenir compte et que la loi néglige entièrement. Nous voulons parler de la famille de l'épouse, facteur d'une grande importance ainsi que nous I'avons vu et nullement négligeable. Il est certain que la famille 


\section{La vie des paysans chinois}

de la femme s'opposera toujours au divorce; elle le considère comme une mesure injuste, injurieuse, et cela non seulement parce qu'elle nuit à la « face », mais aussi, pour une raison encore plus puissante.

En Chine, une femme ne peut rentrer dans la maison paternelle après un mariage malheureux - comme il est d'usage courant en Europe - parce qu'il ne s'y trouvera aucun moyen de subvenir à ses besoins. Un lopin de terre de superficie suffisante est distrait de la propriété familiale pour l'entretien des parents et I'on partage ce qui reste entre les frères. Aucun lot, aucune parcelle ne revient aux sœurs. Telle est la raison impérative pour laquelle toute fille doit se marier afin d'avoir des moyens réels d'existence. A la mort de ses parents, et si elle était retournée chez eux après son divorce, ses frères, et plus sûrement encore leurs femmes, la chasseraient hors du domaine comme une étrangère qui n'a pas le droit de dépendre de sa famille alors qu'elle « appartient » à une autre. Dans de pareilles conditions, il est peu probable que I'on permettrait à un mari de demander le divorce contre sa femme, sauf pour une raison valable, à moins que celle-ci n'ait la possibilité de se tirer d'affaire, c'est-à-dire de se remarier.

Après l'adultère, la cause de divorce la plus fréquente est celle que les lois d'Occident qualifient par euphémisme « d'incompatibilité d'humeur », ce qui, en Chine, signifie tout simplement querelles domestiques tapageuses, au point de rendre l'existence commune intolérable même à un Chinois. Inutile de remarquer que pour en arriver là, il faut vraiment que 


\section{La vie des paysans chinois}

ces batailles dépassent toute mesure. Chacun des motifs de divorce cités plus haut se prête bien entendu aux interprétations les plus variées des faits invoqués. Si les juges agissaient seulement d'après la loi sans que la famille de la femme fasse entendre des protestations, il se commettrait probablement de grosses injustices. De toute façon, quel que soit le règlement auquel on arrive dans chaque cas particulier, il sera forcément le résultat d'un compromis dans lequel les amis du parti le plus faible prendront soin que ses intérêts ne soient pas lésés.

Nous avons souvent fait allusion à la nécessité inéluctable qui pousse les jeunes Chinois à se marier tôt. Pour les étrangers, la façon d'agir des parents de situation moyenne à l'égard d'un fils qui approche de sa vingtième année et est encore célibataire, a quelque chose de ridicule et pathétique à la fois. Un très vieux dicton chinois prétend que lorsque filles et garçons sont mariés, «I'on a expédié la grosse affaire de la vie ». Les parents chinois considèrent le mariage de leurs fils tout comme ceux d'Europe envisagent le moment où les garçons échangeront leurs robes enfantines pour le pantalon réglementaire. L'existence ne devient véritablement sérieuse pour eux qu'après ce changement de décor et il serait ridicule et peu rationnel d'en retarder l'échéance.

Par un sentiment de fausse modestie, les personnes les plus intéressées à un mariage ne risqueront même pas une allusion à son sujet. La mère est à peu près la seule personne qui puisse faire comprendre à une jeune fille qu'il serait temps de penser 


\section{La vie des paysans chinois}

aux fiançailles, et cette suggestion fournit généralement matière à des scènes orageuses.

Un professeur chinois bien connu de l'auteur, diplômé à vingttrois ans dans un collège de mission, s'avise un beau jour qu'il n'est pas encore fiancé. Aussitôt des amis arrangent l'affaire sans que le jeune homme ait l'air de s'en douter - il avait certainement été consulté à chaque nouvelle démarche - et le moment vient où il doit se rendre chez ses parents pour s'entretenir avec eux de l'époque du mariage. Mais l'impressionnable jeune homme n'eut pas le courage de s'exécuter et il chargea de la visite un ami complaisant - « un oncle de cour $\gg-$ invoquant ce prétexte tout à fait suffisant :

- Comment pourrai-je causer d'un pareil sujet avec mon père et ma mère!

Depuis que ces lignes furent écrites, l'auteur a reçu la visite d'un ami chinois qui, d'un air satisfait bien que fort embarrassé, venait lui parler d'une « petite affaire » personnelle. Cet ami a passé la quarantaine sans s'être jamais marié et possède en commun avec ses deux frères une modeste propriété de deux acres anglais environ. Il venait d'y passer plusieurs mois pendant lesquels I'on n'avait jamais parlé de mariage. Parti en voyage pour quelques semaines, le frère aîné lui dépêcha peu de temps avant son retour un messager spécial, à plus de $300 \mathrm{li}$, pour l'avertir qu'il avait inopinément arrangé des fiançailles entre lui, célibataire de quarante ans, et une jeune fille de dix-sept ; or la famille de celle-ci réclamait l'exécution immédiate du contrat. Cet entretien se termina par une demande pressante d'argent : 


\section{La vie des paysans chinois}

le Chinois suppliait l'ami étranger de lui consentir un prêt de vingt cordons de sapèques pour le trousseau de sa fiancée, car lui-même ne possédait ni revenus, ni biens indépendants. Quatre-vingt-dix-neuf Chinois sur cent déclareront, en pareille circonstance, qu'une telle union, ou toute autre de ce genre, se résume admirablement dans ce seul mot : « hao », autrement dit :

— Très bien ! Voilà certainement ce que I'on doit faire maintenant.

La question de dépense leur paraît aussi indifférente qu'elle le serait pour nous s'il s'agissait de pourvoir aux funérailles d'un proche parent.

Les père et mère chinois n'aiment jamais à courir le risque de retarder jusqu'après leur décès le mariage de leurs enfants, surtout des fils. Ils craignent que les enfants déjà mariés ne se montrent peut-être pas disposés à fournir les fonds nécessaires pour cet événement, en admettant qu'ils le laissent s'accomplir. Ces affaires matrimoniales nécessitent le partage des terres dont une partie est attribuée à chaque fils marié, et la nature humaine se résigne difficilement à multiplier à plaisir les ayants droit sur une propriété qui n'est que trop souvent insuffisante même dans son entier. C'est ainsi que les parents prudents souhaitent que cette « affaire capitale de l'existence » soit réglée tant qu'ils sont en mesure d'en surveiller eux-mêmes l'exécution.

L'inexorable nécessité qui veut que les fils se marient subsiste, alors même que le jeune homme en question est peu fait pour le mariage, qu'il est même parfois incapable de 


\section{La vie des paysans chinois}

contracter une union. Nous connaissons des cas nombreux dans lesquels un garçon infirme, sans espoir de guérison, se marie quand même, et les parents de la jeune fille y consentent uniquement en raison des conditions avantageuses que cette union présente. Des garçons sujets à l'épilepsie, des jeunes gens plus ou moins fous, parfois complètement idiots, peuvent tous trouver, et trouvent en effet, des épouses, à condition bien entendu que leurs parents soient dans une bonne situation de fortune. A violer aussi brutalement les lois de la nature, on voue les filles à de grandes souffrances ; leur vie est gâchée, sans compter la multiplicité des scandales qui résultent de cet état de choses.

Un autre trait de l'existence maritale en Chine, peu remarqué jusqu'à ce jour par les étrangers, vaut la peine d'attirer notre attention. C'est l'enlèvement des femmes légalement mariées. Le cas suivant nous éclairera sur la méthode usitée en pareille occurrence et sur les difficultés de découvrir ceux qui s'en rendent coupables. Là, les principaux acteurs sont le père et le beau-père de la mariée, tous deux connus de l'auteur qui assista également au mariage. Cela se passait au mois de décembre 1881.

La fiancée, comme cela arrive si souvent, était encore une enfant. Lors de ses visites au village natal, déplacements qu'autorisent les usages locaux, la mariée ne séjournait guère dans la maison paternelle, n'y trouvant pas sans doute un accueil très chaleureux de la part de la seconde femme de son père ; elle préférait se rendre chez sa grand'mère, personne 


\section{La vie des paysans chinois}

vieille, à moitié aveugle et mal pourvue en literie. Dans un logis du voisinage habitait un cousin de la jeune femme, « inspecteur du sel », c'est-à-dire chargé d'en réprimer la contrebande. Sa femme était la fille d'une veuve fortement suspectée de se livrer elle-même à ces pratiques illicites avec, bien entendu, la connivence de son gendre. Le couple s'était, disait-on, marié sans avoir eu recours à des intermédiaires, c'est pourquoi leur conduite était l'objet de critiques incessantes. A chacune de ses visites au village maternel, la jeune femme qui nous occupe prit I'habitude de descendre chez ses cousins et non chez son père. La plupart du temps le cousin était absent, retenu au dehors par son service de surveillance ou par celui de la contrebande. Or, après une visite de dix jours à son village natal, la jeune femme revint au foyer de son mari - presque un enfant également ; elle y demeura cinq jours, puis reprit la route de son village. Une belle-sœur plus jeune, âgée de seize ans, l'accompagna pendant les deux tiers du chemin, après quoi la jeune femme renvoya son escorte et continua seule sa route. Quelques jours après, la propre sœur de la mariée rencontrant le beau-père à une foire, lui demanda pourquoi cette dernière n'était pas revenue à son village comme il avait été convenu. C'est ainsi que pour la première fois, I'on découvrit que la jeune femme était absente de ses deux logis. Les mesures mises en œuvre pour retrouver ses traces caractérisent admirablement certains à-côtés de la vie chinoise. Il est presque impossible en Chine de faire quoi que ce soit assez secrètement pour que personne n'en ait vent, et, dans un cas aussi sérieux que la disparition d'une jeune mariée, il 


\section{La vie des paysans chinois}

semblerait que les chances de pouvoir dissimuler l'événement sont minimes.

Le beau-père se rendit au village où elle avait habité et il apprit que lorsqu'elle y venait en visite, on la laissait aller partout où il lui plaisait. Revenant un jour de chez son cousin, elle aurait dit, à en croire les racontars, que sa personne valait cinq onces d'argent. L'on rapportait aussi que la femme du cousin avait été vue en train de guetter l'arrivée de la jeune disparue la nuit même où on l'aperçut pour la dernière fois, c'est-à-dire au moment où elle venait de congédier la belle-sœur qui l'accompagnait. Tels furent les seuls renseignements que I'on put recueillir.

Le beau-père déposa une plainte devant le magistrat du district, exposant les faits et mettant en cause le père de la jeune femme ainsi que quelques autres personnes. Le père, le cousin et la belle-mère de ce dernier ripostèrent par une contreaccusation. En conséquence, l'agent de police de la localité reçut l'ordre de se mettre à la recherche de la disparue. Ce fonctionnaire, d'une incompétence notoire, n'aurait jamais été capable de la découvrir, quand même il eût véritablement voulu poursuivre une enquête. Une deuxième pétition adressée au magistrat demeura également sans résultat : il n'y avait rien à espérer du policier qui ne s'intéressait pas à l'affaire.

Après de multiples échecs, le malheureux beau-père se résolut à une dernière tentative, expédient d'un désespéré, mais le seul qui lui restait. Il profita de ce que le juge, au cours d'une tournée, traversait son village, pour venir s'agenouiller devant la 


\section{La vie des paysans chinois}

chaise à porteurs et exposer ses griefs. Le magistrat ne put que lui répéter ce qui avait été déjà dit au tribunal, qu'il ignorait tout de l'affaire, qu'il n'entrait pas plus dans ses attributions de retrouver du bétail égaré que de rattraper les belles-filles qui font l'école buissonnière. A son avis, ajouta-t-il, le beau-père n'avait aucune preuve de ce qu'il avançait : peut-être même accusait-il à tort des personnes innocentes. Et, pour en finir, il donna à ses porteurs l'ordre du départ.

Restait le seul espoir de retrouver la disparue en s'attachant à suivre tous les indices que le hasard pourrait fournir. En pareil cas, chacun s'abstient de donner le moindre renseignement pour aussi bien informé qu'il soit, et cela dans la crainte d'être cité comme témoin dans un formidable procès et de se trouver peutêtre un jour la principale victime des débats. Ces considérations jouent en général un rôle si prépondérant qu'elles entravent souvent tout progrès possible de l'instruction. Dans le cas qui nous occupe, les principaux intéressés ne purent s'empêcher de songer à ce qui s'était passé, en pareille occurrence, il y a de cela beaucoup d'années, dans un village voisin où la femme d'un homme qui travaillait pour le compte d'un autre, avait été enlevée - avec son consentement bien entendu - pendant l'absence de son mari. Celui-ci réussit à découvrir le village où elle s'abritait, mais comme cette localité était importante, il ne put jamais trouver le logis qui la cachait et où finalement elle mourut. L'auteur a eu personnellement des relations avec deux familles ayant subi des mésaventures du même genre, et avec une troisième où la femme qui habitait avec un premier mari dont elle divorça devait être enlevée, mais le plan échoua. 


\section{La vie des paysans chinois}

Il est naturellement impossible de savoir exactement jusqu'à quel point l'enlèvement des femmes mariées est pratiqué en Chine, mais on a parfois I'occasion d'obtenir certains aperçus sur la question dans des régions qui sont au delà de notre champ de vision habituel. Ces aperçus, nous pouvons les glaner dans les comptes rendus publiés par les journaux chinois assez friands de ce genre de faits divers. N'étant nullement tenus au courant des intérêts plus graves de l'Empire, les Chinois trouvent beaucoup d'attrait à des récits qui se rapportent à diverses personnalités, comme le font du reste en Europe certaines catégories de lecteurs. De pareils commérages se récoltent généralement dans les yamen où beaucoup de ces cas ont déjà reçu la consécration des poursuites judiciaires, tandis que d'autres sont en voie d'arrangement grâce à l'intervention des «prêcheurs de paix ». Ce genre de reportage alimente également la Gazette de Pékin. Il n'est pas rare que ces enlèvements aboutissent à un assassinat ou à des batailles en règle; nombreux sont les gens qui restent sur le terrain et le Gouverneur se trouve alors dans l'obligation d'adresser un rapport à Pékin. D'après ces données, n'a-t-on pas le droit de conclure que « les corbeaux sont également noirs dans tous les pays »?

Nous avons signalé la vente des filles par leurs parents; nous allons maintenant nous occuper de celle des femmes par leurs maris. Cette tractation, moins fréquente que la première, se fait le plus souvent sous l'aiguillon de la pauvreté et l'auteur se souvient d'un cas où le mari, écrasé de dettes, fut mis en prison. Sans espoir d'en jamais sortir, il avertit sa famille et lui fit dire de vendre sa femme, puis avec le produit de l'opération, il acheta sa 


\section{La vie des paysans chinois}

liberté. L'on peut dire que la fréquence de ces ventes est en rapport direct avec le prix des grains.

Il existe une autre méthode de traiter ce genre d'opérations commerciales. Elle est bien connue des Chinois et peut être adoptée toutes les fois que la vie de famille devient trop onéreuse. Le mari et la femme entreprennent une tournée de mendicité dans les régions où la récolte a été particulièrement fructueuse. Pendant les mauvaises années, I'on peut voir des milliers de couples de cet acabit parcourir les campagnes pour ramasser partout où ils le peuvent de quoi pourvoir à leur misérable subsistance. L'homme qui désire vendre sa femme la fait passer pour sa sœur et déclare que la faim l'oblige à s'en séparer. Il se résignera à la vendre à quelqu'un qui désire prendre femme et qui va de la sorte s'en procurer une à meilleur compte. L'épouse, les larmes aux yeux, consent au marché : l'argent est remis à son « frère », puis celui-ci s'éloigne pour ne plus reparaître. Après quelques jours ou quelques semaines passées dans sa nouvelle demeure, la « sœur » nouvellement mariée s'arrange pour sortir furtivement un beau soir, emportant tout ce qu'elle peut de ses propres vêtements, et d'autres encore. Elle rejoint son « frère » et le couple repart vers « des bois frais et de nouveaux pâturages ». Avec leur instinct aigu de I'analogie, les Chinois ont inventé pour ce tour de passe-passe l'expression «fauconner avec une femme », en souvenir du chasseur qui porte son faucon au poing et le lâche seulement quand le gibier est en vue afin que l'oiseau puisse revenir le plus vite possible. Ce dicton « jouer au faucon avec une femme » désigne un complot dans lequel deux personnes sont engagées. 


\section{La vie des paysans chinois}

Des enquêtes poursuivies dans certaines régions nous apprennent que la pratique de «fauconner » est très répandue, car il ne manque jamais de gens faciles à duper et qui espèrent trouver femme au rabais.

Les Chinois ont coutume de tourner en ridicule I'homme qui se vante d'un marché dans lequel il s'agit d'une femme, mais il est fort probable qu'en pareille circonstance, tous agiraient de même. Un Céleste âgé, habitant le même village que l'auteur, acheta une femme dans des conditions qui lui paraissaient exceptionnellement avantageuses. Pour qu'elle ne puisse s'échapper, il I'ancra positivement en l'attachant à un pieu planté dans sa cour, comme il aurait fait pour un âne. Les voisins se moquaient de lui et il ne se privait pas de leur rendre la pareille, jusqu'au jour où la femme disparut soudain, événement qui le ramena à une compréhension plus raisonnable des « cinq relations ».

Dans cette question, le sentiment public se place à un point de vue fort juste, mais, dans la pratique, le Céleste ne se laisse jamais guider par le sentiment. Tout le monde admet qu'un homme doué de jugement ne doit pas épouser une femme dont le mari est encore vivant, pour la raison, suffisante en ellemême, qu'il ne peut prévoir les conséquences, parfois sérieuses, de cet acte. Mais l'instinct est très fort qui pousse le Chinois à essayer de rouler le sort. «Meilleur marché qu'une bête ! » tel fut le cri du cœur d'un Céleste, ami de l'auteur, quand il vint lui faire part de son second mariage : celui-ci ne lui avait coûté aucun débours en dehors de l'achat d'un modeste trousseau. 


\section{La vie des paysans chinois}

Mais ce même Chinois, lorsqu'il eut appris à connaître la bellesœur, plus âgée, versa des larmes abondantes pendant plusieurs lunes : sa tranquillité lui sembla à jamais compromise.

La doctrine chinoise qui impose à chacun une descendance mâle a pour conséquence naturelle que, dans le cas où une première femme ne donne pas de garçon à son mari, celui-ci devra en prendre une seconde ou même une concubine pour atteindre ce but. En réalité, cette pratique est limitée au petit nombre de familles qui se trouvent dans une bonne situation de fortune, car les autres ne pourraient s'offrir un luxe pareil. Nul ne conteste les mauvais côtés de l'expédient et il est heureux pour la société chinoise qu'on n'y ait pas recours sur une plus grande échelle. Leur esprit pratique a suggéré aux Chinois une méthode infiniment plus simple pour arriver aux mêmes résultats, et le procédé est beaucoup moins répréhensible. C'est l'adoption d'enfants de branches collatérales de façon à conserver ininterrompue la ligne normale de succession et empêcher ainsi l'extinction d'une des branches de la famille.

Il arrive souvent qu'un fils vienne à mourir avant d'avoir été marié et qu'il soit utile d'adopter non un fils, mais un petit-fils. Or, l'adoption d'un petit-fils, lorsque le fils n'a pas été marié, paraît au Chinois un acte paradoxal. Trouver un remède à cette situation après la mort du fils célibataire semblerait pour une mentalité occidentale un dilemme sans issue, il n'en est pas de même pour le sentimental Chinois. Afin de résoudre ce problème, il a inventé le procédé de marier les morts, ce qui, 


\section{La vie des paysans chinois}

parmi les innombrables singularités des usages chinois, est bien la pratique la plus singulière de toutes.

Pour conserver intacte la ligne de succession, les Célestes estiment nécessaire que chaque génération ait ses propres représentants, qu'ils soient ou non des anneaux réels de la même chaîne. Pareille question, du reste, ne peut guère se poser que dans les familles très riches. Mais, dans un cas de ce genre et lorsque disparaît un jeune homme auquel on estime qu'il faut, post mortem, une femme, la famille se met à la recherche d'une jeune fille récemment décédée et les intermédiaires habituels présentent alors une demande afin d'unir les deux cadavres par des liens matrimoniaux ! Cette proposition ne pourra probablement s'adresser qu'à une famille pauvre ; dans les milieux aisés, elle serait sans effet. Si elle est acceptée, les négociations aboutiront à une cérémonie mi-nuptiale, mifunéraire, au cours de laquelle la «fiancée » décédée sera transférée avec un grand luxe de porteurs au cimetière de sa nouvelle famille et couchée à côté de son « mari ». Le petit-fils nouvellement adopté se prosterne devant le corps de sa « mère » et les autres cérémonies se déroulent suivant le rite coutumier.

L'auteur a connu personnellement une jeune fille chinoise qui fut ainsi mariée, après sa mort, à un jeune homme également décédé, originaire d'un village voisin. Questionné à ce sujet, le père de l'épousée voulut bien reconnaître que le procédé n'était pas très rationnel, quoique la mère, ajouta-t-il, fût disposée à accepter la proposition. En ce cas particulier, la véritable raison 


\section{La vie des paysans chinois}

résidait certainement dans le désir de célébrer aux dépens d'une autre famille, des funérailles pompeuses en I'honneur d'une jeune fille, aveugle de naissance et dont les parents étaient trop pauvres au moment de sa mort pour pouvoir l'ensevelir dans un autre linceul qu'une natte.

L'usage de marier ensemble deux personnes décédées n'est pas rare en Chine. Il a son origine dans I'axiome bien connu de Mencius, à savoir que des trois lignes de conduite indiquant de la part des enfants un manque de devoir filial envers les parents, la pire est de ne laisser aucune postérité. Cette formule semble constituer la base sur laquelle repose, depuis les temps les plus reculés, toute la vie familiale des Chinois. Elle nous explique le manque de considération qui frappe les Célestes adultes célibataires. Lorsqu'ils meurent encore relativement jeunes, ils sont « jetés dehors », soit en réalité, soit au figuré et on ne leur accorde aucune place dans les sépultures de famille. Celles-ci sont exclusivement réservées aux enfants mariés, les célibataires impénitents ne doivent pas s'attendre à y être accueillis après leur mort. Le même principe semble s'appliquer aux hommes décédés et dont les femmes se sont remariées. C'est pour parer à des cas de ce genre qu'a été imaginée l'étrange solution de marier une femme vivante à un individu qui n'est plus de ce monde. La crainte de mourir de faim peut seule justifier une pareille décision de la part de la femme; nombreuses sont en effet les veuves chinoises qui restent sans ressources lorsqu'elles ne se remarient pas. Quant au motif qui pousse la famille du marié décédé à cette extrémité, c'est le désir de ne pas laisser de génération incomplète dans les tombes 


\section{La vie des paysans chinois}

ancestrales. Si la famille du marié ne jouit pas d'une situation relativement aisée, elle ne risquera pas les frais et les ennuis d'introduire chez elle une épouse pour un mari qui n'existe plus. Si d'autre part, la veuve possède quelque bien, il est à présumer qu'elle ne cherchera pas à contracter une seconde union. En résumé, le mariage d'une femme vivante avec un homme mort sera probablement limité à des cas où la famille étant pauvre, la veuve s'est remariée, puis sa situation matérielle s'étant améliorée dans la suite, cette famille aura voulu combler le vide qui risquait de se produire dans les tombes ancestrales.

C'est sans doute pour cette raison que de pareils mariages sont en somme assez rares, si rares même que nombre de Chinois instruits, d'un bon milieu social, n'en ont jamais entendu parler et qu'ils n'hésitent pas à s'inscrire en faux contre leur existence. Sans doute des enquêtes suffisamment poussées permettraient-elles de découvrir et de spécifier des cas conformes à nos dires, établissant la réalité de cette coutume qui répugne tant à notre mentalité, mais que les Chinois tiennent pour toute naturelle et logique.

Nous savons déjà que lorsque quelqu'un veut adopter un fils et ne trouve pas dans le cercle familial un candidat convenable, il a recours à des jeunes gens, apparentés ou non, ou même complètement étrangers, « cueillis » n'importe où. Les résultats de ces choix au petit bonheur sont parfois décevants et pénibles pour le couple qui se donne tant de mal aux fins de s'assurer un héritier. Souvent il découvre la vanité de ses efforts, car la piété filiale ne se commande pas. 


\section{La vie des paysans chinois}

Mais, quels qu'en soient les inconvénients incontestablement grands et nombreux - le plan d'adoption des Chinois est toujours infiniment préférable à celui d'introduire dans le foyer familial une «petite épouse », autrement dit une concubine. Aussi ne nous étonnons pas que les Célestes aient caractérisé les relations entre la véritable épouse et la femme supplémentaire par l'expression significative : « siroter du vinaigre ».

Nous avons personnellement connu quelques familles où se trouvaient des concubines. Chez deux d'entre elles, les épouses secondaires avaient été acquises à peu de frais, par suite d'une famine qui sévissait cette année-là dans la région. L'une de ces malheureuses arriva un jour précipitamment dans la cour d'une famille chez laquelle habitait l'auteur de ce livre, échevelée, hurlant - résultat d'une de ces « gorgées de vinaigre ». L'homme qui l'avait choisie insulta publiquement sa propre mère dans les termes les plus grossiers parce qu'elle prenait la défense de la victime.

Dans un autre cas, un homme d'âge assez avancé, crut, en prenant une seconde femme, s'assurer de la sorte un héritier ; ses prévisions furent déçues. Il avait l'habitude d'inviter des femmes chinoises déjà mûres à venir chez lui pour « exhorter ses épouses à ne pas tant abuser des «gorgées de vinaigre », précaution qui, du reste, n'eut aucun succès. Lorsqu'il mourut, la concubine fut mise à la porte bien que le défunt mari passât pour avoir laissé une assez jolie fortune en tant que simple villageois. Dans les cas où la concubine a un fils et si, à la mort 


\section{La vie des paysans chinois}

du mari, les affaires sont convenablement réglées, elle entre en possession d'un lopin de terre qui lui est réservé tout comme à une femme légitime.

Dans un troisième cas, un voisin de l'auteur, homme d'un certain âge, était marié à une femme d'une quarantaine d'années. Des deux autres, mortes antérieurement, I'une avait laissé une fille âgée aujourd'hui de vingt ans. Le père se rendait souvent à Pékin pour ses affaires. En pareille occurrence, les Chinois aiment assez à se donner du confortable en s'offrant deux épouses : la légitime veille au logis conjugal et la «petite » agrémente celui où I'homme passe la plus grande partie de son temps. Dans le cas qui nous occupe, lorsque I'homme rentra définitivement au foyer conjugal, il ramena avec lui sa femme secondaire, décision particulièrement propre à alimenter «les gorgées de vinaigre ». Cette épouse additionnelle n'était qu'une enfant, plus jeune que la fille du mari.

Au moment du Jour de l'an, le bruit courut que cet homme refusait à sa femme légitime l'autorisation d'aller rendre visite à la tombe de ses ancêtres, mais insistait pour que la jeune concubine vînt avec lui accomplir ces rites. D'autres rumeurs, vraies ou fausses, commencèrent à circuler sur sa conduite à l'égard de sa première femme : on lui prêtait l'intention de I'abandonner ou de demander le divorce. Tous ces bruits finirent par arriver jusqu'au village dont celle-ci était originaire. Aussitôt une députation assez nombreuse, composée de gens respectables, se mit en branle. Elle se rendit au village du mari et fit des démarches à l'effet de provoquer une rencontre de la 


\section{La vie des paysans chinois}

bande avec le chef du clan partisan du mari. Sur ces entrefaites, quelques jeunes gens de ce même village, ne voulant pas laisser à leurs aînés le temps d'arranger l'affaire par les voies lentes de la diplomatie chinoise, arrivèrent en bande devant la maison du mari, enfoncèrent, sans plus attendre, la porte barrée de l'entrée et se jetèrent brutalement sur cet homme sans défense.

Les assaillants s'étaient armés d'alênes mais non de couteaux, du moins l'affirmaient-ils. L'attaque fut déclanchée tard dans la nuit, quand I'obscurité empêchait de distinguer les amis des ennemis. Le mari, succombant sous le nombre, ne tarda pas à s'écrouler et l'on constata peu après qu'il avait reçu dix-sept coups d'alènes dans la poitrine et, dans le dos, deux terribles blessures faites avec un couteau dont la lame avait pénétré jusqu'aux poumons. Les assaillants prétendirent que ces dernières blessures devaient être portées au compte de voisins immédiats, ennemis personnels de la victime. Au bruit de la lutte ceux-ci seraient accourus et trouvant I'ennemi à leur merci - la chose ne put d'ailleurs être prouvée - ils auraient profité de la circonstance. Les assaillants s'étaient mis ainsi dans leur tort ; ils furent traduits en justice et durent s'assurer le concours d'un certain nombre de personnes influentes pour agir en leur faveur et les aider à sortir de ce mauvais pas. Ces façons d'agir réussissent généralement en de telles affaires, grâce à de nombreuses rixes et à de multiples festins pour les parties lésées.

Ces leçons de choses abondent, plus ou moins, dans toutes les parties de la Chine, et cependant parmi les gens aisés, il 


\section{La vie des paysans chinois}

reste encore bien des hommes qui n'hésitent pas à tenter l'expérience, quoique l'adage populaire dise : «Si votre femme s'y refuse, ne prenez pas de concubine. » Lorsque chacun voudra bien se conformer à cet avis, la pratique du concubinage ne tardera sans doute pas à disparaître.

Quand le voyageur traverse la Chine, il voit souvent sur les chemins ruraux qu'il parcourt de bon matin la plupart des habitants installés par terre, devant leur porte, très occupés à s'ingurgiter de la nourriture à l'aide de ces bâtonnets dénommés avec tant d'à-propos « fils habiles », tout en bavardant avec le voisin le plus proche. Le Chinois moyen ne saurait concevoir que tous les membres d'une famille prennent place autour d'une table et s'attendent les uns les autres pour manger ensemble ainsi qu'il est d'usage dans les pays d'Occident.

Cette coutume chinoise - et toute orientale - est à la fois typique et suggestive. Elle marque une conception de la famille et de la position que la femme y occupe absolument différente de celle à laquelle nous sommes accoutumés en Europe. Elle accentue le fait que yang - le mâle - est le chef, l'être qui gouverne l'univers, tandis que yin la femme - est la femelle « passive », « inférieure ». L'idée que la femme puisse être la compagne de l'homme n'existe pour ainsi dire pas en Chine, car la femme n'y est pas la compagne de I'homme et elle ne peut jamais le devenir dans une société constituée telle que nous la voyons aujourd'hui. Une jeune mariée qui vient d'arriver dans sa nouvelle famille n'aura avec aucune personne moins de relations apparentes qu'avec son «mari ». Celui-ci rougirait d'être surpris 


\section{La vie des paysans chinois}

en conversation avec elle et, de façon générale, un Chinois semble bien rarement s'exposer à cette honte. Si, par hasard, les jeunes mariés ont le bon sens de vouloir faire plus ample connaissance et semblent échanger véritablement quelques idées, toute la famille s'en amuse en même temps qu'elle s'en étonne. Nous avons entendu citer une famille, chez laquelle se trouvaient de nouveaux mariés, qui prenait un malin plaisir à faire un nœud de plus à une corde chaque fois qu'elle surprenait le jeune couple causant en tête à tête : plus tard, on leur présenta cette corde hérissée de nœuds pour tourner en ridicule leur intimité !

La fiancée chinoise n'a devant elle aucune perspective de bonheur dans son nouveau foyer, même si elle y est bien vêtue, bien nourrie et que peut-être on ne la maltraite pas. Elle devra s'attendre à être tenue en tutelle tant que durent les années où elle est, pendant un temps de fait, et théoriquement toujours, une « enfant ». Une discipline aussi rigoureuse est peut-être nécessaire pour rendre la jeune épousée apte aux devoirs de la position qui I'attend lorsque, belle-mère à son tour, elle se trouvera à la tête de nombreuses brus : mais c'est une bien dure nécessité. Malgré tout, il ne faudrait pas poser en principe qu'il ne puisse naître parfois un véritable attachement entre bellesmères et belles-filles car, dans ces cas exceptionnels, la nature humaine sait s'élever au-dessus des entraves conventionnelles où la retiennent prisonnière des coutumes inflexibles.

Pour se défendre contre toutes les forces hostiles, souvent liguées contre elle, l'épouse chinoise ne dispose que de deux 


\section{La vie des paysans chinois}

armes: I'une, c'est la famille de sa mère qui, nous le savons, ne possède aucun pouvoir réel. On ne saurait mieux la comparer qu'au feu de poupe d'un navire, sans utilité dans la marche en avant et dont la lueur blafarde s'épand sur le chemin déjà parcouru, mais ne permet pas de retrouver le sillage du bateau.

La deuxième de ces armes, la jeune femme la trouve en ellemême. Si elle est pourvue d'une langue déliée et douée de ce dur bon sens assez répandu parmi les Célestes, il faudrait que son nouveau « home » fût bien extraordinaire pour qu'elle n'arrivât pas à se maintenir à la place qui lui est due. La véritable habileté s'affirme toujours, et le peu de lumière dont dispose une femme chinoise finira certainement par pénétrer dans les recoins les plus obscurs du boisseau familial sous lequel elle est forcément cachée. $\mathrm{Si}$ la Chinoise possède un tempérament coléreux, si elle est de taille à déchaîner de temps à autre autour d'elle un véritable ouragan pour la cause la plus insignifiante et à laisser souffler la tempête indéfiniment à la vitesse de cent milles à I'heure, sa position sera sûrement intangible. La plus acariâtre des belles-mères hésitera à rompre des lances avec une belle-fille qui ne craint ni hommes, ni démons, et sait faire face à toutes les éventualités. Une Chinoise en colère n'est pas, tant s'en faut, un spectacle rare, mais quand sa rage est au paroxysme, le Vésuve lui-même ne serait pas plus indomptable.

Il arrive parfois qu'un Chinois aux manières douces, sans aucun goût pour les tempêtes, se trouve lié à une Xantippe qui ne relâche pas un seul instant les rênes de son gouvernement. 


\section{La vie des paysans chinois}

L'homme prudent n'hésite pas alors à acheter «à tout prix » la paix, et le règne omnipotent de la femme s'en trouve assuré. Des cas de ce genre sont fréquents. Nous en découvrons la preuve dans ce qui peut se voir et s'entendre chez la société chinoise aussi bien que dans l'abondance des dictons qui y font allusion, tels que : «L'homme qui craint ce qui est à l'intérieur », en d'autres termes : «I'homme dominé par sa femme ». Malgré I'adage courant :

Un vrai chat tue les souris,

Un vrai homme gouverne sa maison,

il est souvent fait allusion à la punition par laquelle l'homme doit « s'agenouiller près du lit, en tenant une lampe sur sa tête », châtiment qu'impose au mari désobéissant la femme qui règne dans son logis.

Lorsqu'une Chinoise a reçu du Ciel le don de savoir vociférer à un point tel que, suivant les dictons populaires, « les gens ne savent plus distinguer l'Est de l'Ouest », que « les montagnes vacillent » et que «la terre tremble », que «les hommes sont exténués et les chevaux fourbus », un pareil don constitue assurément sa meilleure sauvegarde. Celle-ci est semblable au toucan de l'Amérique du Sud dont la seule apparition, dit-on, suffit à disperser ses ennemis, lesquels ne se soucient pas d'attendre des preuves plus effectives de son pouvoir. Mais pour peu que ce bienfait lui ait été refusé, il reste une troisième ressource, celle d'adopter une ligne de conduite absolument opposée : la femme tiendra sa langue en toute circonstance et en dépit des provocations qui l'assailliront. Pour la plupart des 


\section{La vie des paysans chinois}

Chinoises, cette dernière tactique paraît être un tour de force aussi difficile que la navigation aérienne, mais, de temps à autre, un exemple isolé vient nous démontrer que la difficulté n'est pas insurmontable.

La situation qu'occupe actuellement la femme en Chine est un héritage des temps les plus reculés ainsi que le prouve la littérature ancienne dont nous donnons un exemple en tête de ce chapitre. Les instructions et les prohibitions contenues dans le Livre des Rites - I'une des œuvres classiques les plus vénérées - condensent les principes essentiels qui ont toujours réglé la conduite des Célestes à l'égard de leurs femmes. L'enseignement classique chinois sur ce sujet signifie en substance que la femme est aussi inférieure à I'homme que la Terre est inférieure au Ciel, et qu'elle ne parviendra jamais à être son égale.

D'après les philosophes chinois, la mort et le mal tirent leur origine du « Yin » ou principe féminin du dualisme chinois, tandis que la vie et la prospérité proviennent de la sujétion du Yin au Yang ou principe mâle. C'est donc obéir à la loi de la nature que de maintenir étroitement la femme sous le joug de I'homme et de ne lui accorder aucune initiative personnelle. Cette théorie et la pratique qui en découle ont pour corollaire que l'idéal auquel doit viser la femme ne réside nullement dans le développement intellectuel et la culture générale, mais dans un esprit de soumission. La femme ne peut pas aspirer à un bonheur personnel, elle doit vivre et travailler pour l'homme et la seule manière d'échapper à cette dégradation, c'est de devenir mère et mère d'un fils. Les mêmes lois règlent l'existence de la femme 


\section{La vie des paysans chinois}

dans la vie éternelle. Elle y appartiendra au même mari, et des sacrifices offerts par sa descendance dépendra son bonheur ${ }^{1}$.

On a souvent fait la remarque qu'il serait aussi faux d'attribuer les maux qu'endure la femme chinoise au système moral qui a façonné et conservé l'Empire chinois que de rendre le christianisme responsable de tous les maux moraux et des mauvaises mœurs dont les pays chrétiens donnent le spectacle. Il existe entre les deux cas une différence fondamentale. Les fautes contre la morale furent de tout temps combattues par le christianisme ; si certaines persistent encore, c'est bien malgré ses efforts incessants et ses inlassables protestations. Le christianisme, agissant d'après une conception relativement élevée de la femme, conception qui est celle des races teutoniques, rehaussa peu à peu la femme et nous assistons aujourd'hui à son plein épanouissement. La théorie de Confucius, d'autre part, est à la fois erronée et imparfaite. L'on ne s'avancera pas trop en la rendant responsable, pour une large part, des maux qui affligent les femmes chinoises. En même temps, il est important de constater que, pas plus pour les maux qui proviennent d'un enseignement moral défectueux que pour d'autres, l'éthique chinoise n'a été capable de fournir soit des préventifs, soit des remèdes.

Nous devons donc considérer la situation de la femme chinoise comme la résultante et le fruit le plus caractéristique du Confucianisme. A notre avis, ce fut un fruit empoisonné et, dans

\footnotetext{
1 Voir un petit pamphlet du Dr Ernst Faber intitulé : Tite Status of Woman in China. Shangai, 1899. On y trouvera de nombreuses citations des Classiques sur cette question.
} 


\section{La vie des paysans chinois}

la récapitulation de ses effets, nous ferons ressortir avec insistance sept péchés mortels commis à l'égard de la femme et qui découlent de ce système.

I. - En se plaçant au point de vue purement chinois, il n'existe aucune objection de principe contre l'éducation de la femme chinoise. Dans les immenses encyclopédies des Célestes, nous découvrons que sur 1.628 volumes, 376 sont consacrés à des femmes célèbres et dans ceux-là quatre chapitres traitent de la science féminine et sept autres des productions littéraires dues à des femmes, œuvres aussi nombreuses qu'utiles. Mais, par rapport au nombre incalculable de femmes qui vécurent dans le passé, ces cas exceptionnels ne sont que des lueurs isolées dans de vastes espaces interstellaires d'une profonde obscurité. Pourtant, en vue de la régénération future de la Chine, leur valeur, en tant que documents historiques pour les Chinois épris d'antiquité, est inestimable ${ }^{1}$.

En dehors de quelques exceptions rares et de peu d'importance, les femmes chinoises ne reçoivent généralement aucune éducation. Leur cerveau est laissé à l'état nature si bien que des millions d'entre elles se figurent n'en pas posséder, opinion que pères, maris, frères n'hésitent pas à encourager de leur mieux et d'après laquelle ils agissent d'habitude.

\footnotetext{
1 Voir à ce sujet le livre du $\mathrm{D}^{\circ}$ Ernst Faber : The Famous Women in China. Shangai, 1890 et Typical Women of China, par feu miss A. C. Safford, traduction abrégée d'un ouvrage chinois célèbre et qui fait autorité en la matière.
} 


\section{La vie des paysans chinois}

II. - La vente des femmes et des filles. Celle-ci se pratique si naturellement et, pourrait-on presque ajouter, si inévitablement dans certaines conditions, que les Chinois trouvent cette coutume chose toute naturelle. Néanmoins, sauf pendant les années de famine, le cas semble assez rare dans certaines régions de l'Empire, mais dans d'autres, il est normal et constant que I'on trafique des jeunes filles comme I'on vend des chevaux et du bétail.

Dans quelques parties du nord de la Chine, I'on voit assez souvent un homme ayant contracté des dettes dont il ne peut s'acquitter, se séparer de sa fille en dernière ressource, alors que, dans d'autres districts, cette pratique ne peut être considérée comme exceptionnelle, vu le grand nombre de jeunes filles qui, à ce que I'on assure, proviennent de cette région. Lorsque I'on questionne les Chinois eux-mêmes à ce sujet, ils reconnaissent les faits, les réprouvent même, n'empêche qu'ils concluent toujours par cette phrase : «Comment y remédier ?» Dans les conditions actuelles de l'Empire la question ne saurait recevoir de réponse.

III. - Mariages prématurés et trop nombreux. Une grosse part des malheurs matrimoniaux qui sévissent en Chine peut très justement être attribuée à l'immaturité des victimes. Traiter des enfants comme s'ils étaient des adultes tout en agissant à leur égard comme envers des gamins ou des gamines qui ont besoin d'être gardés et surveillés, ne paraît pas être une façon normale de procéder et les résultats 


\section{La vie des paysans chinois}

obtenus ne font rien moins que la justifier. Qu'un jeune couple représente une entité distincte dont on doit respecter l'indépendance individuelle est une conception que le Confucianisme traite avec mépris, si toutefois il en admet même l'idée. Le mariage obligatoire pour les jeunes filles emprisonne la société chinoise dans une routine de fer et ne laisse aucune place au développement individuel. Toute lutte isolée entreprise contre ce servage outrageant est en butte au soupçon, enfin cette coutume fait de la femme non mariée la violation personnifiée des décrets de la Providence et des lois de I'homme.

IV. - Infanticide des enfants du sexe féminin. Cette coutume est la conséquence directe, sinon légitime, du principe qu'il faut des enfants mâles, et cela dans un système social où la pauvreté règne en maître, où une bouche de plus signifie souvent la famine imminente. Dans I'un des chapitres de ses «Ombres de la Pagode » sur « l'Extension d'un grand crime », miss Fields rassemble une grande quantité de témoignages recueillis dans les différentes provinces et les résume de la façon suivante:

« J'ai constaté qu'un groupe de 160 femmes chinoises ayant toutes passé la cinquantaine, avaient donné le jour à 631 garçons et 538 filles. De ces fils, $366-60$ $\%$ environ - vécurent plus de dix ans tandis que 205 filles seulement - $38 \%$ - atteignirent cet âge-là. Les 160 mères - de leur propre aveu - avaient supprimé 


\section{La vie des paysans chinois}

158 de leurs filles, mais aucune n'eût songé à supprimer un garçon. Comme il ne se trouvait là que quatre femmes ayant élevé plus de trois filles, il est plus que probable que le nombre des infanticides dépasse de beaucoup le nombre avoué. J'ai souvent entendu dire à une femme qu'elle ne se rappelait pas combien de filles elle avait eues, en tout cas plus qu'elle n'en désirait. Le plus fort chiffre d'infanticides avoués par une mère se montait à onze.

L'infanticide sévira en Chine aussi longtemps que subsistera la croyance que les morts dépendent, pour assurer leur bonheur éternel, des sacrifices que leur offrent les vivants du sexe masculin.

V.- Le concubinage - femmes secondaires - est également le résultat de la théorie de Confucius quant au culte des ancêtres. La misère que causa - et que cause encore - en Chine l'application de ce principe religieux dépasse notre entendement. Rien ne pourra le déraciner a moins que déclinent les croyances qui sont à la base de toutes les formes du culte pour les morts.

VI. - Suicides des femmes et des filles. Les raisons énumérées plus haut prises, soit séparément, soit dans leur ensemble, suffisent amplement à faire comprendre la quantité de suicides que I'on constate dans la population féminine. Il faudrait plutôt s'étonner qu'il n'y en ait pas davantage. Mais 


\section{La vie des paysans chinois}

quiconque voudra se donner la peine de collationner, dans un district donné, les faits de ce genre, sera sans doute surpris de leur fréquence extraordinaire. On en relève même chez les enfants, et pour des causes relativement puériles. A certaines époques, ce mal sembla se propager comme la petite vérole : la soif du suicide devint une véritable épidémie. D'après des renseignements puisés dans les journaux du pays, nous savons - ainsi qu'il a été déjà dit - qu'il existe en Chine des régions où les jeunes filles forment des sociétés secrètes et font vœu de se suicider quelque temps après les fiançailles ou le mariage qu'on leur a imposés. La misère qui les attend dans la vie matrimoniale est escomptée d'avance et elles arrivent ainsi à se défier du destin. On aurait tort d'exagérer les maux dont pâtit la femme chinoise, maux auxquels il y a certainement bien des adoucissements et qui ne sauraient être comparés à ce que souffrent leurs sœurs de Turquie et des Indes. Mais, compte tenu de toutes ces concessions, il n'en reste pas moins que la liste des mortes par suicide fournit la preuve la plus irréfutable de ce que souffrent les femmes chinoises.

VII. - Surpopulation. La race jaune a toujours vécu - et continue à vivre - avant tout préoccupée de se créer une postérité et de faire pour les pères ce que ceux-ci ont fait pour les grands-pères. Dans cet ordre d'idées, ils ont su réaliser la conception que se faisait Wesley de l'Église idéale dans laquelle, ainsi qu'il avait coutume de le dire, les fidèles doivent être « tout à elle et toujours occupés d'elle ». La guerre, la famine, la peste 


\section{La vie des paysans chinois}

font périr des millions de Chinois, mais quelques décades de paix effacent les ravages du passé au point qu'on les perd de vue, de même que les champs de bataille se recouvrent de blés ondoyants dès la fin du carnage.

Quelle que puisse être notre admiration pour la puissance de récupération du peuple chinois pris dans son ensemble et dans tous ses représentants en particulier, nous ne pouvons nous défendre d'une légitime indignation devant un système qui viole ces lois bienfaisantes de la nature, lesquelles mettraient miséricordieusement fin à beaucoup de branches des familles lorsque ces branches ne sont plus en état de donner des rejetons. Il est impossible de constater d'une âme sereine la propagation délibérée, persistante et générale de la pauvreté, du vice, de la maladie, du crime - alors que I'on devrait empêcher ces maux de se multiplier par toutes sortes de restrictions - et de voir cette propagation s'accomplir sous le manteau de la vertu, comme si elle était elle-même une religion, parfois même la seule à laquelle les Chinois portent un intérêt vital.

C'est à ce système que la génération nouvelle doit d'être écrasée sous le poids des responsabilités qui lui incombent du fait qu'elle a à nourrir et à vêtir des dizaines de millions d'êtres humains qui n'auraient jamais dû naître et dont l'existence ne peut être qu'un fardeau pour eux, une période de luttes incessantes, sans répit et sans espoir.

Ce qui frappe plus spécialement un étranger quelque peu observateur, c'est la pauvreté du peuple. Il existe trop de villages par mille carré, trop de familles par village, trop de 


\section{La vie des paysans chinois}

« bouches » par famille. Partout où vous allez, vous entendez la même histoire navrante, éternellement répétée : Pauvreté ! Pauvreté ! Toujours et à jamais pauvreté. L'Empire est grand, les régions inoccupées sont immenses et les ressources non développées indubitablement énormes. Mais, de quelle façon ces richesses inexploitées pourraient-elles être mises en valeur pour que la grande masse du peuple chinois en bénéficie ? D'aucune à notre connaissance, du moins ne pouvons-nous en concevoir sans une perturbation radicale des conditions existantes. La masse bouillonnante de la surpopulation devrait être attirée dans les régions encore vierges où elle fait défaut, et alors seulement pourrait-on disposer d'espace suffisant pour soulager ceux qui restent.

Il est impossible de faire quelque chose d'utile pour des populations comprimées comme des allumettes dans leur boîte. Imaginez un chirurgien qui tenterait de remettre une jambe cassée alors que le blessé se trouve dans un omnibus en marche bondé d'une vingtaine d'autres voyageurs dont la plupart ont également un membre brisé et réclament un secours immédiat ! La première chose à faire serait de décharger tous ces blessés, de les transporter où ils pourraient recevoir les soins voulus, où I'on aurait l'emplacement nécessaire pour vaquer à ces soins et de l'espace pour respirer. Non, il n'est pas facile, nous le répétons, de trouver le moyen par lequel l'économie sociale, même la plus avertie, arriverait à améliorer de façon permanente le sort de la grande masse du peuple chinois sans

avoir procédé au préalable à une nouvelle répartition de l'excédent de population. Mais ici intervient le Confucianisme 


\section{La vie des paysans chinois}

pratique. Ayant poussé à la création de cette multitude grouillante d'êtres humains, il déclare que ceux-ci ne doivent pas abandonner les tombes des ancêtres qui ont besoin de leurs sacrifices ; qu'il est de leur devoir de continuer, dans ces mêmes lieux, à transmettre à leur postérité le soin de perpétuer à jamais ces méthodes et ces rites.

La planète terrestre est encore vaste et elle continuera sans doute, pendant bien des siècles, à disposer d'espaces suffisants pour contenir les millions d'hommes additionnels que les millions existants pourront procréer. Jamais plus qu'aujourd'hui le Monde n'a eu besoin des Chinois et réciproquement les Chinois n'ont jamais eu, plus qu'aujourd'hui, besoin du reste du monde. Cependant si la Chine veut durer, mieux encore si elle tient à progresser comme l'ont fait et continuent à le faire d'autres nations, elle n'y réussira que sous l'impulsion de forces nouvelles. Le Confucianisme a fait ses preuves en tant que puissance constructive et conservatrice. Mais, en même temps et malgré ses mérites, il a commis des fautes impardonnables et ce sont ces «péchés mortels » pour lesquels il devra payer en fin de compte. En tant que facteur de développement, il a donné tout ce qu'il pouvait donner, sa force est épuisée. Tôt ou tard, il devra céder la place à des influences plus fortes, plus sages et meilleures. 


\section{La vie des paysans chinois}

\section{XXIV}

\section{LA MONOTONIE ET LE VIDE DE L'EXISTENCE.}

Il est difficile de se reporter au temps de nos arrière-grandspères alors que les correspondances étaient transmises par des courriers à cheval, le cavalier, messager de la poste, faisant du tricot sur sa monture qui cheminait à douce allure. Mais pour aussi terne, au point de vue moderne, qu'ait dû être l'existence rurale d'il y a un siècle et plus, elle avait de la variété et, finalement, allait de pair avec les grands courants de l'époque. La vitesse avec laquelle progresse la pensée n'est pas nécessairement en corrélation avec la versatilité ou la virilité qui caractérisent l'évolution de l'esprit. Nos ancêtres peuvent n'avoir été que des paysans, mais ils faisaient partie intégrante de la contrée qu'ils habitaient : ils s'élevaient et s'abaissaient au flux et au reflux des marées de l'existence nationale, à l'égal des bateaux ancrés dans le port et soumis aux mouvements diurnes des flots.

Le village chinois est immuable matériellement et intellectuellement. L'homme qui pourrait reporter sa vue cinq cents ans en arrière et contempler le vaste panorama de I'histoire moderne ne verrait sans doute guère plus, et guère moins, que ce qu'il voit aujourd'hui. Les bâtiments actuels n'ont évidemment pas cinq siècles d'existence, mais ce sont des maisons « similaires » dans leur construction et dans leur orientation qui occupaient, il y a un demi-millénaire, ces mêmes 


\section{La vie des paysans chinois}

sites. Quelques familles qui vivaient alors derrière des murs en adobe se prélassent aujourd'hui sous des toits de tuiles, entre des murailles en briques. D'autres se sont éteintes. De ci, de là, une nouvelle famille a pu surgir, mais c'est un fait anormal, exceptionnel. Tous les gens qui habitent aujourd'hui ce groupe de maisons en terre battue sont les descendants directs de ceux qui vivaient là du temps où Christophe Colomb découvrit I'Amérique. Ils font exactement les mêmes choses que leurs ancêtres, ni plus, ni moins, ni autrement. Ils cultivent les mêmes champs et de la même façon - peut-être seulement certains des produits récoltés sont-ils d'importation plus moderne - , ils vont aux mêmes marchés et ceux-ci se succèdent toujours dans le même ordre. Ils achètent, vendent, portent les mêmes vêtements, se marient et sont donnés en mariage sur le même mode qu'autrefois.

Il possédait un esprit très pénétrant ce philosophe qui estimait que pour bien comprendre un peuple, il faut avant tout noter les choses qui, pour lui, vont de soi. Ce qu'imaginera a priori le villageois chinois ne différera guère de ce qu'imaginait I'ancêtre proche ou lointain. Il n'existe dans le village chinois aucune trace de vie intellectuelle.

$\mathrm{Si}$, par hasard, y vivent quelques rares lettrés, ces êtres exceptionnels forment une petite bande à part, n'ayant aucune relation avec leurs voisins ni, pour la plupart, avec leurs propres familles. Un vieil adage dit que « L'homme de lettres parle de livres, et le boucher de cochons ». Nous avons déjà constaté à plusieurs reprises que l'éducation chinoise rétrécit les idées et 


\section{La vie des paysans chinois}

moule l'esprit de l'étudiant de façon à le maintenir dans les ornières de la routine : I'on ne peut s'imaginer jusqu'à quel point ces ornières deviennent peu à peu étroites. Tout examen littéraire est un moment décisif d'où l'étudiant sort gradué ou non. Dans l'un et l'autre cas, le résultat - soit qu'il se rapporte à l'étudiant lui-même, aux élèves qu'il a instruits ou à ses propres fils - est considéré comme une affaire exclusivement personnelle : c'est une sorte de loterie littéraire sur laquelle on a beaucoup misé et dont on désire retirer si possible un profit. $\mathrm{Si}$ un pareil espoir est hors de question, tout l'intérêt de cette affaire littéraire s'évanouit.

Contrairement à ses camarades d'Occident, l'étudiant de village, en Chine, n'est ni un centre ni une source de lumière pour son prochain. Sa vie est un idéal de « subjectivité », la quintessence de l'égoïsme. D'après une superstition très respectée chez les Célestes, le gradué, même s'il ne franchit pas le seuil de sa maison, sait tout ce qui se passe sous la calotte des cieux. Or, comme nous l'avons déjà fait remarquer, cet aphorisme peut être classé au premier rang des nombreuses exagérations qui fourmillent dans la philosophie si réputée de la Chine. L'étudiant type ne connaît absolument rien de ce qui se

passe sous les cieux. La terre est-elle ronde ou carrée ? Il n'a aucune idée arrêtée là-dessus, car cela ne le concerne pas. Les affaires de la nation regardent les mandarins qui y trouvent leur gagne-pain. En quoi peuvent-elles intéresser un lettré pourvu de ses grades ? 


\section{La vie des paysans chinois}

L'auteur de ce livre est en relations avec un ancien maître d'école entré plus tard dans une affaire qui l'obligeait à souvent s'absenter de son domicile. Un an environ après la signature de la paix entre la Chine et le Japon, ce commerçant, qui avait beaucoup voyagé, nous demanda un jour comment s'était terminée la guerre. Il avait relevé de telles contradictions dans les récits qu'on lui faisait à ce sujet, tant dans la capitale de sa province qu'à Tien-tsin, qu'il ne savait plus que croire ; il s'était donc bien gardé de se former une opinion, se disant que dès qu'il se retrouverait auprès de son ami étranger, celui-ci serait sans doute à même de le bien renseigner !

A cette ignorance crasse doublée d'une imperturbable indifférence, il faut ajouter une crédulité illimitée. La croyance au feng-shui, c'est-à-dire à la géomancie d'un district demeure toujours profondément ancrée dans l'esprit des lettrés, même les plus notables de l'Empire. Les insertions publiées par la Gazette de Pékin nous édifient sur cette superstition : elles réclament la transformation de certains édifices, l'érection de tours porte-bonheur pour étendre à un plus grand nombre de compétiteurs la chance de réussir aux examens. Un étudiant qui estime nécessaire de faire battre le tambour au moment d'une éclipse afin de garer le soleil des menaces du «Chien » qui veut le dévorer, acceptera avec une foi égale la nouvelle que dans les pays d'Occident les années sont de mille jours avec quatre lunes se succédant le long de cette période. Si une personne pourvue de quelques vagues notions de chimie lui explique que l'oxyde de carbone versé dans un récipient a le pouvoir d'éteindre toute une rangée de bougies allumées à l'intérieur, il fait aussitôt 


\section{La vie des paysans chinois}

remarquer que le Maître s'est refusé à parler de choses se rapportant à la magie et il clôt brusquement l'entretien par ce verdict sans appel : « C'est sans doute l'œuvre des esprits malins! »

Dans un terrain aussi propice à la crédulité, toute histoire pernicieuse prend racine et, en temps voulu, porte ses fruits amers, ainsi que le constatent à leurs dépens nombre d'étrangers fixés en Chine. N'était l'extrême crédulité des lettrés, il n'y aurait que rarement des mouvement xénophobes, peutêtre même jamais. Il est triste de devoir constater que, surtout dans les campagnes, un nombre considérable d'individus de cette classe croient à la véracité des bruits les plus calomnieux répandus sur le compte des Occidentaux et que plus nombreux encore sont les lettrés totalement indifférents à la question, à moins qu'elle ne vienne à toucher leurs propres intérêts.

L'espèce de vacuité instruite et mi-intelligente qu'on découvre chez l'étudiant de village est plus qu'égalée par la vacuité ignorante de ses voisins illettrés. Si l'un de ces derniers a eu l'occasion de voyager, son éducation sera certainement moins rudimentaire que celle du lettré pour la simple raison qu'elle aura été faite plus ou moins à l'école des réalités. Quant au villageois type, qui ne s'est jamais éloigné de son home, il ne sait rien. Sa conversation se confine dans d'inénarrables inepties et il en sera ainsi jusqu'à ce qu'il aille rejoindre ses ancêtres dans la tombe. A l'exception des heures où il y a le plus de travail, chaque village nous montre un groupe d'hommes assis sur un tronc d'arbre au soleil pendant I'hiver, à l'ombre pendant I'été, ou bien encore 


\section{La vie des paysans chinois}

rassemblés dans le petit temple où se tient la bourse locale. Même en plein hiver, on les voit tassés les uns contre les autres à la recherche de confort et d'un peu de sociabilité ; et ils bavardent ainsi sans se lasser jusqu'à l'heure du repas. L'état passé, présent et futur du temps, les prix des denrées, les potins locaux et surtout les cancans sur le dernier procès en cours fournissent matière à ces interminables papotages. Les questions que pose à Chang le magistrat dans son interrogatoire, ce que Chang répondit, ce que Wang répliqua, ce que le juge a bien pu dire à propos de ceci ou de cela, le tout assaisonné de répétitions indéfinies et de commentaires sans nombre, tels sont les thèmes les plus palpitants et les plus intarissables de leurs entretiens.

Le villageois ne prend aucun intérêt aux changements qui peuvent se produire dans le personnel du Gouvernement à moins qu'il ne s'agisse du magistrat de son propre district. Lorsque, à un certain moment, le bruit courut que I'on avait fait disparaître S. M. Kuang-Hsü, I'auteur fit remarquer à l'un de ses amis chinois qu'il y avait lieu de craindre qu'à cette heure I'Empire fût sans Empereur. Un auditeur, type accompli du villageois insouciant et qui ne savait rien des nouvelles de Pékin, demanda de quel pays nous parlions et, en apprenant qu'il s'agissait de l'Empire du Milieu, il laissa tomber, après un instant de réflexion, le simple mot «Ah » sur le ton d'un homme qui avait redouté quelque chose de pire. Cependant un rustaud de cette espèce sait faire preuve d'astuce lorsqu'il s'agit de ses propres intérêts et il ne manque pas d'une certaine intelligence pratique. Il écoute avec passion les colporteurs d'histoires, aime 


\section{La vie des paysans chinois}

les drames où il est question des grands hommes des Trois Royaumes qui vivaient quelque dix-sept cents ans avant lui ; à I'occasion, il saura même vous parler de leur caractère et de leurs hauts faits. Mais I'histoire moderne et contemporaine est hors de sa portée ; il n'y prend pas goût et, du reste, ne s'en soucie pas. La carte entière de l'Asie pourrait être remaniée sans qu'il s'y intéresse, à condition toutefois, que cela ne l'oblige pas à payer plus d'impôts et ne fasse pas monter le prix du grain.

Nous avons déjà eu l'occasion de dire que le villageois qui est sorti quelque peu de son trou et a voyagé au loin, se distingue en général, et à son avantage, de toutes les cervelles vides qui l'entourent. Il possède une expérience étendue et assez variée dont il consent, quoique sans empressement, à faire profiter les autres. Mais, fait curieux, lorsqu'un villageois de ce genre rentre définitivement chez lui, il retombe très vite dans le type général. Il peut avoir circulé dans les dix-huit provinces et même visité des pays étrangers, du jour où il s'installe à nouveau dans ses vieilles habitudes, il n'a plus le moindre souci de ce qui se passe ailleurs.

En tenant compte de l'importance numérique de la population villageoise de la Chine et lorsque nous songeons combien est pauvre le rendement mental, nous arrivons à nous faire une conception impressionnante de la stérilité intellectuelle de cet Empire au langage fleuri. Les phénomènes qui, en tous lieux, retiennent notre attention ne sont que la manifestation extérieure de forces secrètes, à l'œuvre depuis deux mille ans. Plus nous les étudierons et arriverons à les approfondir, et plus 


\section{La vie des paysans chinois}

impérieusement s'imposera à nous le sentiment que la « réponse au Confucianisme, c'est la Chine ». 


\section{La vie des paysans chinois}

\section{XXV \\ ÉQUILIBRE INSTABLE DE LA FAMILLE CHINOISE.}

@

La famille constitue en Chine l'unité de la vie sociale. Or nous l'avons déjà fait remarquer plusieurs fois - la famille chinoise est un organisme très complexe, qui se présente sous de multiples aspects, lesquels semblent parfois être en contradiction les uns avec les autres. Nous allons étudier l'une des faces de ce polyèdre mais le lecteur voudra bien ne pas perdre de vue qu'alors que nos dires contiendront d'importantes vérités, ils ne seront pourtant qu'une manière entre beaucoup d'autres d'envisager les choses.

L'instabilité d'équilibre de la famille chinoise provient de la constitution de celle-ci, de son entourage et des relations existant entre ces deux facteurs. Examinons d'abord quelquesunes des causes extérieures. Dans la plus grande partie de I'Empire, la quantité de pluie qui tombe chaque année sur une même zone est soumise à d'importantes variations, d'où menace constante de famine. Pendant le dernier quart du XIXe siècle, les étrangers n'ont eu que trop souvent le triste privilège d'étudier, sur une grande échelle, le phénomène de la faim. La misère engendrée par la famine est inconcevable ; nous nous bornerons ici à examiner une seule de ses résultantes, la dislocation de la famille. Rien de plus fréquent que de voir le père partir pour une région lointaine avec l'espoir d'y gagner sa maigre pitance ; quant à sa femme et à ses enfants, il les laisse se débrouiller sur 


\section{La vie des paysans chinois}

place comme ils pourront. De cette manière d'agir il ne faudrait pas conclure que le père n'est pas attaché aux siens ou qu'il désire se séparer d'eux : il part parce qu'il n'a véritablement aucune possibilité « d'agir autrement ».

L'on voit de vastes régions exposées à de soudaines et terribles inondations. Ceux qui trouvent le moyen de s'enfuir vont dans n'importe quelle direction ; ils marchent souvent par groupes, parfois isolément ${ }^{1}$.

Pendant ces migrations au gré du hasard, des enfants naissent, d'autres meurent ; les vieillards succombent également. Parfois des jeunes filles en âge de se marier sont données à un mari de rencontre dépourvu de ressources suffisantes pour faire face aux dépenses d'un mariage habituel. L'usage veut que les secondes noces se célèbrent sans aucun apparat et chaque fois qu'une famille se désagrégera il est fort probable que les veuves trouveront sur-le-champ de nouveaux partenaires, quitte à dissoudre cette union dès qu'il y aura à nouveau pénurie de nourriture.

\footnotetext{
1 Un cas extrême de cette misère chronique se présente dans le district de Hsien, dans le Chih-li, où coulent deux rivières contenues par des digues artificielles très hautes. Beaucoup de villages sont la proie d'inondations annuelles qui détruisent périodiquement un certain nombre de maisons. Aucune récolte d'automne ne peut avoir lieu, mais, dès le retrait des eaux, on y sème du blé. Pendant l'hiver, I'on voit quantité d'immeubles avec leurs portes et fenêtres scellées au plâtre, car la plupart des habitants sont partis mendier, partout où ils le peuvent, leur modeste subsistance. Ils reviennent au printemps suivant pour surveiller leurs champs de blé. Ce genre d'existence est devenu de pratique presque courante, même dans les familles qui possèdent 50 à 60 arpents de terre et qui, ailleurs, compteraient sans doute parmi les gens aisés.
} 


\section{La vie des paysans chinois}

De légers désordres politiques qui deviennent parfois de véritables petites émeutes, causent les mêmes ravages que les famines et les inondations. Des familles dispersées à la suite de ces fléaux ont peu de chance de se reconstituer jamais.

Mais ce n'est pas uniquement aux heures de détresse générale que les familles se séparent. Dans beaucoup de provinces, une proportion considérable d'adultes va gagner sa vie très loin du village paternel.

Des milliers et des milliers de Chinois du nord de la Chine trouvent aussi des moyens d'existence en Mandchourie ou ailleurs, au delà de la Grande Muraille, à des centaines ou des milliers de milles de leur home et une foule d'entre eux ne reviennent jamais au logis familial. Quantité de mères chinoises ignorent le sort de leurs fils partis dès leur jeune âge et dont jamais plus elles n'entendent parler. Les moyens de communication, irréguliers, ne sont pas sûrs. Faut-il donc s'étonner qu'un adage populaire déclare que la mère se lamente dès que le fils s'éloigne d'elle d'une centaine de milles ${ }^{1}$. Le Chinois Enoch Arden revenant au logis après une absence de dix ans, peut-être même de vingt, entre dans sa maison, jette à terre son sac et sans saluer, ni poser une question, il allume une

1 On a raconté à l'auteur un cas de ce genre. Un homme du Honan s'était procuré un stock de marchandises valant plus de 50 dollars mexicains. Il partit pour la Mandchourie distante de 1.500 milles afin de s'informer de ce qu'était devenu le fils de sa sœur qui avait quitté brusquement le logis dans un mouvement de colère. Le stock servit à payer les frais du voyage. Mais cette expédition qui, primitivement, ne devait durer que quelques mois, se prolongea pendant plus d'une année. Le pauvre homme tomba malade, le prix de ses marchandises étant dépensé il dut passer de longs mois à mendier pour payer son retour. Et, en fin de compte, il n'apprit rien sur le sort de son neveu. 


\section{La vie des paysans chinois}

bonne pipe. Peut-être sera-t-il resté si longtemps absent que personne ne le reconnaîtra et que, le prenant pour un vagabond, on voudra l'éconduire, mais lui, il dit simplement :

— «Pourquoi ne me mettrais-je pas à l'aise dans ma propre maison?

Et il reprend sa pipe, remettant à plus tard de plus longues explications.

L'équilibre de chaque famille chinoise est exposé à un genre de calamité qui peut causer plus de mal qu'un tremblement de terre : c'est le procès. Il n'y a guère de jour dans l'existence d'un Chinois où sa tranquillité, sa prospérité, sa vie même ne courent le risque d'être mises en péril par quelque complication dont il n'est nullement responsable, mais à laquelle il ne peut se soustraire. Que le lecteur n'aille pas en déduire que la majeure partie des Célestes doive se débattre dans les mailles perfides de la loi ; tel n'est pas le cas, cependant l'éventualité l'en menace toujours. Un irrésistible mouvement de colère de la part d'un seul Chinois qui se trouve au milieu d'une vingtaine de personnes peut déclencher une crise qui entraînera la victime à dépenser la plus grande partie de ses ressources, lui fera subir en prison une longue détention, la torture, des répressions d'une barbarie inouïe et même la mort par privations dans une geôle, à moins que la famille n'ait les moyens d'empêcher une pareille catastrophe en se laissant rançonner sans merci. Il ne faut pas croire non plus que tout procès comporte des incidents de cette nature, mais ils existent toujours à l'état potentiel, car personne ne saurait prévoir quand et comment se termine un procès. Ce 


\section{La vie des paysans chinois}

ne sont pas seulement les gens directement en cause qui souffrent en pareil cas : ainsi que le dit le proverbe : « lorsqu'une famille est dans la peine, aucun de ses quatre voisins ne peut vivre en paix. »

Nous avons fait remarquer à plusieurs reprises que pas un Chinois, pour ainsi dire, n'est en mesure de sauvegarder son indépendance financière. Rien ne semble plus stupéfiant à un étranger que la façon inconsidérée avec laquelle on contracte une dette, qui, fréquemment porte en elle des germes de ruine future pour la famille entière. Il serait vain de demander pourquoi l'argent fut emprunté : autant demander pourquoi une personne est trempée jusqu'aux os après qu'elle a passé la nuit sans abri en plein brouillard d'Écosse. Des siècles d'expérience ont fait du Chinois un créancier impitoyable et malheur à celui qui doit, mais ne peut payer. La Chine pullule de petits commerçants à capitaux très limités qui arrivent pourtant à joindre les deux bouts à la fin d'une année ordinaire. Un très petit pourcentage de bénéfices permet souvent au négociant de s'enrichir au point d'acheter de la terre, et c'est ainsi que les familles prennent racine dans le sol. Cependant le plus grand nombre perd le capital engagé ; il faut vendre de modestes biens fonciers pour faire face aux charges et ces malheureux finissent par retomber dans la grande communauté des gens sans terres au soleil et sans espoir d'en acquérir. Une seule mauvaise récolte peut entraîner avec elle des conséquences de ce genre chez beaucoup de petits négociants en grains. En Chine, un homme ou une famille, chargé d'une dette qui dépasse les rentrées possibles du débiteur, se trouve dans la situation de quelqu'un 


\section{La vie des paysans chinois}

qui serait lancé sur un tobogan soigneusement huilé au bout duquel l'attend sa perte irrémédiable.

Dans les familles pauvres, les ressources courantes ne permettent pas de faire la part de l'imprévu, de la maladie par exemple : or celle-ci frappe impartialement toutes les classes sociales. Lorsque le gagne-pain est mis hors de cause, lorsque la mère d'une petite maisonnée n'est plus en état de faire bouillir la marmite familiale, alors vraiment le malheur s'installe dans la maison. Si une jeune mariée tombe malade, on envoie aussitôt quérir sa mère car, dans la famille du mari, il ne se trouve jamais personne qui veuille assumer la charge des soins à lui donner, à commencer par le mari lequel se considère comme personnellement lésé par l'indisponibilité de sa jeune femme et prétend le plus souvent se décharger sur sa belle-famille des frais de maladie plutôt que de les acquitter lui-même. Un mal chronique est considéré comme une cause légale de divorce. Nous devons ajouter que jamais encore nous n'avons entendu parler d'un cas où I'on se soit servi de ce prétexte pour l'obtenir. Le sentiment filial d'un fils, dit-on couramment, ne subsiste plus en présence d'une longue maladie et nous possédons des preuves innombrables de la tension qu'elle crée dans une famille. Par contre, nous sommes parfois agréablement surpris de rencontrer des exemples de tendresse et de dévoûment dignes des plus grands éloges. Mais, telle qu'est constituée la société chinoise, ces manifestations ne peuvent être qu'extrêmement rares. Un homme, relation personnelle de l'auteur, lui exposant un jour les symptômes très graves de la maladie de sa femme, ajouta qu'il avait demandé à celle-ci 


\section{La vie des paysans chinois}

combien de temps encore elle comptait se livrer aux gémissements que lui arrachait une véritable agonie causée par des ulcères inguérissables : il s'était même offert à lui procurer une corde afin de le délivrer, lui, de l'inconvénient de la maladie et elle de ses misères. Lorsqu'on lui fit remarquer la cruauté d'une pareille attitude, il reconnut en toute franchise que ses ennuis domestiques l'avaient rendu « stupide ». Un dicton très significatif dit que le malade, quoique pauvre, a contracté une maladie de riche.

Les forces dissolvantes qui ne cessent de s'exercer dans les familles chinoises causent, bien entendu, de plus grands ravages dans les intérieurs pauvres où elles rencontrent moins de résistance que chez les riches. Il existe cependant deux facteurs de décomposition qui ne peuvent opérer et se développer que dans les milieux où règne un certain degré de prospérité. Nous voulons parler du jeu et de l'opium, ces deux vices jumeaux de la race jaune. L'un et l'autre conduisent à pas rapides à la destruction et tous deux ont finalement pour effet, en paralysant la volonté, de rendre impossible toute tentative de réaction. Contre ces maux effroyables, la société chinoise ne connaît aucune sauvegarde, aucun traitement préventif, aucun remède. Il nous serait facile d'illustrer par quelques détails épouvantables de quelle façon insidieuse, universelle, irrésistible ces forces opèrent. Nous sommes seulement surpris que la dévastation ne s'étende pas encore davantage. Le jeu et l'opium comptent parmi les agents les plus corrosifs de la vie sociale chinoise. Il est rare d'entendre parler d'une tentative de réforme contre cet état de choses - il faudrait que l'impulsion vienne du dehors - 


\section{La vie des paysans chinois}

et plus difficilement encore trouverait-on une personne qui puisse ou veuille en prendre l'initiative.

A cette liste des forces maléfiques vient s'ajouter une violation de plus de la moralité sociale. Jusqu'à quel point sévitelle dans les différentes régions, il est impossible à un Chinois et plus encore à un étranger - d'en décider avec quelque autorité. Malgré sa loquacité proverbiale le peuple éprouve à ce sujet un sentiment de réticence de tout point digne d'éloges. On attache peu d'importance à la vie de l'enfant. Il y a toujours dans l'air tant de rumeurs, tant de chuchotements laissant place au soupçon que les gens doués de quelque jugement refusent d'ajouter foi à ce dont on ne leur fournit pas des preuves évidentes. Le code moral chinois est élevé, tant en théorie qu'en pratique. Les arrangements sociaux sont réglés avec un soin que l'étranger traite simplement de pruderie, mais l'expérience de milliers d'années a convaincu les Célestes que ces dispositions sont non seulement sages, mais encore indispensables.

Or, dans les conditions de la vie quotidienne, il est absolument impossible de mettre en pratique toutes les réglementations théoriques. Les femmes âgées meurent et les cours des maisons demeurent fatalement dans un état de délabrement avant-coureur de la ruine. Contre un mauvais beaupère - surtout s'il est veuf - l'économie sociale n'a prévu en Chine ni recours, ni défense. On assure que les insinuations malveillantes rôdent toujours autour de la demeure des veuves. En un mot il est presque permis de poser en principe que 


\section{La vie des paysans chinois}

personne n'a une confiance absolue dans I'un quelconque de ses semblables.

En dépit des témoignages qui semblent infirmer cette opinion, nous avons tout lieu de croire que la morale des Chinois, dans ce qu'elle a de mieux, égale pleinement celle des pays occidentaux. Cependant il ne faut pas perdre de vue que les conséquences d'un relâchement dans la moralité ne sont pas, comme chez nous, susceptibles d'amélioration. Le souci permanent de chacun se réduit à sauver «la face», et pour conserver intact ce respect imaginaire de soi-même, le Céleste en arrivera parfois jusqu'au suicide, mesure ultime à laquelle, de tout temps, il s'est résigné sur la moindre provocation. Il n'y a pas de Chinois qui ne soit absolument affranchi de la crainte qu'un des siens ne prenne un jour ou l'autre cette décision. La loi chinoise a même prévu des mesures répressives contre toute personne accusée d'avoir « persuadé à l'un de ses semblables de se donner la mort », crime social qualifié d'assassinat. Rien mieux que ce fait ne montre la différence profonde qui sépare la civilisation occidentale de celle de la Chine.

L'on peut dire des Chinois qu'ils sont tous profondément attachés à la famille qui leur donna le jour ; nombre d'entre eux ont aussi de grandes affections qui s'adressent à des membres particuliers d'autres branches de la famille. Tout Chinois est animé d'un égal désir de perpétuer la race. Lorsque son espoir est déçu - cas fréquent - cet échec lui est d'autant plus sensible que le Jaune a un attachement profond pour son coin natal. Afin d'arriver à plus de précisions sur les causes de ces 


\section{La vie des paysans chinois}

insuccès, il nous faut pénétrer plus avant dans les dessous de la famille chinoise.

@ 


\section{La vie des paysans chinois}

\section{XXVI \\ FAIBLESSE DU LIEN FAMILIAL.}

Il est impossible de donner un diagnostic exact quant aux raisons profondes du manque d'union dans la vie sociale et familiale des Chinois sans courir le risque de dénaturer de façon flagrante l'idée qu'on doit se faire de la société et du caractère de ce peuple. En retenant simplement les cas les plus authentiques et les plus typiques, nous risquerions de donner une impression inexacte, parce que relative. Toutes les familles portent en elles-mêmes des germes de désunion et si ceux-ci ne produisent pas toujours les fruits qu'on peut en attendre, c'est parce qu'ils sont miséricordieusement étouffés ou entravés dans leur développement.

Au sein de chaque famille chinoise s'opposent fatalement des intérêts contraires. Toute épouse chinoise quitte - non par son propre choix - une autre famille pour se trouver brusquement et irrévocablement greffée comme une plante sauvage sur l'arbre généalogique de son mari. Ainsi que nous le savons, elle n'y reçoit pas un accueil enthousiaste, moins encore affectueux - I'idée n'en vient même pas à l'esprit d'un Chinois -, tout au plus est-elle tolérée, si les critiques agressives lui sont épargnées. Liée à d'autres intérêts dont elle a été, il est vrai, séparée, ses affections y demeurent quand même concentrées. L'attachement qu'ont pour leur mère la plupart des enfants chinois est réel et durable. La mort de la mère constitue, pour 


\section{La vie des paysans chinois}

les filles en particulier, la plus grande des calamités. C'est par la piété filiale, prise sous son aspect le plus imparfait, le plus pratique, que la fille mariée est poussée à vouloir transférer une partie des biens de la famille de son mari à celle de sa mère. Cette tentation, souvent irrésistible, persiste parfois durant la vie entière, non sans de nombreux heurts plus ou moins dramatiques. Les Chinois s'expriment par métaphores au sujet de cette coutume ; ils parleront d'une « fuite dans le fonds » qui est, comme on le sait, difficile à arrêter. On entend dire couramment que sur dix filles mariées, neuf se livrent plus ou moins à de petits larcins. C'est à de pareilles pratiques que I'on attribue souvent l'appauvrissement progressif de certaines familles. L'auteur de ce livre eut un jour l'occasion d'annoncer à un ami chinois le décès récent d'une personne qui lui était alliée par mariage. D'un air pensif le Céleste déclara : « Il est heureux qu'elle soit morte. Elle était gourmande, paresseuse ; de plus elle volait des tas de choses pour sa mère! »

Les visites à la maison maternelle constituent les seules joies substantielles de l'existence de la jeune femme chinoise, et celle-ci s'efforce de les rendre aussi fréquentes que possible, tandis que sa belle-famille s'ingénie à les restreindre, les services que la bru rend dans le home s'en trouvant forcément diminués. Afin de compenser cet inconvénient, on s'arrange à la charger de deux fois autant de couture qu'elle pourra en abattre au cours de son absence, ou bien on l'expédie chez ses parents avec une bande d'enfants, si elle est déjà à un stage assez avancé de sa vie conjugale pour être mère d'un tel troupeau. Le père et les frères regardent souvent une invasion de ce genre 


\section{La vie des paysans chinois}

avec des marques non dissimulées de désapprobation, aussi quoi de plus naturel que la jeune femme soit animée du désir de les apaiser au moyen des dépouilles qu'elle a pu soustraire aux Philistins.

Au décès de la mère, la situation intérieure se trouve matériellement changée. Les belles-sœurs ne mettent plus de frein à leurs critiques quand elles voient la jeune femme apparaître avec sa progéniture affamée, aussi son séjour se passera-t-il sans doute en luttes incessantes pour le maintien de ce qu'elle considère comme ses droits. C'est bien l'un des spectacles les plus pathétiques de la société chinoise, qui abonde en visions de ce genre, que de constater les efforts poursuivis pour tâcher de raviver les étincelles d'un feu dont la flamme est visiblement éteinte. Ne posséder du côté maternel aucune famille chez laquelle elle puisse se rendre constitue, du point de vue de la femme mariée, la plus grande infortune qui puisse lui arriver : c'est proclamer qu'elle n'a plus personne pour prendre son parti aux heures difficiles qu'elle traverse chez ses beauxparents. Mais cesser complètement ces visites familiales équivaudrait à «perdre la face » et personne en Chine n'est insensible à pareille humiliation. Nous avons connu une très vieille femme qui, restée seule au monde, en était réduite à l'âge de 94 ans, à ramasser elle-même son combustible, elle devait vaquer à tous ses besoins sauf celui d'aller puiser de l'eau que, par une faveur toute spéciale, . une parente éloignée voulait bien lui fournir. Son dénûment était tel qu'elle mélangeait du sable à sa maigre pitance afin de la faire durer plus longtemps. Cependant, cette créature misérable s'absentait parfois de son 


\section{La vie des paysans chinois}

home habituel et on avait alors coutume de dire qu'elle était allée en visite dans la « famille de sa mère » laquelle consistait dans les arrière-petits-enfants de ceux qu'elle avait connus dans sa jeunesse !

Le jour où la femme mariée atteint l'âge mûr, l'intérêt qu'elle porte à sa maison natale a quelquefois beaucoup diminué. Elle possède maintenant des jeunes filles en âge d'être mariées, et chacune d'elles à son tour recommence la même expérience qu'a acquise la mère. Pour leurs pères et frères, ces jeunes personnes deviennent à la fois un problème et une menace. Si le taux des naissances féminines pouvait être fixé par voie de ballottage entre les mâles adultes, il est probable que dans un nombre restreint de générations la race jaune aurait cessé d'exister. L'expression « un article sur lequel on a perdu son argent » est une périphrase courante employée pour désigner les jeunes filles. Celles-ci n'ont pas plutôt appris quelques rudiments de couture, de cuisine, etc., qu'on les exporte, et la phrase « répandre de l'eau par terre », devenue un proverbe, est synonyme de fille; ou encore : «L'ivraie n'entre pas en ligne de compte dans la taxe des grains et les filles ne sauront jamais supporter les mères. » Ces façons de parler représentent la manière de penser - je dirais même, la pensée - dominante, sinon fort heureusement la seule du peuple chinois.

Les jeunes filles n'ont pour ainsi dire aucune occasion de se lier entre elles. L'empressement avec lequel, lors de circonstances favorables, ces amitiés se forment et se perpétuent montrent bien tout ce qu'elles perdent à cet 


\section{La vie des paysans chinois}

isolement persistant. Lorsque l'on considère que chaque famille chinoise se compose non seulement du mari, de la femme, de leurs enfants mais encore de fils mariés et de leurs différentes épouses, chacune d'elles introduite au logis d'après les mêmes procédés coercitifs, chacune ayant une volonté ferme et indomptable, mais sans le pouvoir de revendiquer ses droits sauf par des paroles acerbes et des explosions de colère, il est évident qu'il ne peut être question d'union au sein de la famille.

D'après la loi chinoise, tous les frères ont des droits égaux et, bien que l'aîné jouisse de quelques avantages, aucun de ceux-ci n'intervient dans le partage égal du bien familial. Des nouveaux mariés reçoivent parfois des dons en nature, par exemple du coton pour filer et tisser : ils sont alors supposés se suffire avec ce capital augmenté du fruit de leur travail. Souvent le père distribue de son vivant des parts inégales de sa terre entre plusieurs frères, injustice contre laquelle il n'existe d'autre ressource que les protestations. Il en est de même lorsque le père a résolu de priver l'un ou l'autre de ses fils d'une partie de ses droits dans la répartition des biens familiaux.

L'idéal chinois consiste à conserver indivise à tout jamais la propriété familiale. Mais les Célestes eux-mêmes se rendent compte qu'il n'existe pas pour eux de monde idéal et que l'on ne peut éviter un jour ou l'autre le partage des terres. Souvent il arrive que I'un des fils, mécontent, commence à maugréer et charge un voisin de prévenir le père que l'heure a sonné de procéder au partage. L'on met alors l'affaire entre les mains d'un tiers supposé absolument désintéressé, à moins que la famille, 


\section{La vie des paysans chinois}

certaine de pouvoir garder son empire sur elle-même, se croie à même de se passer de cette assistance. Dans le cas où un tiers conduirait les opérations, il commencera par dresser un état des nombreux lopins de terre, des bâtiments, etc., dont il fixe grosso modo la valeur. Puis il s'efforce de diviser le tout en autant de parts qu'il y a de participants. Un lot de terrain est mis en réserve pour «la nourriture des parents dans leur vieillesse »; peut-être en distrait-on un autre pour parer aux dépenses éventuelles du mariage de filles ou garçons plus jeunes. Le reste sera partagé : chaque lot - terres, immeubles, etc. - est soigneusement détaillé par écrit sur un bout de papier que I'on roule, puis tous ces billets de loterie sont déposés dans un bol à riz. On secoue délicatement le récipient, le plus jeune des fils est invité - l'étiquette le prescrit - à tirer le premier, et l'on continue ainsi par rang d'âge jusqu'à épuisement des papiers. Le mobilier de la maison, les jarres à eau, les ustensiles divers, les grains, le combustible amassé au logis, tout doit être présenté au répartiteur qui s'assure que l'on n'a rien soustrait à son examen. Nous avons eu connaissance d'un fils particulièrement chicaneur qui reparut dans la maison paternelle au lendemain d'un partage pour s'assurer que pas une fève, pas même un grain de millet, n'avait échappé à ses investigations. Dans les familles où règne I'harmonie - elles sont rares - tous ces ennuis sont évités. Des Chinois très observateurs prétendent que sur dix familles qui opèrent un partage, sept sinon neuf, auront en guise d'accompagnement une tempête domestique, ces orages variant d'intensité, depuis le grain court et violent jusqu'à l'ouragan qui ne laisse derrière lui que des ruines. 


\section{La vie des paysans chinois}

Le Chinois estime, qu'en principe, les parents, quand ils deviennent âgés, doivent être à la charge de leurs enfants, lesquels se réuniront pour subvenir aux besoins des vieux, ou bien en assumeront à tour de rôle la charge entière.

Cependant les cas où une vieille mère, ayant reçu sa petite part personnelle, doit faire elle-même sa cuisine et pourvoir à tous les travaux du ménage, sont en grand nombre. Un fait indubitable frappe tout particulièrement les Européens, à savoir que l'acte de partager une propriété semble à lui seul étouffer entre proches tout sentiment de responsabilité à l'égard les uns des autres. Lorsque nous demandons pourquoi le Chinois ne vient pas en aide à un fils ou à un frère qui possède une famille nombreuse et n'a rien à se mettre sous la dent, il nous est généralement répondu : «Nous avons partagé il y a peu de temps. » Peut-être la véritable explication de cette impassibilité devant le malheur d'autrui la trouve-t-on dans une suite d'exaspérations accumulées pendant la plus grande partie de sa vie ! Une fois qu'il en est délivré, le Chinois estime qu'il peut légitimement dépenser son énergie pour ses propres fins, laissant aux autres le soin d'en faire autant au mieux qu'ils pourront.

L'on entend souvent dire que lorsque l'un des membres de la famille est absent au moment du partage, les autres, profitant de la situation, lui attribuent une part qu'il n'eût pas acceptée s'il avait pu avoir voix au chapitre. Ce cas se présente tout particulièrement lorsque la famille a des dettes qui se montent à une somme importante. Parfois un jeune homme se voit 


\section{La vie des paysans chinois}

contraint d'entrer dans la vie accablé par un passif de plusieurs centaines de mille de sapèques, résultat d'une association malheureuse de son père avec ses oncles, laquelle remonte peut-être à plusieurs années en arrière.

Un article de bilan des plus indésirables c'est « la taxe des grains sur terrain vide »! Il s'agit dans l'espèce de l'engagement pris de payer une taxe sur une terre inexistante mais à laquelle on a donné l'apparence d'exister au moyen d'un arpentage inexact au cours des années antérieures, soit par inadvertance, soit avec intention. Supposons qu'une famille possède une terre de cent arpents dont il faut vendre des parcelles de temps à autre pour une raison quelconque. Chaque arpenteur travaille sur un bornage imprécis, tel un bout de vieux mur ou un tronçon de maçonnerie dont il ne retrouvera peut-être plus trace. L'acheteur s'efforcera naturellement d'avoir bonne mesure et les agents n'ont aucun intérêt à s'y opposer. Or, personne ne sait exactement ce qui reste de terrain jusqu'au moment où l'on jugera nécessaire de procéder à un mesurage final, et souvent alors il apparaît qu'on est assez loin de compte quant au nombre d'arpents. C'est de déficits de ce genre que résulte l'obligation de payer des «taxes vides » et quoique la taxe soit en elle-même assez lourde pour le propriétaire, on ne connaît en Chine aucun moyen de remédier à une pareille injustice. Il est peu probable que le fils sur qui pèse cet impôt contribue à faire régner I'harmonie dans la maison et, serait-il même disposé à enterrer la question, sa femme ne cessera d'en parler à moins que la chance ne veuille qu'elle soit muette. Une liste complète des occasions possibles et inévitables qui produisent des heurts et 


\section{La vie des paysans chinois}

engendrent de l'amertume dans les relations familiales, occuperait à elle seule un volume entier ; mais celles que nous avons citées suffisent à éclairer le lecteur quant à toutes les autres.

Fait à noter, lorsque la tension a atteint son paroxysme, et plus spécialement lorsque l'individu exaspéré n'a pas les moyens de s'en aller au loin pour échapper à ces maux domestiques, il éprouve souvent la tentation d'administrer du poison à la personne détestée. Si le choix des substances toxiques dont peut disposer le peuple chinois n'était pas si restreint, les tentatives d'empoisonnement seraient beaucoup plus fréquentes ; néanmoins, elles sont assez nombreuses et, de temps à autre, les étrangers eux-mêmes en deviennent les victimes.

Au moment où ce chapitre était en préparation, un ami chinois vint me demander conseil. Il possède un neveu âgé de 36 ans, marié tout récemment. C'est un garçon lourd d'esprit, peu fortuné, qui n'avait jamais été considéré comme un bon parti. Cinq mois environ avant que se passât le fait qui motivait la visite de I'oncle, I'on avait découvert une jeune fille de seize ans qui, en raison de la difformité de l'un de ses membres, ne trouvait pas preneur. Un intermédiaire la proposa au célibataire en question et le mariage se conclut sur la base de huit cordons de sapèques à payer à la famille pour frais de trousseau ; puis le mariage fut célébré dans les délais ordinaires. Ainsi que I'on pouvait s'y attendre le ménage ne fut pas heureux. Au vingtsixième jour de la première lune de l'année courante, le mari absorba un bol de millet qui lui parut d'un goût étrange, mais il 


\section{La vie des paysans chinois}

ne songea pas au poison avant d'avoir avalé le tout et constaté des traces d'arsenic dans le fond du récipient. Après de violents vomissements, il se sentit soulagé. Le surlendemain, l'aventure se renouvela avec aggravation des symptômes. Il fit de vives remontrances à la jeune femme qui retourna à la maison paternelle sise à quelques milles de distance. Le mari, à ce moment très malade, fut soigné par son oncle ; celui-ci venait me demander conseil, le jeune homme paraissant maintenant hors de danger. Que fallait-il faire ? Chez un peuple où le « bavardage » est une cause légale de divorce, il semblait naturel à un étranger que des tentatives d'empoisonnement, pour aussi maladroites qu'elles fussent, constituassent également un motif de divorce. Mais l'oncle m'expliqua qu'il y avait une belle-sœur qui s'y opposait. Et pourquoi ? Sans doute parce qu'après avoir payé huit cordons de sapèques pour une femme, il serait vraiment dommage de la perdre pour une bagatelle ! L'affaire fut mise entre les mains des prêcheurs de paix qui décidèrent que le parent ayant fourni à la femme l'arsenic devait faire «kotow » devant l'homme qui avait absorbé le poison. De plus la famille de la femme verserait quinze cordons de sapèques au mari lésé pour lui permettre de récupérer sa vitalité endommagée. Entre temps, la femme demeura dans la maison de sa mère où, dit-on, elle reçut quelques coups de bâton de I'une des filles du logis. Il n'y eut pas de divorce, le mari ne voulant pas recourir à des mesures extrêmes, en partie à cause du gros placement fait par lui à I'origine, et aussi par crainte du ridicule. En temps voulu, l'épouse sera sans doute renvoyée chez son mari où elle pourra 


\section{La vie des paysans chinois}

renouveler ses expériences quant à l'art de rendre un intérieur agréable.

Jusqu'ici nous nous sommes occupés du désaccord des familles chinoises en tant qu'il est encouragé par cet état de subjectivité intense que nous appelons égoïsme. Il y entre cependant nombre d'autres facteurs avec lesquels il faut compter et qui proviennent des habitudes et des traits inhérents à la race.

Affirmer que tout Chinois est menteur de nature serait commettre une erreur grossière. Nous croyons au contraire que le Chinois est encore le plus véridique de tous les Asiatiques. Il n'y a pas de doute cependant que le manque de spontanéité est pour lui une seconde nature et que ce penchant à la dissimulation réagit sur tous les actes de son existence.

Un Céleste appelé en témoignage devant le juge - où plus que partout ailleurs il importe de dire la vérité - commence généralement son récit - mélange de trois dixièmes de fait et de sept dixièmes de fiction - par ces mots : « Je ne veux pas tromper Votre Honneur ! » et ce faisant, il dit en effet la vérité, car Son Honneur sait parfaitement que le témoin ment et le témoin sait de son côté que Son Honneur n'en doute pas. La seule question qui se pose est donc de connaître le pourcentage des mensonges et auxquelles de ses déclarations appliquer ce qualificatif en particulier. Ces mêmes principes régissent la vie de famille. La plupart des maris ne sont pas si naïfs que d'avouer à leurs femmes le véritable état de leurs affaires. Les enfants à leur tour cachent souvent aux parents ce que ceux-ci devraient 


\section{La vie des paysans chinois}

savoir et ils sont eux-mêmes trompés dès qu'on le juge utile. $A$ une femme chinoise que nous avons connue toute enfant, la mère dit un jour de ne pas aller dans la rue comme elle en avait I'habitude, mais de demeurer au logis et de changer de vêtements. La jeune fille obéit : à peine, était-elle habillée qu'elle se voyait enlevée dans une chaise à porteurs, en route pour la maison de son «mari », car c'était le jour de ses noces! Les conditions sociales qui rendent possibles de pareils incidents doivent forcément donner naissance à d'autres phénomènes désagréables. Un dicton populaire le constate en ces termes : «Celle qui a compris son métier de belle-fille saura prévariquer au milieu de ses deux familles tandis que la belle-fille sans expérience révèle ce qu'elle sait à toutes les deux », et c'est pourquoi elle est en butte à de constants désagréments.

En dépit de la contrainte perpétuelle dans laquelle vivent les femmes, elles arrivent quelquefois à cacher aux maris qu'elles ont un petit avoir déposé entre les mains d'un membre de leur famille. L'auteur connaît un Chinois, âgé de 60 ans environ, pourvu de nombreux petits-enfants, mais il ne veut rien avoir à faire avec sa femme, pas plus qu'elle avec lui. Pendant toute la durée de leur vie conjugale - trente à quarante ans - il l'a soupçonnée de posséder quelque part une forte somme d'argent, placée à intérêts et dont elle ne veut pas le faire profiter. S'il est inexact que tous les Chinois se trompent les uns les autres, il est certainement vrai qu'on en court toujours le danger, source constante d'inquiétude et de suspicion. Comme corollaire à cet état de choses, il arrive souvent que les principaux intéressés dans une affaire soient incapables de se faire une idée exacte de 


\section{La vie des paysans chinois}

faits que tout le monde connaît, mais que chacun se garde bien de raconter.

Mencius prétendait que la pitié est un sentiment commun à tous les êtres humains, et ce qui fut vrai de son temps ne l'est pas moins aujourd'hui. D'autre part ce sentiment se manifeste de diverses manières. Tout Chinois est un soldat rompu aux batailles de la vie, accoutumé à la misère sous toutes ses formes et à tous les degrés. La première pensée du Céleste en face d'un incident douloureux ne sera pas : « N'y a-t-il rien à faire pour remédier à cela ? » En admettent même qu'il lui accorde une pensée, il se dira : «Pourquoi m'en occuperais-je ? 》 Des siècles d'une expérience héréditaire lui ont enseigné à ne pas se laisser aller à des impulsions sentimentales de bienveillance qui pourraient avoir des conséquences désagréables. L'auteur s'est trouvé à même d'entendre un Chinois qui, devant le cadavre d'un homme mort loin de son logis dans des circonstances pénibles, disait simplement : «Ce jouet sera difficile à transporter ! » et cette réflexion prouve bien qu'il n'a pas la moindre conception de ce que nous appelons de la sympathie pour autrui. Quelques années après, ce même individu fut appréhendé par ordre du magistrat du district et enfermé dans une cage où il ne pouvait se tenir que debout, supplice bien plus cruel que de vous dépecer en morceaux, car la victime conserve toute sa connaissance et agonise lentement sans nourriture, ni boisson. Et cette peine lui fut infligée bien qu'on n'eût relevé contre lui aucune charge précise, ni qu'on l'eût fait passer en jugement. Et voici le seul commentaire auquel se bornèrent les 


\section{La vie des paysans chinois}

gens qui l'avaient connu : « Il fallait s'y attendre ! C'est probablement ce qu'il méritait ! »

Le Chinois type est un être bon enfant, de caractère égal, paisible, prêt à jouer son rôle dans l'existence sans rechigner et ne demandant qu'à être traité avec équité. Mais, de même que la surface tranquille de beaucoup de lacs se transforme parfois subitement et roule des vagues violentes sous le coup de bourrasques qui descendent en trombe par les gorges des montagnes, ainsi ce bel équilibre moral du Céleste peut être entamé, détruit par de terribles crises de colère qui métamorphosent brusquement ce membre paisible d'une société bien ordonnée en un homme qui semble être un démon incarné. Que la vie vaille ou non d'être vécue a toujours été supposé « dépendre du foie ». En Chine, I'on pourrait plutôt affirmer que cela dépend de la rate. Quelques-uns de nos lecteurs se souviendront peut-être de la légende de cet Américain de distinction auquel son père fit un jour cadeau d'une petite hachette. Curieux d'éprouver la qualité de l'outil, il en essaya aussitôt le tranchant sur le cerisier favori de la maison, et cela avec succès. Lorsque le père découvrit le méfait, il demanda quel était le coupable et l'enfant ayant crânement avoué son acte, il le serra dans ses bras en déclarant qu'il préférerait perdre un grand nombre de cerisiers plutôt que d'entendre son fils proférer un mensonge. Cette histoire se déroula probablement dans le court espace de dix minutes. Afin d'illustrer certains traits de la désunion qui fait l'objet de notre étude, nous allons donner à pareil incident une interprétation chinoise. 


\section{La vie des paysans chinois}

M. Hua Hsing-tun était un fermier aisé qui possédait dans sa cour un beau grenadier dont il se montrait très fier. Le plus jeune de ses fils trouva un jour à portée de sa main une faucille récemment affûtée pour couper la moisson le lendemain matin. Armé de cet instrument, l'enfant se mit à taillader tout ce qu'il rencontrait sur son chemin : c'est ainsi que le grenadier s'effondra sous le troisième coup de faucille. Effrayé des ravages qu'il venait d'accomplir, le gamin s'enfuit jusqu'à l'autre bout du village où il se mit à jouer avec quelques-uns de ses camarades. Il leur raconta qu'un cousin - le troisième fils de son quatrième oncle - avait fait le coup. Un voisin l'entendit et s'empressa de se rendre à la maison de M. Hua. Le malheureux vociférait tout en cherchant à découvrir l'individu qui avait massacré son arbre préféré. Dès que l'orage se fut un peu calmé le voisin, tout en contemplant le désastre, confia à un autre voisin que le coupable n'était autre que le neveu de Hua ; puis les deux hommes s'éloignèrent. Comme personne, à l'intérieur du logis n'a eu vent de la chose, Hua, fou de rage, continue à hurler dans la rue du village, à la recherche de celui qui a coupé son arbre. Un de ses fils plus âgés, ayant appris I'histoire par les deux voisins, la répète à son père et celui-ci, mis enfin sur la bonne piste, se

précipite dans la cour de son quatrième frère. Il n'y rencontre que sa belle-sœur qu'il se met à insulter dans les termes les plus outrageants. Un instant interloquée, elle comprend bientôt la situation et commence à invectiver son beau-frère à l'aide d'un vocabulaire qui laissait bien loin derrière lui les grossièretés que lui avait servies ce dernier. Le plaignant vide les lieux et retourne dans la rue poursuivi par la femme qui hurle à tue-tête. 


\section{La vie des paysans chinois}

Sur ces entrefaites, l'infortuné neveu supposé coupable d'être I'auteur du méfait, attiré par ces clameurs arrive chez lui. L'oncle en fureur I'y poursuit et, après l'avoir abreuvé d'injures, le traitant de rejeton illégitime d'ancêtres plus vils encore, lui assène un formidable coup de bâton. La mère du garçon, folle de rage, attaque à son tour son beau-frère et le saisit par sa natte. Elle est aussitôt tirée en arrière par le second frère aidé de quelques voisins : une cinquantaine de personnes assistent maintenant à ce spectacle. Plusieurs femmes entraînent de force la belle-sœur $\mathrm{N}^{\circ} 4$ jusque chez elle, mais, tout le long de la route, ses clameurs de protestation continuent et, dans un dernier accès de rage, elle se laboure le visage où ses ongles longs et acérés creusent de profondes entailles ruisselantes de sang. A ce moment rentre le mari. Furieux de l'offense faite à sa famille, il insulte à son tour frères et ancêtres et déclare qu'il va sur-le-champ déposer une plainte au yamen. Après s'être muni d'argent, il se met en route ; mais il est suivi pendant plusieurs milles par six hommes qui, au cours de deux heures de palabres, essayent de lui faire entendre raison en promettant de «prêcher la paix ». Vers minuit seulement chacun rentre chez soi. Les cinq jours suivants sont consacrés à des colloques entre tiers qui tiennent également des conciliabules avec les principaux intéressés. Enfin tout s'arrange. Hua, l'aîné, devra organiser un repas du prix minimum de dix cordons de sapèques pendant lequel il reconnaîtra qu'il commit une erreur en insultant dans la circonstance sa belle-sœur. Le plus jeune frère acceptera ces excuses en présence de quatorze hommes choisis parmi ceux qui furent mêlés à l'affaire. Lorsque le repas aura été consommé, 


\section{La vie des paysans chinois}

« I'harmonie » sera enfin rétablie. Mais que dire de l'auteur du méfait ? «Oh ! mais ce n'est qu'un enfant ! » et sur ce mot l'incident est clos, puis oublié.

Les querelles chinoises ont quelque chose d'odieux en raison de la soudaineté avec lesquelles elles éclatent, de leur violence et du fait qu'elles ont lieu le plus souvent en public. Ce dernier trait semble particulièrement répugnant à la civilisation occidentale qui n'a pas elle-même encore appris comment éviter les discussions domestiques. Comme tout conflit intime tombe immédiatement dans le domaine public, l'élément « face » entre aussitôt en jeu, exigeant un règlement qui réhabilitera la partie lésée vis-à-vis de toute la création, laquelle est toujours supposée contempler le spectacle de l'œil du critique.

L'un des phénomènes les plus attristants de la vie chinoise, c'est de constater avec quelle soudaineté, avec quelle spontanéité, toute affection naturelle, toute relation amicale peut, dans certaines circonstances, se flétrir à jamais. Si le membre d'une coterie vient à entrer en collision avec les préjugés de la génération précédant la sienne ou même avec celle à laquelle il appartient, ses grands-pères, père, grandsoncles, cousins et frères le menacent fréquemment de lui casser les jambes, de lui brûler les yeux avec de la chaux vive, etc., menaces qu'ils mettent assez souvent à exécution. Pour mitiger les conséquences d'une dispute où fut employée la violence, I'on déclare souvent qu'il n'y a pas eu intention de tuer, mais seulement de briser assez d'os à l'individu en question pour le mettre hors de combat. 


\section{La vie des paysans chinois}

Que I'affaire aboutisse à un procès et chacun de protester qu'on n'arrivera jamais à un compromis tant que l'adversaire n'aura pas été dépouillé de son dernier lopin de terre. La tension d'esprit dans laquelle vivent nombre de Chinois, toujours incertains si les menaces proférées ne seront pas réalisées tôt ou tard, conduirait vite un Occidental à la folie ou au suicide, peutêtre même aux deux. La conclusion de ces colloques orageux, c'est souvent l'obscur sous-entendu : « Nous verrons plus tard! »

Les Chinois sont de fervents adeptes de la méthode des récompenses et des punitions. Un homme connu pour ses méfaits ne rencontrera jamais ombre de sympathie, quelle que soit l'infortune qui le frappe à son tour : c'est un tigre dans une fosse. Un individu de cette espèce qui avait contracté des ulcères où s'ébattait une innombrable vermine se traîna jusqu'à la terrasse d'un temple de son village natal. Tantôt il demeurait prostré dans le coma, tantôt la douleur lui arrachait des cris épouvantables : les voisins passaient devant lui en l'insultant. « C'est la vengeance du Ciel ! » lui criaient-ils.

Le caractère chinois s'accommode facilement de certains allégements à des conditions qui, à première vue, sembleraient devoir lui rendre l'existence intolérable. Dans les cœurs des Célestes, comme dans les nôtres, l'espoir renaît, indéracinable. A généraliser les expériences du prochain aussi bien que les siennes, le Chinois acquiert la quasi certitude qu'en fin de compte rien ou presque rien ne s'arrange. Il s'attend à rencontrer partout de la fausseté, de la suspicion, de l'oubli ; et 


\section{La vie des paysans chinois}

il est rarement déçu. Souvent il se trouvera sous la dépendance de gens qui seraient heureux de se débarrasser de sa personne et qui ne se font pas faute de le lui rappeler. Avant comme après, il sait, à n'en pas douter, que les prêts qu'il a dû consentir ne seront jamais remboursés à l'heure dite, ni en totalité ; que l'aide promise, si même accordée, le sera à contre-cœur et aboutira peut-être à de l'inimitié de la part de celui qui l'oblige. Il a dans l'esprit, dit le proverbe, les « deux cents années à venir », mais bien souvent il sait parfaitement que jamais aucun nombre « d'années à venir » ne suffiront à le redresser devant le monde. Et cependant, il conserve malgré tout une sérénité aimable, une bonne humeur qui pour nous seraient choses aussi impossibles que de respirer à l'aise dans l'atmosphère malsaine d'une chambre à coucher chinoise. Il y est accoutumé, nous ne le sommes pas. Un homme de ce type, affligé d'une femme acariâtre, laquelle, exaspérée par le second mariage imprévu d'un frère de son mari, veuf depuis vingt ans, remplissait la maison de ses scènes tumultueuses, déclara à l'auteur de ce livre, que, depuis trois mois, il n'avait pas un seul instant « respiré en paix ». Et cela était dit. non pas sur un ton de complainte, mais avec l'accent de quelqu'un qui répondrait à une question au sujet d'un cor malencontreux qu'il a au pied. Dans de pareilles conditions, nombre de Chinois font preuve d'une dose de mansuétude dont nous ne trouverions pas, je le crains, la contre-partie en Europe où, depuis des siècles, les droits individuels ne se sont pas fondus dans ceux de la famille. L'on dit de ces gens qu'ils « avalent les injures en silence»; leur nombre est, dit-on, illimité, et il le sera toujours. 


\section{La vie des paysans chinois}

Quiconque est bien au courant de leur vie réelle, ne pourra jamais exagérer les maux qui affligent les Chinois, car le tableau le plus monté en couleurs semble souvent encore pâle devant le spectacle des réalités. Cependant, chacun se demande s'il existe des moyens de remédier à cet état de choses. Puisque la plupart de ces maux paraissent inséparables de la pauvreté qui est à la base de toute discorde chinoise, on serait tenté de croire qu'une fois la pauvreté abolie, la désunion dans les familles disparaîtra à son tour. Cette théorie renferme peut-être quelque vérité, mais elle est en défaut devant ce fait que les maux auxquels on voudrait remédier sont presque aussi répandus parmi les Chinois de la classe aisée que parmi les pauvres, sans compter que chez ceux-là ils sont encore plus apparents et plus impossibles à réprimer.

La discorde morale ne peut se guérir que par une thérapeutique radicale et non par des panacées superficielles. Il existerait pourtant un remède, d'ordre économique plutôt que moral. Administré sur une large échelle et pendant une ou deux générations, il pourrait opérer une révolution telle que la Chine ne se reconnaîtrait plus. Si l'on arrivait à retarder les mariages jusqu'à ce que les jeunes gens soient arrivés à l'âge de la maturité et si, à l'occasion du mariage de chacun des fils, la propriété familiale était partagée de telle façon qu'un conflit d'intérêts cessât de constituer une menace permanente, le plus grand ferment de misère serait étouffé dans son germe.

Lors de certaines enquêtes poursuivies par les services maritimes à l'effet de découvrir les causes de naufrage des 


\section{La vie des paysans chinois}

grands cargos qui se perdirent corps et biens dans le Canal de Formose, l'on a constaté souvent que le navire avait été pris dans un fort courant impossible à discerner, puis entraîné fatalement à sa perte. Les habitudes ataviques des Chinois, favorisant l'agglomération d'un grand nombre d'individus sous un même chef, constituent ce courant qui dérive inéluctablement vers la désunion et la désintégration.

Nous croyons fermement que la tension qu'exerce sur l'esprit et sur le caractère un conglomérat de tant d'êtres humains comprimés dans le bloc familial est telle qu'aucune société au monde ne saurait l'endurer, car pareille tâche est au-dessus des forces humaines. Il n'y a pas de doute que les maux qui on découlent sont inévitables, intolérables, et que les Chinois n'ont actuellement à leur disposition aucun moyen d'y remédier. 


\section{La vie des paysans chinois}

\section{GLOSSAIRE DE TERMES TECHNIQUES}

Boy : Terme qu'emploient les étrangers pour désigner en Chine le domestique en chef, quel que soit son âge.

Cash ou sapèque : Pièce de monnaie en cuivre dont la valeur correspond à 1/1000 de dollar mexicain environ ; elle est percée d'un trou pour permettre son enfilage sur un jonc, etc. Le cordon ou ligature de sapèques comporte mille pièces, mais dans certaines régions le cordon est de 500 sapèques seulement, équivalant actuellement au tiers d'un dollar or.

Catty : La livre chinoise, égale à 605 grammes.

Chin-Shih : «Étudiant inscrit », ce qui correspond au troisième degré littéraire et au docteur ès lettres d'Occident.

Chou : Sous-préfecture. Ses attributions ne comportent pas nécessairement la juridiction administrative sur toute la région.

Chü-Jên : « Homme choisi ». Le second degré dans la hiérarchie des Lettrés. Correspond au licencié ès lettres.

Compound : Enceinte ou cour intérieure contenant un certain nombre de maisons appartenant à une seule famille ou bien un établissement industriel ou autre.

Feng-Shui : Littéralement «vent-eau ». Système compliqué de superstitions géomantiques par lequel est désigné l'esprit protecteur des sites et des monuments.

Fu : Préfecture administrée par un préfet et comprenant plusieurs districts.

Han-Lin : « Forêt de crayons ». Le dernier degré littéraire à obtenir pour avoir droit à un emploi officiel.

Hsien : District ou zone administrée par le magistrat du district.

Hsiu-T s'ai : « Talent florissant ». Le premier grade de la hiérarchie littéraire ; un bachelier.

K'ang : Fourneau en briques dont la plate-forme supérieure sert de lit. 


\section{La vie des paysans chinois}

K'otou ou Kotow : L'acte de se prosterner et de se frapper la tête contre le sol en signe d'hommage ou d'adoration.

Li : Mesure de longueur correspondant à 578 m. 35.

Squeeze : Contribution forcée extorquée par les intermédiaires entre les mains desquels passe l'argent du public.

Taël : Dénomination européenne de la monnaie chinoise liang qui vaut 1000 tsien ou sapèques. Mesure de poids correspondant à 27 gr. 8 . Elle diffère suivant les provinces ; c'est la seizième partie de la livre chinoise, catty.

Tao tai : Fonctionnaire de $3^{\mathrm{e}}$ rang, intendant d'un district.

Yamen : Bureau et résidence d'un fonctionnaire chinois. 